Het onderzoek is uitgevoerd in de afdeling Kindergeneeskunde, subafdeling Longziekten, Erasmus Universiteit en Academisch Ziekenhuis Rotterdam/Sophia Kinderziekenhuis.

Het onderzoek is subsidiair gesteund door het Nederlands Astma Fonds (Naf project nrs. $238 ; 279 ; 79.31 ; 80.26$ ).

Ontwerp en uitvoering van de omslag: Fiel van der Veen, Haarlem.

The study is performed in the department of Pediatrics, subdivision of Respiratory Diseases, Erasmus University and University Hospital Rotterdam/Sophia Children's Hospital, the Netherlands.

The study is supported by research grants from the Netherlands Asthma Foundation (Grant numbers $238 ; 279 ; 79.31 ; 80.26$ ).

Coverdesign: Fiel van der Veen, Haarlem 



\title{
BRONCHIAL RESPONSIVENESS IN CHILDREN
}

\author{
ACADEMISCH PROEFSCHRIFT \\ TER VERKRIJGING VAN DE GRAAD VAN \\ DOCTOR IN DE GENEESKUNDE \\ AAN DE ERASMUS UNIVERSITEIT ROTTERDAM \\ OP GEZAG VAN DE RECTOR MAGNIFICUS \\ PROF. DR. J. SPERNA WEILAND \\ EN VOLGENS BESLUIT VAN HET COLLEGE VAN DEKANEN. \\ DE OPENBARE VERDEDIGING ZAL PLAATSVINDEN OP \\ WOENSDAG 30 SEPTEMBER 1981 \\ DES NAMIDDAGS TE 3.45 UUR
}

DOOR

HERMAN J. NEIJENS

geboren te Den Burg (Texel)

1981

Drukkerij Onkenhout B.V.

Hilversum 
PROMOTOR : PROF.DR. K.F. KERREBIJN

COPROMOTOR : PROF. DR. H. J. DEGENHART

CO-REFERENTEN: PROF. DR. C. HILVERING

PROF. DR. K. DE VRIES 
Aan Suzanne, Karlien en Floortje

Ter nagedachtenis aan mijn vader 


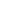


CONTENTS

CHAPTER 1. INTRODUCTION TO THIS THESIS $\ldots \ldots \ldots \ldots \ldots$

1. motives and definitions $\ldots \ldots \ldots \ldots \ldots \ldots \ldots \ldots \ldots \ldots \ldots \ldots$

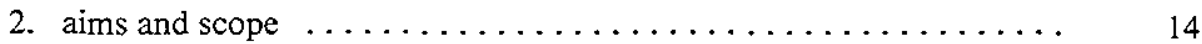

3. remarks about terminology and methods ............. I5

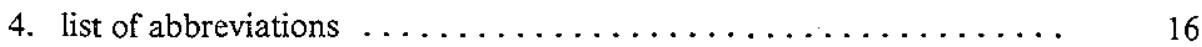

CHAPTER 2-5. REVIEW OF THE LITERATURE $\ldots \ldots \ldots \ldots \ldots$

CHAPTER 2. HISTORICAL VIEW .............. 19

CHAPTER 3. REGULATION OF THE BRONCHIAL DIAMETER 21

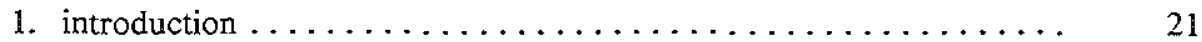

2. bronchial smooth muscles $\ldots \ldots \ldots \ldots \ldots \ldots \ldots \ldots \ldots \ldots \ldots$

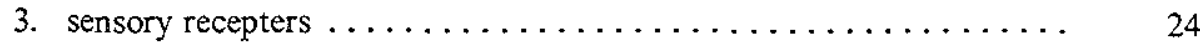

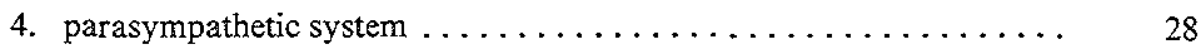

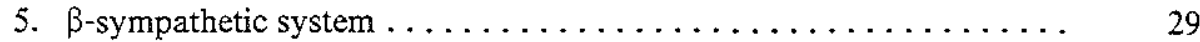

6. $\alpha$-sympathetic system $\ldots \ldots \ldots \ldots \ldots \ldots \ldots \ldots \ldots \ldots \ldots \ldots \ldots \ldots$

7. non-adrenergic inhibitory nervous system $\ldots \ldots \ldots \ldots \ldots \ldots \ldots . \ldots \ldots$

8. APUD system $\ldots \ldots \ldots \ldots \ldots \ldots \ldots \ldots \ldots \ldots \ldots \ldots \ldots \ldots \ldots \ldots \ldots$

9. mediator release, cellular aspects $\ldots \ldots \ldots \ldots \ldots \ldots \ldots \ldots \ldots$

10. mediator release in vivo $\ldots \ldots \ldots \ldots \ldots \ldots \ldots \ldots \ldots \ldots$

11. mucus secretion and mucociliary transport $\ldots \ldots \ldots \ldots \ldots \ldots$

CHAPTER 4. BRONCHIAL RESPONSIVENESS TO ASPECIFIC STIMULI, PARTICULARLY HISTAMINE . . . . 43

1. introduction $\ldots \ldots \ldots \ldots \ldots \ldots \ldots \ldots \ldots \ldots \ldots \ldots \ldots \ldots \ldots \ldots \ldots$

2. methods of measurements $\ldots \ldots \ldots \ldots \ldots \ldots \ldots \ldots \ldots \ldots \ldots$

3. histamine-induced bronchial responses as studied in animal experiments $\ldots \ldots \ldots \ldots \ldots \ldots \ldots \ldots \ldots \ldots \ldots \ldots \ldots \ldots \ldots \ldots \ldots \ldots \ldots$ 
4. histamine-induced bronchial responses as studied in humans $\ldots \ldots \ldots$

5. relationship between bronchial responsiveness and diseases and symptoms $\ldots \ldots \ldots \ldots \ldots \ldots \ldots \ldots \ldots \ldots \ldots \ldots \ldots \ldots \ldots \ldots \ldots \ldots$

6. course of bronchial responsiveness with age $\ldots \ldots \ldots \ldots \ldots \ldots$

CHAPTER 5. BRONCHIAC RESPONSIVENESS TO EXERCISE .. 61

1. introduction $\ldots \ldots \ldots \ldots \ldots \ldots \ldots \ldots \ldots \ldots \ldots \ldots \ldots \ldots \ldots \ldots \ldots \ldots$

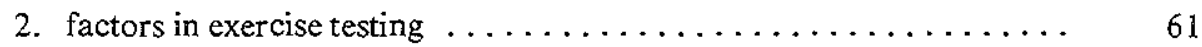

3. protective effects of pharmacological agents on EIB $\ldots \ldots \ldots \ldots .65$

4. mechanisms in EIB/causes of hyperresponsiveness to exercise . . . . 67

5. relationship between EIB and bronchial responsiveness to inhaled

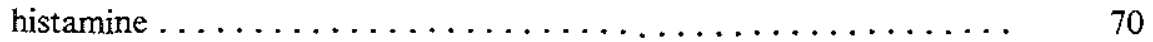

CHAPTERS $6-8$. THE STUDIES $\ldots \ldots \ldots \ldots \ldots \ldots \ldots \ldots$

CHAPTER 6. GROUP A

Studies of the methods of measurement ............ 73

6.1. Bronchial responsiveness as a function of inhaled histamine and the

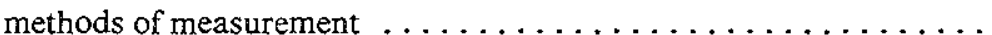

CHAPTER 7. GROUP B

Studies of the mechanisms involved in bronchial hyperresponsiveness

7.1. Exercise-induced bronchial obstruction as an expression of bronchial hyperreactivity: a study of its mechanism in children . . . . . . . . .

7.2. Site of maximal flow-limitation in exercise-induced bronchial responsiveness due to exercise

7.3. The correlation between increased reactivity of the bronchi and mediator releasing cells in asthma $\ldots \ldots \ldots \ldots \ldots \ldots \ldots$

7.4. Release of histamine from leucocytes and its determinants in vitro in relation to bronchial responsiveness to inhaled histamine and exercise in vivo

\section{CHAPTER 8. GROUP C}

Studies of the relationship between bronchial responsiveness and the bronchial reaction to stimulants which provoke symptoms in daily

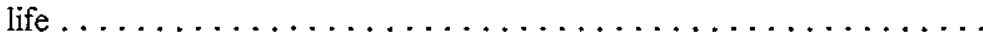


8.1. Relationship between the bronchial responsiveness to inhaled histamine and the degree of bronchial obstruction after exercise ......

8.2. Study on the significance of bronchial hyperreactivity in the bronchial obstruction after inhalation of cat dander allergen $\ldots \ldots$.

8.3. Significance of the bronchial responsiveness to histamine in allergeninduced bronchial obstruction on different occasions . . . . . . . . 149

CHAPTER 9. GENERAL DISCUSSION $\ldots \ldots \ldots \ldots \ldots \ldots \ldots \ldots$

ALGEMENE DISCUSSIE . . . . . . . . . . . 159

CHAPTER 10. SUMMARY ................ 163

SAMENVATTING $\ldots \ldots \ldots \ldots \ldots \ldots \ldots \ldots \ldots$

REFERENCES ................ 169

POSTSCRIPTUM ................ 191

CURRICULUM VITAE .............. 193 


\section{CHAPTER 1. INTRODUCTION TO THIS THESIS}

\section{Motives and definitions}

For a long time the investigations into the mechanisms of asthma were mainly focussed on allergy. Detailed studies were performed on allergens, $\operatorname{IgE}$ antibodies and mediator release from mast cells. However, it became apparent that allergy could not explain all aspects of asthmatic disease. The bronchial response to the non-allergic stimuli, such as physical and chemical agents, exercise, emotions and viral infections, was difficult to conceive on the basis of the IgE-mast cell model.

Also, the allergen-induced bronchial response revealed unexplained features. The large molecules of most allergens hardly penetrate through the intact bronchial mucosa. Nevertheless bronchial obstruction occurs immediately after inhaling an allergen. Moreover the obtained reaction is not localized as could be expected in a pure IgE-mast cell reaction, but generalized.

This implies that mechanisms which differ from the IgE-mast cell system may be important in the occurrence of an asthmatic reaction. Animal studies have shown that an imbalance in the autonomic nervous system may be an important factor. Various mechanisms seem to be involved in the overall reaction of the bronchi.

The severity of the bronchial obstruction after non-allergic challenges varies between persons. This phenomenon is called bronchial responsiveness or reactivity.

The degree of bronchial responsiveness is defined as the severity of the bronchial obstruction as indicated by lung function measurements, in relation to a standardized non-allergic stimulus.

Bronchial hyperresponsiveness is defined as a condition of increased reactivity of the bronchi i.e. the occurrence of bronchial obstruction after a stimulus in a dose which does not provoke such a reaction in most individuals. Bronchial hyperresponsiveness is present in many asthmatic patients but not in most healthy subjects.

Many different agents and actions are able to evoke exaggerated bronchial responses in susceptible subjects. Thus the state of hyperresponsiveness is mostly not confined to a particular stimulus. Stimuli which are allergens are often called specific, while other stimuli are named non-specific.

Non-specific stimuli which are used to arouse bronchial responsiveness in experiments are:

1. Physical: carbon dust (Widdicombe et al., 1962); cold air (Wells et al., 1960; de Vries et al., 1964; Deal et al., 1980); fog (de Vries et al., 1964). 
2. Chemical: Sulphur-dioxide ( $\mathrm{SO}_{2}$ ) (Frank et al., 1962; Islam et al., 1972a; Nadel et al., 1965; de Vries et al., 1964).

Nitrogen-oxide $\left(\mathrm{NO}_{x}\right)$ (Orehek et al., 1967a).

Ozone (Holtzman et al., 1979).

Citric acid (Simonsson et al., 1967).

Ammonia.

Ether.

3. Forced respiratory manoeuvres: hyperventilation, laughing (Nadel \& Tierney, 1961; Hafer \& Cropton, 1968; Simmonsson et al., 1967; Gayrard et al., 1975a; Orehek et al., 1975a; Kivity \& Souhrada, 1981).

4. Exercise.

5. Natural occurring agents:

histamine

acetylcholine

serotonin (Booy-Noord et al., 1969a)

bradykinin (Simonsson et al., 1973)

Prostaglandin $\mathrm{F}_{2 \mathrm{x}}$ (Mathé et al., 1973; Patel, 1975a).

6. Pharmacological agents:

propanolol

phenylephrine.

\section{Aims and scope}

The aim of the research described in this thesis is to get more insight into various aspects of bronchial responsiveness. The literature is reviewed and discussed in the first part of this thesis (chapters 2-5) and emphasis is placed on recent developments. In the review results from studies in animals and in humans are correlated as much as possible.

Our own studies are designed to analyse various aspects of the mechanisms in bronchial responsiveness in children, as well as the role of bronchial responsiveness in the occurrence of symptoms. These studies, started in 1976, are divided into three groups:

a. Dose- and time-response relationships using inhaled histamine. These are analysed and the methods for the measurement of bronchial responsiveness considered (chapter 6).

b. Studies on mechanisms of:

1. The relative contribution of the autonomic and the mast cell system in the pathogenesis of bronchial responsiveness using exercise is studied by means 
of protective agents (paragraph 7.1).

2. The pattern of bronchial obstruction after exercise is evaluated with flowvolume curves using air and helium/oxygen mixtures (paragraph 7.2).

3. The feasibility of leucocytes as a model for hyperresponsiveness at a cellular level are performed by measuring the release of mediators (paragraphs 7.3 and 7.4).

c. The clinical significance of the relationship between bronchial responsiveness and the occurrence of bronchial obstruction after contact with allergens and after exercise (chapter 8).

\section{Remarks about terminology and methods}

The terms bronchial responsiveness and reactivity are both used to express the same phenomenon i.e. the degree of bronchial obstruction which occurs in relation to the dose of the trigger. We used mostly the term responsiveness.

We have preferred the term bronchial obstruction instead of bronchoconstriction because during the reduction in bronchial calibre it is impossible to separate the contribution of smooth muscle constriction, bronchial mucosal swelling and hypersecretion. In paragraph 7.1, 7.2 \& 7.3 the term bronchoconstriction is used instead of bronchial obstruction because of editorial reasons. In the introduction and the review of the literature the term bronchoconstriction is used if we wanted to indicate smooth muscle contraction.

The sympathetic system is often called the adrenergic system in the literature. We considered the terms synonymous. The term sympathetic is preferred by us, but we used the term adrenergic in the studies 7.1 and 7.2 for editorial reasons.

We used inhaled histamine and exercise as stimuli to assess the non-allergic bronchial responsiveness. The severity of the bronchial obstruction due to each of both stimuli is considered as indicative for the degree of the bronchial responsiveness. This is justified in paragraphs 5.5, 7.1 and 8.1.

The histamine threshold, or the provocation dose, is defined as the dose of the agonist after which a given degree of bronchial obstruction occurs.

The term "releasability" is used according to the American literature. By releasability is meant the degree of mediator release in relation to the stimulus applied.

We have used the term asthma instead of chronic non-specific lung disease 
(CNSLD) (Fletcher et al., 1962) or in Dutch "Chronische Aspecifieke Respiratoire Aandoeningen" (CARA) (Orie et al. 1961). This is done because the studies are exclusively performed in children with chronic or recurrent reversible bronchial obstruction. Children with "pure" bronchitis without bronchoconstriction are not included. Characteristics of patients such as atopy, are only mentioned if relevant for the results. The children had neither detectable infections during the studies nor anatomical deformations of the respiratory system.

The studies are performed in non-smoking children from the age of approximately 7 years on. The children with asthma are selected from the outpatient clinic of the Sophia Children's Hospital according to criteria mentioned in the various studies. The healthy children studied came from a school in the neighbourhood of the Sophia Children's Hospital. All children and their parents have given their consent being fully informed about the study.

\section{List of abbreviations}

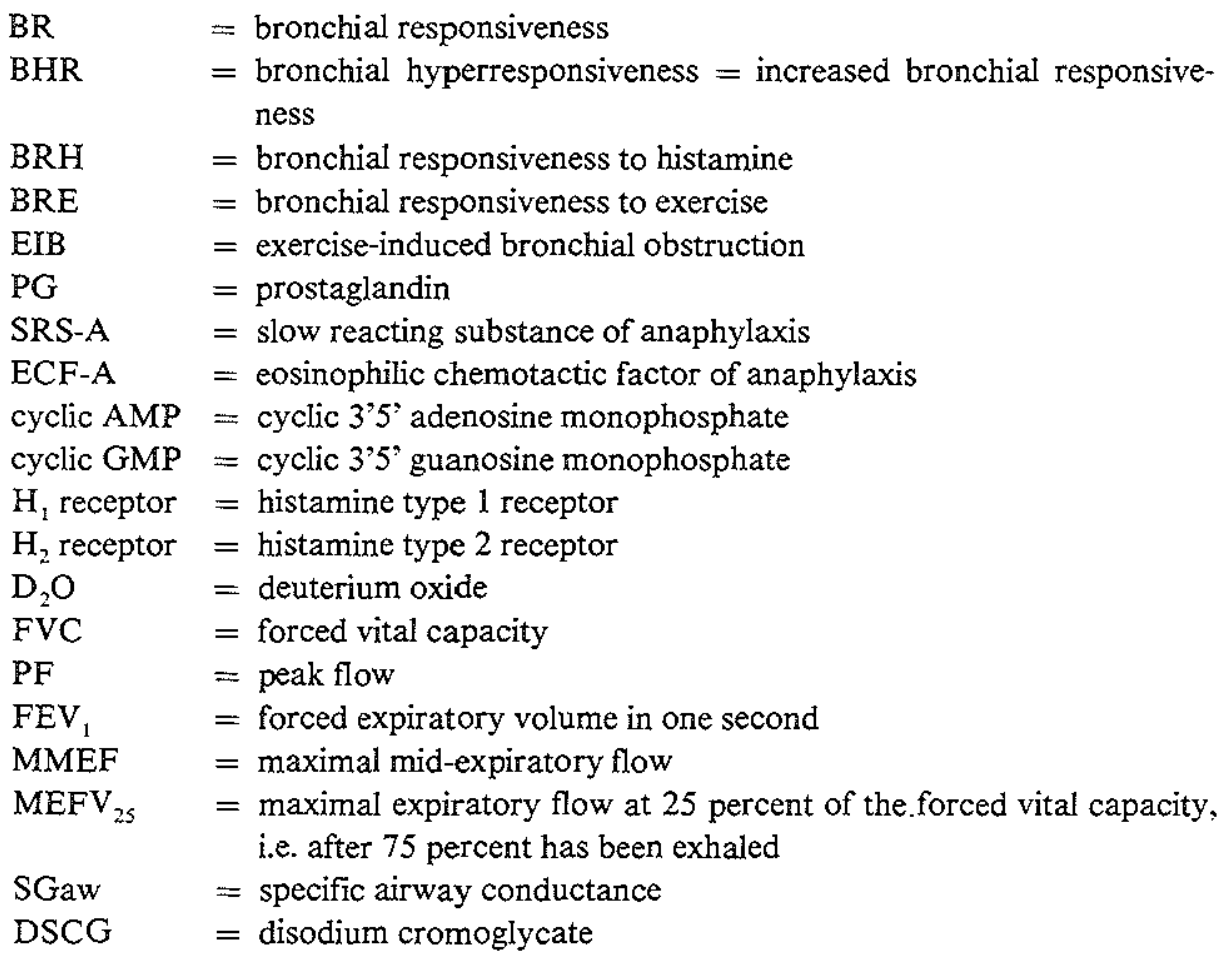




\section{CHAPTERS 2-5}

REVIEW OF THE LITERATURE ON BRONCHIAL RESPONSIVENESS 



\section{CHAPTER 2. HISTORICAL VIEW}

The phenomenon of BHR was already observed in the first half of this century. Alexander and Paddock (1921) used pilocarpine, while Weiss et al. (1929) administered histamine as a stimulus. Both investigators used the intravenous route. Dautrebande et al. (1941) demonstrated BHR using aerosolised carbacholcholine.

Most investigators formed the impression that BHR was related to asthma. Tiffeneau (1945) tried to quantify the phenomenon properly using a test in which the dose of the agonist that corresponds with a certain amount of bronchial obstruction was determined ("dose liminaire", later called threshold or provocation dose). As stimuli he used acetylcholine, histamine and citric acid. It appeared to him that the degree of BHR increases with the severity of asthma $(1955,1958)$. Other investigators reported similar observations using acetylcholine and histamine (Curry et al., 1946; Herxheimer, 1951).

Curry administered the agonist intra-muscularly. Later on inhalation provocation was general accepted as the best route of administration because it gives an immediate response and has a low risk compared to injection.

Parker et al. (1965) used methacholine, an analog of acetylcholine with increased stability, in a fixed dose. Also other agents appeared to elicit reactions in BHR i.e. serotonin, bradykinin (Herxheimer \& Stresemann, 1961) and prostaglandin $\mathrm{F}_{2 \alpha}$ (Mathé et al., 1973).

Since 1960 de Vries, Orie and coworkers performed several studies on BR. They used mainly histamine, although other agents were applied as well. The threshold was used as criterion for BR. Reproducibility, changes in BR during 24 hours (de Vries et al., 1962a), comparison of different stimuli (de Vries et al., 1964, 1968) and investigation of the mechanism by administration of pharmacological agents (Booy-Noord et al., 1969b) were performed. They noticed "profiles of BR" by studying BR induced by several agents and the effect of blockade in different categories of patients with chronic respiratory diseases (Gökemeijer, 1976). At present de Vries et al. are studying the role of the $\beta$-sympathetic receptor and the effects of $\beta$-blockade with propanolol (Koëter et al., 1981) on BR.

Studies of the mechanisms involved in BHR have been done mainly in animals by several authors notably Widdicombe and coworkers and Nadel and cowerkers (paragraph 4.3).

As the method of measuring BR got a wider application, the experience rose. 
The impression that BHR was a characteristic of a group of related diseases which is called in the Netherlands Chronische Aspecifieke Respiratoire Aandoeningen (Cara or CNSLD) was confirmed. In these patients BHR appeared to be frequent, whereas it decreased in frequency in patients with chronic bronchitis or allergic rhinitis. In normal persons BHR is rare. 


\section{CHAPTER 3. REGULATION OF THE BRONCHIAL DIAMETER}

\subsection{Introduction}

BHR can be considered as a disregulation of the diameter of the bronchi. The bronchial diameter is determined by the tone of the bronchial smooth muscle and the thickness of the mucosa, at least during tidal breathing. Bronchial obstruction in BHR seems to be mainly the result of smooth muscle action because its rapid appearance and the immediate effect of $\beta$-sympathomimetics. Mucosal swelling and sputum secretion have probably a minor role in BR in most patients.

The bronchial smooth muscle tone is increased by parasympathetic activity and decreased by $\beta$-sympathetic activity, although other factors may also play a role, as will be discussed in this chapter.

\subsection{Bronchial Smooth Muscles}

\section{a. General remarks}

Smooth muscle extend from the trachea to the alveolar ducts. It runs circularly and spirally (Miller, 1947). Contraction results in obstruction of the airways. A relationship probably exists between the bronchial smooth muscle tone and the diameter of the bronchi. Hypertrophy and hyperplasia of the smooth muscle, which occur in asthmatic patients (Takizawa \& Thurlbeck, 1971), must be of importance in BR. An increased amount of muscle is able to develop more tension and can presumably narrow the bronchi to a greater extent than muscle present in normal amounts.

\section{b. Receptors}

Contraction and relaxation of the smooth muscle of the tracheobronchial tree is dependent on neurogenic and humoral factors. These act through specific receptors on the bronchial smooth muscle wall.

A review is given by Fleisch (1973). The smooth muscle receptors can be divided in two groups according to their receptor mediated responses by an agonist.

Group I are receptors which give rise to muscle contraction. They consist of muscarinic (parasympathetic), $\alpha$-sympathetic, histamine ${ }_{1}\left(\mathrm{H}_{1}\right)$, serotonin, bradykinin, prostaglandin $\mathrm{F}_{2 \alpha}$ and angiotensin receptors. 
Group II includes receptors which induce muscle relaxation. The most important are $\beta$-sympathetic, prostaglandin $\mathrm{E}$ and probably histamine ${ }_{2}\left(\mathrm{H}_{2}\right)$ receptors. Histamine receptors are discussed in paragraph 3.9.

Many authors agree that the muscarinic, $\beta$-sympathetic and $\mathrm{H}_{1}$ receptors are involved in physiological and pathological processes. The roles of the other receptors mentioned is not clear and this is especially true for $\mathrm{H}_{2}$ receptors.

The distribution of receptors probably differs among various levels of the airway. This is illustrated by the observation of Eyre (1969) in sheep. Histamine produced contraction of the smooth muscle of the trachea and central bronchi, but relaxed those in the peripheral bronchi. Only the histamine-induced contractions of the trachea and the central bronchi could be blocked by a $\mathrm{H}_{1}$ antagonist. Ahmed et al. (1980) and Chand et al. (1980a) also found a difference in reactivity of central and peripheral airway smooth muscles to histamine and to carbachol in sheep and rhesus monkeys.

\section{c. Cyclic nucleotides and smooth muscle function}

The importance of cyclic AMP and GMP as modulators of cell action in a variety of tissues is well established (Sutherland, 1970). Increase in the level of cyclic AMP by the administration of dibutyryl cyclic AMP can induce relaxation of a variety of smooth muscles, including that of the bronchi (Krye \& Schultz, 1972).

$\beta$-sympathetic agonists stimulate adenylate cyclase and hence cause increase of cyclic AMP and relaxation of smooth muscle tone. The intracellular concentration of cyclic GMP has been shown to increase in relation with agents that promote smooth muscle contraction, such as acetylcholine and other cholinergic agents, $\alpha$-sympathetic agonists and histamine (Schultz et al. 1973). However, both cellular responses, increased smooth muscle tone and increased cyclic GMP were poorly correlated. Increase in cyclic GMP seemed to be secondary to an increase in the cytoplasmatic concentration of calcium (Schultz et al., 1975). The role of cyclic GMP in the mechanism of smooth muscle contraction and relaxation is therefore not yet clear (Schulz, 1977).

The precise model of action of the cyclic nucleotides in smooth muscle contraction is not yet clear. It is thought that cyclic AMP affects the tonus by increasing the removal of calcium from the cytoplasm.

Some studies on the involvement of cyclic nucleotides in smooth muscle preparations were performed in vivo. Barnett et al. (1978) measured in the dog lung in vivo the tissue concentrations of cyclic AMP and GMP which were correlated with the airway resistance and compliance as parameters of the bronchial smooth muscle tone. Their results differ from the results of the in vitro studies, but are difficult to interpret because of the complexity of the mechanisms involved in whole tissues in 
vivo. Matsumura et al. (1976) studied the effect of administration of cyclic nucleotides in mice in $\because$ hich the $\beta$-sympathetic function was blocked by propanolol. The bronchial obstruction after histamine or allergen inhalation was less after prior administration of cyclic AMP. Administration of cyclic GMP was shown to be without effect. Atkins et al. (1980) could not find a change in plasma levels of cyclic nucleotides in humans after challenge with allergen or methacholine.

It is concluded that cyclic AMP and possibly cyclic GMP have a role in regulation of bronchial smooth muscle tone, although their precise involvement in vivo is not yet clear. However, it must be realised that determination of cyclic GMP is difficult to perform accurately. Thus many studies are of limited value. The role of the cyclic nucleotides is more extensively discussed in relation to mediator release (see par. 3.9).

\section{d. Dose-response relationship}

The log dose-response relationship which represents the tone developed in smooth muscle preparations in vitro in relation to the dose of an agonist, has a $\mathrm{S}$-shaped pattern. This indicates a small increase in response in the low dose range, followed by rapid increase in the middle dose range, and only a slight increase in the high range of doses (Stephens et al., 1968).

The dose-response curve of bronchial smooth muscle is dependent on the influences of extra- and intra-cellular factors. In vitro and animal studies show that the sensitivity of the muscle to various stimuli increases after surgical or chemical denervation. This is seen not only in skeletal muscle, but also in smooth muscle preparations of different origins (Fleming et al., 1973). The increase applies to sympathetic- and parasympathetic receptor stimulants, as well as to histamine. This supersensitivity results in a smaller dose of an agent required to produce a given response than under normal conditions.

In the literature two main categories of sensitizations are distinguished. First, those concerning changes in the effective concentration of agonists at receptors (termed prejunctional) which give rise to a horizontal shift in the dose-response curve (figure 1, type a).

Secondly, those concerning changes in the responding tissue (muscle cells) beyond the initial combination of agonists and receptors (termed post-junctional), which are related to change in the magnitude of the response (figure 1, type b) (Kalsner, 1974; Westphal et al., 1975). Stephens et al. (1980) showed that a type b difference existed in the histamine dose-response curves of sensitized and control animal airway smooth muscles. These studies may have some relevance in vivo. However, there is no evidence of a relationship between this phenomenon and BR at the present time. 
The mechanisms of smooth muscle activity in histamine-induced bronchial obstruction is discussed in paragraph 4.3.2 and 4.4.2.

Figure 1.

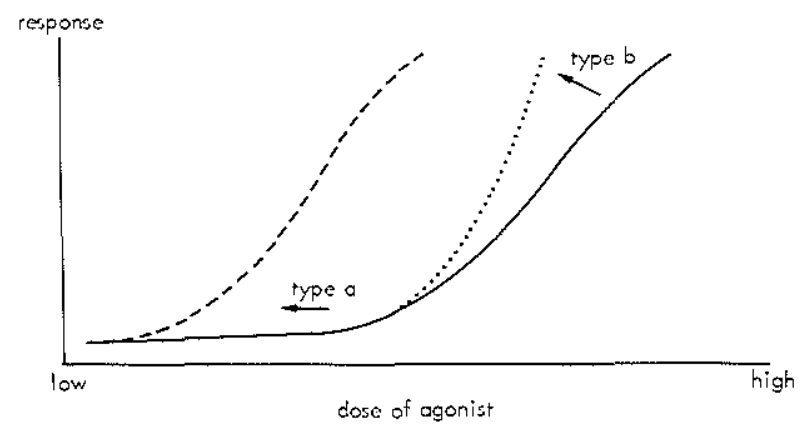

The relationship between the dose of the agonist and the response in contraction of bronchial smooth muscle in vitro.

$\left.\begin{array}{r}\text { Sensitizations: type a prejunctional } \\ \text { type b postjunctional }\end{array}\right\}$ see text

\subsection{Sensory receptors}

The sensory receptors are generally considered to be part of the parasympathetic nervous system (paragraph 3.4). These receptors are discussed in a separate paragraph because of the recent interest showed in them in the literature.

The sensory receptors in the respiratory tract play a role in the regulation of the bronchial smooth muscle tone, the laryngeal calibre, the mucus secretion and the pattern of breathing. Also receptors located outside the respiratory system, for instance in the carotid body, may influence the bronchial smooth muscle tone (Nadel \& Widdicombe, 1962a). These receptors may induce additional effects such as increase in blood pressure (Nadel \& Widdicombe, 1962b). The results of the studies in this field are complex and sometimes controversial, which probably reflects problems caused by difficult techniques and different animal species (Widdicombe, 1977).

The sensory receptors are situated in the airways and can be identified by microscopic and histochemical techniques. Their location has been determined by stimulation studies in the nose and pharynx (Kaufman \& Wright, 1969; Allison et al., 1974), larynx (Nadel \& Widdicombe, 1962b; Boushey et al., 1974) and bronchi (Tomori \& Widdicombe, 1969; Widdicombe, 1978).

The nasal receptors generally cause sneezing and bronchodilatation, but may induce bronchial obstruction (Widdicombe, 1977). Receptors in the larynx may in- 
duce coughing, expiratory efforts, swallowing, bronchial obstruction, mucus secretion. laryngeal constriction, hypertension and bradycardia (Phipps \& Richardson, 1976).

The sensory receptors in the airways can be divided into three classes:

a. Irritant receptors. These receptors are sensitive to inhaled substances, such as carbon dust, sulphur dioxide, ammonia, cigarette smoke, ethyl ether vapour and histamine (Simmonsson et al., 1967; Mills et al., 1969; Widdicombe, 1975). The irritant receptors are also stimulated by pulmonary congestion and oedema, anaphylaxis and microembolism (Mills et al., 1969; Sellick \& Widdicombe, 1969), pneumothorax (Sellick \& Widdicombe, 1969) and possibly hypocapnia (Coleridge et al., 1978).

The localisation of the irritant receptors extends from the trachea to the large bronchi, with a concentration at the carina and hili (Mortola et al., 1975). Irritant receptors seem to be identical with the afferent nerve endings which lie between the epithelial cells of the mucosa (Widdicombe, 1977). The intercellular contact of the mucosal cells is accomplished by tight junctions (Diamond et al., 1978). Along with the decrease in tightness of the junctions, as occurs in mucosal damage, the irritant receptors become more exposed to the intrabronchial lumen.

Stimulation of the irritant receptors causes rapidly adapting irregular discharges in the connecting nerve fiber which are myelinated and afferent in origin. The reflex actions of receptors in the trachea and main bronchi include constriction of smooth muscle, increase in mucus secretion, cough and laryngeal constriction. Those located deeper in the lung cause hyperpnoea rather than cough and do not increase secretion (Tomori \& Widdicombe, 1969; Fillenz \& Widdicombe, 1971).

Other names for irritant receptors are rapidly adapting deflation or expiration receptors.

b. The stretch receptors. These are stimulated by distension of the lung and bronchi. They occur more in the extrapulmonary than in the intra-pulmonary airways and they seem to be located in the smooth muscles. After stimulation, by maintained inflation of the lungs, their myelinated nerves show a slowly adapting pattern of discharge. Their reflex action includes inhibition of inspiration, which is known as the Hering-Beuer inflation and deflation reflex (Widdicombe, 1954), and a decrease in tracheal and bronchial smooth muscle tone.

The stretch receptors are influenced by inhaled $\mathrm{CO}_{2}$. A low airway $\mathrm{CO}_{2}$ concentration stimulates them (Bartlett \& Sant'Ambrogio, 1976). 
c. The juxta-pulmonary capillary receptors, or in short type $\mathrm{J}$ receptors are also named alveolar nociceptive. These receptors are assumed to be located especially in the respiratory bronchioles and alveolar ducts in the proximity of the pulmonary capillaries (Paintal, 1973). They are sensitive to mechanical forces and assumed to be stimulated by an increase in capillary or interstitial pressure. Under normal circumstances they seem to be of little biological significance. However, they may be triggered in cases of tissue damage as a result of accumulation of interstitial fluid or mediator release.

Their reflex actions include apnoea or rapid shallow breathing, laryngeal constriction, hypotension and bradycardia (Paintal, 1973). The type J receptors seem to have a weak reflex bronchoconstrictive action (Karczewski \& Widdicombe, 1969).

Recently c-fibres have been described, which have some features in common with type J receptors (Coleridge \& Coleridge, 1977).

Because the irritant receptors are supposed to be the main sensory receptors involved in BR, some experiments are reviewed which elucidate their physiology.

Direct stimulation of the receptors has been shown by Sampson et al. (1975). In experiments in dogs, they recorded nerve discharges as a measure of irritant receptor activity and intra-tracheal pressure as a measure of the bronchial smooth muscle tone. These parameters were related to histamine and acetylcholine inhalations. Acetylcholine caused a larger rise in tracheal pressure than an equimolar dose of histamine, but the irritant receptor discharge activity due to histamine was higher compared to that by acetylcholine. This discrepancy indicates a direct activation of the receptors by histamine but not by acetylcholine. After the inhibition of muscle contractions by a $\beta$-sympathetic agonist, the tracheal pressure due to the inhalation of histamine dropped considerably $(81 \%)$, while the receptor discharge was only slightly lower ( $26 \%$ ) than without a $\beta$-sympathetic agonist.

Vidruk et al. (1977) extended these experiments in dogs in which a fibre-optic bronchoscope was used to determine the location of receptor endings in the bronchi and to apply histamine and other stimuli directly on or near the receptor. The result was measured by means of the afferent nerve discharge and by observation of the bronchial diameter. Histamine stimulated most of the receptors, whereas acetylcholine and buffer solution did not. Isoproterenol had only a slight effect on the response to histamine.

The investigators concluded that smooth muscle contraction was not essential for the stimulation of irritant receptors and that histamine could stimulate them. In these studies most receptors could be activated by one or more of the following agents: histamine, ammonia, ether and cigarette smoke. Histamine turned out to be the most consistent stimulus. It activated approximately 80 percent of the receptors. The activity in the afferent nerve began to increase about 10 seconds after the triggering of the receptor and simultaneously the tracheal pressure increased (Sampson et al.. 1975). Responses could repeatedly be obtained from the same receptor site: their action was not related to any phase of respiration. 
Acetylcholine, used as stimulus in these experiments, was unable to activate the irritant receptors, although a clearcut bronchoconstricting action was observed.

Dixon et al. (1979a, 1980a) studied the ability of histamine, acetylcholine and serotonin ( $=5$ hydroxytryptamine) to activate lung irritant receptors and to induce reflex bronchoconstriction. All agents given by aerosol and intravenously, produced increased discharge of the irritant receptors, increased total lung resistance and induced a fall in dynamic compliance. The changes in lung function due to histamine and serotonin, were markly reduced by vagal cooling (a specific afferent fibre block). This points to the involvement of the afferent parasympathetic nerve system in the mechanism by which the triggered irritant receptors cause bronchial obstruction. This was not found with regard to acetylcholine.

Histamine induced irritant receptor activity can be blocked by a $\mathrm{H}_{1}$ antagonist (chlorphemiramine) and not by a $\mathrm{H}_{2}$ antagonist (cimetidine). This suggests that irritant receptors comprise or are linked to a $\mathrm{H}_{1}$ receptor (Dixon et al., 1979b). In a further study these investigators showed that irritant receptors are sensitized by respiratory infections (Dixon et al., 1979c).

The permeability of the airway epithelium increases after exposition to ozone (Matsumura, 1970), histamine, methacholine (Boucher et al., 1978) and cigarette smoke (Simani et al., 1974). This could be concluded from the penetration depth of a dye into the intercellular spaces of the airway epithelium in various species. This suggests that the tight junctions have loosened and permit penetration for external influences towards the irritant receptors.

Studies with agents that damage the bronchial epithelium, such as ozone, show that irritant receptors are more susceptible when the airway epithelium is disrupted (Boatman et al., 1974). The possibility that irritant receptors are intrinsically modified by these agents is supported by the observation that their sensitivity to intravenous histamine is also increased in states of BHR (Dixon et al., 1979c). Short term inhalation of a low concentration of ozone reveals a marked increase in BR to inhaled histamine in healthy dogs (Lee et al., 1977). This was abolished by both vagal cooling and atropine, which indicates that afferent and efferent parasympathetic pathways are involved.

As a bronchodilator aerosol had no protective effect, it was concluded that changes in bronchial smooth muscle tone were not involved. However, Linn et al. (1978) showed that the reactivity of bronchial smooth muscles increased after very high doses of ozone. Similar findings using ozone in atopic and healthy human subjects by Golden et al. (1978) and Holtzman et al. (1979) indicate that the pathways in humans are the same as in dogs in this respect. These observations are consistent with the hypothesis that ozone increases bronchial responses by altering the exposure or sensitivity of the sensory receptors.

Other agents, which can damage the bronchial epithelium, may affect BR as well. A viral infection in non-asthmatic individuals temporarily increases the 
threshold to inhaled histamine (Empey et al., 1976). Hall et al. (1978) did similar observations using methacholine. The BHR with methacholine during conditions causing epithelial damage has to be explained by other mechanisms than the irritant receptors. Other parts of the autonomic nervous system or bronchial smooth muscles are candidates in this respect.

$\mathrm{BR}$ also increases after influenza vaccination as was shown by Ouelette et al. (1965) in asthmatics. Healthy and asymptomatic asthmatic subjects showed a temporarily increased $B R$ to inhalation of nitrates after an acute respiratory infection by influenza A virus (Utell et al., 1980).

An inhaled local anaesthetic can inhibit irritant receptors (Dain et al., 1975). However, bupivacaine can also block the efferent nervous pathways as was shown in further studies in dogs and cats. This means that the blocking effect of local anaesthetics does not necessarily imply the sole involvement of the sensory receptors, but may regard the impact of nervous fibres in general. Cross et al. (1976) and Thomson (1979) showed that the cough reflex to either tactile or chemical stimulation was abolished by bupivacaine. Dain et al. (1975) found a significant drop in the bronchial response to histamine, in contrast to Cross and Thomson, who did not. This difference might be explained either by incomplete blocking or by the relatively limited involvement of sensory receptors in histamine-induced bronchial obstruction.

\subsection{Parasympathetic nervous system}

The efferent fibres of the parasympathetic nervous system in the respiratory tract run in the vagal nerve. The preganglionic fibres connect the central nervous system with the parasympathetic ganglia located in the walls of the airways, and then form post-ganglionic fibres, which supply bronchial smooth muscles and mucosal glands. These fibres terminate on the endorgans by means of muscarinic receptors (El-Bermani \& Grant, 1975). The neurotransmitter of the muscarin receptor is acetylcholine, which is inactivated by acetylcholine-esterase. The acetylcholine effect can be blocked by atropine and atropine-like substances.

Many studies imply that the parasympathetic system is the most important regulator of the bronchial smooth muscle tone. Electrical stimulation of the vagal nerves causes bronchial obstruction as detected by lung function measurements and radiologic techniques (Olsen et al., 1965; Nadel et al., 1971).

The normal bronchomotor tone will decrease after abolition of the vagal activity by vagotomy (Colebatch \& Halmagyi, 1963) or by atropine (Nadel \& Widdicombe, 1963), and thus results in bronchodilation. Vagal stimulation causes bronchial obstruction in the large and small bronchi, but not in the bronchioles and alveolar ducts (Colebatch and Halmagyi, 1963; Nadel et al., 1971). The pattern of bronchial obstruction due to electrical stimulation of the vagal nerve is similar to that after inhalation of an allergen as was shown by Nadel et al. (1971) and by 
Kessler et al. (1973), with tantalum bronchography in dogs.

The evidence that vagal efferent pathways are involved in allergen-induced bronchial obstruction is supported by the fact that allergen-induced bronchial reactions can be inhibited by blocking of the vagal nerve activity by vagal section or application of atropine (Mills and Widdicombe, 1970; Gold et al., 1972; Yu et al., 1972).

Blocking the afferent parasympathetic fibre by cooling prevents bronchial obstruction induced by allergen or histamine inhalation in dogs (Gold et al., 1972). When the antigen aerosol was administered to one lung, airflow resistance increased in both lungs. If the vagus of the challenged lung was blocked by cooling, bronchial obstruction was inhibited in both lungs (Gold et al., 1972).

These results show that efferent and afferent parasympathetic fibers are of critical importance for the regulation of the bronchial diameter under resting conditions and after challenge with allergen or histamine and that this reflex spreads from its starting point over both lungs.

\section{5. $\beta$-sympathetic system}

The pathways of the sympathetic or adrenergic system have been studied by histochemical techniques in several animals (El Bermani, 1978). The description in animals conforms in general terms to that in humans (Spencer \& Leof, 1964; Richardson, 1979).

The sympathetic pathways of the lung originate from the extra-pulmonary stellate ganglia in which preganglionic fibres synapse into postganglionic ones. The plexus of sympathetic nerves is associated with the bronchial arteries.

Direct sympathetic innervation of the bronchial smooth muscles is scarce in animals (Mann et al., 1971) and not definitively demonstrated in man. Sympathetic fibres terminate on the parasympathetic ganglia (Jacobowitz et al., 1973) and probably in the mucosal glands (Spencer and Leof, 1964).

The role of the sympathetic system in the regulation of the bronchial smooth muscle tone appears from the following observations. After section of the sympathetic fibres in dogs, a modest bronchial obstruction appears, which indicates that a small degree of sympathetic dilator tone normally exists in the airways (Green \& Widdicombe, 1966; Woolcock et al., 1969).

Electrical stimulation of sympathetic fibre is followed by bronchodilation. This effect is abolished by $\beta$-sympathetic antagonists (Woolcock et al., 1969; Minatoya \& Ludena, 1967).

Sympathetic blockade, normally followed by bronchial obstruction (Castro de la Mata et al., 1962), was without effect when the parasympathetic action was inhibited (De-Kock, 1970; Mc Cullock et al., 1967). 
After section of the vagal nerves, stimulation of the sympathetic nerves has no effect. However, bronchoconstriction after parasympathetic stimulation is inhibited by stimulation of sympathetic nerves (Boushey et al., 1980).

Although the results of studies on the effect of the sympathetic system on the resting tone of the bronchial smooth muscle differ, most investigators assume that the magnitude of the effect depends upon the baseline parasympathetic tone and that under resting conditions the parasympathetic activity dominates that of the sympathetic.

Woolcock et al. (1969) tried to relate the action of the sympathetic and parasympathetic system to various airway levels. In dogs they recorded the airway resistance, as a measure of obstruction in the central bronchi, and frequency dependent compliance as a measure of obstruction in the peripheral bronchi. The bronchial obstruction by parasympathetic stimulation after a $\beta$-sympathetic antagonist (propanolol) was most pronounced in the central bronchi. They speculated that although the parasympathetic tone influences all levels of the airways, it was stronger counteracted by the sympathetic action in the peripheral than in the central bronchi.

The sympathetic system consists of a scanty fibre network and of receptors which are not connected with the network and react to circulating agonists and antagonists. There is good evidence which support the presence of sympathetic receptors in bronchial smooth muscles (paragraph 3.2). Although the role of the sympathetic system in asthmatic patients seems to be pronounced, the anatomical pathways by which this is effected is not clear. Various explanations have been proposed. Smooth muscle function may be modified by a change in blood flow due to a change in sympathetic tone of the blood vessels. Also an overflow of transmitter from nerve endings in the blood vessels may reach the sympathetic system in the smooth muscle. Furthermore sympathetic innervation of the parasympathetic ganglia (Vermeire \& Van Houtte, 1979) may interfere with the parasympathetic activity. Additionally circulating catecholamines released by the adrenal glands may act on the sympathetic receptors in the bronchial smooth muscle wall. Probably, several connections between the afferent and the efferent fibres and the sympathetic and parasympathetic system seem to be operative.

In 1948 Ahlquist proposed to divide the sympathetic receptors into $\alpha$ and $\beta$ types, according to their response to agonists and antagonists. Lands in 1967 classified the $\beta$-receptors in two autonomous subgroups: $\beta_{1}$, with mainly cardiac effects, and $\beta_{2}$, having mainly bronchial and vascular effects. In the lung $\beta_{2}$ receptors appear to predominate the $\beta_{1}$-receptors. The precise role of $\beta_{1}$-receptors in asthma is unclear and interconversion between both receptors is not established. Also subtypes in $\alpha$-receptors are distinguished, $\alpha_{1}$ and $\alpha_{2}$ but this is not discussed further on.

Kunos and Szentivanyi (1968) suggested that $\alpha$ - and $\beta$-receptors are con- 
formations of a single receptor site controlled by the metabolic milieu of the tissue. They reported that in frog hearts a reduction in temperature induces conversion of $\beta$-receptors into $\alpha$-receptors. The original observation on the effect of temperature in shifting the balance of the sympathetic receptors has been extended to include similar shifts under a number of conditions associated with low metabolic activity, hypothyroidism, hypoxia (Voelkel et al., 1981), muscarinic, cholinergic stimulation and adrenalectomy (Lefkowitz and Hofman, 1980). Although different opinions exist and the mechanism involved is unclear, changes between $\alpha$ - and $\beta$ - receptors may have biological significance. A change from $\beta$ - to $\alpha$-receptors implicate an increase in bronchial obstruction. For further discussion see paragraph 4.4.5.

In conclusion, the $\beta_{2}$-sympathetic activity seems to be important in the reversal of the bronchial obstruction, although the precise mechanisms involved are not quite clear. The sympathetic fibres and the catecholamines output of the adrenals seem to cooperate.

\section{6. $\alpha$-sympathetic system}

Presence of $\alpha$-sympathetic receptors has been shown in the airways of different species (Castro de la Mata et al., 1962). In man, Mathé et al. (1971) found evidence for bronchial obstruction induced by $\alpha$-sympathetic agonists in vitro, but only in the presence of $\beta$-sympathetic blockade. The stimulation of $\alpha$-receptors by agonists in vivo was demonstrated in human bronchial smooth muscle by some investigators (Adolphson et al., 1971; Simmonsson et al., 1972a), but not by others (Stone et al., 1973).

$\alpha$-receptor activity can be demonstrated more easily in the smooth muscle of asthmatic patients than in smooth muscles of non-asthmatic persons (Kneussel \& Richardson, 1978). Bronchial smooth muscle obtained from patients with asthma contracted when exposed to an $\alpha$-sympathetic agonist (noradrenaline). This could be blocked by a specific $\alpha$-blocking agent (phentolamine). In persons without bronchial hyperresponsiveness, $\alpha$-receptor activity in smooth muscle could only be found after pre-treatment with histamine.

Simmonson et al. (1972a) found in asthmatic patients a large increase in $\alpha$-receptor-induced bronchial obstruction after endotoxin, and much less so in patients without asthma. This observation may indicate a role of $\alpha$-receptors in asthmatic reactions after infections.

The role of $\alpha$-receptor activation has been evaluated by studying the effects of $\alpha$-agonists and antagonists in propanolol-, histamine- and exercise-induced bronchial obstruction. Prime et al. (1972) found in humans, after blocking the $\beta$-sympathetic receptors with propanolol, that the administration of phenylephrine (an $\alpha$-sympathetic agonist) caused bronchial obstruction. This could be prevented 
by premedication with an $\alpha$-antagonist. Also Patel and Kerr (1975) studied the effect of $\alpha$-receptor blocking drugs in reversible airway obstruction. Inhalation of thymoxamine or phentolamine caused a smaller bronchodilatation than produced by a $\beta$-sympathetic agonist. The combination of the $\beta$-sympathetic agonist and the $\alpha$-antagonist was more effective than each given alone.

Activity of the $\alpha$-sympathetic receptors seems to enhance the bronchial obstruction induced by histamine or exercise as can be concluded from studies in which they are specifically antagonized. More details are given in paragraph 4.3.6, 4.4 .6 and 5.3 respectively.

Henderson et al. (1979) studied the $\alpha$-sympathetic responsiveness by comparison of the constriction of the cutaneous vascular bed and the dilatation of the pupillary sphincter muscle by an $\alpha$-sympathetic agonist (phenylephrine) in healthy individuals and patients with asthma and allergic rhinitis. In patients with asthma the $\alpha$-sympathetic response was enhanced.

It is to be concluded from these studies that $\alpha$-sympathetic receptors do not appear to be prominent, but seem to be subordinate to $\beta$-sympathetic receptors. However, stimulation of $\alpha$-receptors results in bronchial obstruction. They may have an additional role to the parasympathetic activity, especially in certain conditions, such as infections. However, this is not definitely established.

\subsection{Non-adrenergic or non-sympathetic inhibitory nervous system}

Several studies indicate the presence of a nervous system that diminishes the bronchial smooth muscle tone, but does not belong to the sympathetic system (Bando et al., 1973, Coburn \& Tomita, 1973; Coleman \& Levy, 1974). Electrical field stimulation of the trachea of guinea pigs in the presence of sympathetic and parasympathetic blockade resulted in a decrease of the obstruction induced by an allergen or histamine inhalation (Richardson \& Bouchard, 1975). Also in man this phenomenon could be demonstrated. The electrical field stimulation-induced relaxation was neither blocked nor modified by sympathetic blocking agents, which indicates the non-sympathetic origin of this mechanism (Richardson \& Beland, 1976). However, nerves have to be involved, because of the blocking capacity of tetrodotoxin.

The system which is thought to be responsible is called the non-adrenergic inhibitory nervous system, a similar system in the gastro-intestinal tract has been previously described (Crema et al., 1968; Burnstock \& Costa, 1973).

The relevance of the non-adrenergic nervous system is obscure. Because the anatomical distribution, the neurotransmitter involved and specific antagonists are unknown, the non-adrenergic inhibitory system function is difficult to study. 
However, the possibility exists that it has an important additional role to the $\beta$-sympathetic system in the counteraction of bronchial obstruction.

\subsection{APUD-system}

The human tracheal epithelium, like that in other mammals, has been found to contain granulated cells with dense cores of 80 to $150 \mathrm{~mm}$ in diameter, which stain with silver techniques and show fluorescence with an amine technic (Lauwerijns et al., 1970). These are believed to be part of the APUD system (Cutz et al., 1975). They are named APUD for Amine Precursor Uptake and Decarboxylation.

APUD cells are described to have neural and endocrine functions (Tischler et al., 1977). They have the ability to take up, decarboxylate and store aromatic-amine precursors, such as 5-hydroxytryptophan and dopa, synthesize aromatic-amine or polypeptide-secretory products or both. These cells are present in several endocrine organs, the gastro-intestinal tract and the bronchi.

It has been proposed that their cells represent hypoxia sensitive chemoreceptors within the bronchial mucosa. They may produce amines or kinine-related substances which act upon the pulmonary circulation or modify the caliber of the airway lumen by an action on bronchial smooth muscle (Lauwerijns and Peuskens, 1969).

As they are relatively numerous and appear well-differentiated in fetal lungs (Cutz et al., 1975), APUD cells may be particularly involved in regulation of fetal lung circulation or play a role in the cytodifferentiation of pulmonary epithelium. Their role in BR is unknown.

\subsection{Mediator release, cellular aspects}

Mast cells and basophilic leucocytes have the ability to release mediators, which can produce the typical signs and symptoms of the acute allergic reaction (Lichtenstein \& Austen, eds., 1977; Daems, Quanjer \& Reerink-Brongers, eds., 1976; Pepys \& Edwards, eds., 1979).

This process is studied in mast cells obtained from chopped human lung tissue or by peritoneal lavage of animals, as well as in basophilic leucocytes.

The mediator release process is non-cytoxic and is in many aspects similar to other secretory processes (Lichtenstein, 1978). Two stages are usually distinguished: the first is calcium dependent and the second is energy-dependent. This energy is supplied by anaerobic glycolysis. However, recent evidence points to a decrease in intra-cellular ATP-cyclic AMP concentrations in conjunction with calcium influx into the cell, suggesting a requirement of energy supplied by stores in the first stage of the release process (Mongar \& Foreman, 1979).

As in other secretory processes, the mediator release process is modulated by the intra-cellular levels of cyclic nucleotides (Sutherland, 1970). 
Once the cell is sensitized fixing the Fc part of the $\operatorname{IgE}$ antibody molecule to its cell-bound $\operatorname{IgE}$ receptor, it is triggered when challenged with the appropriate antigen or anti-IgE. However, other mechanisms may also trigger mediator release. In the IgE-induced release of mediators bridging of two cell-bound IgE molecules by antigen or anti-IgE takes place (Ishizaka et al., 1973; Ishizaka 1978). This leads to the accumulation of monomethylated lipids in the membrane, which open the calcium channels (Hirate \& Axelrod, 1978). (Figure 2)

Calcium uptake is required for the release of mediators in response to an antigen-IgE interaction at the membrane site (Foreman \& Mongar, 1972). The calciuminflux results in a fall in intra-cellular concentration of cyclic AMP (Mongar \& Foreman, 1979). This modifies the cyclic AMP control, resulting in an increase in the degree of assembly of the microtubules and the initiation of the secretory process (Gillispie \& Lichtenstein, 1972). (Figure 3)

Figure 2.

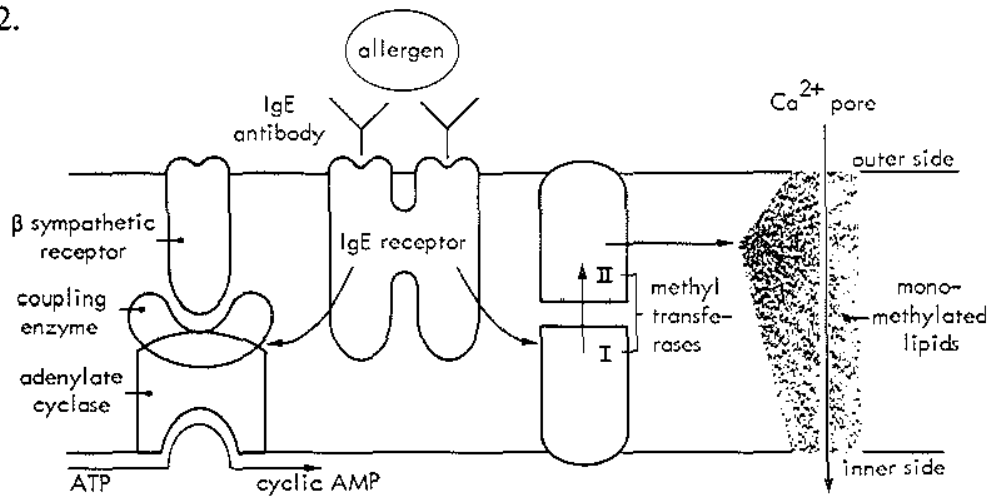

Schematic representation of the membrane events of mast cells in relation to the IgE receptor.

Receptor units situated in the outer cell membrane are thought to regulate intracellular processes. $\beta$-sympathetic agonists increase intra-cellular cyclic AMP levels, whereas parasympathetic agonists increase intra-cellular cyclic GMP levels. Adenylatecyclase, which is closely linked to the $\beta$-sympathetic receptor, converts adenosine triphosphate into cyclic AMP in the presence of magnesium ions. Cyclic GMP is formed in a similar fashion by activation of the enzyme guanylate cyclase which is triggered by the parasympathetic (cholinergic) receptor. Both cyclic nucleotides are inactivated by phosphodiesterases to form inactive $5^{1}$-AMP and $5^{1}$-GMP respectively. Thus the levels of cyclic AMP and cyclic GMP are influenced by the membrane-bound receptors on the one hand and the intra-cellular degrading enzymes on the other hand.

In vitro studies with human leucocytes and lung tissue have shown that increased concentration of intra-cellular cyclic AMP induced by $\beta$-sympathetic agonists or inhibition of phosphodiesterases, depress mediator release (Lichtenstein 
Figure 3.

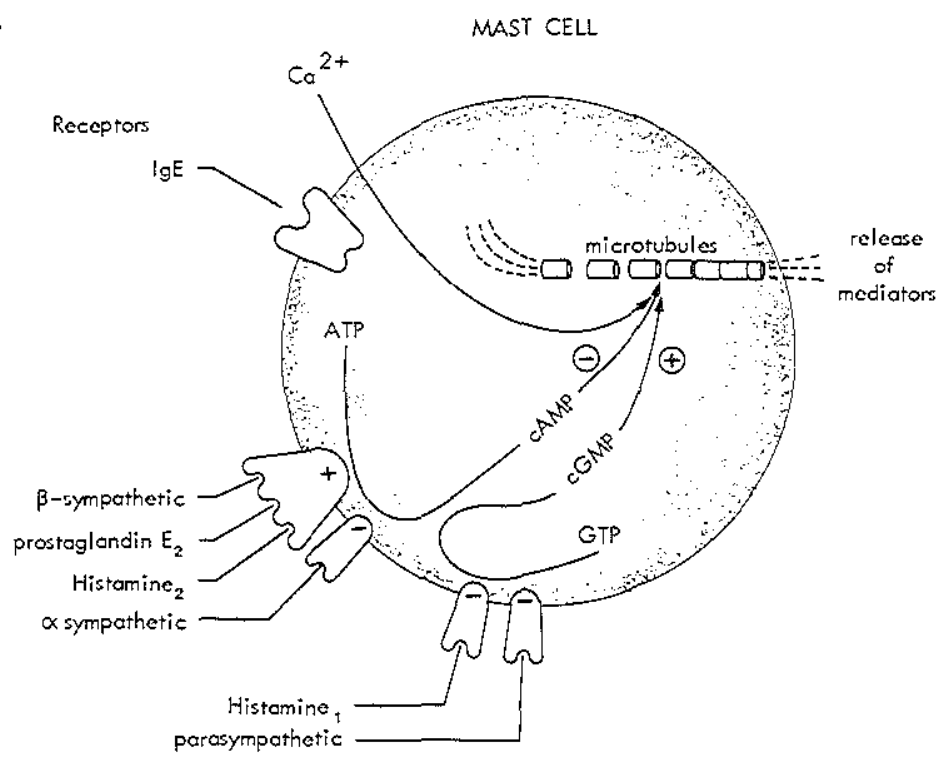

Schematic representation of the regulation of mediator release from mast cells.

\& Margolis, 1968; Orange et al., 1971). This is in contrast to other secretory processes where an increase in the intra-cellular cyclic AMP facilitates the secretion of a hormone (Sutherland, 1970).

Besides the $\beta$-sympathetic receptor other receptor entities have been described which influence the intra-cellular cyclic AMP concentration:

1. $\alpha$-sympathetic receptors are supposed to decrease the cyclic AMP concentration (Orange et al., 1971).

2. $\mathrm{H}_{2}$ receptors increase cyclic AMP and create a negative feed-back system of histamine release.

3. prostaglandin $\mathrm{E}_{2}$ receptors increase cyclic AMP concentration.

These receptor-units have been shown to exert their actions on the cyclic AMP concentration via the enzyme adenylate cyclase.

Enhancement of the intra-cellular cyclic GMP concentration without changing the intra-cellular cyclic AMP concentration has been shown to increase mediator release (Kaliner et al., 1973; Kaliner, 1977). Such an effect could be induced by acetylcholine or carbamylcholine via the parasympathetic receptor (Kaliner, 1977). 
Also $\mathrm{H}_{1}$ receptors, which stimulate mediator release are situated on mast cells and basophils. The factors and circumstances which determine the involvement of the $\mathrm{H}_{1}$ or $\mathrm{H}_{2}$ receptors are not quite clear. $\mathrm{H}_{1}$ receptors seemed to be linked to the cyclic GMP and $\mathrm{H}_{2}$ receptors to cyclic AMP system. (Platshon \& Kaliner, 1978)

Neither parasympathetic nor $\alpha$-sympathetic stimulation augments mediator release from human leucocytes, but these actions do have effects in human mast cells. It is not clear whether parasympathetic and $\alpha$-sympathetic receptors do not exist on basophils or are not functional.

Each mast cell and basophil possesses hundreds of granules containing preformed mediators. During the degranulation process the granules move to the cell surface along channels formed by assembly of microtubules and action of the microfilaments. Then granular and plasma membranes merge and finally the granules are released (Padawar, 1979). The evidence for the involvement of microtubules in a secretory phase includes the inhibitory effect of the microtubule binding agent colchicine upon both human leucocytes and rat mast cells and the enhancing effect of the microtubule stabilizing agent $\mathrm{D}_{2} \mathrm{O}$ upon both systems (Gillespie \& Lichtenstein, 1972; Gillespie et al., 1968). Cytochalasin B, which effects microfilaments, enhances release from human leucocyte suspensions (Colten \& Gabbay, 1972) and thus microfilaments are likely to be involved in the release process.

The inhibitory effect of an increased amount of intra-cellular cyclic AMP might be linked up with decrease of calcium influx and with inhibition of the assembly of the microtubules (Gillespie, 1971). Also impaired fusion of granular and plasma membranes are observed as result of an increase in cyclic AMP (Kaliner \& Austen, 1974a \& b). However, the influence of cyclic GMP and the interrelationship between cyclic AMP and cyclic GMP in human tissues is not clear. This is partly due to the difficulties in accurate determination of cyclic GMP concentrations.

The number of recognized mast cell-derived mediators involved in the pathogenesis of allergic phenomenon has increased extensively in the past decade. These molecules are chemically and biologically diverse. They generate various histological and physiological phenomena (Wasserman, 1979). These mediators are partly liberated from the granules from the mast cells or basophils (primary mediators) and partly induced from other sources by the primary mediators. Their biological activities are mentioned in table 1. 
Table 1 Mediators from mast cells and basophilic leucocytes

\begin{tabular}{lll}
\hline Mediator & State in tissue & Biological activities \\
\hline Histamine & preformed & contracts smooth muscle, increases venular \\
& permeability, stimulates sensory receptors. \\
& modulates prostaglandin synthesis: sup- \\
& presses mast cell and basophil mediator \\
& release. modulates chemotaxis. inhibits $\mathrm{T}$ \\
& lymphocytes. \\
& increases cardiac rate and force of contrac- \\
& tion, augments gastric acid secretion.
\end{tabular}

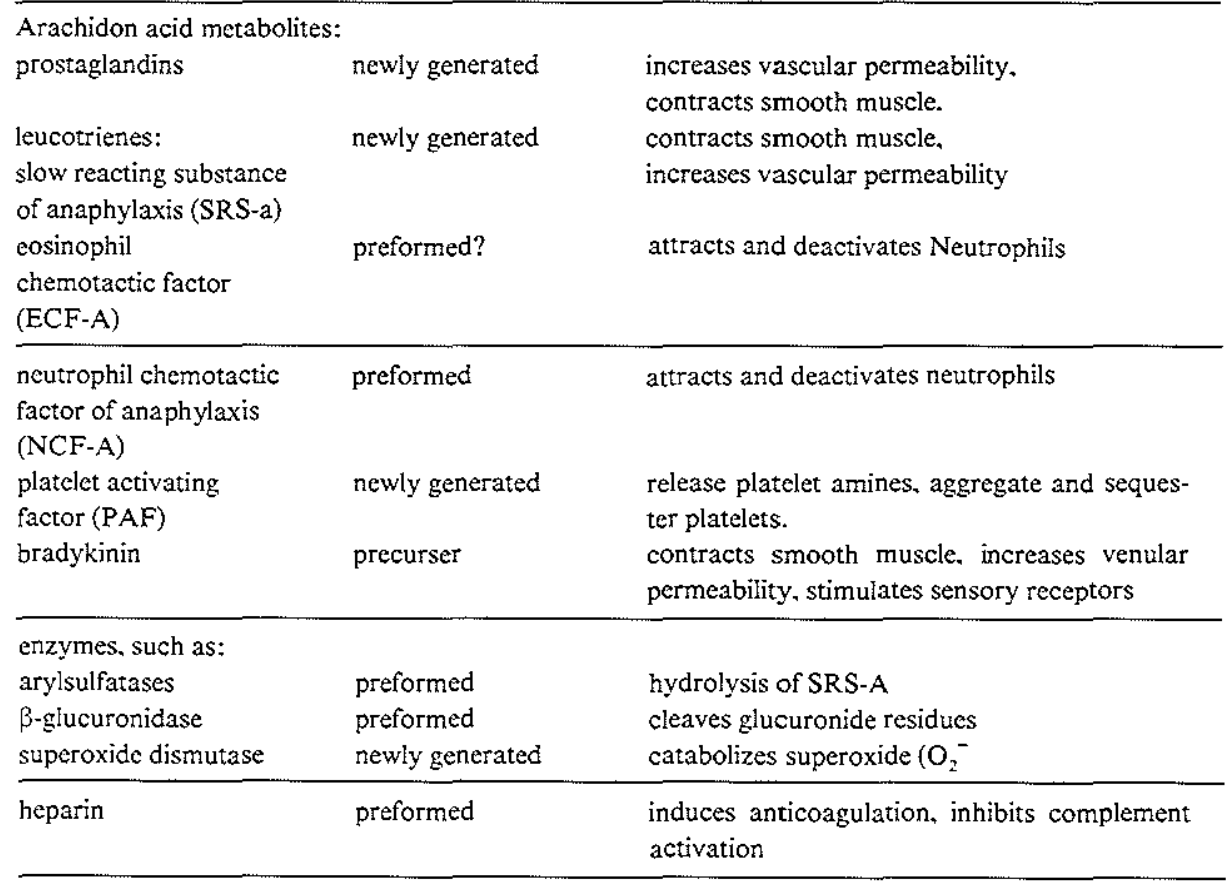

Two mediators will be discussed: Histamine, because of its central role, and the prostaglandins, because of recently developed insight into their relationship with SRS-A.

\section{Histamine}

Histamine is formed out of histidine, catalyzed by a specific L-histidine decarboxylase. Histamine is released from mast cells and basophils in a two step process: an expulsion of granules, followed by release of histamine from the heparinprotein complex of the granule. 
Histamine is metabolized in several ways. It is methylated in the presence of the enzyme histamine-N-methyltransferase and deaminated by histaminase. It is also con jucated to deoxyribose. The relative importance of the routes can vary. The body appears to have an amazing capacity to destroy histamine. This is necessary because of the potentially lethal effects of histamine.

In the blood of most species, including man, histamine is mainly present in the basophils. The amount of histamine in peripheral blood seems to correlate with the severeness of symptoms (Simon et al., 1977). It is also related to the occurrence of bronchial obstruction induced by allergens (Bhat et al., 1976) or methacholine (Atkins et al., 1980).

Histamine causes dilation of capillaries in the peripheral organs, resulting in pooling of blood in the capillary bed and a fall in systemic blood pressure. It also causes a substantial loss of plasma through the capillary epithelium leading to edema. Histamine also induces constriction of smooth muscle in organs such as bronchioles, uterus, ileum and spleen. Histamine promotes gastric acid secretion and is believed to have a role as a synapse transmitter in the central nervous system (Calcutt, 1976).

The existence of two types of receptors, $\mathrm{H}_{1}$ and $\mathrm{H}_{2}$ receptors, was first established by Black et al. (1972). The $\mathrm{H}_{1}$ receptor functions are inhibited by the classic anti-histamines. They are predominantly located in smooth muscle, glands and mast cells of the respiratory system and the skin. The $\mathrm{H}_{2}$-receptors are blocked by burimamide or cimetidine, but not by the classic anti-histamines. These $\mathrm{H}_{2}$ receptors are present in the stomach and also in the lung (Black et al., 1972). Mast cells and bronchial smooth muscles appear to have $\mathrm{H}_{2}$ receptors in addition to $\mathrm{H}_{1}$ receptors. $\mathrm{H}_{1}$ receptor stimulation produces smooth muscle contraction and vasodilation, while triggering of $\mathrm{H}_{2}$ receptors inhibits mediator release and smooth muscle contraction. For further discussion of histamine receptors see paragraph 4.4.1.

\section{Prostaglandins*}

PG's are not stored and the production is induced by the release of other mediators like histamine (Orehek et al., 1973; Grodzinska et al., 1975). Tone in airway smooth muscle preparation from guinea pig in vitro has been attributed to release of PG (Farmer et al., 1974).

PG's are formed from arachidonic acid. The enzyme cyclo-oxygenase catalyses the formation of endoperoxides, which can be transformed into thromboxanes and $\mathrm{PG}$ 's. Several types of $\mathrm{PG}$ 's are distinguished: $\mathrm{PGF}_{2}$ and $\mathrm{PGD}_{2}$

\footnotetext{
* which are relevant in this respect.
} 
(Wasserman et al., 1977), which give bronchial obstruction and $\mathrm{PGE}_{2}$, which induces bronchodilation.

The lipoxy-genase pathway produces a group of intermediates, now called leucotrienes. These agents appear to be linked or are identical to SRS-A. This is based on similarities concerning leucocyte stimulation, physico-chemical characteristics (Samuelsson et al., 1980a \& b) and effects on the bronchial tissues (Hanna et al., 1981). Various leucotrienes have been designated alphabetically. SRS-A from different sources seems to consist of variable amounts of leucotrienes $C$ and $D$ with leucotriene D as the main component of human lung SRS-A (Samuelsson, 1980a \& b). Drazen et al. (1979) postulated that SRS-A is a selective constrictor of peripheral airways. Also leucotriene $B$ can be generated and possesses chemotactic activity. It may be related or identical to ECF-A.

Table 2 A simplified diagram of arachidonic metabolites

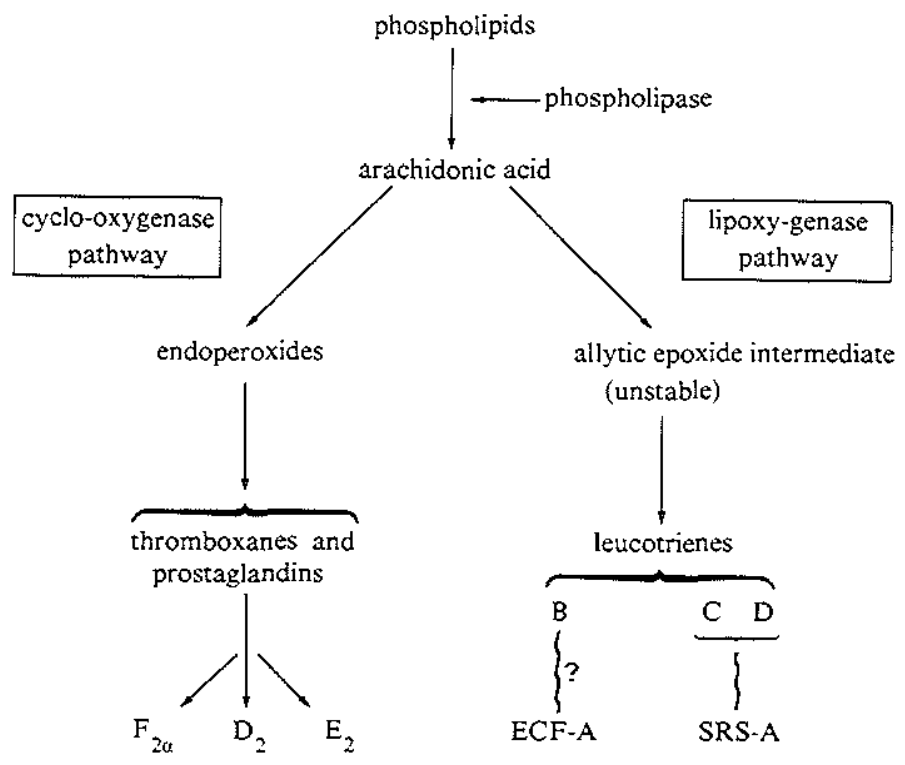




\subsection{Release of mediators in vivo}

\section{Distribution of mast cells}

The majority of mast cells are situated outside the basement membrane of the bronchial mucosa and are in close vicinity to bloodvessels and airway smooth muscle. Only a few (about $1 \%$ in the dog) are situated superficial to the basement membrane (Brinkman, 1968; Gold et al., 1977a). Histamine-releasing cells, probably mast cells or basophils have been detected in the bronchial lumen of humans (Patterson et al., 1977). The number of mast cells per $\mathrm{mm}^{3}$ increases from the trachea to the peripheral bronchi. The amount of histamine in lung tissue is closely related to the distribution of the mast cells. Both are maximal in the peripheral airways (Gold et al., 1977a).

2. Interactions between the release of mediators and other factors involved in bronchial obstruction

It is striking that inhaled allergens can trigger release from mast cells located in the bronchial wall. This occurs about 30-60 seconds after the inhalation. Allergens are large (about 10 to $20 \times 10^{3}$ Dalton) and little diffusible molecules, which hampers a quick penetration into the bronchial wall. After the inhalation of radiolabelled allergens which was followed by bronchial obstruction in guinea pigs, Richardson et al. (1973) could only find allergens on the surface but not in or under the epithelium of the bronchial mucosa.

The bronchial reaction can be initiated by release of mediators from mast cells in the airway lumen (Patterson et al., 1977). These mediators may increase the permeability of the bronchial epithelium (Boucher et al., 1978).

Subsequently, submucosal mast cells may be degranulated, and sensory endings may be stimulated thus causing a parasympathetic reflex. These mediators may also activate bronchial smooth muscle without involvement of nervous reflexes.

Several observations support the involvement of the nervous system in the process of bronchial obstruction after the release of mediators in vivo. After the inhalation of allergens in the dog, bronchial obstruction was observed with tantalum bronchograms in all airways from the trachea to small bronchi ( $0.3 \mathrm{~mm}$ in diameter). The investigators concluded that the reaction was maximal in the peripheral bronchi and could be inhibited by cholinergic blockade with atropine (Kessler et al., 1973). Under essentially the same circumstances the number of mast cells and the amount of histamine decreased in the central but not in the peripheral bronchi (Gold, $1977 \mathrm{~b}$ ). Thus the bronchial obstruction in the peripheral airways is probably not due to local mediator release, but results from a reflex induced action. Although histamine and other mediators may be carried via the circulation from the central 
to the peripheral bronchi, it seems more probable that mediators trigger the parasympathetic reflex mechanism (see paragraph 3.4 ) which results in a generalized airway obstruction.

A further argument for the involvement of the nervous systems in allergeninduced bronchial reactions is the reduction in bronchial obstruction after blockade of the parasympathetic nerve (see paragraph 3.4).

Mast cell release in vivo may be influenced by the autonomic nervous system. Mediator release from mast cells in vitro is modulated by changes in the levels of the cyclic nucleotides which are under control of the parasympathetic- and the sympathetic membrane bound receptors (see paragraph 3.9). Acetylcholine has been shown to induce release of histamine from rat mast cells (Fantozzi et al., 1978). Kiernan (1975) has presented evidence for mast cell degranulation in cutaneous axon reflex vasodilatation in the rat. Gold (1977b) could not find degranulation of mast cells or release of histamine after methacholine or electrical stimulation of the nerves in animals. However, Atkins et al. (1980) found in humans increase in arterial histamine levels after methacholine challenge. If the mast cells can be influenced by the autonomic nervous system, a mutual relationship exists. This can generate vicious circles, which may explain severe and prolonged bronchial reactions.

Also the sympathetic activity has an impact upon the bronchial reactivity to allergen inhalation. After a $\beta$-sympathetic antagonist the allergen-induced bronchial obstruction increases (Ouelette \& Reed, 1967; Gold, 1977b).

It may be concluded that in allergen-induced bronchial obstruction in addition to the role of the mast cells in the bronchial wall, mediator release from intra-luminal mast cells, permeability of the bronchial epithelium and a vagally mediated reflex are important. The parasympathetic nerves seem to be responsible for modulation and distribution of the signal generated by the mediator release from mast cells in vivo. It appears that parasympathetic hyperresponsiveness and $\beta$-sympathetic hyporesponsiveness aggravates BR in relation to the inhalation of allergens.

\subsection{Mucus secretion and mucociliary transport}

Mucus is produced by mucosal goblet cells as well as submucosal glands. Because of their size and activity submucosal glands are believed to be the major contributors to the airway secretion (Reid, 1960). Most studies on mucus secretion are done in animals, but great differences between the mechanism of mucus secretion in animals and humans are unlikely (Gallagher et al., 1975).

Nadel and coworkers (1977) studied the influence of various agents on water and active ion transport in the tracheas of various species using a short circuit technique, radio-isotopes and micropipettes. Parasympathetic and the $\beta$-sympathetic 
stimulation increased mucus secretion.

The effect of $\alpha$-sympathetic stimulation was far greater than that of the $\beta$-sympathetic, parasympatholytic or histamine effect (Marin et al., 1977). Sputum production can also be induced by histamine and prostaglandin $F_{2 \alpha}$ (Lopes-Vidriero et al.. 1977).

Mucociliary transport depends on the volume and viscosity of the sputum, on the effectiveness of ciliary activity and on the cough reflex. Parasympathetic agonists (Corssen \& Allen, 1959; King et al., 1979) and $\beta_{2}$-sympathetic agonists (Santa Cruz et al., 1974) stimulate mucociliary transport in animals and man. After vagal blockade by atropine, King et al. (1979) observed a decrease in mucus collection rate. Chronic stimulation of vagal receptors in airways may reflexly stimulate submucosal glands excessively and may cause hyperplasia of the glands, which may even increase bronchial reactions. These phenomena may play a role in the effector mechanism of hyperresponsive reactions, although this is not the most prominent contributor. The $\alpha$-sympathetic role in vivo in this respect is unclear, but may be important. 


\section{CHAPTER 4. BRONCHIAL RESPONSIVENESS TO VARIOUS STIMULI, PARTICULARLY HISTAMINE}

\subsection{Introduction}

In this chapter the role of the various factors which determine BR will be discussed with emphasis on the effect of histamine. The results of studies in animals will be discussed and an attempt will be made to correlate these with results in humans.

The last paragraph will deal with the clinical and epidemiological consequences of $\mathrm{BR}$.

\subsection{Methods of measurement of bronchial responsiveness}

In order to determine a relationship between the dose of a bronchial challenge agent and the response both variables must be measured accurately. As differences in methodology may influence the results, the methods have to be standardized as much as possible.

The following factors are of importance in the registration of BR:

\section{a. Choice of provocation agents}

Histamine and the acetylcholine derivates, methacholine and carbacholine, are currently used in the assessment of BR. Other agents are seldom used.

In order to obtain a local action and to minimize side effects, provocation agents are generally given by inhalation (Curry et al., 1946; Kang et al., 1976).

With the exception of exercise (see chapter 5) and hyperpnoea, other stimulants are more complicated to apply. Voluntary hyperpnoea is used by some investigators to test BR (Kivity \& Souhrada, 1981).

Recently, rapid breathing of cold air has proposed as stimulus in testing BR (Deal et al., 1980).

Histamine has an important role as a mediator in asthma according to our present view. Due to its relatively short lasting action, histamine is unlikely to produce cumulative effects provided intervals of several minutes are allowed between inhalations (Orehek et al., 1976b; study in paragraph 7.1). Histamine biphosphate solution, which is commonly used, is relatively stable and has virtually no side effects when used according to the methods applied in this country (see paragraph 6.1). 
Acetylcholine is the parasympathetic neurotransmitter acting on the muscarinic receptor. It is rapidly inactivated by cholinesterase. Methacholine and Carbachol ${ }^{\circledR}$ are parasympathomimetic agents which produce their effects in the same way as acetylcholine. Cholinesterases have small effects on carbachol and only slowly inactivate methacholine. Thus these agents have a relatively long lasting effect and thus cumulative dose response curves will be obtained after serial inhalations with short intervals. In most patients BR for histamine and acetylcholine are closely related (de Vries et al., 1964; Gökemeijer, 1976; Juniper et al., 1978).

\section{b. Delivery of the aerosols}

Challenges usually consist of serial doses of the stimulant, using not more than 2 -fold increments in dose with a controlled time interval between doses. To minimize the effects of an acid pH on the airways, it is appropriate to dissolve the agents in an aqueous diluent. $A \mathrm{pH}$ of 7 can be obtained by the addition of $\mathrm{NaCl}$ and $\mathrm{NaHCO}_{3}$ (ATS News, 1980).

Most investigators vary the dose of the agonist by increasing the concentrations keeping the volume of each inhalation constant, according to Tiffeneau et al. (1955) and de Vries et al. (1964).

The dose and distribution in the bronchi will be determined by the characteristics of the nebulizer used (Ferron et al., 1976) and also by patient factors like the breathing pattern and the presence of obstruction (Orehek et al., 1977b). The distribution of the aerosol is further dependent on the particle size. Small particles penetrate deeper and are better retained than large particles. Particles of more than $4 \mu$ diameter tend to deposit in the delivery system and large airways (Ferron et al., 1976). Particles less than $0.4 \mu$ in diameter have decreased deposition and tend to be exhaled. It has to be kept in mind that the relatively large particles, which are deposited in the central airways, will contain a much higher dose of agonist than the relatively small particles (Brain \& Valberg, 1979).

The goal of the distribution pattern has attracted little discussion. One can speculate that histamine deposited according to the distribution of the mast cells will immitate best the natural situation. Alternatively, the pattern of deposition may have little importance because of the generalizing effect of the reflex mechanisms. The last concept is supported by Ryan et al. (1981a) who found the same bronchial reaction when two different patterns of distribution with equal doses were used. In another study (Ryan et al., 1981b) the nebulizer output, but not particle size (between 1.3 and $3.5 \mu \mathrm{M}$ diameter) altered the response.

Several methods of aerosol generation are currently in use:

1. The continuous flow method with a closed system. The subject inhales the 
agent containing aerosol continuously. If the subjects inspiratory air flow is at least equal to the flow of the aerosol, the amount generated during inspiration will be fully inhaled. The dose administered then equals the nebulizer output per time multiplied by the product of the subjects inspiratory time and the number of breaths during the provocation period.

2. The intermittent flow method. The aerosol generation is performed by a unit which automatically triggers nebulization by the onset of inspiration and limits the duration of nebulization for a pre-set time, which should be within the first half of inspiration (Chai et al., 1975; Cropp, 1975a; ATS News, 1980). An aerosol given early during inspiration tends to penetrate less deeply than when inhaled at the end of inspiration (Riley et al., 1976). It is, however, not established whether this is an important factor to the bronchial reaction induced by histamine inhalation.

3. The continuous reservoir method. Orehek et al. (1976b) pointed out that variations in inspiratory volume, inspiratory flow and respiratory frequency alter the dose of aerosol reaching the bronchi. Inhalation of an aerosol of known concentration from a spirometer or a bag-in-box permits the accurate assessment of the amount inhaled. The inhaled dose can be calculated by the stored aerosol concentration multiplied by the number and volumes of breaths (Orehek et al., 1977; Utell et al., 1979). different.

The characteristics of the aerosols from the various delivery systems may be

\section{c. Condition of the subjects}

Various physiological, pathological and therapeutic factors may influence BR.

1. Breathing pattern. Tidal breathing favors penetration of an aerosol in the peripheral airways and forced in- and expiration favors deposition in the central airways (Riley et al., 1976). Breathing patterns applied are tidal breathing for some minutes (2') (Cockcroft et al., 1977a), deep in- and expiration during a short time ( $1 / 2$ minute) (Chai et al., 1976) or a combination (Kerrebijn \& Neijens, 1981). Forced inspiration may induce bronchial obstruction in some patients (Nadel et al., 1961; Gayrard et al., 1975a; Orehek et al., 1976b). However, inhalation to total lung capacity may sometimes temporarily decrease bronchial obstruction (Ankin et al., 1979).

2. Bronchial patency, as indicated by the baseline pulmonary function may influence the bronchial reponse (Love \& Muir, 1976) and thus the assessment of BR (de Vries, 1970; Orehek et al., 1976b; Gökemeyer, 1976).

However, the relationship between relative low initial lung function values and relative high degree of $B R$ is generally rather weak (Cade \& Pain, 1971; 
Kerrebijn et al., 1977), but it may compromize comparisons of measurements in the case of wide differences in baseline bronchial conditions.

3. Recent exposure to allergens (Gökemeyer, 1976; Zimmerman \& Ulmer, 1977), respiratory infections and polluted air (see paragraph 4.4.3) may influence the response to bronchial provocation.

4. Drugs administered prior to the test may result in a change in responsiveness.

5. The circadian rhythm influences BR: the BR is at highest around 4 o'clock a.m. and at lowest about 4 o'clock p.m. (de Vries et al., 1962a).

These factors are discussed extensively in various reviews (Orie \& Sluiter, 1961; Orie \& Sluiter, 1964; Orie \& van der Lende, 1970; Gökemeyer, 1976; ATS News, 1980)

\section{d. Measurement and calculation of the response}

Several techniques are used to assess the bronchial response. For routine use bronchial obstruction can be registered by means of measurement of the pulmonary function. This may be performed with a forced expiration technique such as spirometry or flow-volume measurement. The PF, FEV, MMEF or the end-expiratory flows $\left(\mathrm{MEFV}_{25}\right)$ can thus be registered. They are highly reproducible (Cropp, 1975a $\&$ b) but sensitive to forced respirations in some asthmatics. Alternatively, determination of airway resistance by body plethysmography is also used. The measurement is highly sensitive and requires no full inspiration nor forced expiration. However, its value will be influenced by closure of the glottis which easily happens in children. Moreover the equipment is complicated to manage and expensive.

The change in lung function indicating a significant bronchial obstruction, must exceed the intra-subject variability and has to be related to carefully obtained baseline values. The minimum changes which must be obtained before a test can be considered positive depend upon the parameter used, but are arbitrary. An example of criteria is given in ATS News (1980).

Two factors can be calculated from the dose-response curve, according to Orehek et al. (1977). The sensitivity to the provocation agent is determined by the dose which corresponds to a significant reaction ("the threshold"), while the reactivity is given by the slope of the curve after the threshold ("the response rate").

With standardized methods the results concerning the thresholds are reproducible (de Vries et al., 1962; Juniper et al., 1978; Habib et al., 1979).

Several working committees are charged to produce guidelines for the stan- 
dardization of BR testing to help to obtain comparable results between different laboratories. In the U.S.A. the "Guidelines of the programme directors of the Asthma and Allergic Disease Centers (AADC)" were published in 1975 (Chai et al., 1975 ) and the "ATS Guidelines for bronchial inhalation challenges with pharmacologic and antigenic agents" appeared recently (ATS News, 1980). In Europe the "Working Group on Bronchial Hyperreactivity of the European Society for Clinical Respiratory Physiology" is currently preparing guidelines for standardization (Kerrebijn, 1981).

Because of differences in output and characteristics of the aerosol, use of the same nebulizer and inhalation technique would be preferable. Because it seems unlikely that this is feasible within a short time, a comparison of the results of a limited number of delivery systems and methods is a practical approach which will enable us to interrelate the results of various publications better than is possible at present. More studies are needed in this respect.

\subsection{Histamine-induced bronchial responses as studied in animal experiments}

\subsubsection{Introduction}

Inhaled histamine causes bronchial obstruction by smooth muscle contraction produced by a direct effect on the $\mathrm{H}_{1}$ receptors and an indirect effect on irritant receptors and reflex mechanisms.

\subsubsection{Role of bronchial smooth muscles}

It has been shown that histamine contracts smooth muscles in vitro in a dosedependent way (Schild et al., 1951; Fleisch et al., 1973) (see paragraph 3.2). This also occurs in vivo as is suggested by experiments in guinea pigs and dogs after a nervous blockade (Gold et al., 1976; Dunlop and Smith. 1977).

\subsubsection{Role of the epithelium and the sensory receptors}

As histamine activates sensory receptors in the airways and hence induces bronchial obstruction via a parasympathetic reflex (see paragraph 3.3 and 3.4), the state of the airway epithelium and the receptors may influence the response.

The activation of irritant receptors by histamine has been demonstrated in rabbits (Mills et al., 1969), cats (Armstrong \& Luck, 1974) and dogs (Sampson \& Vidruck, 1975; Dixon et al., 1979a). Also type J receptors may be activated by histamine resulting in bronchial obstruction and rapid, shallow breathing (Karczew- 
ski \& Widdicombe, 1969).

BR to histamine increases after epithelial damage by ozone inhalation in dogs (Easten \& Murphy, 1967; Lee et al., 1977). Also respiratory infection in dogs increases BR to histamine and the rate of discharge of irritant receptors (Dixon et al., 1979c).

Blocking the irritant receptors by a local anaesthetic decreases the histamineinduced bronchial obstruction in dogs (Dain et al., 1975).

Based on the effect of epithelial damage caused by various influences and supported by the effect of a local anaesthetic, the sensory receptors are likely to play a role in histamine-induced reactions in animals.

\subsubsection{Role of the parasympathetic system}

Reflex bronchial obstruction after histamine aerosols has been studied extensively in animals. Mills \& Widdicombe (1970) found that vagotomy significantly reduced the histamine-induced increases in total lung resistance in guinea pigs, but had only a small effect on peripheral airway obstruction as detected by changes in compliance. Similarly Douglas et al. (1973b) reduced the bronchial obstruction produced by aerosolized histamine in guinea pigs by parasympathetic postganglionic blockade with atropine and ganglionic blockade with hexamethonium. Studies by Gold et al. (1972) and Dain et al. (1975) support the role of the vagal nerve in histamine-induced bronchial obstruction.

Drazen \& Austen (1975) found in the guinea pig that the effect of a low dose inhaled histamine on airway resistance and compliance was abolished by atropine. With higher doses both a direct effect and a parasympathetic effect seemed to play a role. In contrast, Loring et al. (1977) could not detect an effect of atropine on the histamine dose-response curves in dogs. However, the delivery of the agents and techniques used (see paragraph 4.2), and species differences may explain some of the variations in the results of these studies.

The state of the airway epithelium may also be an important determinant in the degree of the vagal component as discussed in paragraph 3.3 .

Thus, it can be concluded that bronchial obstruction after the inhalation of histamine is caused by a direct effect on the smooth muscle as well as an indirect activation via a parasympathetic reflex. The relative contribution of the direct effect gets larger with increasing doses of histamine. These effects are discussed and illustrated in paragraph 3.2.d and figure 1 . 


\subsubsection{Role of the $\beta$-simpathetic system}

A general introduction about this system is given in paragraph 3.5 .

Experimental models of $\mathrm{BR}$ have been created in the mouse and guinea pig. Increased bronchial sensitivity to histamine and other agents occurred after administration of Bordetella pertussis vaccine or $\beta$-sympathetic antagonists (Fishel et al., 1962). In this condition sympathetic functions were decreased, not only inside but also outside the respiratory tract. These include the epinephrin-induced vascular response, increase in heart rate and blood glucose level. Based on these observations. Szentivanyi (1968) suggested that an underlying abnormality in bronchial asthma is an inherited or acquired abnormality of the $\beta$-sympathetic receptor function. For further discussion see paragraph 3.5 and 4.4 .5 .

The effect of the sympathetic hypofunction in histamine-induced bronchial reactions has been studied in various animal experiments. Diamond (1972) found an increase in the histamine response after administration of a $\beta$-sympathetic antagonist or after cutting the sympathetic nerves in guinea pigs. These observations were confirmed by several others (Douglas et al., 1973b; Drazen, 1978).

Snapper et al. (1981) found the effect of $\beta$-blockade in dogs to be most pronounced in the peripheral airways.

Also catecholamines released by the adrenal glands have an influence on the bronchial response to histamine. Colebatch \& Engel (1974) showed that adrenalectomy increased histamine-induced lung function changes in cats.

Release of catecholamines, mainly adrenaline, is induced from the adrenal medulla by histamine directly in cats and via sympathetic reflex pathways in dogs (Staszewsky-Barczak \& Vane, 1965). Drazen (1978) studied the effect of adrenalectomy and of a $\beta$-sympathetic antagonist on the bronchial reaction induced by intravenous histamine in guinea pigs. The results suggest that the sympathetic nervous system modifies the response to histamine, whereas circulating catecholamines influence the recovery.

It may well be that $\beta$-sympathetic hyporesponsiveness is under genetic control, as particular inbreds of the mouse have $\beta$-hyporesponsiveness whereas others do not (Wardley et al., 1970). Pauwels et al. (1980) produced similar findings in rats.

It may be concluded that the $\beta$-sympathetic system is functioning as a homeostatic counteracting system. Hyporesponsiveness enhances BR to histamine.

\subsubsection{Role of the a-sympathetic system}

Drazen (1978) found that $\alpha$-antagonists decrease the histamine response under 
conditions of $\beta$-blockade. The overall contribution of $\alpha$ and $\beta$ receptors was evaluated by determining the effect of chemical sympathectomy with 6-hydroxydopamine on the histamine response. The histamine response decreased after this selective destruction of the sympathetic nerves. This effect was dose-related and greatest at high doses of histamine. This suggests that the combined $\alpha$ - and $\beta$-sympathetic fibres act to enhance histamine responses, probably by $\alpha$-sympathetic outflow.

Douglas et al. (1973b) concluded from their study in guinea pigs that those animals with a relatively high $B R$ seem to have the most pronounced hyperresponsiveness to $\alpha$-sympathetic agonists.

It is concluded from these experiments in animals that $\alpha$-receptors seem to play an additional role in histamine-induced reactions although their influence may vary.

4.3.7/8. Role of the non-adrenergic inhibitory nervous and APUD systems.

The role of the non-adrenergic inhibitory nervous system and the APUD system have not been studied with regard to histamine responsiveness with the exception of that mentioned in paragraph 3.7 and 3.8 .

\subsection{9/10. Role of the mast cells}

The role of the mast cells in histamine-induced bronchial obstruction is difficult to assess. It has been studied by stabilizing mast cells with DSCG. DSCG has been shown to stabilize mast cells (Cox et al., 1970; Spataro \& Bosman, 1976) and a binding site for DSCG on mast cells and basophils has been found (Mazurek et al., 1980).

In the dog histamine-induced bronchial obstruction was inhibited after both the inhalation and intravenous administration of DSCG (Jackson \& Richards, 1977). However, the authors speculate from their findings that DSCG may also have an effect on lung irritant receptors, which complicates the interpretation of these blocking studies.

In a further study DSCG was shown to be without effect on irritant receptors (Dixon et al., 1979d), but DSCG reduced action potentials in C-fibre endings (Dixon et al., 1980b) and these may be involved in histamine-induced bronchial obstruction (Karczewki \& Widdicombe, 1969).

\section{Conclusions of paragraph 4.3}

Based on studies in animals, inhaled histamine seems to activate sensory 
receptors which cause a parasympathetic reflex bronchial obstruction. The condition of the epithelium influences the response because the exposure of the sensory receptors to the intra-luminal stimuli depends on the integrity of the mucosa. However, histamine can also produce bronchial obstruction in animals with their parasympathetic nerve systems blocked. It is therefore most probable that histamineinduced bronchial obstruction, results from both a direct non-reflex effect of histamine on bronchial smooth muscle and an indirect vagally mediated reflex bronchial obstruction. Hyporeactivity of the $\beta$ and hyperreactivity of the $\alpha$-sympathetic system aggravate the histamine response, but the relative contribution of both systems in unclear. The role of mast cells is not defined at this moment but their activation and thus contribution to the bronchial response after histamine inhalation cannot be excluded.

\subsection{Histamine-induced bronchial responses as studied in humans}

\subsubsection{Introduction}

In order to analyse if the mechanisms of histamine-induced bronchial obstruction in animals is similar to that in humans, investigations on the effect of agents with various modes of action in histamine-induced reactions will be mentioned.

The effect of histamine-receptor antagonists has been reported in several studies. $\mathrm{A} \mathrm{H}_{1}$ antagonist (see paragraph 3.2) diminished histamine-induced bronchial obstruction after the inhalation of histamine, but not after methacholine (Woenne et aI., 1978; Casterline et al., 1979). The actions of $\mathrm{H}_{1}$ and $\mathrm{H}_{2}$ receptor antagonists were compared on histamine-induced reactions by Eiser et al. (1978) and by Nathan et al. (1979a; 1981). The dose of histamine which caused a $20 \%$ decrease in $\mathrm{FEV}_{1}$ was higher after the $\mathrm{H}_{1}$ antagonist chlorpheniramine and lower after the $\mathrm{H}_{2}$ antagonist cimetidine than the dose without these agents. This suggests that $\mathrm{H}_{1}$ and $\mathrm{H}_{2}$ receptors are present in human airways and have opposite actions. However, the effect of the $H_{1}$ receptor dominates. Busse and Sosman (1977), Chand (1980) and Nathan et al. (198I) suggest that the $\mathrm{H}_{2}$ receptor deficiency may be present in asthmatic patients and be partly responsible for exaggerated responses.

Ruffin et al. (1978) compared the effectiveness of central versus diffuse airway deposition of histamine aerosols, controlled by a radiotracer method. Histamine aerosol deposited predominantly in the central airways was more effective than the diffusely deposited histamine. This suggests that the receptors mediating the action of histamine are located mainly in the large airways or that the triggering of the centrally located receptors can induce a "complete" bronchial response. 


\subsubsection{Role of the bronchial smooth muscles}

It is difficult to determine the relative contribution of intrinsic properties of the bronchial smooth muscle and extrinsic regulation mechanisms to the bronchial obstruction after histamine challenge. As already pointed out, the contribution of intrinsic properties may be increased by hypertrophy and hyperplasia of the bronchial smooth muscle (paragraph 3.2).

The similarity of the bronchial reactions after histamine and methacholine (see paragraph 4.2) in which different types of receptors are involved, underline the importance of the smooth muscle responsiveness.

The main regulation disturbance seems to be present outside the bronchial smooth muscles, as the hyperresponsivity to various stimuli found in vivo was much less when bronchial smooth muscles of the same subjects were challenged with comparable stimuli in vitro (Simonsson et al., 1973; Douglas et al., 1973a).

\subsubsection{Role of the sensory receptors and the epithelium}

The integrity of the airway epithelium and the sensitization of the sensory receptors (see paragraph 3.3 and 3.4) which appear to be involved in the bronchial obstructive reaction caused by histamine inhalation in animals (see paragraph 4.3.3), are likely to be important in humans. Damage to the airway epithelium by ozone exposure in asthmatics (Holzman et al., 1979) and healthy subjects (Golden et al., 1978), or by respiratory infections (Empey et al., 1976; Laitinen et al., 1976) increases BR to histamine.

The effect of inhibition of sensory receptors by a local anaesthetic, bupivacaine was studied in humans by Thomson (1979). He found no protective effect on histamine-induced bronchial obstruction, although the cough reflex elicited by citric acid aerosol was abolished. However, these results were complicated by the bronchoconstrictor effect of bupivacaine, which may have eliminated a protective effect. Although Thomson's work does not support a role of sensory receptors in the bronchial responsiveness to histamine in humans, the observations based upon the effect of epithelial damage strongly indicate their role in this regard.

\subsubsection{Role of the parasympathetic system}

In human studies the results of parasympathetic blocking agents are variable and have mainly been performed in asthmatics. Simmonson et al. (1967) showed that atropine sulphate abolished the bronchial obstructive effect of histamine. However, large doses of histamine could not be blocked. In contrast Woenne et al. (1978) found only little effect of an inhaled parasympatholytic (ipratropium) on histamineinduced bronchial obstruction in children. Similarly Casterline et al. (1976) found a 
minimal effect of an inhaled parasympatholytic (atropine sulphate). On the other hand Cockcroft et al. (1977b) and also Thomson (1979) observed a clear protective effect in normal subjects with an upper respiratory infection. The differences in effect of parasympatholytics may be partially explained by the relative amount of histamine used.

Holtzman et al. (1980) studied the influence of an inhaled ganglionic blocking agent (hexamethonium) and muscarinic antagonist (atropine) on the bronchial response to histamine in atopic subjects. Bronchial obstruction was prevented by both agents in all patients. The inhibitory effect of a ganglionic blocker has been previously observed by Booy-Noord et al. (1969b).

Hyperresponsiveness of the parasympathetic system was studied by investigating the reaction of the pupillary constrictor muscles to a topically instilled cholinomimetic. Parasympathetic hyperresponsiveness was found in all atopic and non-atopic asthmatics in contrast to that in normals (Smith et al., 1980).

It is concluded that the parasympathetic system plays a role in BR to histamine in humans, although the evidence is less pronounced than in animal studies. It may well be that the parasympathetic action is most pronounced in reactions to relatively small amounts of histamine.

\subsubsection{Role of the $\beta$-sympathetic system}

When inhaled, $\beta$-sympathetic agonists have a pronounced protective effect on the occurrence of histamine-induced bronchial obstruction as was shown by Casterline et al. (1976) with albuturol and Cockcroft et al. (1977b) with salbutamol. In both studies the effect of the $\beta$-sympathetic agonist exceeded that of parasympatholytics and other agents.

As mentioned in paragraph 4.3.5, in 1968 Szentivanyi published his hypothesis of hyporesponsiveness of the $\beta$-sympathetic receptor as a basic defect in asthma. The function of the $\beta$-sympathetic receptor can be studied in vitro by measuring various metabolic responses as well as by determination of plasma or urine cyclic AMP levels after a $\beta$-sympathetic agonist.

Support for the idea of Szentivanyi has been provided by various studies in humans. A diminished response to intravenous isoproterenol ( $\beta$ agonist) in terms of hyperglycaemia and cardiovascular effects was found in asthmatic subjects compared to normals (Cockson \& Reed, 1963: Lockey et al., 1967). Ouelette \& Reed (1967) showed that after pharmacologic $\beta$ blockade ragweed sensitive individuals without clinical asthma exhibited increased bronchial sensitivity to inhaled ragweed allergens.

Many studies have been performed to measure pulmonary function with and without $\beta$-sympathetic blockade (Bouhuys et al., 1971; Ryo \& Townley, 1972; Mc 
Geady et al., 1968; Turner et al., 1971). Although the results are variable, in general the asthmatics were more sensitive to $\beta$-blockade than healthy subjects.

A $\beta$-sympathetic antagonist (propanolol) induced an increased responsiveness to histamine and methacholine in asthmatics, in a few patients with allergic rhinitis, but not in normal subjects (Zaid \& Beall, 1966). Ply-Song-Sang et al. (1978) found an increase in BR to intravenous histamine after $\beta$-blockade by propanolol. Also Orehek et al. (1975b) in normals and Townley et al. (1976) in normal and allergic rhinitis subjects showed an increase in BR to acetylcholine after a $\beta$-sympathetic antagonist.

The function of the $\beta$-sympathetic receptor has been studied in vitro by measuring the effects of a $\beta$-sympathetic agonist on human leucocytes. $\beta$-sympathetic agonist induced changes in intra-cellular cyclic AMP were found to be less in asthmatics than in normal controls (Parker \& Smith, 1973; Logsdon et al., 1973; Haddock et al., 1975). Parker \& Smith (1973) noted that the decrease in responsiveness was most marked in periods of active asthma and returned towards normal during clinical remissions.

Apold et al. (1977) detected a relationship between the abnormality in the plasma cyclic AMP response to intravenous epinephrine and the histamine-induced bronchial responsiveness. Evidence was put forward indicating that hyporesponsiveness could be simulated by treatment with sympathetic agonists (Nelson et al., 1975; Conolly \& Greenacre, 1976; Kalisker et al., 1977; Morris et al., 1977; Bruynzeel et al., 1979). However, $\beta$-sympathetic hyporesponsiveness was also demonstrated without simultaneous medication (Busse \& Lee, 1976; Shelhamer et al., 1980). Apold \& Aknes (1977) and Busse et al. (1980) found a correlation between hyporesponsiveness of the $\beta$-receptor in vitro and $B R$ to inhalation of histamine. The $\beta$-sympathetic response of leucocytes in vitro was found to be lower in asthmatics than in healthy persons (Lemanske et al., 1980). In a further study these investigators showed that this decreased leucocyte reaction in asthmatics became even more pronounced after incubation with a virus (Busse et al., 1980). This indicates that $\beta$-hyporesponsiveness may increase during periods of infection. Thus increased bronchial responsiveness, which is often present in such periods, may be associated with decrease of $\beta$-sympathetic responsiveness.

The usage of radiolabelled ligands have made it possible to quantify the number of $\beta$ - or $\alpha$-receptors. Using this technique Brooks et al. (1979) and Kariman (1980) found a decrease in the number of $\beta$-sympathetic receptors on lymphocyte membranes from asthmatic subjects than on those obtained from normals. The asthmatics were not being treated with sympathomimetic agents for a long time. A relationship was established between the number of $\beta$-receptors and the severity of the disease. Szentivanyi (1979a, 1979b) measured the number of $\beta$ - and $\alpha$-receptors in the lungtissue and lymphocytes of asthmatics with reversible airway obstruction, and patients without obstruction. The ratio of the number of $\beta$ - to $\alpha$-sympathetic receptors was much lower in asthmatic patients than in the other group. This sug- 
gests an important role for the $\beta$-sympathetic system in bronchial tone regulation. Furthermore it indicates that a conversion of $\beta$ - into $\alpha$-receptors (see paragraph 3.5) may be a basic defect in asthma and the hyporesponsiveness of the $\beta$-sympathetic system. A $\beta$-sympathetic hypofunction may explain partially the increased responsiveness of the bronchi.

\subsubsection{Role of the a-sympathetic system}

Few studies have been performed on the role of the $\alpha$-sympathetic system in BR to histamine in human subjects. Kerr et al. (1970) demonstrated that in asthmatics $\alpha$-blockade with phentolamine and phenoxybenzamine, reduced the intravenous histamine-induced bronchial obstruction. Similar findings were observed with thymoxamine, a more specific $\alpha$-blocking drug (Gaddie et al., 1972; Prime et al., 1972).

These studies indicate that sensitivity of $\alpha$-receptors may play an additional role in the generation of histamine-induced bronchial obstruction. The $\alpha$-receptors are probably stimulated in the course of the sympathetic counteractivation and hence produce an adverse effect.

\subsection{7/8. Role of non-adrenergic and $A P U D$ systems}

Information about the non-adrenergic inhibitory and apud systems in histamine-induced bronchial obstruction in humans is not available.

\subsection{9/10. Role of the mast cells}

As in animal studies, the role of the mast cell system in BR to histamine in humans can be approached by assessing the influence of DSCG and by measuring the release of mediators.

As mentioned in paragraph 4.3.9., doubt concerning the mode of action of DSCG, makes interpretation of its blocking effect uncertain. Also Harries et al. (1981) suggested that DSCG has an action on irritant receptors or bronchial smooth muscle as it blocked sulphur dioxide induced bronchoconstriction in asthmatic patients. To date controversy surrounding the mode of action has not been solved. The measurement of other mediators such as the neutrophil chemotactic factor, has recently been developed and may reveal a new approach to the detection of mast cell involvement (Austen, 1980; Orr et al., 1980).

DSCG was found to decrease BR to histamine in some asthmatic patients (Kerr et al., 1970; Pauwels et al., 1978; Woenne et al., 1979), although in other 
studies this effect was not found (Kang et al., 1976; Thomson et al., 1979). These differences are difficult to explain, but may be caused by the observed large intersubject variability and the use of small study groups.

Methacholine-induced bronchial obstruction was found to be associated with a rise in arterial histamine level (Poon et al., 1977; Allen et al.. 1978: Atkins et al., 1980).

It is concluded that a role of mast cells in BR to histamine or methacholine is suggestive, but not conclusively proved.

\section{Conclusion of paragraph 4.4}

Although the studies in humans with agents that influence the histamineinduced bronchial responsiveness are not quite in agreement with those in animals, they generally confirm the concept of the mechanisms found in animal experiments. The role of the parasympathetic system is less clear in humans. However, it is most probable that histamine produces a sensory receptor plus a parasympathetic reflex action, and a direct smooth muscle activation. Their relative contribution may vary with factors such as the dose of histamine, the inhalation technique, the state of the epithelium and the vagal tone. The mast cells may also be involved. The $\alpha$-sympathetic activity may act as a third system involved in the bronchial response to histamine.

The $\beta$-sympathetic system regulates the counteraction and hypofunction of the $\beta$-system will result in BHR. The immediate response to histamine is inhibited by the sympathetic fibre system. which can be accomplished in several ways (see paragraph 3.5). Circulating catecholamines from the adrenal medulla become involved after the immediate response. The adrenals are triggered by their nervous innervation or by circulating histamine. It can be speculated that the non-adrenergic inhibitory system may be involved as a second counteracting system, but to date there are very few studies to support this idea.

\subsection{Relationship between bronchial responsiveness and diseases and symptoms}

\section{Bronchial asthma}

Asthmatics frequently have greater BR to histamine or methacholine than normal subjects (Curry, 1946; Makino, 1966; Itkin, 1967; Cockcroft et al., 1977a: Orehek et al.. 1977). 
BR to histamine or methacholine varies widely within the group of asthmatics and a relationship between the severity of the symptoms and the degree of BR is often found. This is illustrated in a number of studies. Makino (1966) noted a relationship between a score representing asthmatic symptoms during one year and the threshold for histamine or acetylcholine. Cockcroft et al. (1977a) found that the severity of BR and asthma were correlated, although a large overlap was present. Similar findings were published by Spector \& Farr (1975).

Also occupational asthma is related to BR (Lam et al., 1979; Cockcroft et al., 1979a: Freedman et al., 1981).

Several investigators have shown that the degree of BR contributes to the occurrence and the severity of the bronchial obstruction caused by some defined stimulants.

There is a relationship between allergen-induced bronchial obstruction and BR. This was shown by Kreukniet \& Pyper (1973) with cat dander allergen, Killian et al. (1976) with pollen and house dust allergen, Bryant \& Burns (1976) with house dust allergen, Nathan et al. (1979b) with pollen allergen, Cockcroft et al. (1979b) with various allergens and Neijens et al. (1979) with cat dander allergen.

Exercise-induced bronchial obstruction is also related to the degree of BR (Kiviloog, 1973a: Mellis et al., 1978; Anderton et al., 1979: Neijens et al., 1980). For a detailed discussion about exercise and allergens in relation to BR is referred to the paragraphs 5.4 plus 8.1 and 8.2 respectively.

A high incidence of BHR is found in patients with chronic bronchitis, but this is less pronounced than in asthmatics (Gökemeijer, 1976). Bronchitics have a greater responsiveness to acetylcholine than to histamine (Gökemeijer, 1976).

\section{Allergic rhinitis due to pollen allergen}

Subjects with hayfever often have a moderate degree of BR ranging between that of asthmatics and healthy individuals. Townley et al. (1965) have compared these groups according to their BR to histamine and methacholine. Patients with hayfever were considerably less sensitive to methacholine than the asthmatics. With histamine the difference was less pronounced. The BR to histamine in the hayfever patients was three to four times that of normals.

Cockcroft et al. (1977a) found the prevalence of BR to histamine in patients with rhinitis to be intermediate (22-40\%) compared to that in asthmatics $(69-100 \%$, depending on the severity of symptoms), and that in presumed healthy subjects $(3 \%)$. 
Mitchel et al. (1978) found an increased BR to methacholine in $51 \%$ of children with cystic fibrosis compared to $98 \%$ of asthmatics. However, they found BHR in only $20 \%$ of cystic fibrosis children, against $100 \%$ of asthmatics when histamine was the stimulus. There was a correlation between BR and the pulmonary function. but not with allergic rhinitis or allergen skin tests. Thus, BR is not invariably a feature of cystic fibrosis, but may be present and relevant in some patients.

Davis et al. (1980) reported an abnormal sympathetic and cholinergic sensitivity in cystic fibrosis patients.

\section{Cigarette smoking}

Barter and Campbell (1976) showed in a prospective study in smokers that the progressive deterioration of the $\mathrm{FEV}_{1}$ correlated with the degree of $\mathrm{BR}$ to methacholine. They concluded that BR might be a predisposing factor of the vulnerability to cigarette smoke, although BR might also be a secondary phenomenon. Also Gerrard et al. (1980) found a higher BR to histamine in smokers compared to non-smokers.

\section{Conclusion of paragraph 4.5}

Although $\mathrm{BHR}$ is often present in asthma, it is not exclusive to this disease, as it may be present in other disease states, which are more or less related. It is even found in healthy persons.

\subsection{Course of bronchial responsiveness with age}

Information about the variation of the severity of BR with time not only reveals indications about endogenous and exogenous factors, but also of the relevance of BR and the benefit of treatment. Murakana et al. (1974) found an increased BR to acetylcholine in symptomatic asthmatic patients compared to that in a group of patients in remission for at least three years. Both groups did not differ in skintests or allergen specific IgE concentrations. However, Townley et al. (1975) found an increased $\mathrm{BR}$ in a large percentage $(82 \%)$ of former asthmatics, but this was a retrospective study.

The number of subjects with BHR to histamine increases with age. This was found in a population study by van der Lende et al. (1973). In this study no relationship was found between BR and either sex, allergy, eosinophilia, smoking or air pollution. However, a relationship was present between $B R$ and the baseline pulmonary function values. These studies indicate that both exogenous and endogenous 
factors might be involved in $\mathrm{BR}$.

Various studies tried to estimate the endogenous component of BR. Falliers et al. (1971) studied identical twins both with asthma. There was a wide variability between their bronchial responsiveness to methacholine, sensitivity to allergens and the intensity of symptoms, thus dismissing the concept of a genetic influence.

However, evidence for genetic influence on BR was found by Takino et al. (1971) in two families of guinea pigs, König \& Godfrey (1974) in identical but not in non-identical twins and by Guirgis et al. (1976) using genetic markers. These latter two studies were performed in humans.

It seems that an endogenous component in $\mathrm{BR}$ is an important determinant. However, exogenous factors may effect BR. More information is needed in this respect. 



\section{CHAPTER 5. BRONCHIAL RESPONSIVENESS IN RELATION TO EXERCISE}

\subsection{Introduction}

Exercise-induced bronchial obstruction (EIB), synonymous with exerciseinduced bronchospasm or exercise-induced asthma, is characterized by a dyspnoea which occurs after a short period of strenuous exercise. This symptom is frequently observed in asthmatic subjects, especially in children. Dyspnoea as result of respiratory insufficiency is not considered here. EIB can be quantified by lung function measurements, which show a characteristic pattern after strong exercise in a susceptible person. During a 4 to 10 minutes period of exercise a small but detectable improvement in lung function (bronchodilatation) occurs, this is followed by a deterioration (bronchial obstruction) at the end of or shortly after the completion of the exercise period. The clinical and physiological abnormalities, regardless of severity, are usually most marked during the first ten minutes after exercise and decrease over a period of 15 to 45 minutes.

Thomas Willis noted more than 300 years ago that various forms of exercise could provoke asthma. Up untill about 1960 scattered reports appeared on this subject. Since then an increased awareness has occurred which started by the observations of Jones and colleagues $(1962,1963)$.

Exercise-induced bronchial obstruction has been studied using various lung function techniques in several groups of subjects (paragraph 5.2) and the effects of drugs have been investigated (paragraph 5.3). Subsequent investigations have extended our understanding of EIB and the influence of protective agents.

\subsection{Factors in exercise testing}

The changes that are produced by exercise are dependent on the type and severity of exercise and the condition of the inhaled air. The following variables may affect the response to exercise:

\section{a. Amount of metabolic stress}

When the amount of exercise increases, a linear rise in heart-rate, ventilation and oxygen-consumption occurs. Along with oxygen consumption post-exercise bronchial obstruction sharply increases. This relationship applies equally to an increase in exercise time or strength of exercise (Godfrey, 1974; Edmunds et al., 1978). 


\section{b. Type of exercise}

Differences in the response to exercise at the same workload have been reported in a group of asthmatic children by Anderson et al. (1971) and Godfrey et al. (1973). Free-range running caused more EIB than treadmill running. Cycling revealed a lower drop in lung function than running, while walking and swimming were even less effective in causing a post-exercise fall. Sports such as swimming and kyaking, which primarily use the arms, are less likely to induce bronchial obstruction.

The differences in response to exercise were originally thought to be due to factors such as the use of different muscle groups. However, doubt about these explanations has been raised by several studies.

Anderson et al. (1975) have shown that cranking a bicycle ergometer with the arms can be as challenging as running provided the oxygen consumption is comparable. Arm work produced a greater airway obstruction than leg work but was also accompagnied by a greater metabolic load as judged by heart rate (Strauss et al., 1977a). If the load on the legs was increased, the differences between arm and leg exercise disappeared. The authors concluded that the workload and the mass of the exercising muscles determines the metabolic rate and thus the bronchial response. Similarly, running and cycling with equal metabolic load, defined by the oxygen consumption, revealed no differences in bronchial response to exercise (Fitch \& Morton, 1971: Miller et al., 1975). The bronchial challenge capacity of running or walking were compared under equal metabolic conditions by varying the slope in order to obtain similar minute ventilation and oxygen consumption. Both tests revealed an equally severe postexercise fall in lung function (Kilham et al., 1979).

A linear relationship exists between the oxygen consumption during exercise and the leg muscle volume. Maximum oxygen uptake in relation to age could be smoothed to a nearly linear horizontal line when corrected for leg muscle volume. This was not the case when corrected for lean body mass. Also the differences between both sexes, was almost abolished by such a correction (Davies et al., 1972). From these observations it appears that metabolic load, assessed by the oxygen consumption. depends upon the muscle mass. This may explain to a great extend the variability in EIB between persons of different age and sex and between different forms of exercise.

Thus it is most probable that the bronchial reaction after different forms of exercise is largely related to the metabolic load. The metabolic load is influenced by the strength of the exercise and the muscle mass. But also other factors play a role, these include fittness (paragraph 5.3) and environmental factors (paragraph 5.4). 


\section{c. Duration of exercise}

The influence of the duration of exercise upon the bronchial response was studied by Silverman \& Anderson (1972a). Asthmatic children were exercised on a treadmill set at a constant speed $(5 \mathrm{~km} / \mathrm{h})$ and slope (10\%). The duration of exercise was randomly varied between 1 and 16 minutes. The severity of exercise-induced bronchial obstruction increased with the duration of the test up to 6 to 8 minutes. Less post-exercise obstruction occurred in some subjects with exercisetests longer than 8 minutes. This was confirmed by Eggleston \& Guerrant (1976).

\section{d. Slope of the treadmill exercise test}

Silverman \& Anderson (1972a) studied the influence of the slope on the bronchial response to exercise. Asthmatic children ran for 6 minutes at a constant speed $(5 \mathrm{~km} / \mathrm{h})$ on various occasions while the slope of the treadmill was varied at random between $0 \%$ and $20 \%$, The post-exercise fall increased up to a slope of $15 \%$. Greater slopes were not associated with a further increase in post-exercise fall. The effect of the slope on the workload depends on the body weight of the patient.

\section{e. Time interval between exercise tests}

Exercise tests performed at 2 hourly intervals on the same day did not show significant changes in baseline or post-exercise lung function, according to the study of Silverman \& Anderson (1972a). James et al. (1976) repeated exercise-tests in asthmatic children at hourly intervals. They observed a progressively less bronchial response. The influence on exercise-induced bronchial obstruction by previous exercise was extensively studied by Edmunds et al. (1978). The ability to induce the same amount of bronchial obstruction was mainly recovered within 2 hours and always fully within 4 hours.

Thus a refractory period of about 2 hours exist.

\section{Standardization of exercise tests}

In order to keep the results comparable the exercise tests should be standardized for the variables mentioned. Several proposals for standardization have been published (Silverman \& Anderson, 1972a; James et al., 1976; Eggleston \& Guerrant, 1976).

Since monitoring of the oxygen consumption is seldom available in routine laboratories, the metabolic load has mostly to be assessed by the heart rate. An increase of the heart rate to $90 \%$ of the predicted maximum for age, is comparable 
to $60-85 \%$ of the maximum oxygen consumption (Godfrey, 1974; Eggleston \& Guerrant. 1976).

Godfrey (1974) studied progressive and steady-state exercise tests and found that standard steady state running tests gave the most reproducible responses. Silverman \& Anderson (1972a) and Godfrey (1975) considered 6 to 8 minutes running at steady state sufficient to develop a heart rate of 180 beats per minute in children or 160 beats per minute in adults. This can best be achieved by running on a treadmill with a slope. Eggleston \& Guerrant (1976) published a diagram of the relationship between height and treadmill speed required to obtain $90 \%$ of the predicted maximum pulse rate at a slope of 10 to $15 \%$. Intermittent exercise such as stepping or running up and down stairs is a less reproducible challenge.

Silverman \& Anderson (1972a) examined the reproducibility of exercise tests by calculation of the coefficient of variation (standard deviation divided by mean $\times 100 \%)$. Standard running was more reproducible than cycling. If standard running was repeated on the same day with intervals of about 2 hours, the coefficient of variation was approximately $30 \%$. The coefficient of variation increased to about $50 \%$ if the intervals between tests were longer than one week.

\section{Assessment of the bronchial response to exercise}

The bronchial response to exercise can be quantified by lung function measurements. The largest response will be approximated if measurements are repeatedly performed after the completion of exercise. The severity of the response has been expressed in different ways. Jones et al. (1966) have proposed the lability index, which is defined as the highest value minus the lowest, divided by the baseline value multiplied by $100 \%$. Also the fall in a lung function value as percentage of baseline or predicted value, is used. The relationship between the lability index and the fall has been considered by Silverman and Anderson (1972a). Both were strongly correlated, although a quantitative difference existed. Although the lability index provides an usefull expression of both phases of the response, the fall in lung function seems the most relevant in terms of phenomenon and symptoms. The percent fall is commonly used as indication of the severity of the bronchial obstruction after exercise.

Various lung function indices have been proposed as an expression of the bronchial response. Cropp (1975b) compared the results of various factors obtained by measurement of spirometry and body plethysmography. The measurement of SGaw revealed the largest change at any time during the post-exercise period. Changes in PF and MMEF were comparable, but were somewhat less than the SGaw. The change in the FEV 1 was less marked than in SGaw, MMEF and PF. The change in SGaw was significantly, but not linearly correlated with the decreases in PF. MMEF and FEV ${ }_{1}$. Cropp concluded that the FEV 1 was not the best measure 
of exercise-induced bronchial obstruction and the use of the MMEF would reveal larger responses. However, Kattan et al. (1978) came to the opposite conclusion. They judged the lung function indices by their ability to surpass the intra-individual variability and not by the absolute percentage. The flow at 50 and $25 \%$ of the VC revealed the greatest mean fall, but the PF and the $\mathrm{FEV}_{1}$ were the most sensitive indices in this respect.

Occasionally other lung function indices have been proposed such as the volume of trapped air (Svenonius et al., 1978) but they have no advantage over the conventional ones.

\subsection{Protective effects of pharmacological agents on EIB}

Atropine and related parasympathetic blocking agents have little protective effect on EIB. Atropine given by injection could not block EIB in the study of Chan-Yueng et al (1971), although Simonsson et al. (1972b) have shown that atropine can have some inhibitory effect. Parasympathetic antagonists by aerosol are somewhat more effective. Chan-Yueng (1977) could diminish EIB by Sch 1000 in the majority of the patients studied. Using a newer variant (ipratropium bromide), Thomson et al. (1978) observed a marked protective effect in 8 from 13 patients. Also Godfrey \& König (1976) found a partial effect. Hartley and Davies (1980) studied the same agent in a normal dose $(0.1 \mathrm{mg})$ and a very high dose $(1 \mathrm{mg})$ per aerosol. They showed that the high dose was more effective than the normal one. Thus factors like deposition and dose may play a role in the relatively poor effectivity of parasympathetic blocking agents in EIB.

The blocking capacity of $\beta$-sympathetic agonists in EIB is excellent in most patients when given by aerosol (Godfrey \& König, 1976; Hetzel et al., 1977; Tashkin et al., 1977). The effect of oral preparations is variable and less pronounced (Morse et al., 1976; Seale et al., 1977).

a-sympathetic blocking drugs (indoramin and thymoxamine) can partially inhibit EIB as shown in the studies of Bianco et al. (1974), Gross et al. (1974) and Patel et al. (1976). Beil \& de Kock (1978) found in a rather small study, inhibition of EIB after $\alpha$-sympathetic blockade by phentolamine. Also the increase in EIB produced by a $\beta$-sympathetic antagonist could be counteracted by the addition of phentolamine. These results point to a possible role of an activated $\alpha$-sympathetic receptor and an imbalance in the functions of the $\alpha$ - and $\beta$-sympathetic system in EIB.

The effect of DSCG on EIB has been assessed in several studies. In a preliminary communication Davies (1968) reported that DSCG had a protective 
effect in 8 adult patients with EIB. More recent studies revealed a nearly complete inhibition of EIB in the majority of patients, but with little or no effect in the remaining patients (Poppius et al., 1970; Silverman et al., 1972a; Chan-Yueng, 1977). DSCG protects more patients than parasympatholytics, such as Sch 1000 (ChanYeung, 1977) and ipratropium bromide (Thomson et al., 1978). An interesting observation about the mode of action of DSCG was demonstrated by Silverman \& Andrea (1972), who showed that it inhibited EIB if given before exercise but not if administered immediately afterwards.

Xanthine derivatives such as aminophyllin and theophyllin, give protection in EIB (Bierman et al., 1975b). According to Chryssanthopoulos et al. (1979a) the therapeutic serum concentration seems to have no influence, Kiechel et al. (1976) state that a level of at least $10 \mu \mathrm{g} / \mathrm{ml}$ is needed.

Corticosteroids orally or inhaled are of little value in the protection of EIB (König et al., 1974; Hartley et al., 1977a; Yazigi et al., 1978).

The aerosolized $\mathrm{H}_{1}$ receptor antagonist clemastine, markedly inhibited the bronchial response to exercise (Hartley \& Nogrady, 1980) which suggests an important role of histamine in EIB.

Some reports on other protective agents on EIB are interesting. Diethylcarbamazine parmoate, which inhibits the release of slow reacting substance of anaphylaxis in the rat, provided some protection against EIB in 15 of the 20 asthmatic children studied (Sly \& Matzen, 1974). Aspirin, given with the intention to influence the prostaglandin $\mathrm{F}_{2 \alpha}$ metabolism, had no effect on EIB (Taveira da Silva \& Hamosh, 1976). The calcium antagonist verapamil inhibited EIB and was comparable in effectiveness to DSCG (Patel, 1981).

The relative potencies of agents were compared in various studies. Godfrey \& König (1976) compared the inhibitory effect on EIB of a placebo, a parasympathetic antagonist (atropine), a $\beta$-sympathetic agonist (salbutamol) and DSCG all given by aerosol, together with an oral xanthine derivative in asthmatic children. The proportion of children who were clearly protected compared to those taking the placebo, amounted to $100 \%$ for the $\beta$-sympathetic agonist, $80 \%$ for DSCG and the xanthine preparation and $60 \%$ for the parasympathetic antagonist. Also Tashkin et al. (1977) compared the effectiveness of a placebo, a parasympathetic antagonist (atropine), a $\beta$-sympathetic agonist (isoproterenol), the combination of both and DSCG in asthmatic children. Post-exercise bronchial obstruction was partially inhibited by each of the agents in progressive order. The combination of a $\beta$-sympathetic agonist and parasympathetic antagonist revealed a better degree of protection than each alone. Our study (paragraph 7.1) reveals comparable results. Also psychological procedures, placebo or deconditioning procedures, seem to have a benefit in EIB (Heimlich et al., 1966; Khan \& Olson, 1977; Godfrey \& Silverman, 1973; Schwank \& Scherrer, 1978).

The effect of training could not be shown (Fitch et al., 1976), although it may 
improve the fitness and pulmonary function slightly (Shephard, 1977; Degre et al., 1977: Belman \& Mittman, 1980).

The therapeutic effects of inhaled agents in EIB can be summarized as follows. The $\beta$-sympathetic agonists are the most effective and parasympathetic antagonists are the least effective. The combination of both seems to be additive. The effect of DSCG is intermediate, but variable among patients. $\alpha$-sympathetic antagonists have a partial protective potency.

\subsection{Mechanisms in EIB: causes of hyperresponsiveness to exercise}

In the past the mechanisms of EIB have been obscure, however recent studies have provided some insight into that problem.

\section{Consequences from the pharmacological studies}

Based on the studies with agents to influence EIB (paragraph 5.3) the following hypotheses regarding the mechanism involved may be constructed. The reaction of the sympathetic system seems very important in EIB. Because of the strong protective effect afforded by $\beta$-sympathetic agonists, it is possible that a relative hyporesponsiveness of the $\beta$-sympathetic system (paragraph 4.4.5) or an imbalance between $\beta$ - and $\alpha$-receptors in favour of the $\alpha$-receptors could be important factors. The $\alpha$-receptors, whose antagonists were shown to inhibit EIB, could respond to a rise in the norepinephrine level during exercise. An inadequacy of the interaction or time scedule between the adrenal response and the sympathetic counteraction in the respiratory system, is also a possible explanation for EIB. The plasma levels of norepinephrine and epinephrine in relation to exercise were found to be lower in subjects with, compared to without EIB (Barnes et al., 1981).

The poor efficacy of parasympathetic antagonists is surprising in view of the importance of the vagus in bronchial obstructions caused by various stimuli in animal experiments (paragraph 3.4 and 4.3.4). Insufficient blocking of the parasympathetic action might be the explanation for this failure. If the pharmacologic blocking is complete in the studies with a partial parasympatholytic effect, other factors besides the vagus have to play an important role in EIB.

The protective effect of DSCG, a drug that is thought to act mainly by stabilizing mast cells, is often put forward as evidence that mediator release from mast cells plays an important role in most patients with EIB. Some observations are reported which suggest a possible effect of DSCG on the parasympathetic system (Jackson \& Richards, 1977; Harries et al., 1981) (See paragraph 4.3 .9 and 4.4.9). If this mode of action should be proven, the interpretation of DSCG blocking 
studies will have to be adapted.

Also the refractory period after EIB is consistent with the concept of a release of stored mediators. However, the evidence for mediator release in relation to EIB is not conclusive. Various investigators have looked for histamine in the peripheral arterial blood after exercise. Ferris et al. (1978) found a remarkable increase. Charles et al. (1979) measured a peak in the histamine concentration immediately after exercise which was however unrelated to the degree of bronchial obstruction. Mc Fadden et al. (1979; 1980) could not detect an increase in relation to exercise. Thus, although mediator release from mast cells is likely to occur in EIB direct prove is lacking.

\section{Physiology of exercise}

Heavy exercise is accompanied by hyperventilation, hypocapnia and lactate acidosis (Godfrey, 1974; Wasserman, 1978). These indices have been thought to play a role in EIB. Although no causal relationship could be observed between EIB and hypocapnia, lactate acidosis, acidaemia or change in the arterial oxygen tension (Silverman et al., 1972b), various detailed studies have been performed which further deny such a relationship.

Hyperventilation has been thought to be a cause of EIB because of hypocapnia (Herxheimer, 1946). Hypocapnia, down to $20 \mathrm{~mm} \mathrm{Hg}$, usually induces airway obstruction (Newhouse et al., 1964). Experiments with the administration of $\mathrm{CO}_{2}$ during exercise revealed variable results (Chan Yeung et al., 1971; Vassalo et al., 1972: Fisher \& Hansen, 1976).

Mc Fadden et al. (1977a) studied the role of hyperventilation under isocapnic conditions using a partial rebreathing technique. This did not produce any measurable change in lung function. When the $\mathrm{pCO}_{2}$ was lowered to about $20 \mathrm{~mm} \mathrm{Hg}$. a moderate bronchial obstruction appeared which was not comparable to that in EIB. Another study with hyperventilation under isocapnic conditions, obtained by adding $\mathrm{CO}_{2}$ to the inspired air, showed that hyperventilation produced the same degree of bronchial obstruction as exercise, irrespective of the concentration of $\mathrm{CO}_{2}$ (Zeballos et al., 1978). These authors claimed that their results differed from these of Mc Fadden (1977a) because of differences in the humification of the inspired air. Thus it would seem that although hyperventilation is involved in the mechanism of EIB, the $\mathrm{CO}_{2}$ wash out is not a causative factor.

In order to examine if acidosis contributed to EIB. sodium bicarbonate was infusing during and after exercise to prevent acidosis, but this porcedure could not influence the occurrence of EIB (Strauss et al., 1977b). The possible role of lactate was considered by lactate infusions in resting subjects in a quantity exceeding that after exercise. No bronchial obstruction appeared and it was concluded that lactic acidemia per se does not cause EIB. 


\section{Condition of inhaled air during exercise}

Several observations highlighted the importance of the condition of the inhaled air in EIB.

Weinstein et al. (1976) studied the effect of humification and found that exercise-induced bronchial obstruction was more severe when subjects breathed dry air compared to humified air. This observation has been confirmed by Bar-Or et al. (1977) in a climate chamber where a high relative humidity $(90 \%)$ revealed a diminished bronchial response compared to a low relative humidity (25\%). Also Chen \& Horton (1977) could virtually prevent EIB by having their patients inhale air at high humidity and body temperature. Cold air at subfreezing level substantially enhanced the bronchial response to exercise, but not without exercise (Strauss et al., 1977c). In a further study Strauss et al. (1978) compared temperature and humidity and their interaction with EIB. Heating the air from room to body temperature had no clear effect on the bronchial response. When the humidity was increased in combination with room temperature, the degree of bronchial obstruction diminished. The lung function changes could be completely prevented by fully saturated inhaled air at room temperature. In patients having EIB, when breathing with their mouth open, nasal breathing virtually abolished the post-exercise bronchial obstruction. This may be explained by the humidifying and heating capacity of the nose (Shturman-Ellstein et al., 1978).

During hyperventilation with exercise the evaporation capacity is easily surpassed, especially when mouth breathing is used and the inspired air is relative dry and cold. The drier and colder the air, the more evaporation at the airway mucosa will occur. An excellent relationship was found between the condition of the inspired air, i.e. the temperature and the humidity, and the degree of EIB (Deal et al., 1979a; 1979b: Mc Fadden \& Ingram, 1979). Patients with EIB are more sensitive to airway cooling. than healthy subjects without EIB, as hyperventilation associated with exercise produced similar degrees of airway cooling in both groups ( $\mathrm{O}^{\prime} \mathrm{Cain}$ et al., 1980).

The mechanism by which these triggers act, is not clear. In order to study the involvement of the airway sensory receptors, oropharyngeal anaesthesia has been applied. A two percent lidocaine spray diminished the decrease in lung function after exercise in contrast to saline, but this effect was variable (Mc Nally et al., 1979). However, using hyperventilation with cold air as an equivalent of exercise, Fanta et al. (1980) could not inhibit bronchial obstruction with lidocaine.

The condition of the inspired air is now believed to be important in the triggering of exercise reactions, but its precise mechanism in inducing bronchial obstruction is not yet known. 
Based upon the available information the mechanisms which lead to BR can be constructed as follows:

Bronchial obstruction can be generated by a parasympathetic reflex or mediator release, probably in a variable interaction. The counteraction depending on the sympathetic response, may be impaired by an imbalance between $\alpha$ - and $\beta$-receptors. The relationship between the severity of the bronchial responses to exercise and the responsiveness to inhaled histamine (paragraph 5.5) would suggest that in both phenomena comparable mechanisms are involved. However, some differences do exist. The pronounced protective effect of DSCG and the refractoriness both point to an involvement of mast cells in exercise, which is less clear in the responsiveness to histamine. Airway epithelium and sensory receptors are probably involved in the responsiveness to histamine, but are not proven to be involved in responsiveness to exercise at the present time. (Deal et al. 1978)

\subsection{Relationship between EIB and bronchial responsiveness to inhaled histamine}

The bronchial reaction due to exercise and $B R$ have similarities, as was suggested by Simonsson et al. (1972b). They observed that most subjects with EIB. also had increased BR to other stimuli, such as hyperventilation and cold air. Kiviloog (1973a) found that in most patients the severity of the bronchial obstruction due to exercise, was related to BR to methacholine. Schachter et al. (1978) correlated the degree of EIB with various data obtained from case histories. The incidence of upper respiratory tract infections, the bronchial reactions to tobacco smoke and to cold weather were related to EIB in descending order. This was not the case with a history of allergy. A strong correlation was found between the severity of the bronchial response to exercise and to histamine in children (Mellis et al.. 1978: Neijens et al., 1980) and adults (Anderton et al., 1979), as well as to methacholine in adults (Eggleston, 1979).

These findings and those in paragraph 5.2 suggest that EIB is dependent on two factors: an increased responsiveness of the bronchi in addition to the type and strength of the exercise stimulus.

A difference between the bronchial responses to exercise and histamine was shown by Schoeffel et al. (1980) and Ruffin et al. (1981). They showed that the bronchial response to repeated histamine challenges, with intervals of 40 minutes, did not diminish to the same extent as exercise tests performed with the same intervals. They concluded that the refractoriness to EIB (James et al., 1976: Edmunds et al.. 1978: Schnall \& Landau, 1980) was much less pronounced with histamine challenge.

In the opinion of various authors (Kiviloog, 1973a: Editorial Thorax, 1979) and of our group (see paragraph 7.1) EIB may be considered as an expression of BR. 


\section{CHAPTERS 6-8 The Studies}





\section{CHAPTER 6. STUDIES TO THE METHODS OF MEASUREMENTS}

\subsection{Bronchial responsiveness as a function of inhaled histamine and the methods of measurement}

H. J. Neijens, M. Hofkamp, H. J. Degenhart and K. F. Kerrebijn

\section{Summary}

Methodical factors in the determination of bronchial responsiveness to histamine were studied in two groups of asthmatic children. In the first, dose-response relationships of inhaled histamine and the provocation dose defined as the threshold (PD) were calculated by various methods, using different techniques of analysis of the dose-response relationship. These PD correlated strongly, but their absolute values varied. A $15 \%$ decrease in $\mathrm{FEV}_{1}$ was a suitable criterion for the $\mathrm{PD}\left(\mathrm{PD}_{15}\right)$. Other fixed criteria $\left(\mathrm{PD}_{20}\right.$ and $\left.\mathrm{PD}_{25}\right)$ revealed $\mathrm{PD}$ values which had an arithmetical relationship with $\mathrm{PD}_{15}$ and produced no advantage. However, the $\mathrm{PD}$ calculated on the basis of the intra-subject variability had a considerable variation with those using a fixed criterion. The response rate (slope of the dose-response curve) is unrelated to the threshold.

The time-response relationship was analysed in group two. Bronchial obstruction after the inhalation of the PD and the preceeding dose lasted for about 15 minutes. Nevertheless no accumulative effect was found giving sequential histamine concentrations inhaled at three minutes intervals.

\section{Introduction}

Increased bronchial responsiveness (BR) is a hallmark of asthma (3.17). The severity of the bronchial obstruction induced by several triggers, such as allergens

1. This study is supported by the Netherlands Asthma Foundation.

2. Presented at the meetings of the Hyperreactivity Group of the Netherlands Asthma Foundation. Leusden. The Netherlands, september 24the, 1980 and of the Working Group on Bronchial Hyperreactivity of the European Society for Clinical Respiratory Physiology. Göteborg, June 3rd. 1981.

3. Accepted for publication in The Bulletin Européen de Physiopathologie Respiratoire/Clinical Respiratory Physiology. 
(2.11.14.15) and exercise (12.13.16) is related to the degree of BR. Determination of the presence of exaggerated $B R$ is increasingly used to establish or diagnose asthma and to estimate its severity. BR is determined by measuring airflow limitation induced by agents like histamine or acetylcholine (3.17) and recently a test using cold air and hyperpnea has been proposed (4). Most laboratories use a method in which the agents are inhaled in increasing concentrations. From the dose-response curves the histamine provocation dose (PD) or threshold is delineated, which is the concentration at which a defined bronchial obstruction appears (18) and a response rate can be calculated. Repeated measurements give reproducible results when performed within a couple of days in the same individual $(9,10)$, but are influenced by differences in methods and criteria of judging the response.

We have compared the PD from the dose-response curves using several analysis techniques, and various criteria for defining significant bronchial obstruction. We have also studied accumulative effects of sequential doses of histamine and its influence on the threshold and response rate.

The time-response relationships after histamine inhalations have also been measured.

\section{Methods}

1. The histamine challenge was performed by inhalation of histamine biphosphate solution in saline in sequential concentrations (doses $1 / 2,1,2,4,8,16,32$ and 64 g. $\left.1^{-1}\right)(18)$. At the beginning and twice during the inhalation each patient performed a submaximal vital capacity manoeuvre, after which they inhaled the aerosol at slow tidal volume breathing (12-15 per minute) for 30 seconds. The time between the inhalations was 3 minutes, unless otherwise mentioned.

Histamine was nebulised by a Doppel Inhaler (Wiesbaden) (flow $61 . \mathrm{min}^{-1}$ ) the characteristics of which are described elsewhere (6). Saline solution was inhaled before histamine in order to exclude non-specific responses. Before and after every inhalation the lung function was measured by flow-volume curves. The forced expiratory volume in the first second $\left(\mathrm{FEV}_{1}\right)$ was indicated by a time signal and used for the results. Each measurement was performed three times in an optimal way. The highest is taken as the result. Changes were expressed as a percentage of the baseline.

2. The dose-response relationship was studied in 18 patients (group I, 11 boys and 7 girls, mean age 13.2 years with a range from 8 to 16.4 years). After the concentration which caused a decrease in $\mathrm{FEV}_{1} \geqslant 15 \%\left(\mathrm{PD}_{15}\right)$ was achieved, three successive concentrations were inhaled, each after an interval of one hour to avoid accumulative effects. This was not performed if severe bronchial obstruction occurred. The dose-response relationships were calculated by linear 


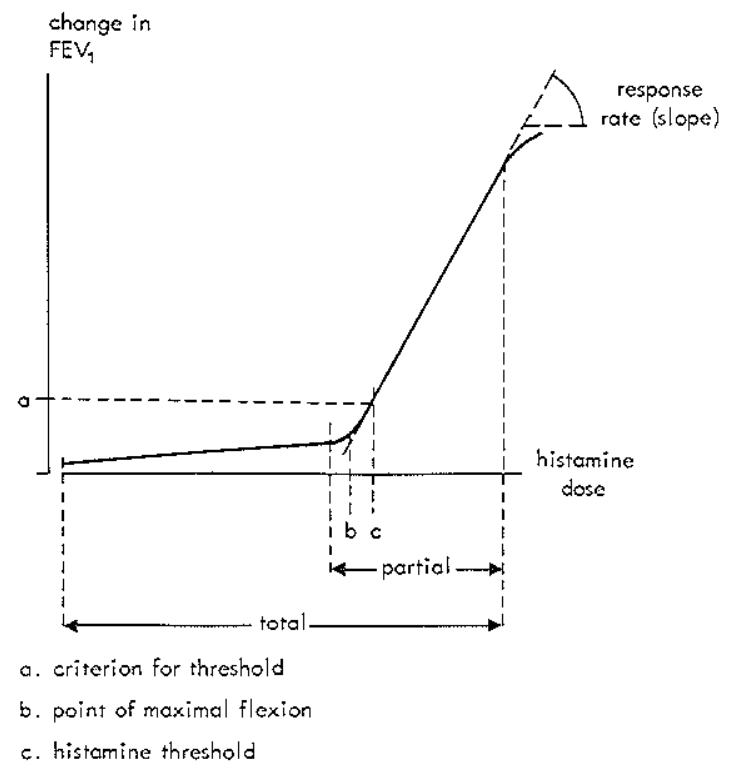

Figure 1. A smoothed dose-response curve (patient number 8 ) reflecting the change in FEV, resulting from inhalations of sequential concentrations histamine biphosphate plotted on a ${ }^{2} \log$ scale.

$\mathrm{a}=$ the change in $\mathrm{FEV}$, which is the criterion for the provocation dose.

$\mathrm{b}=$ the point of maximal inflexion

$c=$ the histamine concentration which corresponds to a given change in $\mathrm{FEV}_{1}$, i.e. the provocation dose or the threshold.

total $=$ analysis using every response obtained

partial $=$ analysis using the responses from where they deviate from baseline.

and square regression equations.

Log dose response curves were constructed as follows (Figure 1):

A. by calculating a linear regression equation using every response obtained ("total dose-response curve");

B. by calculating a square regression equation using every response obtained;

C. by calculating a linear regression equation using the responses from where they definitely deviate from baseline ("partial dose-response curve"); this was visually determined;

D. by handdrawing the best fitting parabolic curve through all responses.

$\mathrm{PD}$ according to $\mathrm{A}, \mathrm{B}, \mathrm{C}$ and $\mathrm{D}$ were defined as the calculated concentration from the corresponding dose-response curve according to a certain degree of bronchial obstruction.

E. $\mathrm{PD}_{15}$ was defined as the lowest administered concentration after which at least a significant bronchial obstruction cccurs ("stepmethod"). 
$\mathrm{PD}_{15}$ were compared with the $\mathrm{PD}$ producing a $20\left(\mathrm{PD}_{20}\right)$ and $25 \%$ decrease $\left(\mathrm{PD}_{25}\right)$ using methods $\mathrm{B}$ and $\mathrm{E}$. Similar calculations were done to the $\mathrm{PD}$ using a decrease in $\mathrm{FEV}_{1}$ of twice the coefficient of variation of the baseline values $\left(\mathrm{PD}_{2 \mathrm{cv}}\right)$, which reflected the intra-subject variability $(9.10)$.

The point of maximal inflexion is defined as the histamine concentration at which the dose-response curve bends maximally (Figure 1). This point is approximated by the histamine concentration $(x)$ and the response $(y)$, where the radius of curvature $(\mathrm{K})$ is minimal.

$$
\mathrm{K}=\frac{\mathrm{d}^{2} \mathrm{y} / \mathrm{dx} \mathrm{x}^{2}}{\left[1+(\mathrm{dy} / \mathrm{dx})^{2}\right]^{3 / 2}}
$$

3. The time-response relationship after the inhalation of histamine was studied in group II (18 patients, 10 boys and 8 girls, mean age 11.6 years with a range of 9.4 till 13.9). After the $\mathrm{PD}_{15}$ (according to method $\mathrm{E}$ ) was reached, the $F E V_{1}$ was repeated every five minutes until its value was about 5 percent below the baseline value.

The concentration of histamine which was defined as the PD and the preceding concentration ("subprovocation dose $=$ sub PD) were again administered at intervals of two hours ("single $\mathrm{PD}_{15}$ and sub $\mathrm{PD}_{15}$ ). After each dose the recovery of the $\mathrm{FEV}_{1}$ was recorded as before.

The changes in $F E V_{1}$ after the inhalation of the single $\mathrm{PD}_{15}$ and sub $\mathrm{PD}_{15}$ were compared to those after the $\mathrm{PD}_{15}$ and sub $\mathrm{PD}_{15}$ in complete sequence of doses (series).

4. The patients were selected from the outpatient clinic for respiratory disease of the Sophia Children's Hospital in Rotterdam. In the two weeks prior to the study the patients were in a stable condition according to the clinical history and had not received cromoglycate or oral corticosteroids. Other drugs were withdrawn three days prior to the study. Patients and their parents were fully informed and they gave their consent for the study.

\section{Results}

The results in group I are given in Table 1. The baseline $F E V_{1}$ and the $\mathrm{PD}_{15}$ calculated according to the various methods are shown in Table 2 . The trend in the differences of the $\mathrm{PD}_{15}$ according to the various methods is significant (Friedman's test $P<0.001$ ), i.e. the trend in the median values reflects the trend in the values of most individuals.

In most patients the pattern of the dose-response curves is curvilinear (a second degree polynomial). The first part of the curve increases slightly and is in most patients followed after a point of maximal inflexion by a rapid increase (the 
Table 1. Changes in $\mathrm{FEV}_{1}$ after the inhalation of saline and histamine biphosphate, expressed as percentage of the baseline value for height.

\begin{tabular}{|c|c|c|c|c|c|c|c|c|c|c|}
\hline \multirow{2}{*}{ Patients } & \multicolumn{10}{|c|}{ Histamine concentration (G.L $\left.L^{-1}\right)$} \\
\hline & Saline & 0.25 & 0.50 & 1 & 2 & 4 & 8 & 16 & 32 & 64 \\
\hline 1 & +5 & 0 & -2 & -19 & -49 & -20 & -74 & & & \\
\hline 2 & 0 & -3 & -5 & -32 & -14 & -16 & -70 & & & \\
\hline 3 & +7 & -10 & -5 & -2 & -48 & -53 & -63 & & & \\
\hline 4 & 0 & -2 & -2 & -21 & -12 & -21 & -29 & -26 & & \\
\hline 5 & +5 & -1 & -3 & +2 & -39 & -46 & -53 & -63 & & \\
\hline 6 & -5 & -7 & -4 & -7 & -16 & -23 & -52 & -41 & -41 & \\
\hline 7 & 0 & 0 & 0 & -1 & -10 & -40 & -42 & -61 & & \\
\hline 8 & +2 & 0 & 0 & -5 & -12 & -23 & -32 & -44 & & \\
\hline 9 & 0 & -4 & -6 & -8 & -11 & -18 & -42 & -24 & -47 & \\
\hline 10 & 0 & 0 & 0 & 0 & -10 & -17 & -49 & -47 & -57 & \\
\hline 11 & -1 & -3 & -2 & -2 & -7 & -7 & -46 & -35 & -59 & \\
\hline 12 & +1 & 0 & -2 & -2 & 0 & -5 & -38 & -43 & -27 & -59 \\
\hline 13 & -1 & -5 & -5 & -7 & -7 & -8 & -27 & -30 & -75 & \\
\hline 14 & -3 & +3 & +2 & +2 & -3 & -9 & -19 & -31 & -34 & -47 \\
\hline 15 & +1 & +3 & 0 & +1 & 0 & 0 & -27 & -27 & -65 & \\
\hline 16 & +3 & +5 & +3 & -6 & -6 & -6 & -13 & -9 & -30 & -78 \\
\hline 17 & -2 & +2 & +4 & +4 & -2 & +1 & -9 & -16 & -37 & -52 \\
\hline 18 & +2 & +6 & +5 & +2 & 0 & -2 & -2 & -3 & -29 & -52 \\
\hline
\end{tabular}

response rate) (Figure 1). The curvilinear pattern is highlighted by the square regression equations using every response obtained which describe the dose-response relationship better than the linear regression equations with significantly better correlation coefficients (F-test) in 12 of the 18 patients (Table 3 ). The methods differ in their ability to take the point of maximal inflexion into account. Methods $B$ (square analysis of the total curve) and $\mathrm{C}$ (linear analysis of the partial curve) are superior in this respect. Method B is a simple and accurate procedure and is therefore considered as the reference method. 
Table 2. Histamine $P D_{15}$ calculated by different methods.

\begin{tabular}{|c|c|c|c|c|c|c|}
\hline \multirow{5}{*}{ Patients } & \multirow{5}{*}{$\begin{array}{c}\text { Baseline } \\
\text { FEV, } \\
\% \\
\text { Predicted }\end{array}$} & \multicolumn{5}{|c|}{ Methods } \\
\hline & & \multicolumn{4}{|c|}{ Dose-response curve } & \multirow{4}{*}{$\begin{array}{l}\text { Step } \\
\text { E }\end{array}$} \\
\hline & & \multicolumn{2}{|c|}{ Total } & \multirow{3}{*}{$\frac{\text { Partial }}{\text { Linear }}$} & \multirow{3}{*}{$\begin{array}{c}\text { By hand } \\
\text { D }\end{array}$} & \\
\hline & & & & & & \\
\hline & & A & B & & & \\
\hline 1 & 97 & 0.7 & 0.9 & 0.7 & I & 1 \\
\hline 2 & 84 & 0.8 & 1.4 & 0.8 & 1 & 1 \\
\hline 3 & 69 & 0.7 & 1.0 & 1.2 & 1.1 & 1 \\
\hline 4 & 88 & 1.7 & 1.3 & 1.6 & 2.6 & 1 \\
\hline 5 & 58 & 0.9 & 0.9 & 1.2 & 1.3 & 2 \\
\hline 6 & 92 & 1.1 & 1.1 & 1.4 & 2.I & 2 \\
\hline 7 & 81 & 1.3 & 2.0 & 1.9 & 2.5 & 2 \\
\hline 8 & 74 & 1.8 & 2.7 & 2.0 & 2.2 & 4 \\
\hline 9 & 102 & 1.6 & 2.2 & 2.2 & 2.6 & 4 \\
\hline 10 & 84 & 2.5 & 2.5 & 2.5 & 2.4 & 4 \\
\hline 11 & 85 & 1.8 & 3.5 & 3.5 & 4 & 8 \\
\hline 12 & 93 & 2.6 & 4.4 & 4.0 & 6.6 & 8 \\
\hline 13 & 92 & 1.8 & 4.6 & 4.3 & 6.1 & 8 \\
\hline 14 & 105 & 4.0 & 6.3 & 5.6 & 6.1 & 8 \\
\hline 15 & 76 & 3.0 & 6.0 & 7.4 & 8 & 8 \\
\hline 16 & 78 & 3.8 & 9.4 & 9.4 & 15.3 & 8 \\
\hline 17 & 77 & 5.7 & 11.5 & 10.8 & 13.3 & 16 \\
\hline 18 & 80 & 8.7 & 14.6 & 11.6 & 25.2 & 32 \\
\hline & & 1.7 & 2.4 & 2.1 & 2.5 & 4 \\
\hline
\end{tabular}


Table 3. Correlation coefficients of the linear and square regression equations of total doserespons curves. (Method A and B).

\begin{tabular}{|c|c|c|}
\hline \multirow{2}{*}{ Patients } & \multicolumn{2}{|c|}{ Power of regression equations } \\
\hline & Linear & Square \\
\hline I & 0.84 & 0.85 \\
\hline 2 & 0.85 & 0.81 \\
\hline 3 & 0.89 & 0.90 \\
\hline 4 & 0.88 & 0.89 \\
\hline 5 & 0.94 & 0.94 \\
\hline 6 & 0.89 & 0.89 \\
\hline 7 & 0.87 & $0.96^{*}$ \\
\hline 8 & 0.97 & $0.99 *$ \\
\hline 9 & 0.88 & $0.92 *$ \\
\hline 10 & 0.94 & $0.97^{*}$ \\
\hline 11 & 0.87 & $0.93^{*}$ \\
\hline 12 & 0.85 & $0.90^{*}$ \\
\hline 13 & $0.8 \mathrm{I}$ & $0.96+$ \\
\hline 14 & 0.96 & $0.99+$ \\
\hline 15 & 0.81 & $0.97 \dagger$ \\
\hline 16 & 0.75 & $0.92 \dagger$ \\
\hline 17 & 0.88 & $0.99 \uparrow$ \\
\hline 18 & 0.82 & $0.94 \dagger$ \\
\hline
\end{tabular}

Significances of the improvement in correlation (F-test).

$\left[\begin{array}{l}* P<0.05 \\ +P<0.01\end{array}\right.$ 
The relationship between the $\mathrm{PD}_{15}$ with the various methods are shown in log: $\log$ diagrams on a ${ }^{2}$ logarithmic scale (Figure 2). Although the relationship between the $\mathrm{PD}_{1 s}$ according to method $\mathrm{A}$ and the reference method $\mathrm{B}$ correlated well $(r=0.93, p<0.001)$, values differ slightly. The distance between the regression line and the line of identity represents the difference between the results by both methods, which may be estimated by the slope a of the regression equation $y=a x+$ b. In this case the slope is 0.76 indicating that the $\mathrm{PD}_{15}$ with method $\mathrm{A}$ are lower than those with the reference method (B) and this is more pronounced in high than in low $\mathrm{PD}_{15}$. These differences can be explained by the curvilinear pattern of the dose-response relationship.
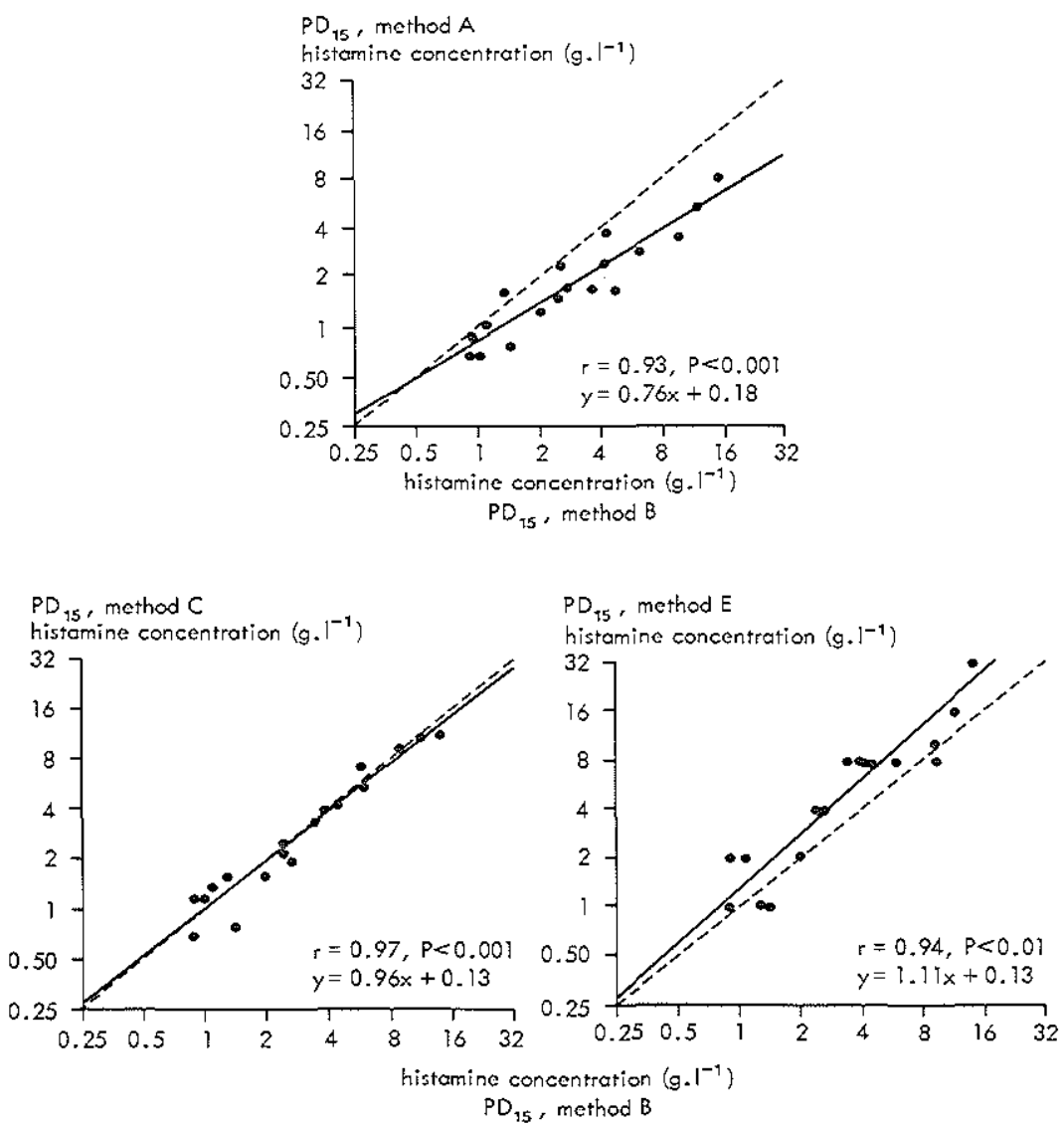

Figure 2. Comparison of the $\mathrm{PD}_{15}$ obtained by various methods.

Calculated regression line —- line if $y=x--\ldots-$ : Method A: linear analysis of every response obtained: Method $B=$ square analysis of every response obtained: Method $\mathrm{C}=$ linear analysis of a part of the responses: Method $\mathrm{E}=$ step. 

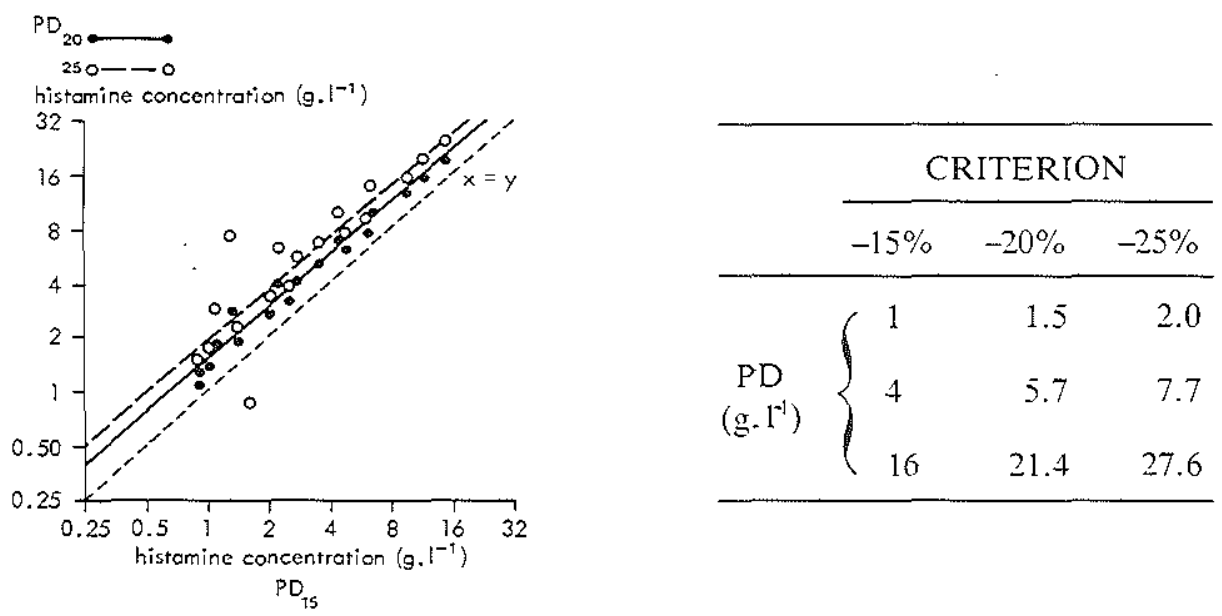

Figure 3. $P D_{20}$ and $P D_{25}$ (y-axis) compared with $P D_{15}$ ( $x$-axis).

Method B.

Regression line if $y=x---$

Regression equations:

LINEAR TERMS:

${ }^{2} \log Y_{20}=0.3946+{ }^{2} \log \left(x_{15}+0.3608\right) r=0.99 . P<0.00 I$

$F=693.17$

${ }^{2} \log Y_{25}=0.7270+{ }^{2} \log \left(x_{15}+I .1599\right) r=0.88 . P<0.00 I$

$F=56.38$

LOGARITHMIC TERMS:

$Y_{20}=0.96 x_{1 s}+0.59$

$X_{2 s}=0.95 x_{15}+1.01$

The $\mathrm{PD}_{15}$ with method $\mathrm{C}$ and method $\mathrm{B}$ correlate well (Figure 2, $\mathrm{r}=0.97$, $P<0.001)$. The regression line is almost the same as the line of identity $(y=x)$, which indicates that the PD with both methods is nearly identical. The $\mathrm{PD}_{15}$ with method $E$ and with the reference method $B$ are also related (Figure $2, r=0.94$, $\mathrm{P}<0.001$ ). The slope 1.11 of the regression line indicates that the $\mathrm{PD}_{15}$ with method $\mathrm{E}$ is somewhat higher than those with method $\mathrm{B}$.

We have analysed the extent to which $\mathrm{PD}$ is influenced by changing the criterion for bronchial obstruction.

In Figure 3 the PD is compared from either a $15 \%$, and $20 \%$ or $25 \%$ decrease in $\mathrm{FEV}_{1}$. The values are calculated according to method $\mathrm{B}$ and reproduced on a logarithmic scale. The regression lines represent the interrelationship of the PD according to the various criteria. The slopes of the regression lines are almost 1 , indicating a parallelism with the line of identity which means constant differences in logarithmic terms $\left({ }^{2} \log\right.$ g. $\left.1^{-1}\right)$ throughout the threshold range. The effect of change of criterion is small and about similar over the whole range as shown by the slope and the high correlation coefficients. The changes in linear terms $\left(\mathrm{g} .1^{-1}\right)$ can be 


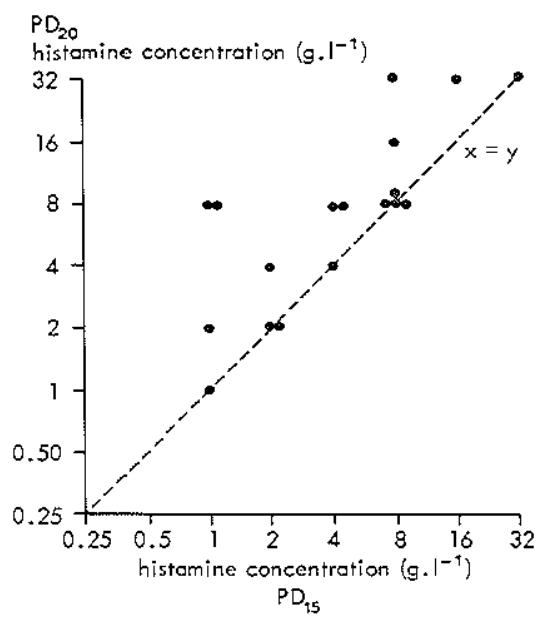

Figure 4. $P D_{20}$ compared to $P D_{1 s}$ using the step method (E). Regression line if $y=x---$.

calculated from the equations which describe the $\mathrm{PD}_{20}$ in relation to the $\mathrm{PD}_{15}$ : ${ }^{2} \log \mathrm{y}_{20=} 0.3946+{ }^{2} \log \left(\mathrm{x}_{15}+0.3608\right)$ and in the case of the $\mathrm{PD}_{25}$ compared to the $\mathrm{PD}_{15}:{ }^{2} \log \mathrm{y}_{25}=0.7270+{ }^{2} \log \left(\mathrm{x}_{15}+1.1599\right)$. In the table next to Figure 3 examples of $\mathrm{PD}$ values in linear terms according to the various criteria are given.

Because method $\mathrm{E}$ is often used their $\mathrm{PD}_{20}$ is compared to the $\mathrm{PD}_{15}$ (Figure 4). In 9 of the 18 patients no difference is seen, in 6 patients the $\mathrm{PD}_{15}$ is 1 concentration lower and in 3 it is 2 concentrations lower than the $\mathrm{PD}_{20^{*}}$. The comparison of $\mathrm{PD}_{15}$ with $\mathrm{PD}_{2 \mathrm{cv}}$ (Figure 5) gives in most cases lower values of $\mathrm{PD}_{2 \mathrm{cv}}$ than $\mathrm{PD}_{15}$ with a wider scatter than between the fixed criteria.

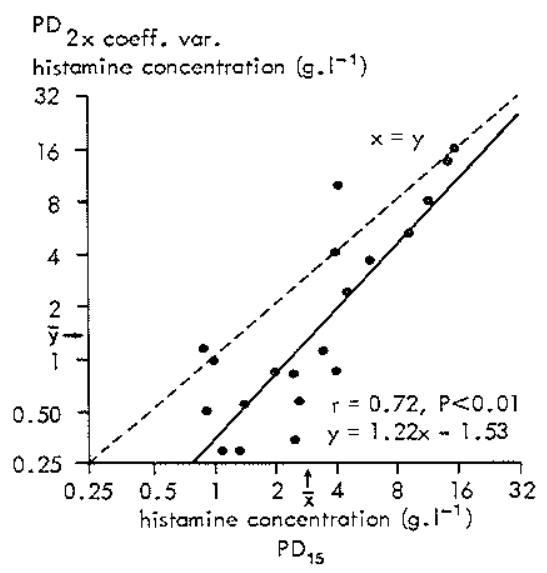

Figure 5. Comparison of the $\mathrm{PD}_{15}(\operatorname{method} \mathrm{B})$ with the $\mathrm{PD}_{2 \mathrm{cv}}$. Regression line if $\mathrm{y}=\mathrm{x} \ldots-\cdots$ 
The bronchial responsiveness to histamine is not only estimated by the concentration which gives a certain degree of bronchial obstruction, but also by the response rate (see Figure 1).

The response rate is assessed by the slope of the linear regression equation of the partial curve (method $C$ ). Figure 6 a shows the relationship between the $P D_{15}$ (method B) and the response rates. As no relationship exists $(r=0.12$, not significant), it can be concluded that the response rate is independent of the PD. Figure $6 \mathrm{~b}$ shows the relationship between the $\mathrm{PD}_{15}$ and the point of maximal inflexion (see Figure 1).

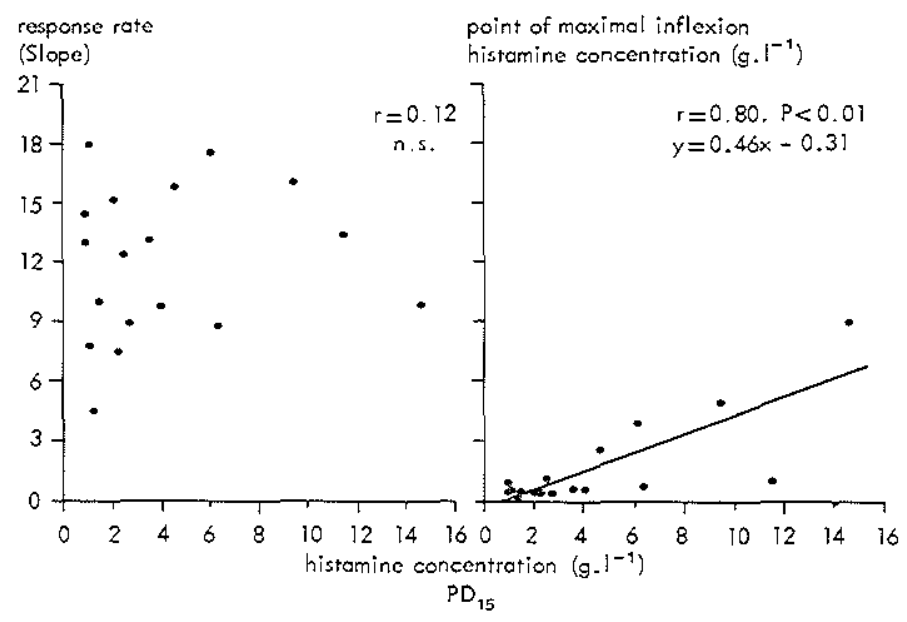

Figure 6. Comparison of the $\mathrm{PD}_{15}$ (method $\mathrm{B}$ ) with the response rate (the regression coefficient of method $\mathrm{C}$ ) and the point of maximal inflexion in two separate graphs.

A significant, positive relationship exists between the histamine concentrations defined as the $\mathrm{PD}_{15}$ and those corresponding with the point of maximal inflexion ( $r=0.80, P<0.001$ ). It appears that the $\mathrm{PD}_{15}$ is predominantly defined by the point of maximal inflexion and not evidently by the response rate. This also holds in the case of $\mathrm{PD}_{20}$.

The results from the patient of group II are shown in Figure 7. The FEV, after each of the histamine inhalations, including the $\mathrm{PD}_{15}$ given as a series, and after the single sub $\mathrm{PD}_{15}$ and the single $\mathrm{PD}_{15}$ is shown as well as the increase in $F E V_{1}$ with time (recovery). Although the decrease after the series is somewhat larger than that after the single doses, the difference do not reach significance (student $T$ test, $P$ $<0.1$ ).

On average the $\mathrm{FEV}_{1}$ is returned till about $5 \%$ below the baseline value after 15 minutes. In this respect there is no difference in the recovery after the series or after a single dose (test according to Gebelein and Ruhenstroth-Bauer (8), $P<0.1$ ). 


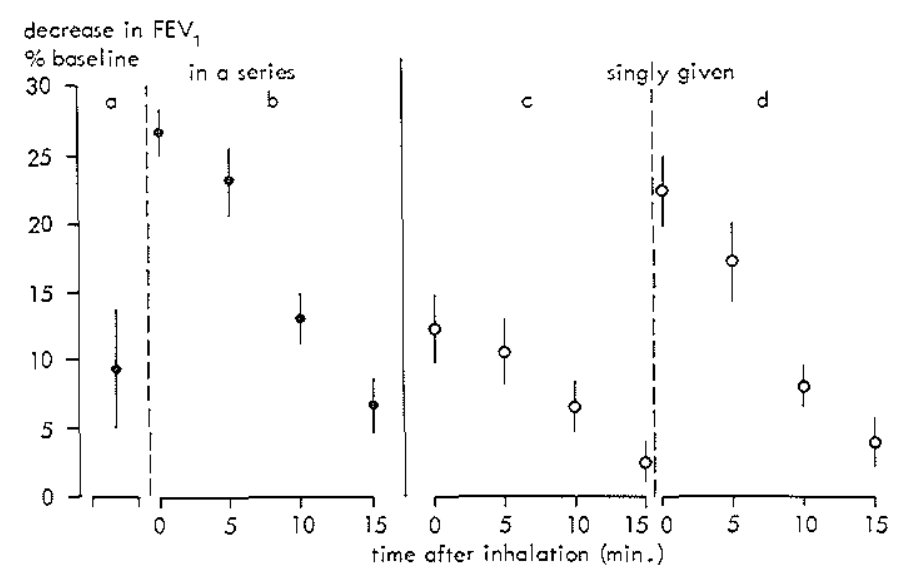

Figure 7. Mean recovery ( \pm sem) of the change in FEV, in 18 patients, with time after the inhalation of histamine in a series or singly given. $a=$ after the histamine concentration prior to the $P D_{1 \varsigma}, b=$ after the $P D_{15}, c=$ equal to a but singly given, $d=$ equal to $b$ but singly given.

Differences in the recovery rate: $b-d$. not significant. $c-d, P<0.01$ (test according to Gebelein and Ruhenstroth-Bauer (8)).

Although the rate of recovery after the sub $\mathrm{PD}_{15}$ and the $\mathrm{PD}_{15}$ as single doses differs, the recovery time is about equal. This indicates that the recovery time does not necessarily depend on the drop in the $\mathrm{FEV}_{1}$. In each patient the baseline values of the three tests were approximately equal. It can therefore be assumed that the results were not influenced by differences in the basic condition.

\section{Discussion}

The dose-response relationship of histamine in the bronchi plotted on a semilogarithmic scale has curvilinear features (second degree polynomial) as in many biological systems. This pattern has similarities to the in vivo equivalent of the left part of the S-shaped curve which reflects the bronchial smooth muscle strength in vitro caused by an agonist (1).

It is widely accepted that the bronchial reaction induced by histamine is short lasting. However, we have shown that it usually takes at least 15 minutes before the $F E V_{1}$ reapproaches the baseline value after inhalation of the $\mathrm{PD}_{15}$ or the sub $\mathrm{PD}_{15}$ (figure 7). Giving histamine concentrations in a series with a few minutes interval could have an accumulative effect, but this is improbable, because it would predominantly effect the response rate, which has no measurable impact on the $\mathrm{PD}_{15}$ (figure 6). These theoretical considerations were confirmed by our observations 
Table 4. Values and percentage decrease in PD in relation with accumulation in a simulated model of a typical dose-response curve.

\begin{tabular}{lcccccc}
\hline \multirow{2}{*}{$\%$ cumulation } & \multicolumn{2}{c}{$\mathrm{PD}_{15}$} & \multicolumn{2}{c}{$\mathrm{PD}_{20}$} & \multicolumn{2}{c}{$\mathrm{PD}_{25}$} \\
\cline { 2 - 7 } & $\left(\mathrm{G} . \mathrm{L}^{-1}\right)$ & $\%$ decr & $\left(\mathrm{G} . \mathrm{L}^{-1}\right)$ & $\%$ decr & $\left(\mathrm{G} . \mathrm{L}^{-1}\right)$ & $\%$ decr \\
\hline 0 & 4.3 & & 6.7 & & 9.9 & \\
10 & 4.1 & 5 & 6.1 & 9 & 8.7 & 12 \\
15 & 4.0 & 7 & 5.9 & 12 & 8.3 & 16 \\
20 & 4.0 & 7 & 5.9 & 12 & 8.3 & 16 \\
30 & 3.9 & 10 & 5.5 & 18 & 7.5 & 24 \\
\hline
\end{tabular}

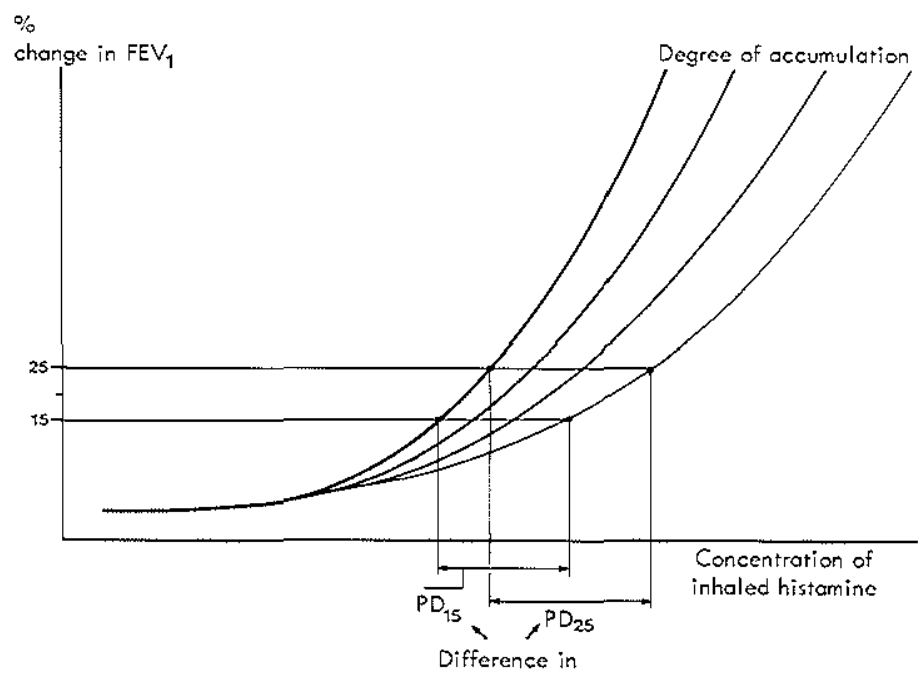

that the drop in $F E V_{1}$ induced by the $\mathrm{PD}_{15}$ after a series or that after a single dose were approximately equal (figure 7). To avoid an eventually occurring strong response rate, we have taken hourly intervals with concentrations above the threshold.

The influence of accumulation has also been analysed in a typical curve in which accumulation is simulated increasing there response rates (Table 4). An influence of accumulation on the threshold may be assumed if the criterion for the threshold is $20 \%$ or more and the increase in the response rate is at least $20 \%$.

Although differences in $\mathrm{PD}_{15}$ between individuals can be defined by all methods, the absolute values may vary. The PD can therefore be calculated most accurately 
with methods that take the curvilinear pattern into account. This can best be done by a square analysis of every response obtained (method B) or a linear analysis of the responses from the point where they definitely deviate from the baseline (method C). As this point may be difficult to define, we prefer method $B$ as the reference method. The commonly used stepmethod (E) generally gives higher values than the reference method. This is the consequence of the method, which defines the PD as the lowest administered concentration after which the chosen criterion is exceeded or at least reached. The difference increases with rising PD, because the histamine concentrations are administered in a geometrical series. A disadvantage of method $E$ is that the drop in $\mathrm{FEV}_{1}$ may differ considerably between individuals with the same PD (Figure 4).

The linear analysis of every response obtained is attractive because of its simplicity, but gives mostly lower values than the reference method (Table 2, Figure 2). With rising PD the differences increase, because the higher the histamine concentration at which the point of maximal inflexion is situated, the more inaccurate a straight line fits the curvilinear pattern. The $\mathrm{PD}_{15}$ determined from a curve constructed by hand is mostly higher than those with the reference method (table 2). Although this line is influenced by subjective variances, it will tend to have a sharper inflexion than that of the reference curve. Thus the point of maximal inflexion and consequently the $\mathrm{PD}$ will rise to a higher value.

If the criterion for significant bronchial obstruction is changed from 15 to 20 or $25 \%$, the PD values increase (Figure 3 ). Quantitatively the difference is not only dependent on the change in the criterion, but also on the value of the original PD. In linear terms a change from 15 to $20 \%$ increases the PD values over the whole range with approximately $30 \%$ and in the case of a change in criterion from 15 to $25 \%$, with approximately $60 \%$. In the case of the stepmethod a change in criterion influences the PD in a variable way.

A different approach for the PD determination is the calculation of the intrasubject variability of the $\mathrm{FEV}_{1}$ prior to the inhalation challenge, and to define twice the coefficient of variation. The PD thus defined is also related to, although generally lower than, that by the $15 \%$ criterion. However, they had a considerable scatter. This is due to the difference in intra-subject variability in the population. A comparison of the biological significance of both methods will have to clarify whether the intra-subject variability is a better criterion for bronchial obstruction than the commonly used fixed ones.

As in studies by Orehek (17) and Habib (9) we found no relationship between the $\mathrm{PD}$ and the response rate. This can be understood from animal studies in which the influence of components which contribute to the mechanism of bronchial obstruction on the dose-response relationship was studied (7). The greater the excitability of the parasympathetic nerve the more the dose-response curve is shifted to the left in a parallel way. The authors stated that bronchial smooth muscle tone was related to the response rate. This is in agreement with the findings in guinea 
pigs from Drazen and Austen (5).

We concluded that a good estimation of the bronchial responsiveness to histamine could be obtained by calculating the $\mathrm{PD}_{15}$ from the total dose-response curve using a square analysis. Linear analysis of the responses which definitely deviate from baseline could also be used, but this was liable to subjective choice of the responses taken for analysis. A $15 \%$ decrease in $\mathrm{FEV}_{\mathrm{I}}$ was a suitable criterion to delineate PD. Other criteria such as 20 or $25 \%$ could be used, but they have no advantage over a $15 \%$ decrease in $\mathrm{FEV}_{1}$, as the PD's according had an arithmetical relationship. Although the PD calculated on the basis of the intra-subject variability is related to that with a fixed criterion, the values showed a considerable scatter. We have shown that the administration of histamine inhalations as a geometrical series with at least three minutes intervals untill the PD was reached produced no accumulative effects. Insight in the dose-response relationship could be augmented if after the $\mathrm{PD}_{15}$, the response of three successive concentrations were measured unless severe bronchial obstruction occured. Hence the PD could be calculated more accurately and the response rate could be determined. The stepmethod was easy to use and gives a fair estimate of the PD. However, results could not easily be compared with those obtained with other methods and different criteria.

\section{Acknowledgements}

The authors wish to thank Jeanette Boogaard, Ineke Strik, Edith Bonzet and Joke Mazee for their technical assistance, Prof. van Strik for statistical advise and Annelies de Reus and Ellen Hermenet for typing the manuscript.

\section{References}

1. BOUSHEY H. A., HOLTZMAN M. J., SHELLER J. R.. NADEL J. A. Bronchial hyperreactivity (State of the art). Am. Rev. Respir. Dis. 1980: /21:389-413.

2. BRYANT D. H.. BURNS M. W. Bronchial histamine reactivity: its relationship to the reactivity of the bronchi to allergens. Clin. Allergy 1976,6:523-532.

3. COCKCROFT D. W., KILLIAN D. N., MELLON J. J. A., HARGREAVE F. E. Bronchial reactivity to inhaled histamine, a method and clinical survey. Clin. Allergy 1977; 7:235-243.

4. DEAL JR. C. E. MC FADDEN JR. E. R., INGRAM JR. R. H., BRESLIN F. E., JAEGER J. J. Airway responsiveness to cold air and hyperphoea in normal subjects and in those with hay fever and asthma. Am. Rev. Respir. Dis. 1980; 121:621-628.

5. DRAZEN J. M.. AUSTEN K. F. Atropine modification of the pulmonary effects of chemical mediators in the guinea pig. J. Appl. Physiol. 1975; 38:834-838.

6. FERRON G. A., KERREBIJN K. F., WEBER J. Properties of aerosols produced with nebulizers commonly used in medicine. Am. Rev. Respir. Dis. 1976:1/4: 899-908. 
7. FLEMING W. W.. MC PHILIPS J. J., WESTFALL D. P. Postjunctional supersensitivity and subsensitivity of excitable tissues to drugs. Rev. Physiol. Biochem. Pharmacol. 1973: 68: 55-I 19.

8. GEBELEIN H., RUHENSTROTH-BAUER. Über den statistischen Vergleich einer NormalKurve und einer Prufkurve. Die Naturwissenschaften 1952: 20:457-461.

9. HABIB M. P.. PARÉ P. D.. ENGEL L. A. Variability of airway responses to inhaled histamine in normal subjects. J. Appl. Physiol.: Respirat. Environ Exercise Physiol. 1979; 47:51-58.

10. JUNIPER E. F.. FRITH P. A., BUNNETT C.. COCKCROFT D. W.. HARGREAVE F. E. Reproducibility and comparison of responses to inhaled histamine and methacholine. Thorax 1978: 33: 705-710.

11. KILLIAN D., COCKCROFT D. W.. HARGREAVE F. E., DOLOVICH J. Factors in allergeninduced asthma: relevance of the intensity to the airways allergic reaction and non-specific bronchial reactivity. Clin. Allergy 1976:6:219-225.

12. KIVILOOG J. Variability of bronchial reactivity to exercise and methacholine in bronchial asthma. Scan. J. Respir. Dis. 1973:54: 359-368.

13. MELLIS C. M.. KATTAN M., KEENS T. G., LEVISON H. Comparative study of histamine and exercise challenges in asthmatic children. Am. Rev. Respir. Dis. 1978: 117:911-915.

14. NATHAN R. A.. KINSMAN R. A., SPECTOR S. L.. HORTON D. J. Relationship between airways response to allergens and non-specific bronchial reactivity. J. Allergy Clin. Immunol. 1979:64:491-499.

15. NEIJENS H. J.. DEGENHART H. J., RAATGEEP H. C., KERREBIJN K. F. Study on the significance of bronchial hyperreactivity in the bronchusobstruction after inhalation of cat dander allergen. J. Allergy Clin. Immunol. 1979; 64: 507-515.

16. NEIJENS H. J., WESSELIUS T., KERREBIJN K. F. Exercise-induced bronchoconstriction: a study of its mechanism in children. Thorax, 1981:36:517-522.

17. OREHEK J.. GAYRARD P., SMITH A. P., GRIMAUD C. and CHARPIN J. Airway response to carbachol in normal and asthmatic subjects. Am. Rev. Respir. Dis. 1977:115: 937-943.

18. DE VRIES K., BOOIJ-NOORD H., GOEI H., GROBLER N. J., SLUITER H. J., TAMMELING G. J.. ORIE N. G. M. Hyperreactivity of the bronchial tree due to drugs, chemical and physical agents. In: Orie N. G. M.. Sluiter H. J. eds. Bronchitis II Second International Symposium. Assen: Royal Vangorcum. 1964: 167-180. 


\section{CHAPTER 7. STUDIES OF THE METHODS OF MEASUREMENTS}

7.1. Exercise-induced bronchoconstriction as an expression of bronchial hyperreactivity: a study of its mechanisms in children

Herman J. Neijens M. D., Taco Wesselius M. D., Karel F. Kerrebijn M. D.

\section{Abstract}

The mechanism of exercise-induced bronchoconstriction (EIB) was studied by observing the protective effects of several aerosolized agents in a double-blind, randomized trial.

EIB is affected not by the placebo, but by all of the agents $(P<0.001)$. Blocking the parasympathetic system had the weakest effect; whilst $\beta_{2}$ adrenergic stimulation produced the strongest effect which was significantly different from the parasympatholytic ( $\mathrm{P}<0.02$ ). The effect of the mast cell stabilizer was found to be intermediate. However, in some of the patients the mast cell stabilizer had a stronger effect than the $\beta_{2}$ adrenergic agonist.

The effect of the parasympatholytic and the mast cell stabilizer varied amongst patients. Their combined effect approached the degree of EIB.

EIB was related to the bronchial hyperreactivity induced by histamine $(\mathrm{P}<0.05)$. Their possible mechanisms are discussed.

\section{INTRODUCTION}

Bronchial hyperreactivity to non-specific stimuli is one of the hallmarks of bronchial asthma ${ }^{1-2}$. This implies the occurrence of bronchoconstriction after the inhalation of physical or chemical stimuli (allergens excepted) to a degree or at a concentration which would have no effect on healthy people. The degree of hyperreactivity is often estimated by the bronchial sensitivity to histamine, acetylcholine or methacholine.

1. This study is supported by the Netherlands Asthma Foundation (grant nr. 279) and Boehringer IngeIheim Ltd. Haarlem who also supplied the agents.

2. Presented at the meetings of the Dutch Paediatric Association. Noordwijkerhout. The Netherlands, september 8th. 1979 and of the British Paediatric Respiratory Group. Nothingham. England. September 1lth, 1979.

3. Published in Thorax, $1981 ; 36: 517-522$. Reprint with permission of the publisher. 
A strong correlation has been found between the bronchial sensitivity to histamine and exercise-induced bronchoconstriction (EIB $)^{3-4-5}$. Some authors ${ }^{4}$ consider EIB an expression of hyperreactivity.

The mechanism of EIB is currently only partially understood. The parasympathetic nervous system, activated by sensory fibres situated in the mucosa of the large airways ("irritant receptors") seems to play a role, because aerosolised parasympatholytic agents ${ }^{6}$ or local anaesthetics ${ }^{7}$ may diminish or abolish EIB. Several studies $^{8}$ point to the important influence of rapid ventilation with cold, dry air as the initiating stimulus which may trigger irritant receptors. $\beta_{2}$ adrenergic agonists block $\mathrm{EIB}^{6}$, whieh suggests that the sympathetic nervous system also plays a role. Disodium cromoglycate often gives protection against $\mathrm{EIB}^{9}$. This may indicate that mediator release from mast cells or from related histamine containing cells in the bronchial lumen ${ }^{10}$ is also involved. Some authors suggest that cromoglycate may influence EIB in other ways ${ }^{5-8-11}$. None of these suggestions have, however, been substantiated ${ }^{5}$. Therefore, we have assumed that the effect of cromoglycate is brought about by mast cell stabilisation ${ }^{12}$.

We measured the protective effect of various agents in a group of asthmatic children who also had EIB. A $\beta_{2}$ adrenergic agonist, a parasympatholytic agent as well as a mast cell stabilizer were all tested as aerosols. In this way the contribution of the various parts of the autonomic nervous system and of mast cells in the mechanism of EIB has been studied.

We present a hypothesis to define the role of these systems in EIB. The bronchial sensitivity to histamine was also measured and related to the protective effect of the agents. It is concluded that the mechanisms of bronchoconstriction induced by exercise and by histamine have much in common.

\section{Methods}

1. 25 Asthmatic patients were studied, 12 did not fulfill all the criteria, therefore the results of the remaining 13 patients were analysed. This group consisted of 9 boys and 4 girls and their ages ranged from 9 to $15^{1 / 2}$ years with a mean of $12^{5} / 12$ years. The patients were selected from the outpatient clinic of the Sophia Children's Hospital in Rotterdam (The Netherlands). The criteria were the initial forced expiratory volume in 1 second $\left(\mathrm{FEV}_{\mathrm{h}}\right) \geqslant 60 \%$ of the mean expected value for height and the exercise-induced decrease in $\mathrm{FEV}_{1} \geqslant 15 \%$ of the initial value in the basal tests on each of the 3 consecutive days (see 4). For each patient these values had to be reproducible, i.e. their coefficient of variation (- standard deviation as percentage of the mean) was less than $15 \%$.

In the 2 weeks prior to the study the patients were in a stable clinical condition and had not received cromoglycate, beclomethasone, oral corticosteroids or $\beta_{2}$ adrenergic agonists. Other drugs were withdrawn 3 days prior to the tests.

2. The exercise test was done on a Jaeger treadmill following the method of 
Eggleston and Guerrant ${ }^{13}$. The slope was $10^{\circ}$ and the running time about 6 minutes. The speed was increased to give a pulse rate of about $175 / \mathrm{min}$. This was reached with speeds between 5 and $12 \mathrm{~km} /$ hour.

3. Bronchoconstriction was detected by lung function measurement using a Finivess flow-volume equipment. The $\mathrm{FEV}_{1}$ was registered by a time signal. The results were based upon the $\mathrm{FEV}_{1}$ values. The maximal expiratory flows at $25 \%$ of the forced vital capacity were also analysed, but no essential differences were found compared to the $\mathrm{FEV}_{1}$ values, consequently they are not mentioned further.

Pulmonary function tests were measured at the following times: before, immediately after and 5,10,15 and 20 minutes after the exercise tests. At every measurement the flow-volume curve was recorded three times and the highest $\mathrm{FEV}_{1}$ values were taken for the results.

The change in $\mathrm{FEV}_{1}$ was expressed as a percentage of the initial value. The criterion taken for bronchoconstriction was a decrease in $\mathrm{FEV}_{1} \geqslant 15 \%$.

4. The study was done on 4 consecutive days. On the first day an exercise test was done after the administration of a placebo. On each of the 3 following days an exercise test was performed twice. At 9 a.m. it was done without a protective agent (basal test). At 10.40 a.m. a protective agent was given. The test was repeated 20 minutes thereafter. A two hour interval between tests would avoid interest influences ${ }^{14}$. The temperature and humidity of the air in the room where the tests took place, were rather constant at approximately $22^{\circ}$ and $70 \%$ respectively: they were, however, not controlled.

5. On each of the test days, one of the following protective agents was given in a random order.

- oxytropium bromide (parasympatholytic), 0,02 $\mathrm{mg}$ per dose aerosol (2 puffs)

- disodium cromoglycate (mast cell stabilizer), $20 \mathrm{mg}$ as aquous solution per ultrasonic nebulizer (Monaghan 670). By using a solution we avoided cromoglycate acting by a hygroscopic effect alone ${ }^{11}$.

- fenoterol ( $\beta_{z}$ adrenergic agonist), $0,4 \mathrm{mg}$ per dose aerosol ( 2 puffs).

The inhalation was performed as follows: after a submaximal expiration, the patient inspired synchronously with the aerosol, the mouth being kept closed over the inhaler opening. During this inspiration the tongue was kept on the floor of the mouth. After inspiration the breath was held for 5 seconds. The technique was learnt using a placebo.

The doses were chosen so that a maximal effect in pharmacological terms could be expected ${ }^{15^{-16}-17}$.

6. The histamine threshold was measured by means of the inhalation of histamine acid phosphate in increasing concentration (doses 1, 2, 4, 8, 16, 32 and 64 
$\mathrm{mg} / \mathrm{ml})^{18}$. At the beginning of the inhalation each patient performed a submaximal vital capacity manoeuvre, after which they inhaled the aerosol at tidal volume for 30 seconds. The time between the inhalations was $3-5$ minutes. The histamine concentration which caused a decrease in $\mathrm{FEV}_{1} \geqslant 15 \%$ of the initial value was called the histamine threshold. With this technique the histamine threshold in healthy children is $\geqslant 32 \mathrm{mg} / \mathrm{ml}$.

7. Statistics.

An analysis of variance was done in order to detect any influences of day- or agent sequence on the initial $\mathrm{FEV}_{1}$ (every day at 9 a.m. and during the day) and the decrease of the $\mathrm{FEV}_{1}$ induced by exercise without protection (basal tests).

The results concerning the effects of the protective agents and the comparison between them were analysed by calculating means and standard errors and hence paired student $T$ tests. The relationship between the decrease in FEV, without agents and the degree of protection by each agent (figure 1) as well as the histamine threshold (figure 4) were analysed by lineair regression equations, from which $p$-values were derived.

The patient groups were divided according to the greatest effect by paired comparison between the three agents. These patient groups were compared according to the initial $F E V_{1}$, the decrease in $F E V_{1}$ induced by exercise without protection and the histamine threshold. The differences were analysed by Wilcoxon tests. The $5 \%$ level was considered as the level of significance.

\section{Results}

In the basal tests no correlation existed between the day - and agents sequences on the one hand and the initial $\mathrm{FEV}_{1}$ and the decrease in $\mathrm{FEV}_{1}$ in the basal tests on the other hand (Analysis of variance). This makes the influence of variables other than the protective agents on the results improbable. The initial $\mathrm{FEV}_{1}$ values at 9 and 11 a.m. did not change significantly, except after the administration of the $\beta_{2}$ adrenergic agonist when they were just significantly higher $(0,02<\mathrm{P}<0,05)$.

Table 1 shows the mean change in $\mathrm{FEV}_{1}$ after exercise without and with protection for the group as a whole. The decrease in $\mathrm{FEV}_{1}$ without protection is $32.4 \pm 3.0 \%$ and the results after the placebo are not significantly different from those without.

After the administration of the protective agents there was either less decrease in $\mathrm{FEV}_{1}$ or even an increase was observed. The results following all protective agents were significantly different from those without $(P<0.001)$. The degree of protection, defined as the difference between the decrease in $F E V_{1}$ with and without agents, was significant for all of them.

If the effects of the protective agents are mutually compared, there appears 
Table 1. Mean changes in FEV, after exercise without and with the placebo and each of the protecting agents.

\begin{tabular}{|c|c|c|c|c|c|c|}
\hline \multirow{2}{*}{ Agents } & \multicolumn{2}{|c|}{$\begin{array}{l}\text { Decrease in FEV, } \\
\text { induced by exercise }\end{array}$} & \multicolumn{2}{|c|}{$\begin{array}{l}\text { Degree of } \dagger \\
\text { protection }\end{array}$} & \multirow{2}{*}{\multicolumn{2}{|c|}{$\begin{array}{c}\text { Difference } \\
\text { between agents } \\
\text { P-value }\end{array}$}} \\
\hline & Mean \pm S.E.M. & P-value & Mean \pm S.E.M. & P-value & & \\
\hline Without & \multicolumn{2}{|l|}{$-32.4 \pm 3.0$} & & & \multirow{5}{*}{ N.S. } & \multirow{5}{*}{$<0.02$} \\
\hline Placebo & $-27.5 \pm 3.2$ & N.S. & & & & \\
\hline Parasympatholytic & $-12.5 \pm 4.7$ & $<0.00 \mathrm{I}$ & $16.6 \pm 4.1$ & $<0.01$ & & \\
\hline Mast cell stabilizer & $-6.7 \pm 2.1$ & $<0.001$ & $25.8 \pm 4.1$ & $<0.001$ & & \\
\hline $\mathrm{B}_{2}$ Adrenergic agonist & $+1.5 \pm 5.2$ & $<0.001$ & $32.5 \pm 5.4$ & $<0.00 \mathrm{I}$ & & \\
\hline
\end{tabular}

Mean \pm S.E.M. are expressed as percentage of the initial values.

$\uparrow$ Difference of change in FEV, with and without agents.

only a significant difference between the parasympatholytic and the $\beta_{2}$ adrenergic agonist $(\mathrm{P}<0.02)$.

In figure 1 the decrease in $\mathrm{FEV}_{1}$ for every patient without protection is compared with the degree of protection given by each of the three agents in a separate graph. The degree of protection ranged up to $20 \%$ in the case of the parasympatholytic, $50 \%$ in the case of the mast cell stabilizer and $60 \%$ in the case of the $\beta_{2}$ adrenergic agonist. It appears to be greater the more pronounced the decrease in $\mathrm{FEV}_{1}$ without protection. A relationship exists between those factors. In the formula $y=a x+b, a$ indicates the slope. The greater the slope, the greater the degree of

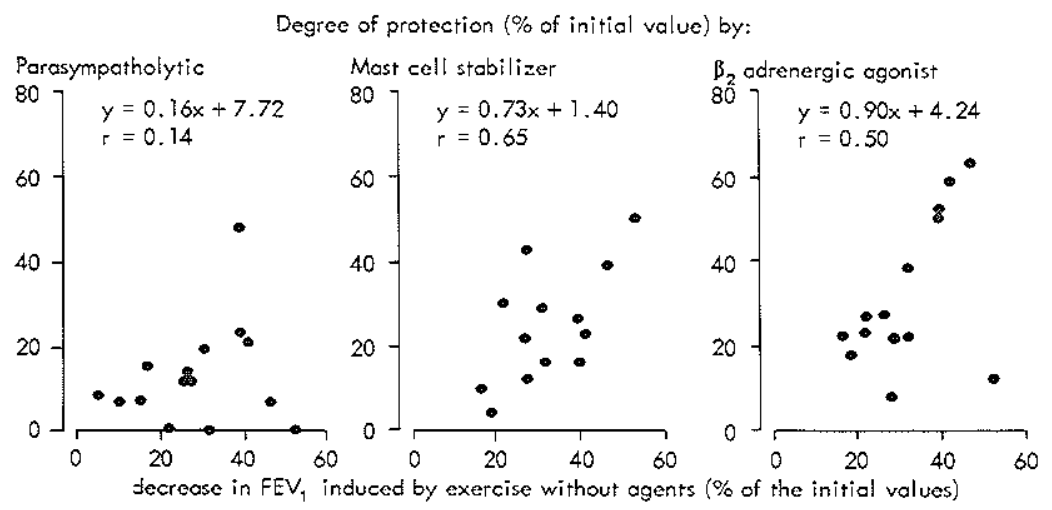

Figure 1. Comparison per patient of the decrease in $\mathrm{FEV}_{1}$ induced by exercise without agents and the degree of protection given by several agents. The degree of protection is the difference between the decrease in $\mathrm{FEV}_{1}$ with and without agents. 
protection. The parasympatholytic gives a slope of 0.16 , the mast cell stabilizer 0.73 and the $\beta_{2}$ adrenergic agonist 0.90 .

From the fact that the degree of protection was related only to the degree of bronchoconstriction without protection (Figure 1) and not to the degree of bronchodilatation after the $\beta_{2}$ adrenergic agonist without exercise (Figure 2), it is to be concluded that the agents were not effective in EIB by initial bronchodilatation but by influencing the mechanism.

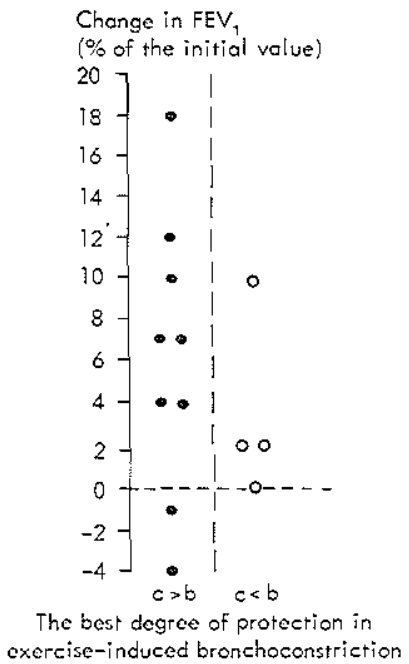

Figure 2. Changes in FEV, without exercise by the $\beta_{2}$ adrenergic agonist in patients in whom the mast cell stabilizer (b) respectively the $\beta_{2}$ adrenergic agonist (c) gave the best degree of protection in EIB.

A check was made to see if some of the patients reacted differently to the group as a whole. For each patient the protective agent which gave the best degree of protection was determined by paired comparison between the agents (Figure 3 ). The parasympatholytic showed superior protection in 3 patients when compared with the mast cell stabilizer and in 1 patient when compared with the $\beta_{2}$ adrenergic agonist. The mast cell stabilizer gave the best protection in 4 patients compared with the $\beta_{2}$ adrenergic agonist.

For each patient these differences in the protection were expressed in quantitative terms as the quotient of the degree of protection of the agents compared, whereby the strongest one is situated in the upper part. Nearly all quotients are markedly greater than 1 , which points to the fact that the differences in degree of protection are relevant. For median values see the figures in the columns of Figure 3. 


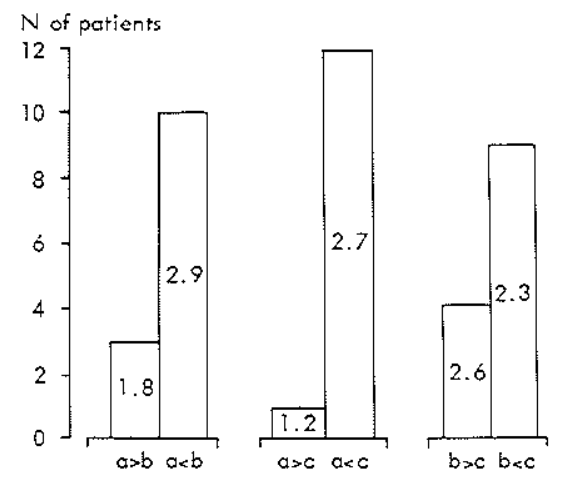

Figure 3. The number of patients according to the best degree of protection in EIB by paired comparison of the agents.

a parasympatholytic; $b$ - mast cell stabilizer; $c>\beta_{2}$ adrenergic agonist.

Equal effects were not found.

The difference in effect is for each patient expressed as the quotient of the degree of protection by the agents compaired. The medians of the quotients are shown in the columns. They indicate that the division of the patients into groups is not based on marginal differences in effect of the agents compared.

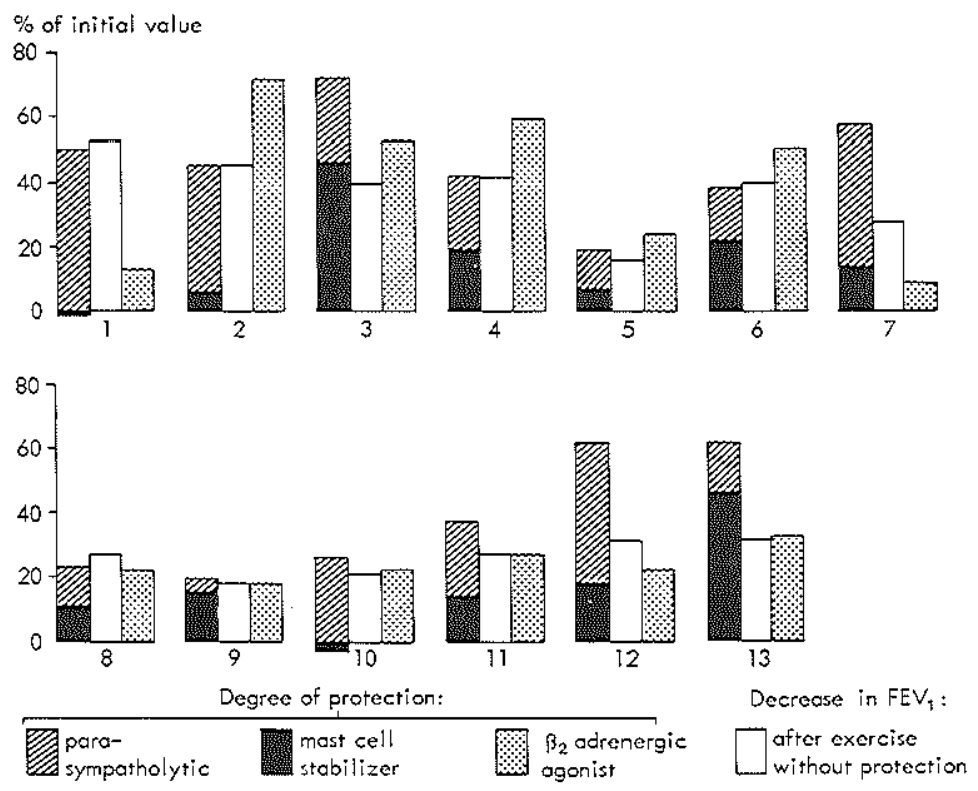

Figure 4. The degree of protection in EIB given by the parasympatholytic and the mast cell stabilizer. illustrated as accumulated effects. compared with that of the $\beta_{2}$ adrenergic agonist and the exercise-induced decrease in FEV, without protection.

Both the degree of protection and the decrease of $\mathrm{FEV}_{1}$ are expressed in percentages of the initial FEV . 
In Figure 4 the comparison is shown between the decrease in $\mathrm{FEV}_{1}$ induced by exercise without protection and the degree of protection of the parasympatholytic and the mast cell stabilizer. The accumulated degree of protection of both agents appears to be about equal (difference less than 10\%) in 9 patients and higher in the other 4 patients compared to the decrease without protection. Figure 4 also shows great individual differences between the accumulated degree of protection given by the parasympatholytic and mast cell stabilizer and the degree of protection given by the $\beta_{2}$ adrenergic agonist.

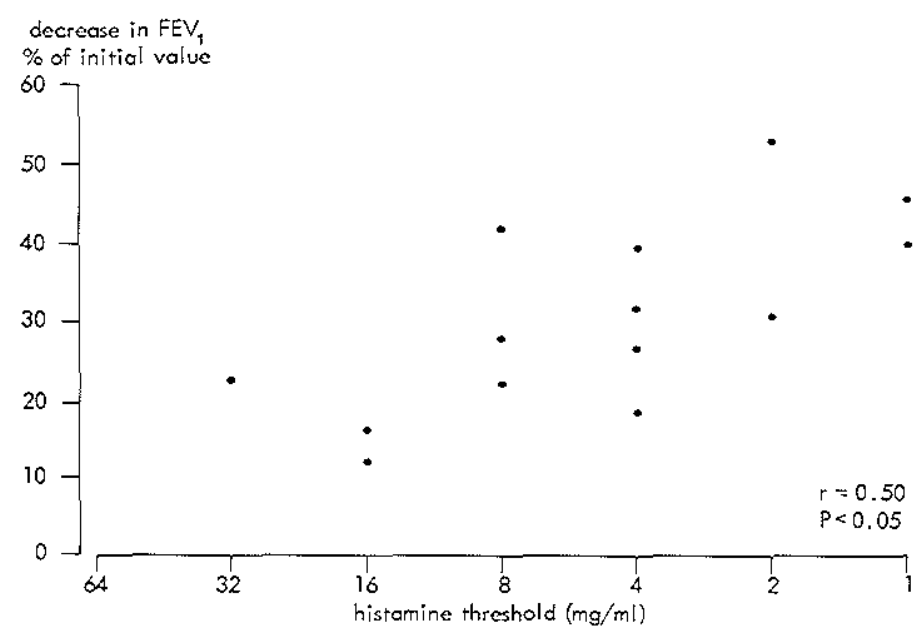

Figure 5. Relationship between the histamine threshold and the exercise-induced decrease in FEV 1 .

Figure 5 shows that the relationship between the decrease in $\mathrm{FEV}_{1}$ induced by exercise without protection and the histamine thresholds is significant $(P<0.05)$. No relationship could be detected between the decrease in $\mathrm{FEV}_{1}$ induced by exercise and the initial $\mathrm{FEV}_{\mathrm{l}}(\mathrm{r}=0.40$, not significant).

In Figure 6 the patients are grouped according to the agent which gave the best protection by paired comparison.

No significant differences between the groups existed in the initial $\mathrm{FEV}_{1}$, decrease in $\mathrm{FEV}_{1}$ after unprotected exercise and histamine thresholds (Wilcoxon tests). 

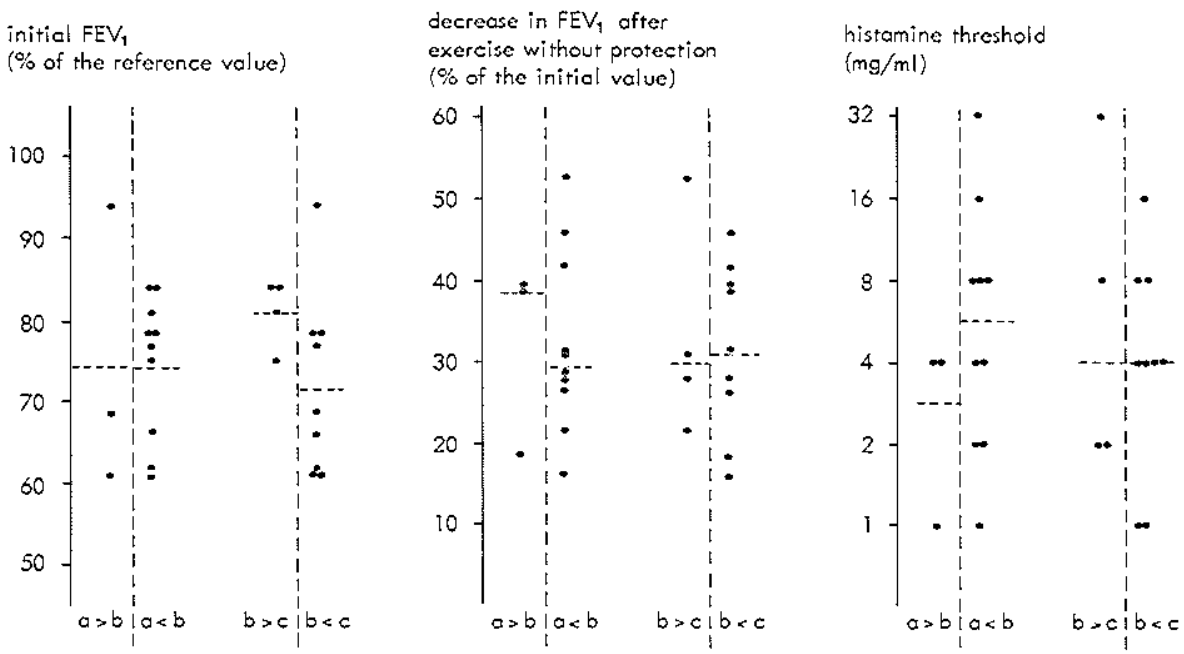

Figure 6. The initial $\mathrm{FEV}_{1}$, the decrease in $\mathrm{FEV}_{1}$ after exercise without protection and the histamine threshold in patient groups divided according to the best protection in EIB by paired comparison of the agents.

$a=$ parasympatholytic: $b=$ mast cell stabilizer; $c=\beta_{2}$ adrenergic agonist.

Median -.....

Differences between the groups are not significant (Wilcoxon tests).

\section{Discussion}

In this study the protective effect of a parasympatholytic, a mast cell stabilizer (cromoglycate) and a $\beta_{2}$ adrenergic agonist on EIB was found to be significant.

We have assumed that a maximal bronchodilatating effect has been provoked by the technique and with the doses used and that the same was true for the protective effect on EIB although this is difficult to prove.

Although the time between administration of the parasympatholytic and the exercise test was a little short and bronchodilatation could have occurred during the recovery time, we do not think this could have influenced the results to a meaningfull degree.

The results were not influenced by variables other than the protective agents. They are in accordance with those of several other authors ${ }^{6-19-20}$. One of them, Tashkin ${ }^{19}$ found that although aerosolized atropine had some protective effect, it could not be differentiated from placebo effect.

Based on Figure 1 and 2, it would seem justifiable to conclude that all protective agents had their effect on EIB mainly by influencing its mechanism during and after exercise and that this could not be explained by initial bronchodilatation. 
It was found that individual differences existed between patients. From the fact that the degree of protection in some patients given by the parasympatholytic is greater than that of the mast cell stabilizer, it may be concluded that in these individuals activation of the vagus is more important than activation of the mast cell system. In contrast to the results of the patientgroup in general, some patients attained a greater degree of protection from the mast cell stabilizer than from the $\beta_{2}$ adrenergic agonist.

In these patients it can be assumed that mediator release from mast cells is relatively important in the mechanism of EIB. It seems that blocking of histamine release from their mast cells by triggering the $\beta_{2}$ adrenergic receptors is only of limited value in contrast to the effect of cromoglycate. Also, $\beta_{2}$ adrenergic relaxation of their bronchial muscles is of relatively little importance in the blocking of the EIB response.

Although this might indicate hyporesponsiveness of their $\beta_{2}$ adrenergic receptors, this does not seem to be so because the bronchodilatation induced by the $\beta_{2}$ adrenergic agonist under resting conditions in these patients was not less than in the others (Figure 2).

Our findings that the degree of protection given by the parasympatholytic together with the mast cell stabilizer seems to be in accordance with the degree of bronchoconstriction without protection can be explained in two ways:

1. A combined action of the parasympathetic nerves and the mast cells in EIB may occur. Which system dominates could not be predicted from the initial lung function values, the bronchodilatation induced by the agents without exercise nor the bronchial sensitivity to histamine (Figures 2,6). Mc Fadden et al. ${ }^{21}$ could also distinguish subgroups in their population with EIB. This is important in view of the treatment as well.

2. A complete stabilisation of the mast cell, resulting in blocking of mediatorrelease, only occurs if besides the cromoglycate sensitive receptors the parasympathetic receptors of the mast cell are blocked as well.

If it turns out that cromoglycate has effects outside the mast cells, the interpretations of blocking studies like this has to be reviewed. Possibly the blocking effect of cromoglycate could then partially be explained by an action on bronchial smooth muscle or irritant receptors. The important place of the mast cells in EIB is however supported by the facts that EIB is followed by a period of latency ${ }^{14}$ and that several authors $\mathrm{s}^{22-23}$ found a rise in arterial histamine concentration after exercise.

The degree of bronchoconstriction induced by exercise has a strong relationship with the bronchial sensitivity to histamine as shown in this and other studies ${ }^{4-}$. This indicates that the mechanisms induced by both stimuli may be related. There is no difference in the bronchial sensitivity to histamine in patients 
with EIB in whom the autonomic nervous system dominates compared to those in whom the mast cells are of major importance.

Thus one might suspect that both these systems play a role in the mechanism leading to bronchoconstriction after histamine inhalation. Although the reaction to histamine could be confined to the direct stimulation of the histamine receptors of the bronchial muscle cells ${ }^{24}$, this is probably not the case. Jackson et al. ${ }^{25}$ showed in rats that the autonomic nervous system was stimulated by the histamine aerosol, since the bronchial response decreased after dissection of the vagus nerve. Studies of Dixon et al. ${ }^{26}$ indicate that this may be due to stimulation of irritant receptors. It seems probable that histamine-induced vagal stimulation also triggers mast cells, because the mast cell stabilizer cromoglycate diminishes the bronchial response to histamine in a part of the patients ${ }^{27-28}$.

Thus large similarities exist between the mechanisms by which histamine and exercise induce bronchoconstriction. This justifies the view that EIB can be regarded as an expression of bronchial hyperreactivity.

\section{Acknowledgements}

The authors wish to thank Jeannette Boogaard, Ineke Strik, Edith Bonzet and Joke Mazee for their technical assistance.

\section{The patients consent}

This study had been designed to gain scientific information and also to demonstrate any pharmacological effects in a particular patient. All of the patients and their parents were fully informed about the methods and the aims of the study.

They gave their consent voluntarily.

\section{References}

1. OREHEK J, GAYRARD P. SMITH A P. GRIMAUD C \& CHARPIN J. Airway response to carbachol in normal and asthmatic subjects. Am Rev Respir Dis 1977; 115: 937-943.

2. COCKCROFT D W. KILLIAN D N. MELLON J J A \& HARGREAVE F E. Bronchial reactivity to inhaled histamine, a method and clinical survey. Clin Allergy 1977; $7: 235-243$.

3. NEIJENS $\mathrm{H}$ J. DEGENHART H J, RAATGREEP H C \& KERREBIJN $\mathrm{K} F$ The correlation between increased reactivity of the bronchi and of mediator releasing cells in asthma. Clin Allergy 1980: 10:535-539.

4. KIVILOOG J. Variability of bronchial reactivity to exercise and methacholine in bronchial asthma. Scand J Respir Dis 1973: 54: 359-368.

5. MELLIS C M. KATTAN M. KEENS T G \& LEVISON H. Comparative study of histamine and exercise challenges in asthmatic children. Am Rev Respir Dis 1978; 117:911-915. 
6. GODFREY S \& KÖNIG P. Inhibition of exercise-induced asthma by different pharmacological pathways. Thorax 1976:31:137-143.

7. MC. NALLY JR. J F. ENRIGHT P, HIRSCH J E \& SOUHRADA J F The attenuation of exercise-induced bronchoconstriction by oropharyngeal anaesthesia. Am Rev Resp Dis 1979: 119:247-252.

8. MC. FADDEN JR E R \& INGRAM JR R H. Exercise-induced asthma. Observations on the initiating stimulus. New Engl J Med 1979; 301: 763-769.

9. DAVIES S E. Effect of disodium cromoglycate on exercise-induced asthma. Br Med J 1968: 3:593-594.

10. PATTERSON R, MC. KENNA I M, SUSZKO I M. SOLLIDY $N$ H, PRUZANSKY J J, ROBERTS M \& KEHOE T J. Living histamine containing cells from the bronchial lumens of humans. J Clin Invest I977:59:217-225.

11. MC. FADDEN JR E R \& INGRAM JR R H. Sites of airways responses in asthma. In: Sadoul P. Milic-Emili J. Simonsson B G \& Clark $T$ J H. eds. Small airways in health and disease. Amsterdam: Exerpta Medica. 1979: 156-160.

12. COX J S G. Disodium cromoglycate mode of action and its possible relevance to the clinical use of the drug. Brit J Dis Chest 1971:65: 187-204.

13. EGGLESTON P A \& GUERRANT J L. A standardized method of evaluating exerciseinduced asthma. J Allergy Clin Immunol 1976:58:414-425.

14. EDMUNDS A $T$. TOOLEY M \& GODFREY S. The refractory period after exercise-induced asthma its duration and relation to the severity of exercise. Am Rev Respir Dis 1978; 117: 247.254 .

15. ALTOUNYAN R E C. Inhibition of experimental asthma by a new compound - Disodium cromoglycate "Intal". Acta Allergol 1967: 22: 487.

16. MEIER J. Dosis- und Zeitwirkungsuntersuchungen mit Ipratropiumbromid und placebo bei chronischer Bronchitis und Asthma bronchiale. Wien Med Wochenschr 1974, 21 suppl.: 29-33.

17. STANESCU D, VAN LEMPUTTEN R. FRANS A. BRASSEUR L Evaluation of lung function indices for bronchodilator trials. Results of a cross-over study of fenoterol. Respiration 1976:33: 1-8.

I8. DE VRIES K, BOOIJ-NOORD H, GOEI H, GROBLER N J, SLUTTER H J, TAMMELING G J \& ORIE N G M. Hyperreactivity of the bronchial tree to drugs. chemical and physical agents. In : Orie N G M. Sluiter H J, eds. Bronchitis II. Second International Symposium. Assen: Royal Vangorcum. 1964: 167-180.

19. TASHKIN D P. KATZ R M. KERSCHNAR H. RACHELEFSKY G S \& SIEGEL S C. Comparison of aerosolized atropine, isoproterenol. atropine plus isoproterenol, disodium cromoglycate and placebo in the prevention of exercise-induced asthma. Ann Allergy 1977: 39: 311-317.

20. CHAN-YEUNG M. The effect of Sch 1000 and disodium cromoglycate on exercise-induced asthma. Chest: $1977 ; 71: 320-323$.

21. MC. FADDEN JR E R \& SOTER N A. A search for chemical mediators of immediate hypersensitivity and humoral factors in the pathogenesis of exercise-induced asthma. In: Asthma physiology. immunopharmacology and treatment. Lichtenstein L M \& Austen K F. eds. New York: Academic Press. 1977:351-364.

22. FERRIS L. ANDERSON S D \& TEMPLE D M. Histamine release in exercise-induced asthma. Br Med J 1978; /: 1967.

23. CHARLES $T$ J. HARTLEY J $P$ R. SEATON A, TAYLER $W$ H \& WESTWOOD A. Arterial histamine in exercise-induced asthma. Clin Sci 1979; 56: 8-9. 
24. FLEISCH J H, KENT K M \& COOPER T. Drug receptors in smooth muscle. In: Austen $\mathrm{K} F$ and Lichtenstein L M. eds. Asthma physiology, immunopharmacology and treatment. Proceedings of an Int. Conf. on asthma. New York: Academic Press. 1973, 139-167.

25. JACKSON D M \& RICHARDS I M. The effects of sodium cromoglycate on histamine aerosol-induced reflex bronchoconstriction in the anaesthetized dog. $\mathrm{Br} \mathrm{J}$ Pharmacol 1977: 61: 257-262.

26. DIXON M. JACKSON D M \& RICHARDS I M. The effects of histamine, acetylcholine and 5-hydroxytryptamine on lung mechanics and irritant receptors in the dog. J Physiol 1979; 287:393-403.

27. KERR $J$ W. GOVINDARAI M \& PATEL $K$ R. Effect of alpha-receptor blocking drugs and disodium cromoglycate on histamine hypersensitivity in bronchial asthma. Brit Med J 1970: 2: $139-141$.

28. WOENNE R. KATTAN M \& LEVISON H. Sodium cromoglycate induced changes in the dose-response curve of inhaled methacholine and histamine in asthmatic children. Am Rev Respir Dis 1979:119:927-932.

\section{Appendix to paragraph 7.1}

The degree of protection by an agent has been defined as the difference in change of lung function with and without an agent. The change in lung function is the difference between the lung function before and after a challenge with a stimulus, in this case an exercise test. The agent given may produce an initial bronchial dilatation as well as protection during and after the challenge. Thus the degree of protection reflexes both influences. These are impossible to differentiate in a reliable way. This holds for the sympathomimetic and the parasympatholytic agents, but not for DSCG.

It is striking that the protective effect of the parasympatholytic is relatively low if it is compared to the large influence of the parasympatholytic activity in animal experiments. However, the possibility exists that the blocking capacity of the parasympatholytic used, may not be optimal as suggested recently. Hartley and Davies (1980) showed that a very high dose of a parasympatholytic protected much better against exercise-induced bronchial obstruction than a normal dose, although the drug-induced bronchial dilatation by both were comparable.

The protective effect of DSCG was not related to the degree of atopy in the patients studied. 
7.2 Site of maximal flow-limitation in bronchial responsiveness due to exercise

Herman J. Neijens M.D., Gianfranco Gargani M.D., Adrie van Kralingen, Nellie van Weezepoel, Karel F. Kerrebijn M.D.

\section{Abstract}

The change in the site of maximal flow-limitation with time in exercise-induced bronchoconstriction was studied in 16 asthmatic children by repeated measurements of maximal flow-volume curves in air and helium-oxygen $(80 / 20)$. Bronchoconstriction shortly after exercise is determined by flow-limitation in the more peripheral airways in nearly all of the patients. Then bronchoconstriction fades away, while the site of maximal flow-limitation returns towards the central airways. Both variables have a significant relationship $(P<0.05)$, which differs with time and among patients.

The degree of protection by the $\beta$-sympathetic agonist is more pronounced (mean $28 \%$ ) than that of the parasympatholytic (mean $3 \%$ ), and its action increases along with the degree of shift in the maximal flow-limitation towards the periphery. The implications for the mechanism involved and the therapy are discussed.

\section{Introduction}

The mechanism of exercise-induced bronchoconstriction (EIB) is not fully understood (4). Mc Fadden and Ingram (11) and also others (17) stressed the importance of hyperventilation with relatively cold and dry air. Several blocking studies in EIB have been done $(8,15,18)$, which have given information about the role of the sympathetic, the parasympathetic and the mast cell systems. However, relatively little is known about the site of flow-limitation after exercise.

Mc Fadden et al. (12) used the density dependency method to analyse the site of maximal flow-limitation in EIB in adults. They concluded that flow-limitation in a number of their patients was located in the central airways and in others in the peripheral airways. Parasympatholytics were found to be most effective in patients

1. This study is supported by the Netherlands Asthma Foundation (grant nr. 279).

2. Presented at the meetings of the European Paediatric Respiratory Society, Baden near Vienna. Austria. October IIthe. 1980 and at the congress "Small airways in relation to chronic obstructive pulmonary disease", The Hague. The Netherlands. January 31st. 1981.

3. To be published in Progress in Respiration Research 1981. 17, in press (the paper of the Baden Meeting) and in the European Journal of Respiratory Disease, in press. 
with central flow-limitation, whilst in patients with peripheral flow-limitation $\beta$-sympathetic agonists were most appropriate. This method is based on the principle that in the peripheral airways laminar flow exists which is not dependent on the density of the gas, whereas turbulent flow which occurs in the larger, more centrally located airways is gas-density dependent according to Despas et al. (3). This means that the flow will increase if breathing is performed, instead of with air, with a gas of lower density. In healthy individuals the limitation of expiratory flow is determined by the diameter of the central airways. Therefore the expiratory flow after exhaling a low density mixture is larger than with air and the difference will be approximately $50 \%$ if $80 \%$ Helium $-20 \%$ oxygen $\left(\mathrm{He} / \mathrm{O}_{2}\right.$ ) is used. If the site of maximal flowlimitation is located in airways with a turbulent flow, the difference between both gases will be unchanged. However, if the flow is largely limited by airways in which it is laminar, the difference will be smaller. Although density independent flow occurs preferentially in more peripheral regions of the airways than density dependent flow does, the precise site were flow changes from being predominantly density independent to density dependent is unknown (14).

In a previous study we found that the majority of asthmatic children is better protected against EIB by a $\beta$-sympathetic agonist than by a parasympatholytic (15). We herewith report results of measurements of the relationship between bronchoconstriction and density dependency with time after exercise in asthmatic children. Also the degree of protection by either a $\beta_{2}$-sympathetic agonist and a parasympatholytic agent and its relationship to the pattern of flow-limitation will be evaluated.

\section{Methods}

1. Lung function was measured by flow-volume curves using Finivess equipment. These were obtained with air and with a low density gas after a wash-in of $\mathrm{He} / \mathrm{O}_{2}$ until the end-tidal nitrogen concentration was $<5 \%$. At every measurement the flow-volume curve was recorded three times and the highest values according to the method of Peslin et al. (16) were taken. The maximal expiratory flow-volume curves with $\mathrm{He} / \mathrm{O}_{2}$ were adapted to those in air with the aid of a computer; The forced vital capacity in $\mathrm{He} / \mathrm{O}_{2}$ was equalized to that in air superimposing the curves at total lung capacity. Hence the flows were adapted accordingly. Flow at $50 \%$ of the vital capacity in air $\left(V_{50}\right.$ air) and $\mathrm{He} / \mathrm{O}_{2}$ $\left(\vee_{50} \mathrm{He} / \mathrm{O}_{2}\right)$ were taken for the calculations. $\vee_{50} \mathrm{He} / \mathrm{O}_{2}$ minus $\vee_{50}$ air is expressed as a percentage of $V_{s 0}$ air and used as a measure for the density dependency.

2. The exercise test was done on a Jaeger treadmill according to the method of Eggleston and Guerrant (6). The slope is $10^{\circ}$ and the running time about 6 minutes. The speed was increased to give a pulse rate of $>175 / \mathrm{min}$. This was 
reached with speeds of between 7 and $12 \mathrm{~km} /$ hour.

An exercise test without a protective agent (basal test) was done on each of two consecutive days at 9 o'clock in similar ways. On each day an identical exercise test was performed, four hours later, this interval would avoid intertest influences (5). The second test was done 30 minutes after administration of a protective agent. The temperature and humidity of the air in the room where the test took place, were rather constant at $22^{\circ}$ and $70 \%$ respectively: they were, however, not controlled.

3. On each of the test days, one of the following protective agents were given in a random order.

- oxytropiumbromide (parasympatholytic), $0.08 \mathrm{mg}$ per dose aerosol;

- fenoterol ( $\beta_{2}$-sympathetic agonist), $0.4 \mathrm{mg}$ per dose aerosol.

The inhalation was performed as follows: after a submaximal expiration, the patient inspired synchronously with the aerosol, the mouth being kept closed over the inhaler opening. During this inspiration the tongue was kept on the floor of the mouth. After inspiration the breath was held for 5 seconds. The technique was learnt using a placebo.

The doses were chosen so that a maximum effect in pharmacological terms could be expected. The influence of the protective agents on EIB is expressed as the degree of protection, which is the difference between the bronchial obstruction in the exercise test with and without agent.

$\bigvee_{s 0}$ air and $\bigvee_{50} \mathrm{He} / \mathrm{O}_{2}$ were measured prior to the exercise. After exercise the same measurements were repeated in the following schedule: $V_{50}$ air at 1,5 , 13 and 22 minutes; $\vee_{50} \mathrm{He} / \mathrm{O}_{2}$ at 4,9 and 19 minutes after exercise (Figure 1 ). In the figure all measurements in air are connected by a continuous line and those in $\mathrm{He} / \mathrm{O}_{2}$ by a dotted line. The distance between the measured point and the corresponding point on the other line was considered as the density dependency. To determine the density dependency with time, mean values of paired measurements have been taken: at 4 and 5 minutes, 9 and 13, as well as 19 and 22 minutes. As reference for $V_{50}$ air the data of Zapletal et al. $(20)$ were used.

4. 16 asthmatic children were studied; their ages ranged from $8 \%{ }_{12}$ to $14^{1} / 12$ years with a mean of $12^{10} /{ }_{12}$ year. The patients were selected from the outpatient clinic of the Sophia Children's Hospital in Rotterdam (The Netherlands).

5. The criteria for selection were:

1. the baseline $\vee_{50}$ air $\geqslant 50 \%$ of the mean predicted value for height;

2. a decrease after exercise $\geqslant 20 \%$ of the baseline value on each of 2 consecutive days; 


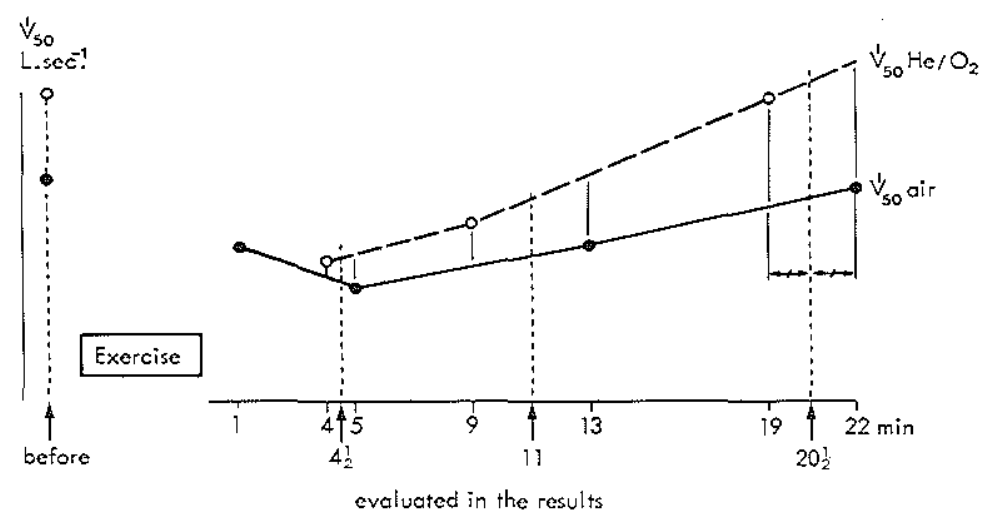

Figure 1. Design of the study and method of calculation. $\uparrow$ evaluated in the results.

3. for each patient these values and the density dependency had to be reproducible, i.e. their coefficient of variation (= standard deviation as percentage of the mean) was $\leqslant 15 \%$;

4. in the 2 weeks prior to the study the patients had to be in a stable clinical condition and without cromoglycate, beclomethasone, oral corticosteroids or $\beta_{2}$-sympathetic agonists. Other drugs were withdrawn 3 days prior to the tests.

Informed consent was obtained from the parents after full information about the investigations had been given.

\section{Results}

In Figure 2 the mean values for all patients are given for both days. The baseline values of $\downarrow_{50}$ air are $74,1 \pm 4,3 \%$ (mean \pm SEM) respectively $73,8 \pm 3,4 \%$ of the reference value. The decrease in $\nabla_{50}$ air is $39,2 \pm 3,5 \%$ respectively $40,3 \pm 3,9 \%$ at $41 / 2$ minutes, $32,3 \pm 3,9 \%$ and $29,3 \pm 3,4 \%$ at 11 minutes and hence $23,5 \pm 5,4 \%$ and $21,4 \pm 17,9 \%$ at $201 / 2$ minutes after exercise.

The mean density dependency, which is also shown in Figure 2, is $42,8 \pm 3,6 \%$ respectively $42,4 \pm 3,1 \%$ before exercise, $16,8 \pm 1,9 \%$ respectively $16,2 \pm 2,8 \%$ at $4 \frac{1}{2}$ minutes, $29,4 \pm 4,6 \%$ respectively $23,6 \pm 3,2 \%$ at 11 minutes and finally $47,6 \pm 3,1 \%$ respectively $43,1 \pm 2,8 \%$ at $201 / 2$ minutes after exercise. 


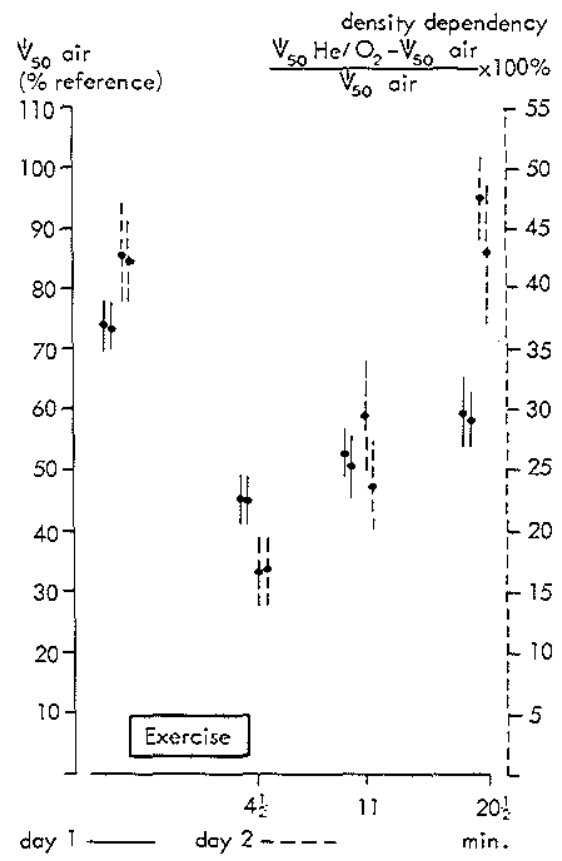

Figure 2. $\downarrow_{50}$ air $(-\rightarrow-)$ and density dependency $(-\rightarrow \rightarrow$ before and after exercise in mean \pm sem on 2 consecutive days, in 16 patients.

In Figure 3 the decrease in $\downarrow_{50}$ air and the density dependency are compared for every patient at $4 \frac{1}{2}(3 a), 11$ (3b) and at $201 / 2$ minutes (3c). The relationship between both factors is significant at the $5 \%$ level (Spearman rho). Shortly after exercise ( $41 / 2$ minutes) a strong bronchoconstriction accompanies a low density dependency and vice versa (figure $3 \mathrm{a}$ ). At a relatively long time after exercise $\left(20^{1 / 2}\right.$ minutes) a slight or moderate bronchoconstriction is associated with a high density dependency. At 11 minutes after exercise (figure 3b) an intermediate situation exists.

In order to compare the density dependency relatively late after exercise (at $20^{1} / 2$ minutes) with the pre-exercise value, both are displaced on a $x$-y diagram (figure 4). In most patients the density dependency late after exercise is higher than prior to exercise.

The relationship between the degree of the bronchoconstriction and the density dependency with time is plotted in a $x$-y diagram for each patient in the way shown in Figure 5. Four types of pattern can be distinguished (Figure 5). The pattern type 

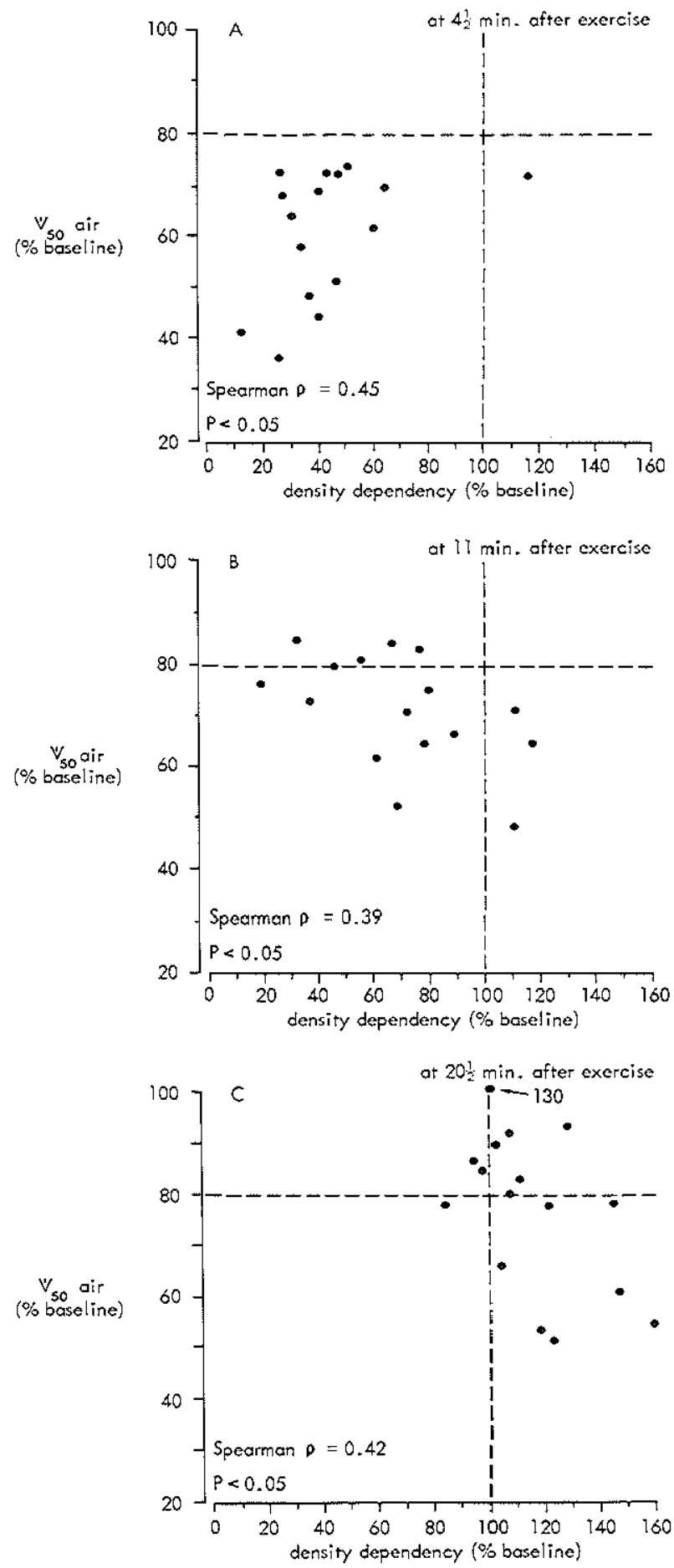

Figure 3. Relationship between $\bigvee_{50}$ air and density dependency at $4 \frac{1}{2}$ minutes (A), 11 minutes (B) and $201 / 2$ minutes (C) after exercise. Test of Spearman is used for significance. 


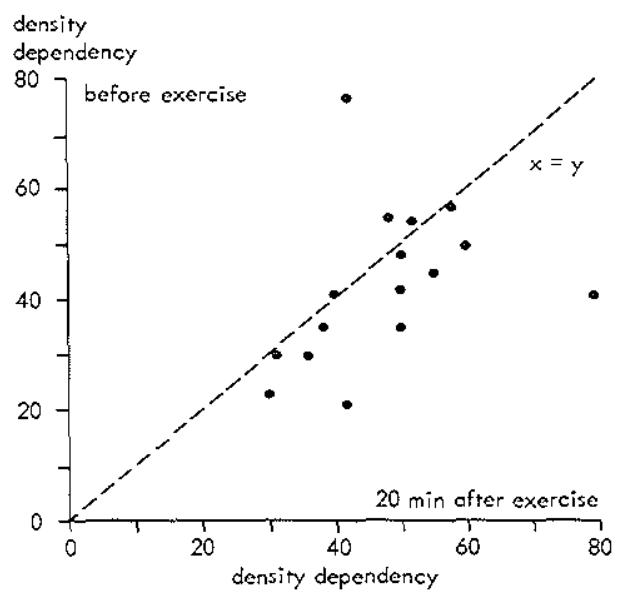

Figure 4. Comparison of the density dependency before (y-axis) and at 20 minutes after exercise ( $x$-axis). $x=y$, line of identity.

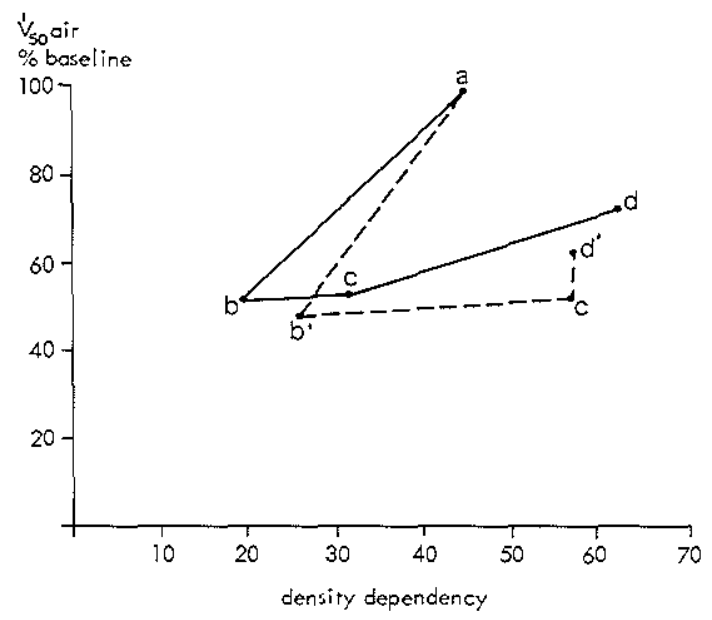

Figure 5. Relationship of bronchoconstriction and density dependency with time of a typical patient.

a before exercise;

b $4 \frac{1}{2}$ minutes after exercise:

c 11 minutes after exercise:

d $20^{\mathrm{t}} / 2$ minutes after exercise.

---1 st day

2nd day 


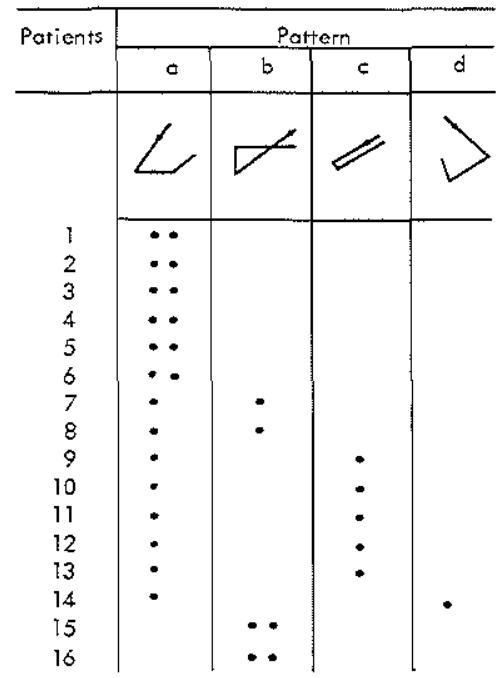

Figure 6. Patterns of the relationship between bronchoconstriction and density dependency with time as shown in figure 4 for each of the patients on two consecutive days (. .).

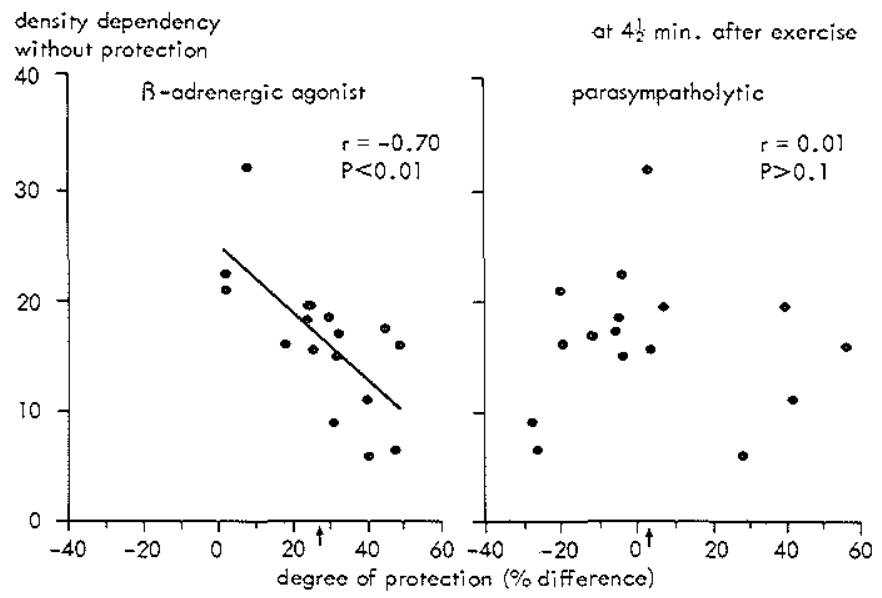

Figure 7. Relationship between the degree of protection defined as the bronchoconstriction (decrease in $\bigvee_{50}$ air) after exercise with and without the $\beta_{2}$-sympathetic agonist (left graph) or the parasympatholytic agent (right graph) ( $\mathrm{x}$-axis) and the density dependency after exercise without protection (y-axis). All values are at $4 \frac{1}{2}$ minutes after exercise.

$\downarrow$ mean degree of protection. 
mostly obtained is that of a safety-pin with its opening to the right (pattern $a$ ). Patterns $b$ and $c$ seem to be closely related to $a$. All patterns reflect a simultaneous decrease in flow and density dependency. Thereafter the density dependency normalises while bronchoconstriction, at least in part, persists. In pattern $b$ low density dependency persists for a while. In pattern $c$ the bronchoconstriction and the density dependency return to baseline simultaneously. Pattern $a$ was observed in 6 patients on both days and in 8 patients on one of the two days. Pattern $b$ was seen in two patients on both days and in another two on one of the days, while pattern $c$ was present in 5 patients on a single day. A completely different pattern (d) was seen only once illustrating bronchoconstriction immediately after exercise in combination with an increase in density dependency.

The mean degree of protection by the agents, defined as the decrease in $\downarrow_{50}$ air after exercise with and without protection, is $28 \%$ with the $\beta$-sympathetic agonist and $3 \%$ with the parasympatholytic drug (Figure 7). A high degree of protection at $4 \frac{1}{2}$ minutes by the $\beta$-sympathetic agonist is associated with a low density dependency and the reverse. This relationship is significant at the $1 \%$ level. The degree of protection by the parasympatholytic agent is not related to the density dependency.

\section{Discussion}

From these data conclusions can be drawn only if we accept that:

1. density dependency occurs if flow-limitation is determined by airways with a laminar flow.

2. density dependent airflow occurs preferentially in more central regions and density independent airflow in more peripheral airways.

These assumptions are not in contradiction with the recent theories on wave speed limitation (2) and on mechanics of increased maximal expiratory flow during $\mathrm{He} / \mathrm{O}_{2}$ breathing in dogs (14) and human lung $(1,13)$.

Therefore the following conclusions can be drawn from this study. Shortly after exercise bronchoconstriction is most pronounced while the site of maximal flow-limitation has moved towards the periphery. Thereafter bronchoconstriction fades away while the site of maximal flow-limitation rapidly returns to the central airways. Because, in most patients, the density dependency at $201 / 2$ minutes after exercise is larger than the value before exercise, the site of maximal flow-limitation may be located more centrally than before exercise. The combination of bronchoconstriction soon after exercise with localisation of the site of maximal flow-limitation in the central airways (type $d$ ) is rarely seen, in contrast to the study of Mc Fadden et al. (13) in adults. 
The wavelike pattern, in which the site of maximal flow-limitation initially moves towards the periphery and hence returns to the more central airways, is in agreement with findings by several investigators in animal studies. In the generation of EIB, the parasympathetic and the mast cell system seem to be involved (4). Kessler et al. (9), in studies on dogs, used electrical stimulation of the vagal nerves as well as allergen inhalation and found the constriction to be maximal in the peripheral airways (1-8 $\mathrm{mm}$ diameter), but not detectable in the smaller ones. Woolcock et al. (19) found that the sympathetic action exceeds the parasympathetic influence most in the peripheral airways. If recovery from EIB is caused for an important part by a sympathetic counteraction, it could be expected from these findings that it would first become obvious in the peripheral airways. This could explain why the $\vee_{50} \mathrm{He} / \mathrm{O}_{2}$ increases more quickly than the $\vee_{50}$ air improves.

The variation observed in the pattern of recovery of the density dependency is unexplained, but may be due to variability of the measurements as well as to physiological factors. If the latter is true the differences in pattern (Figure 6) could be explained at least in part by variability in sympathetic counterregulation.

In order to exclude the occurrance of peripheral airway obstruction due to frequent forced expirations shortly after exercise, identical measurements were performed without exercise in some of the patients, which did not reveal a decrease in $\mathrm{FEV}_{1}$, or a change in density dependency.

We found, like Mc Fadden et al. (12) that the protective effect of the $\beta$-sympathetic agonist increases with a more peripherally located site of maximal flowlimitation.

Similar to others (7) we found a relationship between the degree of bronchoconstriction and the density dependency (Fig. 3). No patients were observed in whom bronchoconstriction and a high density dependency went together after $4 \frac{1}{2} \mathrm{~min}$. This indicates that in none of the individuals the site of maximal flow-limitation was located in the central airways immediately after exercise. We could therefore not evaluate the effect of the parasympatholytic agent in this pattern of reaction like Mc Fadden et al. did (12).

Because EIB may be considered as an expression of bronchial hyperreactivity $(4,15)$, the wavelike pattern of bronchoconstriction might also occur in other reactions due to hyperreactivity such as after histamine challenge. Studies to analyse this are in progress.

\section{REFERENCES}

1. CASTILLE R G. HYATT R E. RODARTE J R. Determinants of maximal expiratory flow and density dependency in normal humans. J Appl Physiol 1980; 49: 897-904.

2. DAWSON S K. ELLIOTT E A. Wave-speed limitation in expiratory flow - a unifying concept. J Appl Physiol 1977: 43: 498-515. 
3. DESPAS P J. LEROUX M, MAKLEM P T. Site of airway obstruction in asthma as determined by measuring maximal expiratory flow breathing air and a helium oxygen mixture. $\mathrm{J} C$ lin Invest. 1972: 51:3235-3243.

4. Editorial: Exercise-induced asthma. Thorax 1979:34:571-574.

5. EDMUNDS A T. TOOLEY M. GODFREY S. The refractory period after exercise-induced asthma, its duration and relation to the severity of exercise. Am Rev Respir Dis. 1978: 117: 247-254.

6. EGGLESTON P A, GUERRANT J L. A standardized method of evaluating exercise-induced asthma. J Allergy Clin Immunol. 1976:58:414-425.

7. FAIRSHTER R D, WILSON A F. Relationship between the site of airflow limitation and localization of the bronchodilator response in asthma. Am Rev Respir Dis. 1980: /22: 27-32.

8. GODFREY S. KÖNIG P. Inhibition of exercise-induced asthma by different pharmacological pathways. Thorax 1976:31:137-143.

9. KESSLER G F. AUSTIN J H M. GRAF P D, GAMSEN G. GOLD W M. Airway constriction in experimental asthma in dogs: tantalum bronchographic studies. J Appl Physiol 1973: 35: $703-708$.

10. KIVILOOG J. Variability of bronchial reactivity to exercise and methacholine in bronchial asthma. Scand J Respir Dis. 1973; 54: 359-368.

11. MC FADDEN JR E R. INGRAM JR R H. Exercise-induced asthma: observations on the initiating stimulus. New Engl J Med. 1979:301: 763-769.

12. MC FADDEN JR E R. INGRAM JR R H, HAYNES R H. WELLMAN J. Predominant site of flow-limitation and mechanisms of postexertional asthma. $J$ Appl Physiol. 1977: 42: 746-752.

13. MINK S N, WOOD L D H. How does $\mathrm{HeO}_{2}$ increase maximum expiratory flow in human lung. J Clin Invest. 1980: 66:720-729.

14. MINK S. ZIESMANN M. WOOD L D H. Mechanisms of increased maximum expiratory flow during $\mathrm{HeO}_{2}$ breathing in dogs. J A.ppl Physiol. 1979: 47: 490-502.

15. NEIJENS H J. WESSELIUS $\Upsilon$ R. KERREBUN $K$ F. Exercise-induced bronchoconstriction as an expression of bronchial hyperreactivity: a study of its mechanisms in children. Thorax $1980: 36: 517-522$.

16. PESLIN R. BOHADANA A. HANNHART B, JARDIN P. Comparison of various methods for reading maximal expiratory flow-volume curves. Am Rev Resp Dis. 1979: 119: 271-277.

17. STRAUSS E R. MC FADDEN JR E R. INGRAM JR R H, JAEGER J J. Enhancement of exercise-induced asthma by cold air. New Engl J Med. 1977; 297: 743-747.

18. TAHSKIN D P, KATZ R M, KERSCHNER H, RACHELEPSKY G S. SIEGEL S C. Comparison of aerosolised atropine, isoproterenol, atropine plus isoproterenol, disodium cromoglycate and placebo in the prevention of exercise-induced asthma. Ann Allergy. 1977: 39:311-317.

19. WOOLCOCK A J. MACKLEM P $\Upsilon$. HOGG J G. WILSON N J. Influence of autonomic nervous system on airway resistance and elastic recoil. J Appl Physiol. 1969: 26: 814-8 18.

20. ZAPLETAL A. PAUL T. SĂMÃNCK M. Die Bedeutung heutiger Methoden der Lungenfunctionsdiagnostik zum Feststellung einer Obstruction der Atemwege bei Kindern und Jugendlichen. $Z$ Erkrank Atm Org. 1977: 149:343-371. 
7.3. The correlation between increased reactivity of the bronchi and of mediator releasing cells in asthma

H. J. Neijens, H. J. Degenhart, R. Raatgeep and K. F. Kerrebijn.

Department of Paediatrics, Subdepartment of Respiratory Diseases, Erasmus University Medical School, Sophia Children's Hospital, Rotterdam, the Netherlands

\section{Summary}

The hypothesis that increased reactivity in asthma is not always limited to the bronchi but also exists in the mediator releasing system was investigated in forty-five asthmatic children, approximately half of whom had exercise-induced bronchoconstriction (EIB). The bronchial threshold to histamine was measured as an indicator of the reactivity of the bronchi and the histamine release from leucocytes without adding allergen (spontaneous histamine release) was considered as an indicator of the reactivity of the basophilic leucocytes. There was a significant correlation between the histamine threshold and spontaneous histamine release and between these and EIB. These findings support the hypothesis.

\section{Introduction}

Many asthmatic patients show exercise-induced bronchoconstriction (EIB) (Bierman, Kawabori \& Pierson, 1975). These patients often have bronchial hyperreactivity to histamine and acetylcholine (Kiviloog, 1973). Because of the protective action of sympathomimetics, parasympatholytics (Godfrey \& König, 1976) and disodium cromoglycate (Davies, 1968), it can be assumed that both the autonomic nervous system and mediator release play a role in the mechanism of EIB.

When measuring histamine release from leucocytes in asthmatic patients sensitive to cat dander allergen, we noticed that histamine was sometimes released in incubations without allergen (Neijens et al., 1979).

I. This study is supported by the Netherlands Asthma Foundation (grant nr. 238).

2. Presented at the meetings of the British Paediatric Respiratory Group. Canterbury, England. September 29th, 1978 and the International Symposium: "The Mast cell, its role in health and disease", Davos, Switserland, April 25th. 1979.

3. Published in: "The Mast cell, its role in health and disease". Pepys $J$ and Edwards AM eds. Pitman Medical, London, 1979, 322-325. (the paper of the Davos Meeting) and in Clinical Allergy 1980: 10:535-539. Reprint with permission of the publisher. 
We called this phenomenon "spontaneous histamine release". Spontaneous histamine release is considered as a measure of the reactivity of leucocytes. In this study we have investigated the hypothesis that in asthma increased reactivity is not limited to the airways but also exists in other systems such as mediator-releasing cells. We have investigated this in patients with EIB. Because it is difficult to obtain live human pulmonary mast cells, leucocytes have been studied.

\section{Materials and methods}

Forty-four asthmatic children (thirty-one boys, fourteen girls), who were under treatment in the outpatient department for respiratory diseases of the Sophia Children's Hospital in Rotterdam were investigated. Their mean age was 10-7 years with a range of $6 \cdot 2-14 \cdot 2$ years. They had been in a symptom-free period for at least 4 weeks. Treatment was stopped $48 \mathrm{hr}$ before the investigations, which were carried out between $09 \mathrm{~h} 00 \mathrm{~min}$ and $11 \mathrm{~h} 00 \mathrm{~min}$. Histamine threshold was measured in the asthmatic children by means of inhalation at a flow of $6 \mathrm{l} / \mathrm{min}$ of histamine diphosphate in increasing dose concentrations of $1,2,4,8,16,32$ and $64 \mathrm{mg} / \mathrm{ml}$ (de Vries et al., 1964). At the beginning of the inhalation each patient performed a submaximal vital capacity manoeuvre after which they inhaled the aerosol at tidal volume for $30 \mathrm{sec}$. With this technique the bronchial threshold to histamine in healthy children is $\geqslant 32 \mathrm{mg} / \mathrm{ml}$.

On the morning before the histamine threshold measurement, venous blood was withdrawn, with the patient at rest, some minutes after venapuncture to minimize variations caused by the procedure (Simon et al., 1977). Spontaneous histamine release was determined by measuring the amount of histamine released from $1 \mathrm{ml}$ of leucocyte suspension incubated without allergen using the method of May et al. (1970). Histamine release was also measured after adding $20 \mu \mathrm{l}$ anti-IgE (Behring Werke $400000 \mathrm{IU} / \mathrm{ml}$ ) in order to estimate allergen-induced histamine release. The leucocyte suspension was in contact with open air. The histamine release measurements were done in all asthmatic and in thirteen healthy persons comparable in age and sex but without a history of asthma or eczema. All measurements were done in triplicate and the values given are the average of these. The standard deviation of triplicate measurements was $0.5 \mu \mathrm{g} / \mathrm{l}$. The number of basophils was counted in duplicate by the method of Moore \& James (1953). The bronchial reaction to exercise was measured in the asthmatic children by running up and down stairs for at least $5 \mathrm{~min}$ and was performed on the day after the histamine threshold. Exercise was considered satisfactory if the pulse rose above 175 beats a minute. Lung function was assessed by spirometry before, immediately after and at $5,10,15,20$ and $30 \mathrm{~min}$ after exercise. A decrease in the forced expiratory volume in $1 \mathrm{sec}$ $\left(\mathrm{FEV}_{\mathrm{i}}\right)$ below $85 \%$ of the initial value within $15 \mathrm{~min}$ of the run was considered as bronchoconstriction. Most of the parameters were found to be distributed abnormally as appeared from tests for skewness and kurtosis, therefore the statistical treatment of the data was done with non-parametrical tests. 


\section{Results}

Figure 1 shows that the spontaneous histamine release is higher in patients with EIB than in either those without EIB (Fisher exact test, $P<0.02$ ) or than in healthy children $(P<0.05)$. The medians of the three groups were respectively $2.4,1$ and $1 \mu \mathrm{g} / \mathrm{l}$. No relationship between other parameters and spontaneous histamine release could be detected. The basophil counts in the respective groups were $31 \pm 25$, $37 \pm 16$ and $20 \pm 16 / \mathrm{ml}$ (mean \pm s.d.). Anti- $\mathrm{IgE}$ induced histamine release in these groups was, respectively, $9.0 \pm 7.2,7.5 \pm 5.4$ and $4.6 \pm 3.0 \mu \mathrm{g} / \mathrm{l}$ (mean \pm s.d.). Initial $\mathrm{FEV}_{1}$ and spontaneous histamine release were also not related (Spearman $p=0.03$, not significant).

It can be seen in Fig. 2 that the relationship between the histamine threshold and the decrease after exercise is very significant (Spearman $p=0.60, P<0.001$ ). In patients with EIB the histamine threshold is significantly lower than in patients without EIB ( $\chi^{2}$ test, $P<0.005$ ). The medians were 4 and $16 \mathrm{mg} / \mathrm{ml}$ respectively.

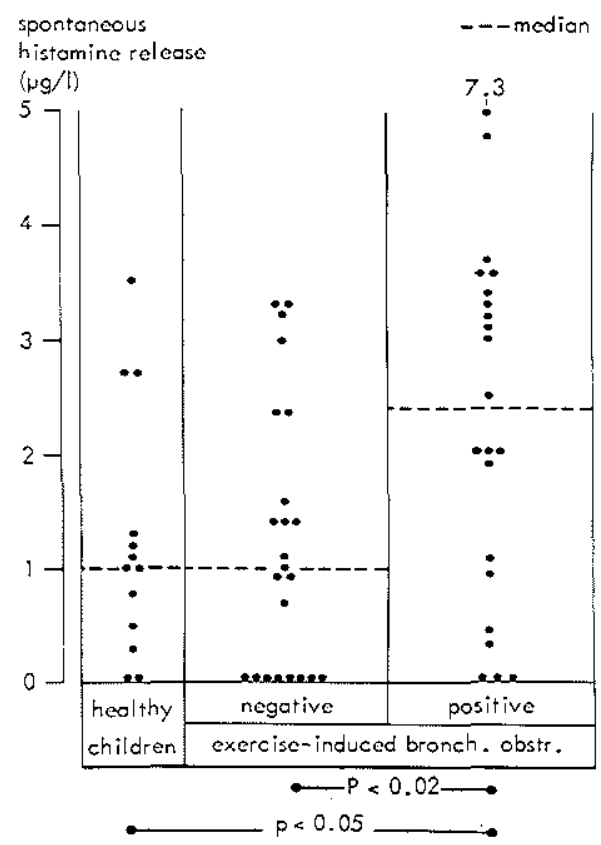

Figure 1. Spontaneous histamine release in asthmatic children. divided according to their sensitivity to exercise, and in healthy children. Fisher exact test. Separation of the groups at $1.5 \mu \mathrm{g} / 1$ level, but this was not critical.

-... Median. 


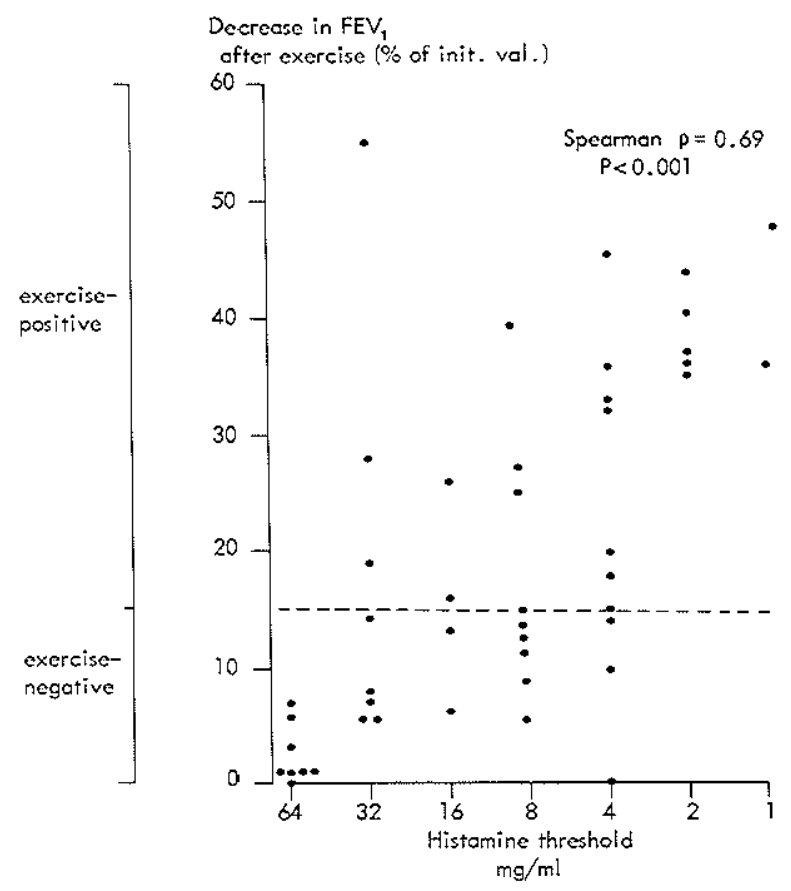

Figure 2. Relationship between histamine threshold and exercise-induced decrease in FEV 1 in asthmatic children. Spearman $p=0.69: P<0.001$.

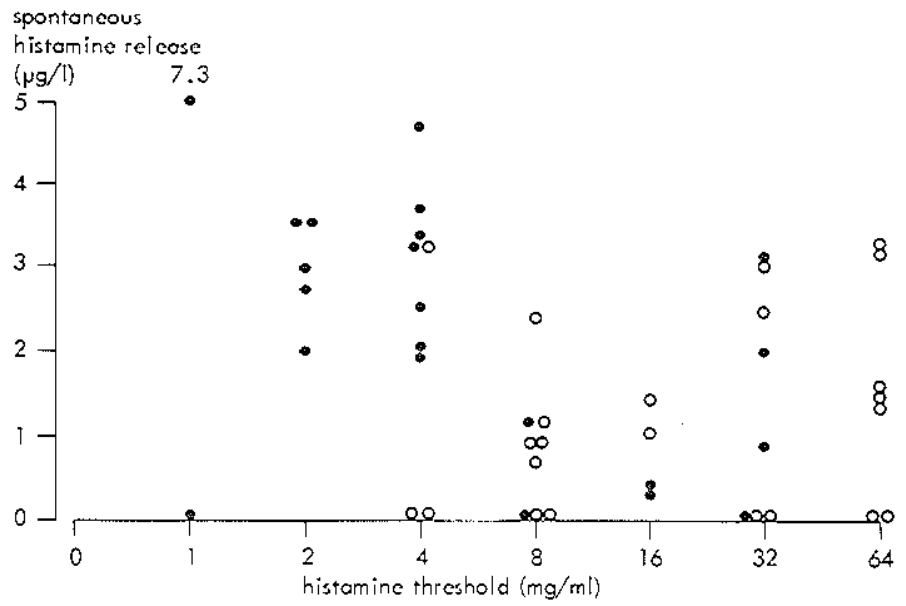

Figure 3. Relationship between the histamine threshold and spontaneous histamine release in relation to bronchoconstriction. Spearman $p$ between spontaneous histamine release and histamine threshold $=0.30 ; P<0.025$. $\bullet$. Exercise, positive; 0 . exercise, negative. 
Figure 3 shows that fourteen out of the seventeen patients with a histamine threshold of $\leqslant 4 \mathrm{mg} / \mathrm{ml}$ also have a spontaneous histamine release of $\geqslant 1.5 \mu \mathrm{g} / \mathrm{l}$; 13 of these have EIB. Eight of the twenty-eight patients with a histamine threshold of $\geqslant 8 \mathrm{mg} / \mathrm{ml}$ have a spontaneous histamine release of $\geqslant 1.5 \mu \mathrm{g} / 1$; two of these have EIB. Six of the twenty patients in whom the histamine threshold is $\geqslant 8 \mathrm{mg} / \mathrm{ml}$ and the spontaneous histamine release $\leqslant 1.5 \mu \mathrm{g} / 1$ have EIB.

From Fig. 3 it also appears that a correlation exists between the degree of spontaneous histamine release and the histamine threshold (Spearman $p=0.30$, $P<0.025)$, whereby the reaction to exercise was not taken into account.

\section{Discussion}

The results of this study indicate that leucocytes from asthmatic patients with EIB often have a greater spontaneous histamine release than leucocytes of both asthmatic patients without EIB and healthy children. This indicates that the leucocytes of a number of patients with EIB in the absence of a known trigger but under carefully standardized conditions, have a greater releasing capacity per unit time. This could not be explained by a difference in the number of basophils, nor by a difference in allergen-induced histamine release as judged by anti- $\operatorname{IgE}$ induced release in patients with and without EIB.

Further the state of the asthmatic disease was not relevant because all patients had been in a symptom-free period for at least 4 weeks and no relationship existed with the initial lung function values.

Findlay \& Lichtenstein (1978) showed that leucocytes of patients with intrinsic asthma released a greater amount of histamine after adding deuterium oxide compared to those of healthy subjects. This may indicate a difference in releasability. May (1976) found that leucocytes of patients with food allergy often had high spontaneous histamine release. Podleski and Grimes (1978) demonstrated hyperreactivity in lymphocytes of patients with obstructive airways disease.

Like others (Mellis et al., 1978; Eggleston, 1979) we found that the decrease in $\mathrm{FEV}_{1}$ after exercise is strongly correlated with the histamine threshold. The histamine threshold reflects the degree of bronchial hyperreactivity of non-allergic stimuli (de Vries et al., 1964). The degree of spontaneous histamine release correlates well with the degree of bronchial hyperreactivity as is shown in Fig. 3. This supports our hypothesis that in asthmatic patients hyperreactivity may not only be present in the bronchi but also in the mediator releasing system.

\section{Acknowledgments}

This work was supported by a grant from the Dutch Asthma Foundation (project number 238). The authors thank Miss I. Dekker for performing the basophil counts and Dr R. G. Pearse for help in correcting our English. 


\section{References}

BIERMAN, C. W., KAWABORI, J. \& PIERSON, W. C. (1975) Incidence of exercise-induced asthma in children. Pediatrics. 56. 847.

DAVIES. S. E. (1968) Effect of disodium cromoglycate on exercise-induced asthma. British Medical Journal, 3, 593.

EGGLESTON, P. A: (1979) The role of bronchial hyperreactivity in exercise-induced asthma. Journal of Allergy and Clinical Immunology, 63, 104.

FINDLAY, S. R. \& LICHTENSTEIN, L. M. (1978) Basophil releasability in patients with intrinsic asthma. Journal of Allergy and Clinical Immunology, 61, 157.

GODFREY, S. \& KÖNIG. P. (1976) Inhibition of exercise-induced asthma by different pharmacological pathways. Thorax. $31,137$.

KIVILOOG. J. (1973) Variability of bronchial reactivity to exercise and methacholine in bronchial asthma. Scandinavian Journal of Respiratory Diseases, 54, 359.

MAY. C. D., LYMAN, M.. ALBERTO, R. \& CHENG. J. (1970) Procedures for immunochemical study of histamine release from leucocytes with small volume of blood. Journal of Allergy and Clinical Immunology, 46, 12.

MAY. C. D. (1976) High spontaneous release of histamine in vitro from leucocytes of persons hypersensitive to food. Journal of Allergy and Clinical Immunology, 58, 432.

MELLIS. C. M.. KATTAN. M., KEENS. T. G. \& LEVISON. H. (1978) Comparative study of histamine and exercise challenges in asthmatic children. American Review of Respiratory Disease, $/ 17.911$.

MOORE. J. E. \& JAMES. G. W. (1953) Proceedings of the Society for Experimental Biology, New York. 82, 601 .

NEIJENS, H. J., DEGENHART, H. J., RAATGEEP, H. C. \& KERREBIJN, K. F. (1979) Study of the significance of bronchial hyperreactivity in the bronchus obstruction after inhalation of cat dander allergen. Journal of Allergy and Clinical Immunology. 67, 507.

PODLESKI, W. K. \& FRIMES. J. R. (1978) Circulating hyperreactive lymphocytes in bronchial asthma. Clinical Immunology and Immunopathology, 9, 236.

SIMON, R., STEVENSON, D. D. ARROYAVE. C. M. \& TAN, E. M. (1977) The relationship of plasma histamine to the activity of bronchial asthma. Journal of Allergy and Clinical Immunology, 60, 312 .

DE VRIES, K.. BOOY-NOORD, H., GOEI, H.. GROBLER, N. J., SLUITER. H. J.. TAMMELING, G. J. \& ORIE, N. G. M. (1964) Hyperreactivity of the bronchial tree to drugs, chemical and physical agents. In: Bronchitis. II (eds N. G. M. Orie and H. J. Sluiter), p. 167. Royal van Gorcum. Assen. 
7.4 Release of histamine from leucocytes and its determinants in vitro in relation to bronchial responsiveness to inhaled histamine and exercise in vivo.

H. J. Neijens, R. Raatgeep, H. J. Degenhart \& K. F. Kerrebijn

\section{Summary}

The hypothesis studied is that an increased responsiveness in asthma is not limited to the airways. 40 asthmatic children were analysed for their bronchial responsiveness (BR) to exercise. 20 patients revealed bronchial obstruction after exercise while the remainder did not. These parameters were compared to the responsiveness of leucocytes, which was determined by their histamine "releasability". 20 healthy children served as controls. Release of histamine induced by calciumionophore aided calcium influx was significantly higher in both groups of asthmatics than in the healthy children $(P<0.005)$. Similar findings were obtained by induction of microtubule aggregation due to deuterium oxide $\left(\mathrm{D}_{2} \mathrm{O}\right)$. The S-shaped doseresponse relationship with $\mathrm{D}_{2} \mathrm{O}$ was shifted to the left in the patients with $\mathrm{BR}$ to exercise compared to patients without $(\mathrm{P}<0.025)$. The slope was increased in both patient groups compared to the healthy children $(P<0.01)$. It is concluded that the mean "releasability" of histamine from leucocytes is higher if BR increases. The histamine release due to both stimulants correlated well $(P<0.01)$. This suggests that the "releasability" is determined by the responsiveness of the microtubules. To a large degree this may also apply to allergen-induced histamine release, as was revealed from studies with anti-IgE. The differences in histamine release found in relation to $B R$ due to exercise were also present if the patients were divided according to $\mathrm{BR}$ due to histamine. A significant relationship existed between the degree of $B R$ to histamine and the responsiveness of the microtubules $(P<0.02)$.

\section{Introduction}

Increased bronchial responsiveness (BR) also called bronchial hyperreactivity, can be observed in many asthmatic patients (Boushey et al. 1979). Increased BR is characterized by the occurrence of bronchial obstruction due to various stimuli with a dose which does not have such a result in persons with a normal responsiveness (Kiviloog, 1973; Neijens et al. 1979).

1. This study is supported by the Netherlands Asthma Foundation (grant nr. 79.31).

2. Presented at the meeting of the European Paediatric Respiratory Society, Berne. Switserland. September 25th. 1981.

3. Published as an abstract in Paediatric Research 1981, in press. Complete paper submitted for publication. 
Dysregulation of various systems, such as lysozymatic release from leucocytes (Busse et al. 1979) and pupillary reflexes (Smith et al. 1980) has been reported in relation to asthma. We have studied histamine release from basophilic leucocytes to investigate cell dysfunction in asthmatic children with increased BR. In a previous study we (Neijens et al. 1980) and others (Findlay and Lichtenstein, 1980) found a correlation between the mean histamine release from leucocytes and the degree of BR.

Our present study questions in which parts of the release process dysregulation occurs. Therefore the influx of calcium into the cells was stimulated with the calcium ionophore A 23187 (Siragarian et al. 1975). This may increase the release of histamine from basophilic leucocytes. The influence of zinc on the calciuminduced histamine release was studied (Kazimierczak \& Máslinski, 1974). Microtubules are thought to be important in the expulsion of mediator containing granules which are necessary for the release of mediators (Padawar, 1979). The effects of induction of microtubular aggregation due to deuterium oxide $\left(\mathrm{D}_{2} \mathrm{O}\right)$ (Gillespie \& Lichtenstein, 1972) was analysed.

\section{Methods}

\section{Design of the study}

The study was done on two consecutive days. On the first day a venepuncture was done and the provocation dose of inhaled histamine was determined. On the second day an exercise test was performed.

2. The asthmatic children were selected from the out-patient clinic of the Sophia Children's Hospital in Rotterdam, based on the following criteria:

1. The patients had to be in a stable clinical condition for at least 3 weeks prior to the study.

2. The ability to perform lung function tests in a reproducible way.

3. All drugs withdrawn at least two days before the study. None of the patients was treated with hyposensitization therapy.

The healthy children were without present or previous symptoms, chronic rhinitis, hayfever or eczema and revealed no bronchial obstruction after exercise.

\section{Measurement of histaminerelease}

A sample of $20 \mathrm{ml}$ venous blood was taken with the patient at rest at 8.30 a.m. From this sample $1 \mathrm{ml}$ suspensions of leucocytes were prepared and incubated with and without one of the following agents:

- $\mathrm{D}_{2} \mathrm{O}, 20,40,60,70$ and $80 \%$ in combination with cytochalasine $\mathrm{E}\left(2.10^{-5} \mathrm{M}\right)$, with appropriate $\mathrm{pH}$ correction.

- Calciumionophore A $23187,0.56 \times 10^{-6} \mathrm{M}\left(0,3 \mathrm{mg} . \mathrm{I}^{-1}\right)$ and $2,80 \times 10^{-6} \mathrm{M}$ (1.5 mg. $\left.\mathrm{l}^{-1}\right)$ with and without $\mathrm{Ca}^{2+}\left(10^{-3} \mathrm{M}\right)$ or $\mathrm{Zn}^{2+}\left(\mathrm{ZnSO}_{4} 1,5.10^{-5} \mathrm{M}\right)$. 
- Anti-IgE, $20 \mu \mathrm{l}$ of a $400.000 \mathrm{IU} / \mathrm{ml}$ solution (Behring Werke) in combination with $\mathrm{Ca}^{2+}\left(10^{-3} \mathrm{M}\right)$.

Release of histamine was measured after one hour's incubation, using the method of May et al. (1970). All measurements were done in triplicate and the values given are the average of the three. The numbers of leucocytes and basophils were counted in the samples, according to the method of Moore and James (1953).

4. The bronchial responsiveness to histamine and exercise was determined as described previously (Neijens et al. 1980).

The patients were divided according to their reaction after exercise: patients with a bronchial obstruction after exercise, i.e. a decrease in the forced expiratory volume in the first second of $>15 \%$ of baseline and those without this phenomenon. The groups were indicated as bronchial responsiveness to exercise positive $(B R E+)$ and negative (BRE -) respectively. The healthy children formed the third group.The patient groups comprised 20 children, the healthy group 22, and all groups were comparable with regard to age and sex. All the subjects and their parents were fully informed about the methods and the aims of the study before they gave their consent.

5. Statistical analysis

Most of the parameters appeared to have an abnormal distribution, therefore the statistical treatment of the data was performed with non-parametric tests.

The differences in results between the three groups were analyzed with a test for multiple comparisons (Conover, 1980). Correlations of the parameters were calculated according to Spearman. The regression lines were determined using the median values of the regression equations of each pair of subjects, according to the method of Nimmo and Atkins (1979). The slopes and intercepts of these lines were compared with the patient groups using Wilcoxon tests.

The $5 \%$ level was considered as the level of significance.

The steepness and the parallel shift of the individual regression lines is expressed as a single value by determination of the "median response", i.e. the histamine release which is the median value of all responses after each of the sequential $\mathrm{D}_{2} \mathrm{O}$ series in an individual. The medium $\mathrm{D}_{2} \mathrm{O}$ response is used in table 1, figure 2 and 3.

Results

The median values of the numbers of leucocytes and basophils as well as the histamine release are shown in table 1 . No significant relationship exists between the number of these cells and the degree of histamine release.

In Figure 1 the mean amount of histamine released by sequential $D_{2} O$ con- 
Table 1

\begin{tabular}{|c|c|c|c|c|}
\hline \multirow[t]{2}{*}{ Group } & & \multicolumn{2}{|c|}{ Number of cells } & \multirow{2}{*}{$\begin{array}{l}\text { Histamine release due to } \\
\mathrm{D}_{2} \mathrm{O} \text { (median response) }\end{array}$} \\
\hline & & Leucocytes* & Basophils & \\
\hline \multirow{2}{*}{ BRE } & $\begin{array}{c}+ \\
(n=20)\end{array}$ & $\begin{array}{c}10^{3} / \mu \mathrm{l} \\
24.9 \\
(8.9-56.3)\end{array}$ & $\begin{array}{c}/ \mu \mathrm{l} \\
26.0 \\
(10.0-74.0)\end{array}$ & $\begin{array}{c}\mu \mathrm{g} . \mathrm{L}^{-1} \\
6.4 \\
(1.7-23.0)\end{array}$ \\
\hline & $(\mathrm{n}=20)$ & $\begin{array}{c}26.2 \\
(5.2-44.5)\end{array}$ & $\begin{array}{c}28.5 \\
(3.0-77.0)\end{array}$ & $\begin{array}{c}4.5 \\
(0.8-15.3)\end{array}$ \\
\hline \multicolumn{2}{|c|}{$\begin{array}{l}\text { healthy children } \\
n=20\end{array}$} & $\begin{array}{c}21.4 \\
(8.9-42.5)\end{array}$ & $\begin{array}{c}27.5 \\
(6.0-70.0)\end{array}$ & $\begin{array}{c}2.8 \\
(1.4-5.3)\end{array}$ \\
\hline
\end{tabular}

* in the leucocyte suspension.

$\mathrm{BRE}=$ bronchial responsiveness to exercise, + and - , see methods.

Histamine release is the median response after all doses of $\mathrm{D}_{2} \mathrm{O}$ for each patient.

All results are expressed as median value with the extreme values between brackets.

No significant relationship exists between the number of cells and the amount of histamine release.

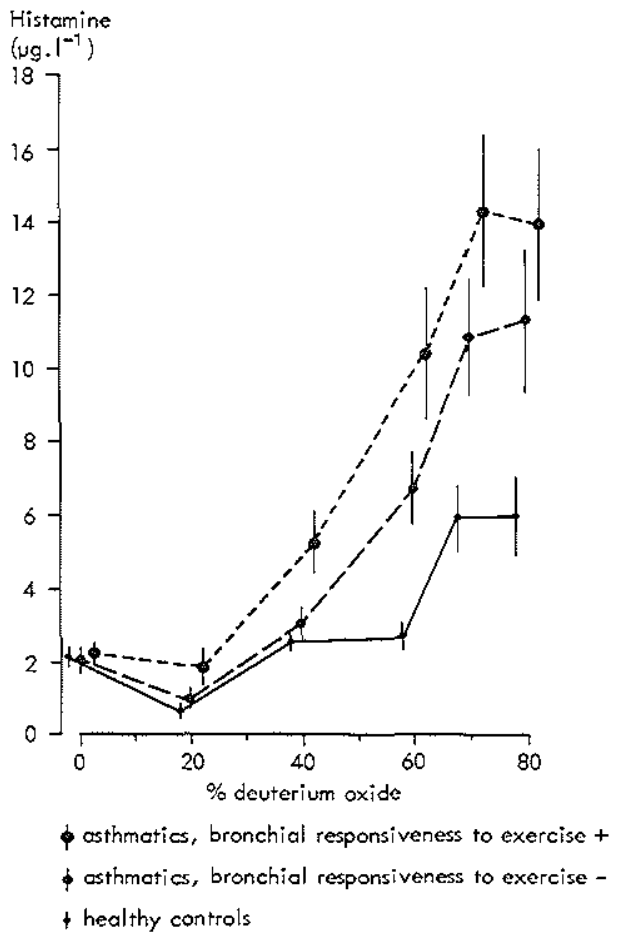

\begin{tabular}{|c|c|c|}
\hline \multicolumn{2}{|l|}{ Variable } & P. Valuc \\
\hline & & Group \\
\hline \multirow{2}{*}{\multicolumn{2}{|c|}{$\begin{array}{l}\text { Release due to } 60,70 \\
\text { and } \$ 0 \%, \mathrm{D}, \mathrm{O}\end{array}$}} & $B R E+B R E-$ hcalthy \\
\hline & & $P<0.0025$ \\
\hline \multirow{2}{*}{$\begin{array}{l}\text { Dose } \\
\text { response } \\
\text { curves }\end{array}$} & slope & $\mathrm{P}<\overleftrightarrow{\longrightarrow 0.01}$ \\
\hline & intercept & $\stackrel{\longrightarrow}{\mathrm{P}<0.025}$ \\
\hline
\end{tabular}

Figure I. Histamine release from leucocytes in vitro as a function of the percentage deuterium oxide. The results are expressed in mean \pm SEM for each of the three groups of subjects. 
centrations is illustrated for each group of subjects. The mean release with 60,70 and $80 \% \mathrm{D}_{2} \mathrm{O}$ is significantly higher in the patient groups than in the healthy individual group $(P<0.0025)$. The dose-response relationship is evaluated by the regression line of the responses at 40 and $60 \%$. The slope in groups BRE positive and BRE negative is significantly steeper than in the healthy individual group $(\mathrm{P}<$ 0.01 ). Between BRE positive and BRE negative patients the slopes do not differ, but the intercepts of their regression lines with the $y$-axis differ significantly $(P<0.025)$. It is therefore concluded that the mean dose response curve in asthmatic children with an increased BRE was shifted to the left compared to the asthmatic children without BRE. The regression lines of the asthmatic children are rotated anticlockwise compared to that of the healthy subjects. Changes can be taken into account by the median response (see methods, statistical analysis).

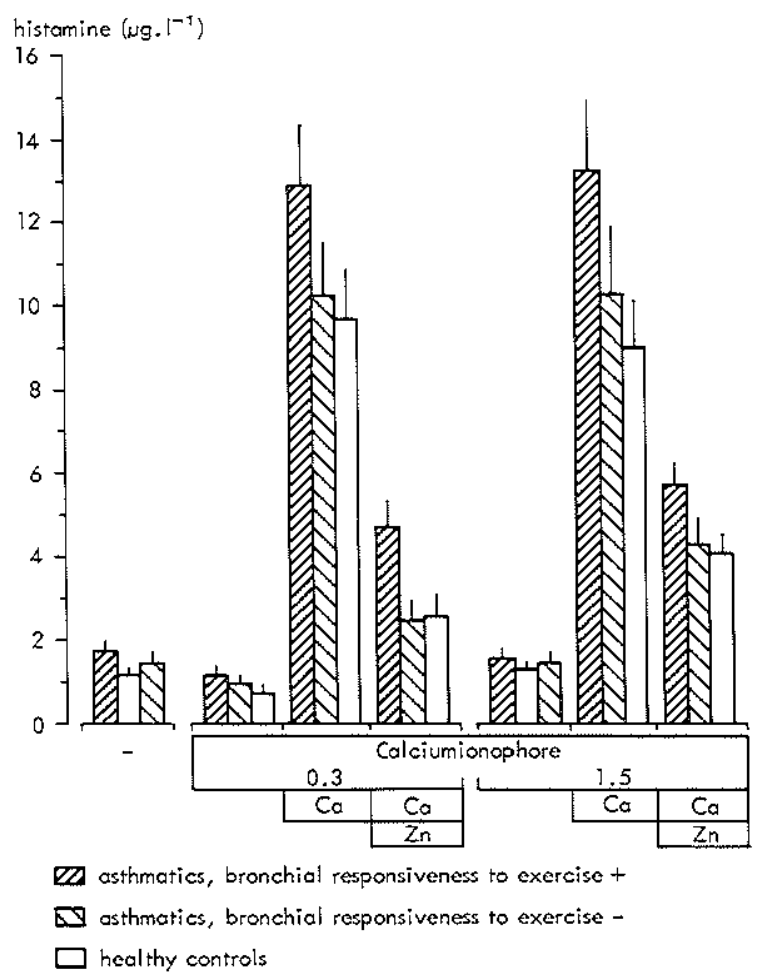

Figure 2. Mean histamine release $( \pm S E M)$ from leucocytes in vitro with and without various agents in three groups of subjects.

Results after the calcium ionophore with calcium are significantly higher in BRE+ subjects than in BRE- subjects $(P<0.005)$ and healthy children $(p<0.005)$. These differences in the presence of zinc are also significant $(P<0.0 \mathrm{I})$. 
The mean release of histamine with the calcium ionophore A 23187 alone or combined with calcium or zinc is shown in Figure 2. In all groups the release of histamine increases markedly after the addition of calcium to the calcium ionophore. There is no significant difference in release with 0.3 and $0.5 \mathrm{mg} 1^{-1}$ calcium ionophore. The mean release by the calcium ionophore plus calcium is greater in the patients with BRE than without $B R E(P<0.005)$ and than in the healthy children $(P<0.005)$. The difference between the release in the patients without $B R E$ and the healthy controls does not reach significance. If zinc is added to the combination of calcium ionophore and calcium the histamine release decreases. However, the differences between the groups persist $(\mathrm{P}<0.01)$.

Figure 3 shows the anti-IgE induced release of histamine for the three groups. It is highest in the patients with BRE, intermediate in those without BRE and lowest in the healthy children. The differences between all groups are significant at the $5 \%$ level.

For each group the histamine release after the calciumionophore plus calcium and the release after $\mathrm{D}_{2} \mathrm{O}$ are compared in a xy-graph (figure 4 a.b.c.). The cor-

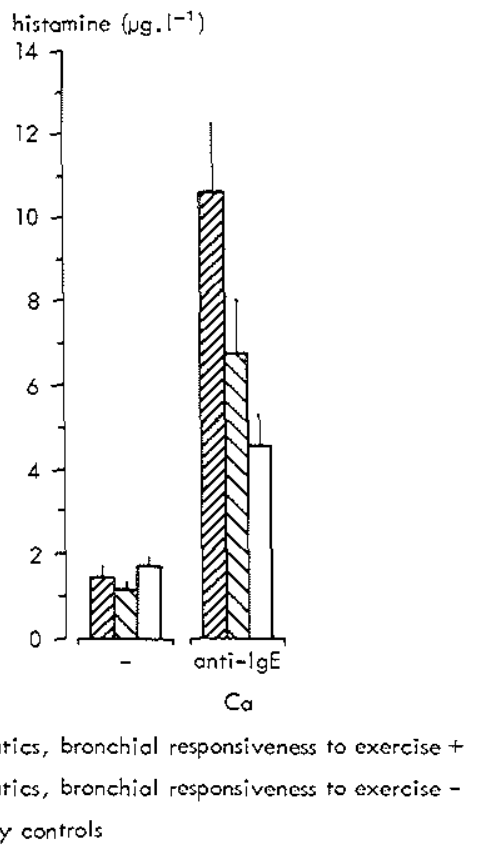

Figure 3. Mean histamine release ( \pm SEM) from leucocytes in vitro with and without anti-IgE plus calcium in three groups of subjects.

The results are significantly different between all groups $(P<0.05)$. 


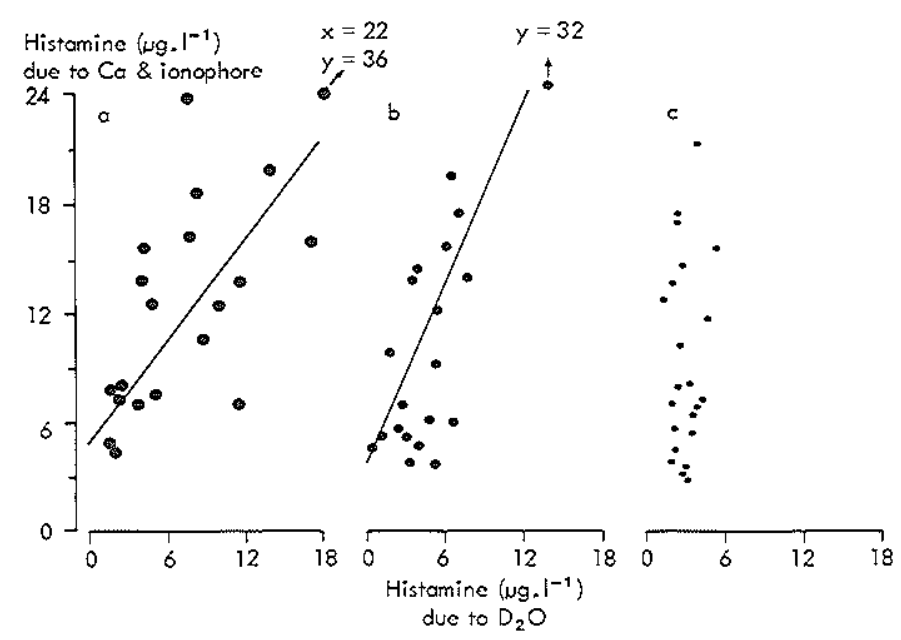

Figure 4. Comparison of the histamine release due to calcium ionophore plus calcium (calcium influx) and that due to $D_{2} O$ (median response) in three groups of subjects graph $\left\{\begin{array}{l}a=\text { asthmatics. BRE+ } \\ b=\text { asthmatics. BRE- } \\ c=\text { healthy subjects }\end{array}\right.$

The relationships are significant in groups of BRE+ and BRE- subjects $(P<0.01)$. In the healthy children a correlation cannot be expressed because of mathematical reasons. The slope of the median regression line is significantly steeper in the BRE- patients than in the BRE+ patients $(\mathrm{P}<0.02)$.

relation is significant $(P<0.01)$ in both groups of patients, but not in the healthy children. The slopes of the regression line in the patient groups differ significantly $(P<0.02)$, decreasing with a higher bronchial responsiveness.

Figure 5 shows the correlation between the histamine release after $\mathrm{D}_{2} \mathrm{O}$ and anti-IgE in the same way as in Figure 4. The correlation is again significant in the patient groups $(\mathrm{P}<0.01)$, but not in the healthy children. The difference between the slopes in the patient groups with and without BRE is significant $(\mathrm{P}<0.01)$, decreasing with a higher bronchial responsiveness.

The patients are also divided into 2 classes according to their histamine provocation doses, as a measure of $B R$ to inhaled histamine. This in vivo parameter of $B R$ is related to the release of histamine in vitro. The relationships approximate to those found in the case of $B R$ to exercise. They are therefore not given in this paper. In Figure 6 the histamine provocation doses and the $\mathrm{D}_{2} \mathrm{O}$ induced histamine release are compared as continuous variables. They are significantly related $(P<0.02)$. 


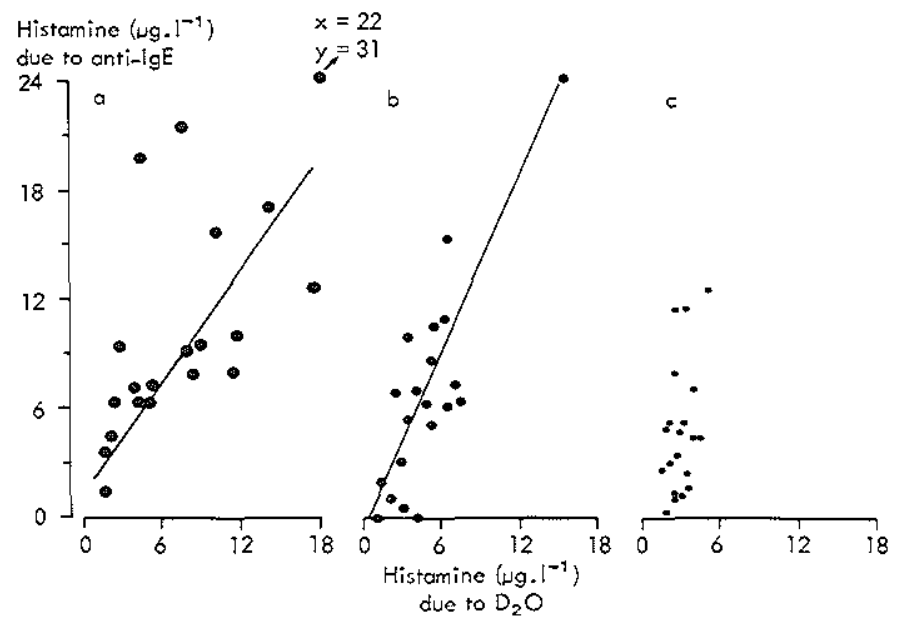

Figure 5. Comparison of the histamine release due to anti-IgE and that due to $\mathrm{D}_{2} \mathrm{O}$ (median response) in three groups of persons:

graph $\left\{\begin{array}{l}a=\text { asthmatics BRE+ } \\ b=\text { asthmatics BRE- } \\ c=\text { healthy children }\end{array}\right.$

The relationships are significant in the patient groups $(P<0.01)$. but not in the healthy children (see legend of Figure 2).

The slope of the median regression line is significantly steeper in the BRE- than in the $B R E+$ patients $(P<0.01)$.

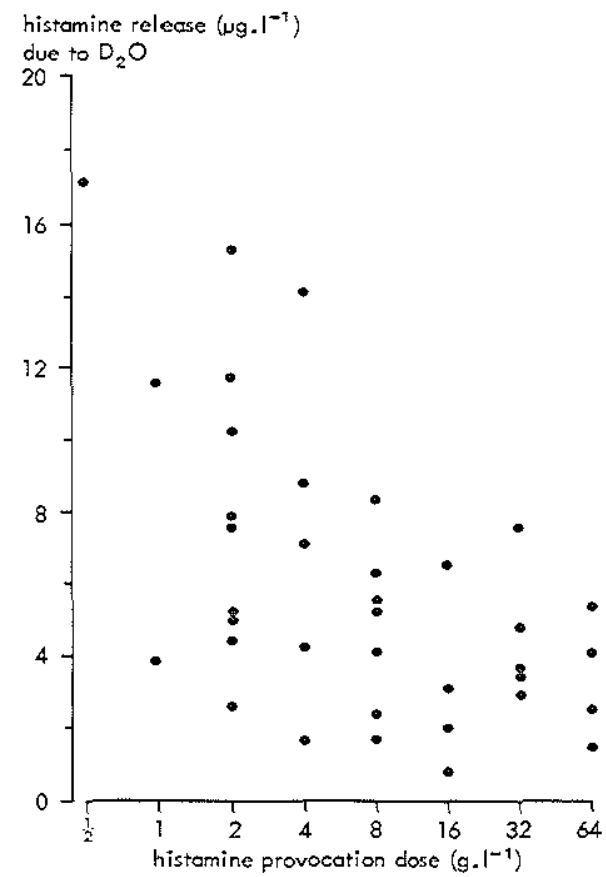

Figure 6. Relationship for each patient between the bronchial responsiveness to histamine (histamine provocation dose) and the histamine release in vitro due to $\mathrm{D}_{2} \mathrm{O}$ (median responses). The relationship is significant (Spearman, rho -0.40, $\mathrm{P}<0.02$ ). 


\section{Discussion}

In a suspension of leucocytes the release of histamine without activation of the IgE-receptor can be induced by influx of calcium (by means of a calciumionophore) and also by activation of the microtubular aggregation (by $\mathrm{D}_{2} \mathrm{O}$ ). This is in agreement with results in other studies (Gillespie et al. 1968; Findlay \& Lichtenstein, 1980). The histamine release is greater in asthmatics with than without BRE, and the release in asthmatics exceeds that in healthy subjects. This indicates that an increase in BR is associated with an increase in the releasability of basophilic leucocytes.

Relatively low concentrations of zinc which are in the range of those found in normal plasma, inhibit the calcium-induced histamine release. Probably it has its effect in the first part of the mediator releasing process, for instance on the influx of calcium, since the mediator release after the activation of the microtubules is not inhibited by zinc (preliminary observations). It may well be that a change in the plasma zinc concentration will influence the mediator release in vivo, but there is as yet no data confirming this suspicion.

The influx of calcium leads to the release of mediators via a series of events (Lichtenstein, 1975). The histamine release after stimulation of an initial step in the sequence (calcium influx) correlates highly with that due to the activation of a step later on in the sequence (induction of microtubular aggregation). It seems that the responsiveness of the total intracellular sequence is determined by the degree to which the microtubules can be activated.

The histamine release after anti-IgE is related to the $\mathrm{D}_{2} \mathrm{O}$ induced release in a similar way. This indicates that at least in part the allergen-induced mediator release is also determined by the degree to which the microtubules can be stimulated.

It is widely accepted that the activity of the microtubules is mainly regulated by the intracellular cyclic AMP concentration (Mongar et al. 1979). However, this may well have other effects on intra-cellular processes which lead to mediator release (Smolen et al. 1980). Although therefore the "releasability" seems to be determined to a large extent by the state of the aggregation of the microtubules, this may not be only factor involved.

Besides the dysregulation of the mechanisms which determine the bronchial diameter and the increased responsiveness of basophilic leucocytes, dysregulation of other systems is also described in asthma. Hyperresponsiveness of the pupillary reflexes was found in asthmatic patients in relation to a cholinergic agent (Smith et al. 1980) and to an $\alpha$-sympathetic agonist (Henderson et al. 1979). The latter study also showed a hyperresponsiveness of the cutaneous blood flow to an $\alpha$-sympathetic agonist in asthmatics. In leucocytes hypofunction of receptors which 
counteract mediator release, such as the $\beta$-sympathetic (Lemanske et al. 1980) and the histamine and prostaglandin $E_{1}$ receptors (Busse et al. 1980) was found in asthmatics. The bronchial smooth muscle had a greater contractibility in asthmatics than in normal subjects (Stephens et al. 1980). The cyclic AMP concentration in bronchial smooth muscle was found to be depressed in relation to the presence of asthma in dogs (Rinard et al. 1979). Thus in asthma a generalised dysregulation seems to be present, which is apparent both inside and outside the respiratory system.

This study leads to the conclusion that the dysregulation which exists in basophilic leucocytes in association with a dysregulation of bronchial responsiveness, may be determined by an identical factor, such as the level of the cyclic nucleotides. Studies to investigate this in more detail are in progress.

\section{Acknowledgement}

This work was supported by a grant from the Netherlands Asthma Foundation (project number 79.31). The authors wish to thank Prof. R. van Strik for statistical advice, Miss I. Dekker for performing the basophil counts, Dr. J. Mason for help in correcting our English and Miss A. de Reus for typing the manuscript.

\section{References}

BOUSHEY, H. A., HOLTZMAN, M. J., SHELlER, J. R. \& NADEL, J. A. (1980) Bronchial hyperreactivity (state of art). American Review of Respiratory Disease, 12 I: 389.

BUSSE, W. W.. ANDERSON. C. L.. DICK, E. C. D. \& WARSCHAUER, D. (1980) Reduced granulocyte response to isoproterenol, histamine. and prostaglandin $E_{1}$, after in vitro incubation with rhinovirus 16. American Review of Respiratory Disease, 122: 641.

CONOVER, W. J. Practical nonparametric statistics, 2 ed. Wiley \& Sons. New York, 1980, p. 171-178.

FINDLAY, S. R. \& LXCHTENSTEIN, L. M. (1980) Basophil releasability in patients with asthma. American Review of Respiratory Disease, 122: 53.

GILLESPIE, E. \& LICHTENSTEIN. L. M. (1972) Histamine release from human leucocytes. Studies with deuterium oxide, colchicine and cytochalasin B. Journal of Clinical Investigation, 5I: 2941.

HENDERSON, W. R.. SHELHAMER, J. H., REINGOLD, D. G.. SMITH, L. J., EVANS. R. \& KALINER. M. (1979) Alpha-adrenergic hyperresponsiveness in asthma. Analysis of vascular and pupillary responses. New England Journal of Medicine. 300:642.

KAZIMIERCZAK. W. \& MAŚLINŚKI, C. (1974) The effect of zinc ions on selective and nonselective histamine release in vitro. Agents and Actions, $4: 1$.

KIVILOOG. J. (1973) Variability of bronchial reactivity to exercise and methacholine in bronchial asthma. Scandinavian Journal of Respiratory Disease, 54: 359. 
LEMANSKE. jr. R. F., ANDERSON. C.. BRAUN, S., SKATRUD, J. \& BUSSE. W. W. (1980) Impaired in vitro $\beta$-adrenergic granulocyte response in chronic obstructive pulmonary disease. American Review of Respiratory Disease, 122: 213.

MAY, C. D., LYMAN. M.. ALberTO, R. \& CHENG. J. (1970) Procedures for immunochemical study of histamine release from leucocytes with small volume of blood. Journal of Allergy and Clinical Immunology, 58:432.

LICHTENSTEIN. L. M. (1975) Sequential analysis of the allergic response: cyclic AMP. calcium and histamine. International Archives Allergy Applied Immunology, 49:143.

MONGAR, J. L. \& FOREMAN, J. C. (1979) Control of histamine secretion. In: The mast cell. its role in health and disease (eds. J. Pepys and A. M. Edwards) p. 30. Pitman Medical, London.

MOORE. J. E. \& JAMES. G. W. (1953) Proceedings of the Society for Experimental Biology. New York. 82: 601.

NEIJENS, H. J.. DEGENHART, H. J.. RAATGEEP. H. C. \& KERREBIJN, K. F. (1979) Study of the signiffcance of bronchial hyperreactivity in the bronchus obstruction after inhalation of cat dander allergen. Journal of Allergy and Clinical Immunology, 67:507.

NEIJENS. H. J., DEGENHART, H. J., RAATGEEP, H. C. \& KERREBIJN. K. F. (1980) The correlation between increased reactivity of the bronchi and of mediator releasing cells in asthma. Clinical Allergy, 10:535.

NIMMO. I. A.. ATKINS. G. L. (1979) The statistical analysis of non-normal (real?) data. Trends in biochemical sciences, $4: 236$.

PADAWAR. J. (1979) Mast cell structure implications for normal physiology and degranulation. In: The mast cell, its role in health and disease (eds. J. Pepys \& A. M. Edwards), p. 1. Pitman Medical. London.

RINARD. G. A., RUBINFELD, A. R., BRUNTON, L. L. \& MAYER, S. E. (1979) Depressed cyclic AMP levels in airway smooth muscle from asthmatic dogs. Proceedings National Academy of Science USA. 76: 1472 .

SIRAGANIAN, R. P., KULCZYCKI, J., MENDOZA, G. \& METZGER. H. (1975) lonophore A 23187 induced histamine release from rat mast cells and rat basophil leukemia (RBL-I) cells. Journal of Immunology, 115: 1599.

SMITH, L. J., SHELHAMER, J. H. \& KALINER. M. (1980) Cholinergic nervous system and immediate hypersensitivity. II An analysis of pupillary responses. Journal of Allergy Clinical Immunology, 66: 374 .

SMOLEN. J. E., KORZAK, H. M. \& WEISSMAN, G. (1980) Increased levels of cyclic adenosine- $3^{\prime} 5^{\prime}$ monophosphate in human polymorphonuclear leucocytes after surface stimulation. Journal of clinical Investigation. 65: 1077.

STEPHENS, N. L., MITCHELl. R. W., ANTONISSEN, L. A., KROMER. U., HANKS, B., KROEGER. E. A. \& KEPRON, W. (1980) Airway smooth muscle: physical properties and metabolism. In: Airway reactivity (ed. F. E. Hargreave), p. I10. Mc Master University, Hamilton.

\section{Appendix to paragraphs 7.3 and 7.4}

The releasability is not related to atopy. We found that the variability in histamine release between persons was independent of the total IgE concentration as well as to the allergen specific IgE concentration to house dust, cat dander and grasspollen allergen. 



\section{CHAPTER 8. STUDIES OF THE RELATIONSHIP BETWEEN BRONCHIAL RESPONSIVENESS AND THE BRONCHIAL REACTION TO STIMULANTS WHICH PROVOKE SYMPTOMS IN DAILY LIFE}

8.1 Relationship between the bronchial responsiveness to inhaled histamine and the degree of bronchial obstruction after exercise

Exercise is a commonly observed cause of bronchial obstruction in part of the asthmatic children. The relationship between bronchial obstruction after exercise and inhaled histamine was analysed in the studies 7.1 and 7.3.

From study 7.1, figure 5 and from study 7.3, figure 2 are shown: here called figure 1 and 2 respectively.

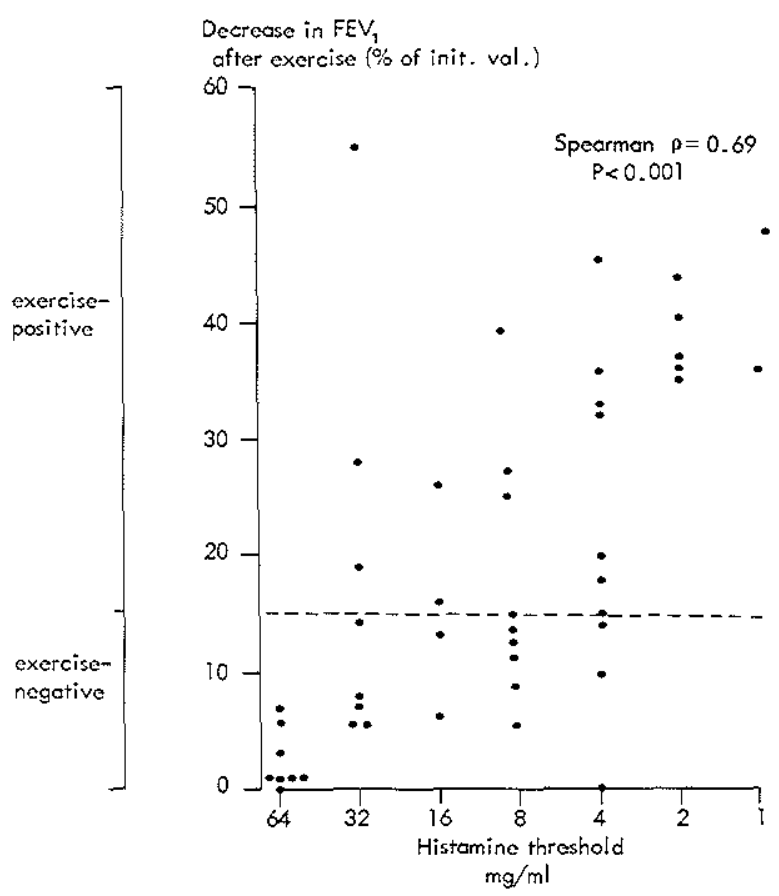

Figure 1. 


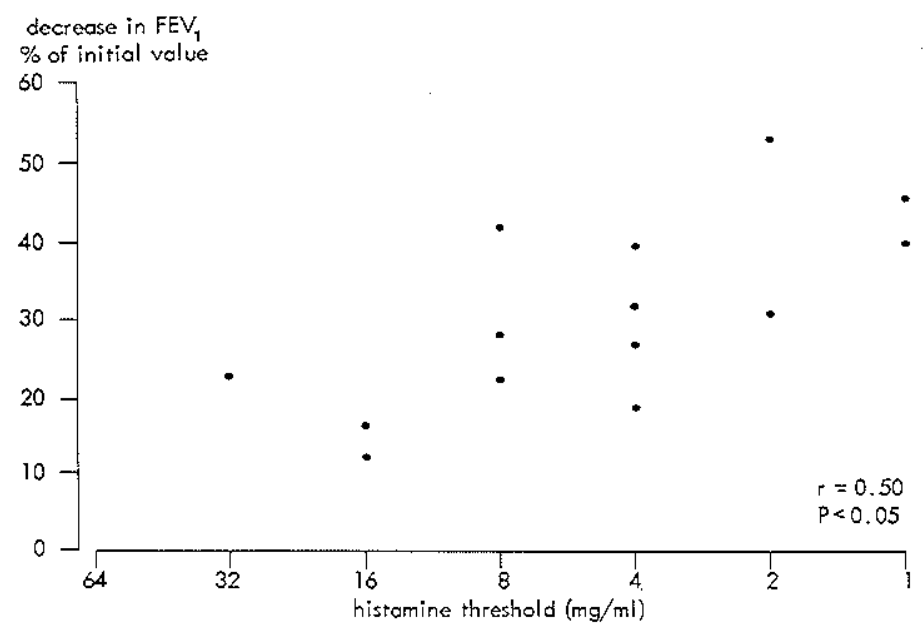

Figure 2.

In both studies a positive relationship was found to exist between the degree of bronchial obstruction after a standardized dose of exercise and the bronchial response after inhaled histamine. This indicates a parallelism in the response of the airways after both stimuli. The higher the BR to histamine, the higher the risk of the occurrence of dyspnoea after exercise and the more severe the reaction. 
8.2 Study on the significance of bronchial hyperreactivity in the bronchus obstruction after inhalation of cat dander allergen

H. J. Neijens, M.D., H. J. Degenhart, Ph.D., H. C. Raatgeep, and K. F. Kerrebijn, M.D. Rotterdam, The Netherlands

from the Department of Paediatrics, Subdepartment of Respiratory Diseases, Erasmus University, Medical School, Sophia Children Hospital.

\begin{abstract}
The role of bronchial hyperreactivity in the process that leads to bronchial obstruction after inhalation of an allergen was investigated. In 30 asthmatic children selected because of a positive skin test to cat dander allergen, we measured the histamine threshold, the reaction after allergen inhalation, the allergen-specific IgE concentration in serum, the lowest allergen concentration to which the intracutaneous skin test was positive (skin titer), and the histamine release of leukocytes after challenge with allergen. These variables were correlated with each other. The highest correlation was found between the inhalation reaction and the combination of the histamine threshold and either the allergen-specific IgE or the skin titer. Inhalation was only positive with a decreased histamine threshold $(<8 \mathrm{mg} / \mathrm{ml})$. With a low histamine threshold, a positive reaction to inhalation is likely to occur at an allergen-specific $\mathrm{IgE}$ concentration of $\geqslant 2 \mathrm{U} / \mathrm{ml}$ or at a skin titer of $\leqslant 2.5 \times$ $10^{-1} \mu \mathrm{g} / \mathrm{ml}$.
\end{abstract}

Introduction

It is a common finding that in many asthmatic patients with known allergies bronchial obstruction does not always occur after contact with the allergen. This points to the fact that, besides allergen-specific antibodies, other factors are important for such a reaction to appear. Our hypothesis was that one of these factors might be a bronchial hyperreactivity, defined as a decreased threshold of the bronchial tree to inhaled bronchoconstrictor agents such as histamine, acetyl-

1. This study is supported by the Netherlands Asthma Foundation (grant nr. 238).

2. Presented at the meetings of the European Society for Clinical Investigation, Rotterdam. The Netherlands, April 21st. 1978, the Dutch Paediatric Association. Tilburg, The Netherlands. May 27th. 1978, and the European Paediatric Respiratory Society, Badgastein, Austria. May 31 ste, 1978.

3. Published in the Journal of Allergy and Clinical Immunology, 1979, 64:507-515. Reprint with permission of the publisher. 
choline, chemical irritants, and smoke. In this study we investigated the role of the bronchial threshold to histamine in the process that leads to bronchial obstruction after inhalation of an allergen. Therefore, the correlations between the reaction to inhalation of cat dander allergen, the bronchial threshold to histamine, the allergenspecific IgE concentration in serum, the intradermal skin test, and histamine release from leukocytes with and without allergen were investigated. The results show that bronchial obstruction after allergen inhalation is highly dependent on the presence of an increased bronchial sensitivity and allergen-specific IgE.

\section{Methods}

Thirty asthmatic children were studied. They were selected because of a positive skin test against cat dander, indicating the presence of cell-bound antibodies, as well as the presence of circulating cat dander-specific $\operatorname{IgE}$ antibodies as measured by means of a radioallergosorbent test (RAST). Twenty also had a positive history of bronchial obstruction after contact with cats. In some of the children, however, these symptoms appeared only from time to time. Informed consent was obtained from all parents after full information about the investigations was given. The mean age was $10.4 \mathrm{yr}$ with a range of 7 to $15 \mathrm{yr}$. There were 15 boys and 15 girls. The study was done during a period in which they had experienced few or no respiratory symptoms during the previous $4 \mathrm{wk}$. During the study the children were admitted to the hospital. Two days before and during the study no medication was given. Procedures were performed between 9 and 12 a.m. in order to avoid the influence of circadian rhythm. The same batch of cat dander allergen was used in all investigations.

Allergen

Cat dander allergen was obtained from Dr. R. Voorhorst in Leiden and from Diephuis Inc. in Groningen. Both products were mixed by us, lyophilized, and kept at $-25^{\circ} \mathrm{C}$. Freshly prepared mixture in physiologic saline was used.

Skin test

An intracutaneous skin test was done with four different concentrations $\left(2.5 \times 10^{-2}, 2.5 \times 10^{-1}\right.$, and $\left.2.5 \times 10^{1} \mu \mathrm{g} / \mathrm{ml}\right)$. In each skin test a control was performed using the solvent. The volar aspect of the forearm was used, and injections were at least $3 \mathrm{~cm}$ apart to avoid induction. ${ }^{1}$ The reaction was considered positive if the diameter of the wheal was $\geqslant 5 \mathrm{~mm}$ after $20 \mathrm{~min}$. The lowest concentration of allergen to which a positive reaction occurs is called the skin titer. 


\section{Allergen-specific IgE antibodies}

The concentration of allergen-specific IgE was measured by the RAST using $\mathrm{CNBr}$-activated Sepharose $4 \mathrm{~B}$ as solid phase. To $1 \mathrm{ml}$ packed activated Sepharose, $5 \mathrm{mg}$ allergen was added. Fifty microliters serum or serum dilution was incubated with $0.5 \mathrm{ml}$ of a $1 \%$ suspension. After overnight incubation, the Sepharose beads were washed, and ${ }^{125}$ I-labeled anti-IgE antibodies, isolated as described $^{3}$, were added. After another overnight incubation, Sepharose-bound radioactivity was determined. The counts found were converted to international units (IU) IgE by comparison with a dose-response curve obtained by incubation of dilutions of an $\operatorname{IgE}$ standard serum with Sepharose-coupled anti-IgE antiserum.

The best correlation with the inhalation reaction could be obtained if the allergen-specific IgE concentration was expressed as the natural logarithm.*

\section{Inhalation test}

Inhalations were done with concentrations of $2.5 \times 10^{1}$ and $2.5 \times 10^{2} \mu \mathrm{g} / \mathrm{ml}$ of the allergen solution. These concentrations were established from the results of a preliminary test which are not shown here.

The nebulizer used is the Doppelinhaler (BlümeI, Wiesbaden) with an airflow of $6 \mathrm{~L} / \mathrm{min}$. The characteristics of this inhaler have been described elsewhere. ${ }^{4}$ The allergen was inhaled for a maximum of $10 \mathrm{~min}$ (first for $1 \mathrm{~min}$; for a further $4 \mathrm{~min}$ if there was no reaction within $15 \mathrm{~min}$; and for another $5 \mathrm{~min}$ if $15 \mathrm{~min}$ thereafter still no reaction occurred). The forced expiratory volume in $1 \mathrm{sec}\left(\mathrm{FEV}_{1}\right)$ was measured prior to, immediately after, and at 1,8 , and $24 \mathrm{hr}$ after the inhalation. The inhalation test was considered positive when the $\mathrm{FEV}_{1}$ diminished to less than $85 \%$ of the initial value.

The best of five successive measurements was taken. A distinction was made between an immediate reaction taking place within $1 \mathrm{hr}$ after inhalation and a delayed reaction between 4 and $24 \mathrm{hr}$ afterwards. During the inhalations the subjects breathed slowly and somewhat more deeply than normal.

After an immediate reaction, an isoprenaline aerosol was inhaled to prevent the development of an asthma attack. Patients with an isolated delayed reaction on the lower dose were retested with the higher dose, which in all of them resulted in an immediate reaction.

\section{Histamine release from leukocytes}

The quantity of histamine released from $1 \mathrm{ml}$ of a leukocyte suspension was

* In all calculations and illustrations. except in Table II and Figure I, allergen specific IgE stands for the natural logarithm of the allergen - specific $\mathrm{IgE}$ concentration. 
measured after incubation for $1 \mathrm{hr}$ with the allergen solution following the modified method of May et al.s The applied allergen concentrations were $2.5 \times 10^{-3}$, $2.5 \times 10^{-2}, 2.5 \times 10^{-1}$, and $2.5 \mu \mathrm{g} / \mathrm{ml}$. The concentrations were chosen after the histamine release in five patients was measured with allergen concentrations in a geometric series composed of 10 steps, ranging from $2.5 \times 10^{-7}$ to $2.5 \times 10^{2} \mu \mathrm{g} / \mathrm{ml}$. Every result is the average of three duplicate measurements.

The maximum release was determined by heating $1 \mathrm{ml}$ of the same leukocyte suspension for $30 \mathrm{~min}$ at $100^{\circ} \mathrm{C}$. The histamine release is expressed as percentage of the maximum release.

\section{Bronchial hyperreactivity}

This was measured by means of the inhalation of histamine biphosphate in increasing concentrations (doses of $1,2,4,8,16,32$, and $64 \mathrm{mg} / \mathrm{ml}$ ). ${ }^{6}$ Histamine was nebulized with the Doppelinhaler (flow of $6 \mathrm{~L} / \mathrm{min}$ ). At the beginning of the inhalation patients performed a submaximal vital capacity (VC) manoeuvre, after which they breathed at tidal volume for $30 \mathrm{sec}$. The histamine threshold was measured on the day prior to the inhalation test. The lowest concentration after which a positive reaction appeared was considered the threshold; for a positive reaction the same criteria were used as in the inhalation test. The strength of the reaction was not taken into account. ${ }^{7}$ The effect was measured immediately after stopping the administration of histamine. The time between inhalations was about $5 \mathrm{~min}$. In adults the reproducibility of the threshold is good when it is repeated at the same hour on successive days. ${ }^{6}$ This also applies to children.* With this technique the bronchial threshold to histamine in healthy children is $32 \mathrm{mg} / \mathrm{ml}$.

In children this value is not age dependent. Because logarithmic transformation did not improve the correlation coefficient with other variables, the histamine threshold is handled as milligrams per milliliter to facilitate the legibility of the results.

\section{Statistical methods}

In the correlation calculations all variables were processed as if they were continuous. This method, although not quite correct, offers from a mathematical point of view important advantages over the method which considers variables as discontinuous. The results obtained by these two methods do not differ to any important extent. ${ }^{8}$

Single and multiple correlation analyses and regression formulas were calculated for the different variables (see Table VI). The inhalation reactions have been expressed both as a differential score (made up of the concentration of the

* Unpublished observations from this laboratory. 
Table I. Results of the tests

\begin{tabular}{|c|c|c|c|c|c|c|c|c|c|c|c|c|c|}
\hline \multirow[b]{3}{*}{ Patient* } & \multicolumn{4}{|c|}{ Inhalation reaction } & \multirow{3}{*}{$\begin{array}{l}\text { Hista- } \\
\text { mine } \\
\text { thres- } \\
\text { hold } \\
(\mathrm{mg} / \mathrm{ml})\end{array}$} & \multirow{2}{*}{\multicolumn{2}{|c|}{$\begin{array}{l}\text { Allergen- } \\
\text { specific IgE }\end{array}$}} & \multirow[b]{3}{*}{$\begin{array}{c}\text { Skin } \\
\text { titer } \\
(\mu \mathrm{g} / \mathrm{ml})\end{array}$} & \multicolumn{5}{|c|}{ Histamine release ( $\%$ maximum) } \\
\hline & \multicolumn{2}{|c|}{$\begin{array}{c}2.5 \times 10^{1} \\
\mu \mathrm{g} / \mathrm{ml}\end{array}$} & \multicolumn{2}{|c|}{$\begin{array}{c}\mathrm{s} .5 \times 10^{2} \\
\mu \mathrm{g} / \mathrm{ml}\end{array}$} & & & & & \multicolumn{4}{|c|}{ With allergen $(\mu \mathrm{g} / \mathrm{ml})$} & \multirow{2}{*}{$\begin{array}{l}\text { With } \\
\text { out } \\
\text { aller- } \\
\text { gen }\end{array}$} \\
\hline & $\begin{array}{c}\text { After } \\
0-1 \\
h r\end{array}$ & $\begin{array}{c}\text { After } \\
8-24 \\
\text { hr }\end{array}$ & $\begin{array}{c}\text { After } \\
0-1 \\
\mathrm{hr}\end{array}$ & $\begin{array}{c}\text { After } \\
8-24 \\
\mathrm{hr}\end{array}$ & & \multicolumn{2}{|c|}{$n \log$} & & $\begin{array}{r}2.5 \times \\
10^{-3}\end{array}$ & $\begin{array}{r}2.5 \times \\
10^{-2}\end{array}$ & $\begin{array}{r}2.5 \times \\
10^{-1}\end{array}$ & $\begin{array}{l}2.5 \\
2.5\end{array}$ & \\
\hline 1 & + & - & + & - & 1 & 4.5 & 90.0 & $2.5 \times 10^{-2}$ & & 34 & & & 20 \\
\hline 2 & - & - & - & - & 1 & -1.2 & 0.3 & $2.5 \times 10^{1}$ & - & - & - & - & 0 \\
\hline 3 & - & - & + & - & 1 & 4.3 & 76.0 & $2.5 \times 10^{-2}$ & & 53 & & & 21 \\
\hline 4 & - & - & + & - & 2 & 5.5 & 245.0 & 2.5 & & & & 11 & 15 \\
\hline 5 & + & - & + & - & 2 & 2.4 & 11.0 & $2.5 \times 10^{-2}$ & & & 45 & & 2 \\
\hline 6 & + & - & + & - & 2 & 1.1 & 3.0 & $2.5 \times 10^{-2}$ & & & 5 & & 0 \\
\hline 7 & - & - & + & - & 4 & 1.1 & 3.0 & $2.5 \times 10^{1}$ & & & 55 & & 4 \\
\hline 8 & - & - & - & - & 4 & -1.2 & 0.3 & $2.5 \times 10^{1}$ & 1 & & & & 0 \\
\hline 9 & - & + & + & - & 4 & 4.9 & 137.0 & $2.5 \times 10^{-2}$ & & 31 & & & 6 \\
\hline 10 & - & - & + & - & 8 & 4.2 & 64.0 & $2.5 \times 10^{-2}$ & & & 88 & & 6 \\
\hline 11 & - & - & + & - & 8 & 4.6 & 99.0 & $2.5 \times 10^{-2}$ & & & 73 & & 2 \\
\hline 12 & - & - & + & - & 8 & 1.4 & 4.0 & $2.5 \times 10^{-2}$ & & & 29 & & 2 \\
\hline 13 & - & + & + & - & 8 & 4.4 & 79.0 & $2.5 \times 10^{-1}$ & & 15 & & & 17 \\
\hline 14 & - & - & - & - & 16 & 1.1 & 3.0 & $2.5 \times 10^{-2}$ & & & & 18 & 6 \\
\hline 15 & - & - & - & - & 16 & -1.2 & 0.3 & $2.5 \times 10^{-2}$ & & & & 10 & 0 \\
\hline 16 & - & - & - & - & 32 & 1.8 & 6.0 & $2.5 \times 10^{-1}$ & & & 41 & & 2 \\
\hline 17 & - & - & - & - & 64 & 0.9 & 2.5 & 2.5 & 2 & & & 2 & 5 \\
\hline 18 & - & - & - & - & 64 & -1.2 & 0.3 & 2.5 & & & 4 & 4 & 7 \\
\hline 19 & - & - & - & - & 64 & 4.2 & 70.0 & $2.5 \times 10^{-2}$ & & & 34 & & 5 \\
\hline 20 & - & - & - & - & 64 & 0.8 & 23.0 & 2.5 & & & 25 & & 20 \\
\hline 21 & - & - & - & - & 1 & 0 & 1.0 & 2.5 & 5 & & & & 4 \\
\hline 22 & - & - & - & - & 4 & 2.0 & 7.0 & 2.5 & & & & 9 & 3 \\
\hline 23 & - & - & + & - & 8 & 3.8 & 46.0 & $2.5 \times 10^{-2}$ & 65 & & & & 57 \\
\hline 24 & - & - & - & - & 8 & 0 & 1.0 & 2.5 & 15 & & & & 6 \\
\hline 25 & - & - & - & - & 8 & 0 & 1.0 & 2.5 & & 5 & & & 4 \\
\hline 26 & - & - & - & - & 32 & 3.5 & 33.0 & $2.5 \times 10^{-1}$ & & & & 18 & 3 \\
\hline 27 & - & - & - & - & 32 & 0 & 1.0 & 2.5 & & & & 6 & 3 \\
\hline 28 & - & - & - & - & 32 & 0 & 1.0 & $2.5 \times 10^{1}$ & & & 20 & & 16 \\
\hline 29 & - & - & - & - & 64 & 0 & 1.0 & 2.5 & & & & 6 & 4 \\
\hline 30 & - & - & - & - & 64 & 1.4 & 4.0 & $2.5 \times 10^{-1}$ & & & & 7 & 8 \\
\hline
\end{tabular}

* Patients 1 to 20, positive history: Patients 21 to 30 , negative history.

allergen in the nebulizer and the type of the reaction) and as a positive/negative score (see Table IV).

In the multiple correlations the inhalation reaction (the dependent variable) was compared with the other variables (independent variables), both singly and in several combinations. The significances of the multiple correlation coefficients are calculated as follows ${ }^{9}$ :

$$
\mathrm{F}=\frac{\mathrm{n}-\mathrm{k}-1}{\mathrm{k}} \cdot \frac{\mathrm{R}^{2}}{1-\mathrm{R}^{2}}
$$


Table II. Relation between inhalation reaction and histamine threshold, allergen-specific IgE, skin titer, and histamine release.

\begin{tabular}{|c|c|c|c|c|c|c|c|c|c|c|c|c|c|c|c|c|c|c|c|}
\hline \multirow{2}{*}{\multicolumn{3}{|c|}{$\begin{array}{l}\text { Inhalation } \\
\text { reaction }\end{array}$}} & \multirow{2}{*}{\multicolumn{3}{|c|}{$\begin{array}{l}\text { Histamine } \\
\text { threshold } \\
(\mathrm{mg} / \mathrm{ml})\end{array}$}} & \multirow{2}{*}{\multicolumn{4}{|c|}{$\begin{array}{c}\text { Allergen- } \\
\text { specific IgE } \\
(\mathrm{U} / \mathrm{ml})\end{array}$}} & \multirow{2}{*}{\multicolumn{4}{|c|}{ Skin titer $(\mu \mathrm{g} / \mathrm{ml})$}} & \multicolumn{6}{|c|}{ Histamine release (\% maximum) } \\
\hline & & & & & & & & & & & & & & \multicolumn{3}{|c|}{ With allergen } & \multicolumn{3}{|c|}{ Without allergen } \\
\hline $\begin{array}{c}\text { Dose } \\
(\mu \mathrm{g} / \mathrm{ml})\end{array}$ & Type* & $\mathrm{n}$ & $\leqslant 8$ & 16 & $\geqslant 32$ & $\geqslant 21$ & $6-20$ & $2-5$ & $<2$ & $2.5 \times 10^{-2}$ & $2.5 \times 10^{-1}$ & 2.5 & $2.5 \times 10^{1}$ & $\geqslant 40$ & $20-39$ & $\leqslant 19$ & $>15$ & $6-15$ & $0-5$ \\
\hline \multirow[t]{2}{*}{$2.5 \times 10^{1}$} & $\mathrm{E}$ & 3 & 3 & & & 1 & 1 & 1 & & 3 & & & & 1 & 1 & 1 & 1 & - & 2 \\
\hline & D & 2 & 2 & & & 2 & & & & 2 & & & & & 1 & 1 & 1 & 1 & \\
\hline \multirow[t]{2}{*}{$2.5 \times 10^{2}$} & E & 7 & 7 & & & 5 & & 2 & & 4 & 1 & 1 & 1 & 5 & 1 & 1 & 2 & 2 & 3 \\
\hline & D & 0 & 0 & & & & & & & & & & & & & & & & \\
\hline Negative & & 18 & 6 & 2 & 10 & 3 & 2 & 3 & 10 & 3 & 3 & 9 & 3 & 1 & 3 & 14 & 2 & 4 & 12 \\
\hline
\end{tabular}

${ }^{*} \mathrm{E}=$ immediate reaction; $\mathrm{D}=$ delayed reaction. 
Table III. Correlation coefficients between single variables in linear terms.

\begin{tabular}{lccccc}
\hline & & & & \multicolumn{2}{c}{ Histamine release } \\
\cline { 5 - 6 } & $\begin{array}{c}\text { Histamine } \\
\text { threshold }\end{array}$ & $\begin{array}{c}\text { Allergen- } \\
\text { specific IgE }\end{array}$ & Skin titer & With allergen & Without allergen \\
\hline Inhalation reaction & $-0.53^{*}$ & $0.60^{+}$ & $0.55^{*}$ & $0.46_{+}^{+}$ & 0.23 \\
Histamine threshold & & -0.24 & -0.13 & -0.26 & 0.04 \\
Allergen-specific IgE & & & $0.64 \dagger$ & $0.60^{\dagger}$ & 0.39 \\
Skin titer & & & & $0.50^{*}$ & 0.23 \\
Histamine release & & & & & 0.35 \\
\hline
\end{tabular}

The variables are used as follows:

Inhalation reaction

$2.5 \times 10^{1} \mathrm{\mu g} / \mathrm{ml}$ allergen: immediate reaction. score 4 .

delayed reaction, score 3.

$2.5 \times 10^{2} \mu \mathrm{g} / \mathrm{ml}$ allergen: immediate reaction, score 2 . delayed reaction, score 1.

no reaction, score 0.

Histamine threshold is the concentration histamine biphosphate after which $\mathrm{FEV}_{1}$ decreased to below $85 \%$ of the initial value.

Allergen-specific $\mathrm{IgE}$ is the natural logarithm of the serum concentration in $\mathrm{U} / \mathrm{ml}$.

Skin titer

$2.5 \times 10^{-2} \mu \mathrm{g} / \mathrm{ml}$ allergen, score 4 .

$2.5 \times 10^{-1} \mathrm{\mu g} / \mathrm{ml}$ allergen, score 3 .

$2.5 \mu \mathrm{g} / \mathrm{m}$ l allergen, score 2 .

$2.5 \times 10^{1} \mu \mathrm{g} / \mathrm{ml}$ allergen, score 1 .

Negative reaction, score 0.

Histamine release is expressed as percentage of the maximal release.

$\mp 0.01 \leqslant \mathrm{p}<0.05$.

$* 0.001 \leqslant p<0.01$.

$+\mathrm{p}<0.001$.

where $\mathrm{n}=$ number of observations, $\mathrm{k}=$ number of independent variables, and $\mathrm{R}=$ correlation coefficients.

The significances which were derived from these $\mathbf{F}$ values have been obtained partly from a standard table of $\mathrm{F}$ distributions, ${ }^{10}$ and partly calculated. We looked for non-linear relationships by trying out other mathematical expressions. Only if quadratic terms were added to linear terms did some of the correlation coefficients increase significantly as shown by the $F$ test modified for two correlation coefficients. The $p$ values of the differences between correlation coefficients (Table V) were calculated by $z$-transformations according to Fisher. ${ }^{12}$ The $5 \%$ level has been considered the level of significance. 
Results

The results are summarized in Table I. Table II shows the relationship between the inhalation reaction after allergen provocation, the histamine threshold, the allergen-specific $\operatorname{IgE}$ concentrations, the skin titer, and the histamine release with and without allergen. In this table the variables are arbitrarily divided into classes. After inhalation of cat dander allergen in $2.5 \times 10^{1} \mu \mathrm{g} / \mathrm{ml}$ concentration, bronchial obstruction occurred in five out of 30 patients. Three of these developed an immediate reaction and two a delayed reaction. The 25 patients who did not respond after inhalation of the allergen in the lower dose were tested with inhalation. of $2.5 \times 10^{2} \mu \mathrm{g} / \mathrm{ml}$. An immediate reaction developed in seven patients, and none showed a delayed reaction.

Inhalation tests were only positive with a histamine threshold of $\leqslant 8 \mathrm{mg} / \mathrm{ml}$. Within the group of patients with a low histamine threshold only six out of 18 had a negative reaction after cat dander inhalation. In a positive inhalation test the concentration of the allergen-specific IgE was always greater than or equal to $2 \mathrm{U} / \mathrm{ml}$; in eight out of 12 patients it was greater than $20 \mathrm{U} / \mathrm{ml}$. In a negative inhalation test the concentration of the allergen-specific IgE was higher than $2 \mathrm{U} / \mathrm{ml}$ in eight patients out of 18 . In nine out of 12 a positive inhalation test was found with a skin titer with a low allergen concentration $\left(2.5 \times 10^{-2} \mu \mathrm{g} / \mathrm{ml}\right)$, while in only three out of 18 the same skin titer was found together with a negative inhalation test. In six out of 12 patients with a positive inhalation test there was a high allergen-induced histamine release $\geqslant 40 \%$ of the maximum release). In patients with a negative inhalation reaction we found such a high allergen-induced histamine release on one occasion, a medium release ( $20 \%$ to $39 \%$ ) on three occasions and low release $(\leqslant 19 \%)$ on 14 occasions.

For further analysis of the correlation between the variables a correlation matrix has been constructed (Table III). This shows the following:

1. The results of the inhalation test, expressed in the differential score as described in Table III, show a significant correlation with the histamine threshold, the allergen-specific $\operatorname{IgE}$ concentration, the skin titer, and the allergen-induced histamine release.

2. The histamine threshold does not show any correlation with the histamine release with and without allergen or with the skin titer.

3. The allergen-specific IgE concentration is correlated equally with the inhalation reaction, the skin titer, and the histamine release with allergen. There is no correlation with the histamine release without allergen or with the histamine threshold.

4. The skin titer shows a significant correlation with the histamine release with allergen but not with the histamine release without allergen.

In order to determine the correlation between more than two variables, multiple correlations have been calculated. Table IV (first and second columns) gives the results of the multiple correlation calculation with linear terms. The combinations of the histamine threshold with the allergen-specific IgE, skin titer, or histamine 
release with allergen show significantly higher correlation coefficients with the inhalation reaction than each of the variables alone (Table V). The combination of the histamine threshold with the allergen-specific IgE concentration gives the best correlation with the inhalation reaction. Combinations of more than two factors do not significantly increase the correlation with the inhalation reaction. When quadratic terms were introduced together with linear, only the combination of the histamine threshold with the skin titer and with the allergen-induced histamine release showed significant improvement in the correlation coefficients at the $1 \%$ level.

The relationship between the reaction to inhalation, the histamine threshold, and the allergen-specific $\operatorname{IgE}$ concentration is shown for each patient in Fig. 1. Where the histamine threshold is $16 \mathrm{mg} / \mathrm{ml}$ or more, all inhalation reactions are negative. Where the histamine threshold is low, a positive reaction to inhalation is likely to occur at an allergen-specific $\operatorname{IgE}$ concentration of $\geqslant 2 \mathrm{U} / \mathrm{ml}$. The same is true at a skin titer with $\leqslant 2.5 \times 10^{-1} \mu \mathrm{g} / \mathrm{ml}$.

\section{Discussion}

In formulating the conclusions to be drawn from this study, a positive inhalation reaction (scores 2, 3, or 4 from Table III) has been considered as indicative of clinically relevant allergy and the histamine threshold as a parameter of bronchial hyperreactivity.

From Table III it can be seen that a statistically significant correlation exists between the histamine threshold and the reaction to inhalation of cat dander allergen. The inhalation reaction shows a significant correlation not only with the histamine threshold, but also with the concentration of the allergen-specific IgE, the skin titer, and the allergen-induced histamine release. The allergen-specific IgE concentration is correlated with the occurrence of the inhalation reaction but not with the degree of the reaction.

From Tables IV and $V$ it appears that the correlation between the inhalation reaction and the combination of the histamine threshold and the allergen-specific $\mathrm{IgE}$ concentration or skin titer is higher than with each separately.

From the fact that the correlation coefficients of the inhalation reaction with the combinations of the histamine threshold with skin titer or histamine release increase when quadratic terms are added to the linear ones, it can be concluded that the correlations between these factors are not rectilinear. Also, the allergen-specific IgE concentration gives the best fit in the correlation calculations if expressed as a natural logarithm. These facts point to nonlinear correlations, which are often found in biologic systems. ${ }^{11}$

The calculations of the regression formulas and correlation coefficients were simplified using normal procedures for continuous variables, despite the fact that several variables had only discrete values. This method, although not quite correct, offers from a mathematical point of view important advantages over methods 
Table IV. Correlation between the inhalation reaction as a dependent variable and several independent variables singly and in groups.

\begin{tabular}{|c|c|c|c|c|}
\hline & \multicolumn{4}{|c|}{ Inhalation reaction } \\
\hline & \multicolumn{2}{|c|}{ Linear terms } & \multicolumn{2}{|c|}{$\begin{array}{l}\text { Linear plus } \\
\text { quadratic terms }\end{array}$} \\
\hline & Score* & $\begin{array}{c}\text { Positive } \\
\text { or negativet }\end{array}$ & Score* & $\begin{array}{c}\text { Positive } \\
\text { or negative } \dagger\end{array}$ \\
\hline Histamine threshold & $-0.53_{+}^{+}$ & $-0.56_{+}^{+}$ & $-0.61 \S$ & $-0.62 \S$ \\
\hline Allergen-speciffc IgE & $0.60 "$ & $0.69 !$ & $0.60 \S$ & $0.69_{+}^{+}$ \\
\hline Skin titer & $0.55_{+}^{+}$ & $0.51_{+}^{+}$ & $0.62 \S$ & $0.57 \S$ \\
\hline Histamine release & $0.46 \S$ & $0.63^{\Perp 1}$ & $0.49^{\prime \prime}$ & $0.64 \S$ \\
\hline Histamine threshold + allergen-specific IgE & $0.73^{1}$ & $0.80^{\mathrm{n}}$ & $0.78^{\prime \prime}$ & $0.82^{11}$ \\
\hline Histamine threshold + skin titer & $0.72^{11}$ & $0.71 "$ & $0.79 \|$ & $0.77^{\prime \prime}$ \\
\hline Histamine threshold + histamine release & $0.63_{+}^{+}$ & $0.72^{\sharp}$ & $0.74^{\|}$ & $0.82^{\prime \prime}$ \\
\hline $\begin{array}{l}\text { Histamine threshold + allergen-specific IgE } \\
+ \text { skin titer } \\
\text { Histamine threshold + allergen-specific IgE }\end{array}$ & $0.76^{\text {u }}$ & $0.8 \mathrm{I}^{\prime \prime}$ & $0.82^{\prime \prime}$ & $0.84^{\prime \prime}$ \\
\hline $\begin{array}{l}\text { + histamine release } \\
\text { Histamine threshold + skin titer }\end{array}$ & $0.73^{\prime \prime}$ & $0.83^{\prime \prime}$ & $0.78^{\prime \prime}$ & $0.86^{\|}$ \\
\hline+ histamine release & $0.76^{\|}$ & 0.79 & $0.82^{\Perp}$ & $0.85^{\prime \prime}$ \\
\hline
\end{tabular}

* Expressed in the same way as in Table III.

+ Positive: scores I-4 (Table III); negative: no reaction after allergen inhalation: all other variables are expressed as in Table III.

$\$ 0.01 \leqslant p<0.05$.

$+0.001 \leqslant \mathrm{p}<0.01$.

"ip $<0.001$.

which consider variables as discontinuous. Moreover, the results obtained do not differ to any important extent. ${ }^{12}$

The correlation coefficients give limited information about the kind and range of the individual variations of the relationship found, especially if the regression model contains multiple linear and quadratic terms. This may limit its value when drawing conclusions from this data. In order to investigate the validity of the correlation coefficients for our conclusions, regression equations were calculated based on all patient data (see Table VI). Using these we predicted which inhalation reaction would occur in each child from his histamine threshold, allergen-specific IgE concentration, and skin titer. The predicted reaction was compared with the observed one. The results can be summarized as follows. Based on the histamine threshold and the allergen-specific IgE concentration, in 14 out of the 30 patients a correct prediction of the differential inhalation score could be made. The inhalation reactions in terms of positive or negative could be correctly predicted in 25 of the 30 patients. Based on the histamine threshold and the skin titer, a correct prediction of the differential score could be made in 13 of 30 patients. The predictions in 
terms of a positive or negative inhalation reaction were correct in 26 of the 30 patients. These results indicate that in our studies conclusions can be drawn from the correlation coefficients.

Bryant and Burns ${ }^{13}$ found, along with a low bronchial threshold for Dermatophagoides pteronyssinus allergen, a lowered histamine threshold. In monkeys who were allergic to Ascaris and who had a positive inhalation reaction with this allergen, Patterson et al. ${ }^{14}$ found a higher bronchial sensitivity for carbacholine than in monkeys with a negative inhalation reaction. Gökemeyer ${ }^{15}$ found a significant correlation between the histamine threshold and the dose of house dust allergen which provoked bronchial obstruction after inhalation.

The histamine threshold could be influenced by the allergen-specific IgE concentration. This is unlikely, however, because no relationship between histamine threshold and the allergen-specific $\operatorname{IgE}$ concentration or the skin titer was found (Table III). Also, Gökemeyer ${ }^{15}$ found no relationship between the histamine threshold and the skin titer. Rademaecker et al. ${ }^{16}$ found that a stronger reaction of the bronchial tree to histamine occurred in monkeys passively immunized with grass pollen reagins. In guinea pigs, Popa et al. ${ }^{17}$ found no influence of sensitization with antibodies against egg-albumen on the bronchial threshold. After inhalation of this allergen, a temporarily increased bronchial threshold was found. Bryant et al. ${ }^{18}$ found no correlation between the histamine threshold and the number of allergens with which a positive prick test was obtained. He also failed to find a relationship between the histamine threshold and the total IgE.

The histamine threshold and the initial lung function are not necessarily independent of each other. ${ }^{19}$. 20 Table VII shows that a slight difference exists between the group of patients with a positive and a negative inhalation reaction and between patients with a decreased and a normal histamine threshold as to their initial FEV ${ }_{1}$. These differences are not statistically significant. We therefore assumed that the relationship between the inhalation reaction and the histamine threshold was not based on differences in the extent of bronchial obstruction at the start of the test.

Gökemeyer ${ }^{15}$ found a slight but significant decrease of the histamine threshold some days after a positive response to provocation with house dust. It is improbable, however, that the lowered histamine threshold in our patients was caused by an allergic reaction. According to their history they had not suffered from symptoms at least $4 \mathrm{wk}$ prior to the examination.

The results of this study support our hypothesis that a decreased bronchial threshold to inhaled bronchial constrictor agents is essential for an inhalation reaction to an allergen to occur in allergic patients.

In some asthma patients there is a permanently decreased bronchial threshold, while in others the bronchial threshold is normal or changing. ${ }^{21}$ The fact that bronchial obstruction after inhalation of allergen seems to occur only with a decreased bronchial threshold can explain why patients from this last category do not always show symptoms after contact with the allergen. This can be confirmed by repeated bronchial provocation tests in the same patient in periods with a normal and a decreased threshold to histamine. This is currently under study. Up to now 
we were able to reinvestigate the patient marked in Fig. 1 with an asterisk 2 wk after an asthma attack. The histamine threshold was $8 \mathrm{mg} / \mathrm{ml}$, and the child showed a delayed reaction after inhalation of $2.5 \times 10^{1} \mu \mathrm{g} / \mathrm{ml}$ and an early reaction after $2.5 \times 10^{2} \mu \mathrm{g} / \mathrm{ml}$. The initial $\mathrm{FEV}_{1}$ was $108 \%$ on the first and $72.5 \%$ on the second occasion. The skin titer and specific $\operatorname{IgE}$ were unchanged.

Clinical asthma based on the history does not always concur with the inhalation reactions. There may be several reasons for this. Apart from changes in reactivity with time, the impression of the patient concerning symptoms caused by contact with a particular allergen might be incorrect.

It seems improbable that the inhalation reaction was influenced by measurement of the histamine threshold, because histamine challenge gives a reaction which only lasts minutes.

It appears that on the basis of the serum concentration of the allergen-specific IgE or the skin titer, the reaction occurring after inhalation of allergen can only be predicted with moderate accuracy in the individual patient. For a more reliable prediction the bronchial threshold should be determined. If this is increased (a histamine threshold $\leqslant 8 \mathrm{mg} / \mathrm{ml}$ using our method), and at the same time an elevated concentration of circulating or cell-bound allergen-specific $\operatorname{IgE}$ is present, bronchial obstruction after allergen inhalation is very likely. If the bronchial threshold histamine is normal $(\geqslant 32 \mathrm{mg} / \mathrm{ml}$ ), an increased allergen-specific IgE concentration does not produce bronchial obstruction after inhalation. Both antibody and bronchial threshold determinations are feasible in most outpatient departments and in most patients.

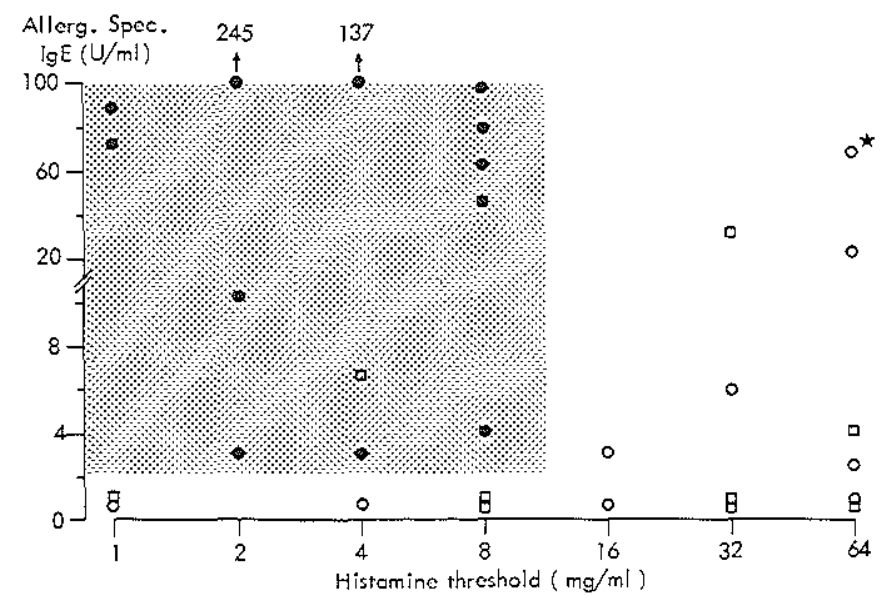

Figure 1. Coherence of histamine threshold and allergen-specific $\operatorname{IgE}$ with inhalation reaction for each patient. Group A (positive history of bronchial reaction after contact with cat): - inhalation reaction positive, $O$ inhalation reaction negative. Group B (negative history): $\exists$ inhalation reaction positive, $\square$ inhalation reaction negative. 
Table V. Differences between the correlation coefficients in Table IV.

\begin{tabular}{|c|c|c|c|c|c|c|c|c|c|c|c|c|c|c|}
\hline & \multicolumn{2}{|c|}{$\begin{array}{l}\text { Histamine } \\
\text { threshold }\end{array}$} & \multicolumn{2}{|c|}{$\begin{array}{l}\text { Allergen-specific } \\
\text { IgE }\end{array}$} & \multicolumn{2}{|c|}{ Skin titer } & \multicolumn{2}{|c|}{ Histamine release } & \multicolumn{2}{|c|}{$\begin{array}{l}\text { Histamine } \\
\text { threshold } \\
+ \text { allergen- } \\
\text { specific IgE }\end{array}$} & \multicolumn{2}{|c|}{$\begin{array}{l}\text { Histamine } \\
\text { threshold } \\
+ \text { skin titer }\end{array}$} & \multicolumn{2}{|c|}{$\begin{array}{c}\text { Histamine } \\
\text { threshold } \\
+ \text { histamine release }\end{array}$} \\
\hline & Score & Pos $/ \mathrm{Neg}^{*}$ & Score ${ }^{*}$ & Pos/Neg* & Score & Pos/Neg* & Score* & Pos/Neg* & Score & Pos/Neg & Score & Pos/Neg & Score & Pos/Neg \\
\hline $\begin{array}{l}\text { Histamine threshold } \\
+ \text { allergen-specific IgE }\end{array}$ & 3 & 2 & 2 & 2 & & & & & & & & & & \\
\hline $\begin{array}{l}\text { Histamine threshold } \\
+ \text { skin titer } \\
\text { Histamine threshold }\end{array}$ & 2 & 2 & & & 2 & 3 & & & & & & & & \\
\hline $\begin{array}{l}\text { Histamine threshold } \\
+ \text { histamine release } \\
\text { Histamine threshold } \\
+ \text { allergen-specific IgE }\end{array}$ & 1 & 2 & & & & & 2 & 1 & & & & & & \\
\hline $\begin{array}{l}\text { + skin titer } \\
\text { Histamine threshold } \\
+ \text { allergen-specific IgE }\end{array}$ & & & & & & & & & 0 & 0 & 0 & 2 & & \\
\hline + histamine release & & & & & & & & & 0 & 0 & & & 1 & 1 \\
\hline $\begin{array}{l}\text { Histamine threshold }+ \text { skin } \\
\text { titer }+ \text { histamine release }\end{array}$ & & & & & & & & & & & 0 & 2 & 1 & 1 \\
\hline
\end{tabular}

$0=$ Not significantly different

$1=0.01 \leqslant p<0.05$.

$2=0.001 \leqslant \mathrm{p}<0.01$.

$3=\mathrm{p}<0.001$.

* Inhalation reactions expressed as in Table IV; all other variables are expressed as in Table IIl. 
Table VI. Regression equations calculated from measurements in 30 patients.

\begin{tabular}{|c|c|c|}
\hline \multicolumn{2}{|c|}{$\begin{array}{l}\text { Inhalation reaction } \\
\text { expressed as *: }\end{array}$} & Regression equation with following variables \\
\hline Pos/Neg & - & $0.6436-0.0117$ (Histamine threshold) \\
\hline Score & - & $1.7356-0.0321$ (Histamine threshold) \\
\hline Pos/Neg & - & $0.1136+0.1618$ (Allergen-specific IgE) \\
\hline Score & - & $0.3422+0.4094$ (Allergen-specific IgE) \\
\hline Pos/Neg & - & $-0.1886+0.2127$ (Skin titer $)$ \\
\hline Score & $\bullet$ & $-0.7705+0.6640($ Skin titer $)$ \\
\hline $\mathrm{Pos} / \mathrm{Neg}$ & - & $0.3390-0.0088($ Histamine threshold $)+0.1383($ Allergen-specific IgE) \\
\hline Score & - & $0.9804-0.0249$ (Histamine threshold) +0.3429 (Allergen-specific IgE) \\
\hline $\mathrm{Pos} / \mathrm{Neg}$ & $\bullet$ & $0.1065-0.0101$ (Histamine threshold) +0.1849 (Skin titer) \\
\hline Score & - & $0.0245-0.0282$ (Histamine threshold) +0.5891 (Skin titer) \\
\hline $\mathrm{Pos} / \mathrm{Neg}$ & - & $\begin{array}{l}0.2198-0.0089 \text { (Histamine threshold) }+0.1178 \text { (Allergen-specific IgE) } \\
+0.0566 \text { (Skin titer) }\end{array}$ \\
\hline Score & $\bullet$ & $\begin{array}{l}0.2306-0.0253 \text { (Histamine threshold) }+0.2142 \text { (Allergen-specific IgE) } \\
+0.3558 \text { (Skin titer) }\end{array}$ \\
\hline
\end{tabular}

* See Table III.

Table VII. The initial values of VC and FEV, according to the inhalation reaction and histamine threshold.

\begin{tabular}{|c|c|c|c|c|}
\hline & & & \multicolumn{2}{|c|}{ Initial values* } \\
\hline & & & VC & $\mathrm{FEV}_{1}$ \\
\hline \multirow[t]{4}{*}{ Inhalation reaction } & Positive & Mean & 107.8 & 94.2 \\
\hline & $\mathrm{n}=12$ & SD & 13.5 & 18.7 \\
\hline & Negative & Mean & 102.8 & 97.7 \\
\hline & $\mathrm{n}=18$ & $\mathrm{SD}$ & 14.0 & 18.6 \\
\hline \multirow[t]{4}{*}{ Histamine threshold } & $\leqslant 8 \mathrm{mg} / \mathrm{ml}$ & Mean & 104.5 & 93.7 \\
\hline & $\mathrm{n}=18$ & $\mathrm{SD}$ & 13.6 & 20.1 \\
\hline & $\geqslant 16 \mathrm{mg} / \mathrm{ml}$ & Mean & 104.8 & 99.9 \\
\hline & $\mathrm{n}=12$ & $\mathrm{SD}$ & 15.2 & 11.9 \\
\hline
\end{tabular}

None of the differences is statistically significant (Student's $t$ test).

* Expressed as percent of the expected value according to height.

A number of studies supported our assumption that histamine release from peripheral leukocytes may be considered a suitable model for mast cell histamine release after allergen challenge. ${ }^{22}$. ${ }^{23} \mathrm{We}$ found that the amount of histamine released after incubation of the leukocytes with allergen correlates well with the serum concentration of specific IgE. This concentration can be considered indicative of the number of cell-bound specific IgE molecules. ${ }^{24}$ It can therefore be understood that the addition of the histamine release did not improve the correlation coefficient between the inhalation reaction and the histamine threshold plus specific IgE con- 
centration or skin titer. The histamine release thus seems unnecessary for the prediction of the reaction after inhalation of allergen in the individual patient.

We thank Dr. R. Voorhorst for making available the allergen, Dr. R. Aalberse for measurement of the allergen-specific IgE concentration, and Dr. J. P. M. de Kroon for statistical advice.

\section{References}

1. VOORHORST R. SPIEKSMA F Th M, VAREKAMP H. House-dust atopy. Leiden, 1969. Stafleu's Scientific Publishing Co.

2. WIDE L. BENNICH H. JOHANSSON S G D. Diagnosis of allergy by an in vitro test for allergy antibodies. Lancet 2: 1105, 1967.

3. AALBERSE R C. BRUMMELHUIS M G J. REERINK-BRONGERS E E. The purification of human policlonal IgE by immunosorption. Immunochemistry 10:295, 1973.

4. FERRON G A. KERREBIJN K F. WEBER J. Properties of aerosols produced with nebulizers commonly used in medicine. Am Rev Respir Dis 114: 899, 1976.

5. MAX C D. LYMAN M, ALBERTO R. Procedures for immunochemical study of histamine release from leucocytes with small volume of blood. J Allergy 46: 12, 1970.

6. DE VRIES K, BOOY-NOORD H, GOEI $H$. GROBLER N J, SLUITER H J. TAMMELING G J. ORIE N G M. Hyperreactivity of the bronchail tree to drugs, chemical and physical agents. in: Orie N G M, Sluiter H J. editors: Bronchitis II: Second International Symposium. Assen. 1964, Royal Vangorcum. p. 167-180.

7. OREHEK J, GAYRARD P, SMITH A P. GRIMAUD C, CHARPIN J. Airway response to carbachol in normal and asthmatic subjects. Distinction between bronchial sensitivity and reactivity. Am Rev Respir Dis 115: 937, 1977.

8. WALKER S H. DUNCAN D B. Estimation of the probability of an event as a function of several independent variables. Biometrica $54: 167,1967$.

9. DANIEL C. WOOD F S. Fitting equations to data. New York, 1971. Wiley-Interscience.

10. ABRAMOWITZ M, STEGUN I A. Handbook of mathematical functions. New York, 1973, Dover Publications. Inc.

11. FINNEY D J. Statistical method in biological assay. London, 1964. Charles Griffin \& Co.

12. SNEDECOR G W, COCHRAN W G. Statistical methods, ed 6. Lowa City, Iowa, 1967, Iowa State University Press.

13. BRYANT D H. BURNS M W. The relationship between bronchial histamine reactivity and atopic status. Clin Allergy, 6:373, 1975.

14. PATTERSON R, HARRIS K E. SUZKO J M, ROBERTS M. Reagin mediated asthma in rhesus monkeys and relation to bronchial cell histamine release and airways reactivity to carbocholine. J Clin Invest. 57:586, 1976.

15. GOKEMEYER J D M. Hyperreactiviteit van de luchtwegen. Thesis, Groningen, 1976.

16. RADEMAECKER M. GEUBELLE F, SALMON J. Inhalation tests in monkeys passively sensitized with human serum. Clin Allergy, 2: 247, 1972. 
17. POPA V, DOUGLAS J S, BOUHUYS A. Airway responses to histamine, acetylcholine and propanolol in anaphylactic hypersensitivity in guinea pigs. J Allergy Clin Immunol. 51: 344, 1973.

18. BRYANT D H, BURNS M W, LAZARUS C. The correlation between skin tests, bronchial provocation tests and the serum level of $\operatorname{IgE}$ specific for common allergens in patients with asthma. Clin Allergy, 5: 145, 1975.

19. DE VRIES $K$. Histamine thresholds and initial lung function values, in: Orie N G M. van der Lende P R, editors: Bronchitis IUI Second International Symposium. Assen, 1970, Royal Vangorcum. p. 359-362.

20. KERREBIJN K F. HOOGEVEEN-SCHROOT H C A, VAN DER WAL M C. Chronic nonspecific respiratory disease in children - a five year follow-up study. Acta Paediatr Scand [Suppl] (263): 3-72, 1977.

21. EMPEY D W, LATINEN L A. JACOBS L. GOLD W M. Mechanisms of bronchial hypersensitivity in normal subjects after upper respiratory tract infections. Am Rev Respir Dis. 113: 131. 1976.

22. LICHTENSTEIN L M. MARGOLIS S. Histamine release in vitro: Inhibition of cathecholamines and methylxanthines. Science 161:902, 1968.

23. AUSTEN K F, WASSERMAN S I. GOETZL E J. Mast cell - derived mediators: Structural and functional diversity and regulation of expression, in: Johansson S G D Strandberg K, Unväs B, editors: Molecular and biological aspects of the acute allergic reaction. New York, 1976, Plenum Press, p. 293-318.

24. STALLMAN P J. IgE on human basophils. Thesis, University of Amsterdam - Rodopi N.V. Amsterdam, 1977. 


\section{Paragraph 8.3}

Significance of the bronchial responsiveness to histamine in allergen-induced bronchial obstruction on different occasions

H. J. Neijens, K. F: Kerrebijn

Department of Paediatrics, Subdepartment of respiratory diseases, Erasmus University, Medical School, Sophia Children's Hospital, Rotterdam, The Netherlands

\section{Summary}

An increase in the bronchial responsiveness (BR) to histamine was associated with a positive in stead of a negative allergen inhalation reaction, while a decrease in $\mathrm{BR}$ diminished the inhalation reaction to allergen. The reaction was unchanged in the patients with a stable BR. This relationship was relevant, because the sensitization to the allergen and the baseline $\mathrm{FEV}_{1}$ were without significance variance.

\section{Introduction}

Bronchial responsiveness (BR) to histamine and metacholine is important in the bronchial reaction to allergen inhalation ${ }^{1}{ }^{2}{ }^{2}{ }^{3}$. Besides the sensitization to a particular allergen, BR is a determinant in the occurrence of bronchial obstruction after allergen challenge. In the same person $B R$ can change. A temporary increase is observed after respiratory infections ${ }^{4} .5$, influenza vaccination ${ }^{6}$ reactions to inhalation of allergens $\mathrm{s}^{7.8}$ and ozone ${ }^{9}$. In asthmatics BR can decrease ${ }^{10}$ during symptomfree periods. The hypothesis that bronchial obstruction after allergen challenge may vary with changes in $B R$ has been studied in asthmatic children.

\section{Methods}

4 patients in whom during a previous study ${ }^{3}$ (first occasion) a combination was found of a histamine provocation dose (PD) in the normal or nearly normal range $\left(\geqslant 16 \mathrm{~g} .1^{-1}\right)$ and a negative reaction to cat dander allergen inhalation, were rechallenged (second occasion) when the PD was found to be decreased $\left(\leqslant 8 \mathrm{~g} \cdot 1^{1-1}\right)$

1. This study is supported by the Netherlands Asthma Foundation. (grant nr. 238)

2. Presented at the Congress "Relationship between respiratory diseases in children and adults". Rotterdam. The Netherlands, November 22th, 1980.

3. Submitted for publicaton. 
Table 1. Comparison of the sensitivity to cat dander allergen, by skin titer and specific IgE concentration. and the baseline values of the $\mathrm{FEV}_{1}$ in relation with allergen inhalation reactions on two occasions.

Patient groups A, B and C as in figure 1.

\begin{tabular}{|c|c|c|c|c|c|c|c|}
\hline & \multicolumn{4}{|c|}{ First occasion } & \multicolumn{3}{|c|}{ Second occasion } \\
\hline & Pat. & $\begin{array}{l}\text { Skintiter } \\
\text { mg. } 1^{-1}\end{array}$ & $\begin{array}{l}\text { Spec. IgE } \\
10^{3} \mathrm{u} .1^{-1}\end{array}$ & $\begin{array}{l}\text { Baseline } \\
\mathrm{FEV}_{\mathrm{I}} \% \\
\text { predicted }\end{array}$ & $\begin{array}{l}\text { Skintiter } \\
\text { mg. } 1^{-1}\end{array}$ & $\begin{array}{l}\text { Spec. IgE } \\
10^{3} \mathrm{u} . \mathrm{I}^{-1}\end{array}$ & $\begin{array}{l}\text { Baseline } \\
\text { FEV }_{1} \% \\
\text { predicted }\end{array}$ \\
\hline \multirow{4}{*}{ 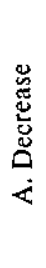 } & 1 & $2.5 \times 10^{-2}$ & 70 & 108 & $2.5 \times 10^{-2}$ & 80 & 72.5 \\
\hline & 2 & 2.5 & 2.3 & 100 & $2.5 \times 10^{-1}$ & 3.3 & 90 \\
\hline & 3 & $2.5 \times 10^{-1}$ & 33 & $11 \mathrm{I}$ & $2.5 \times 10^{-1}$ & 38 & 90 \\
\hline & 4 & $2.5 \times 10^{-2}$ & 190 & 80 & $2.5 \times 10^{-2}$ & 204 & 74 \\
\hline \multirow{4}{*}{ 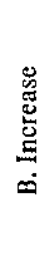 } & 5 & $2.5 \times 10^{-2}$ & 82 & 90 & $2.5 \times 10^{-2}$ & 90 & 89 \\
\hline & 6 & $2.5 \times 10^{-2}$ & 178 & 104 & $2.5 \times 10^{-2}$ & 196 & 106 \\
\hline & 7 & $2.5 \times 10^{-1}$ & 39 & 77 & 2.5 & 51 & 76 \\
\hline & 8 & $2.5 \times 10^{-2}$ & 124 & 96 & $2.5 \times 10^{-1}$ & 104 & 76 \\
\hline \multirow{2}{*}{ 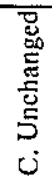 } & 9 & $2.5 \times 10^{-2}$ & 46 & 95 & $2.5 \times 10^{-2}$ & 54 & 78 \\
\hline & 10 & $2.5 \times 10^{-2}$ & 6 & 86 & $2.5 \times 10^{-1}$ & 13 & 82 \\
\hline
\end{tabular}

(group A). A further 4 patients in whom on the first occasion a decreased PD and a positive allergen inhalation reaction was evoked, were studied again when the PD had become normal (group B). The same was done in two patients in whom the PD was unchanged (group $C$ ). The age range of the patients was from 9.1 to 10.10 years.

The period between the first and second occasion varied from 1.1 to 4.1 years. Informed consent was obtained from the parents after full information about the investigations had been given. During both studies the children were in a stable condition and no medication was given between at least two days before the study and its conclusion.

Determination of the bronchial response to histamine and to allergen inhalation were carried out on four consecutive days between 9 and $12 \mathrm{a} . \mathrm{m}$. in order to avoid the influence of circadian rhythm ${ }^{11}$. BR was determined by means of the PD i.e. the lowest histamine concentration out of a series which was followed by a 


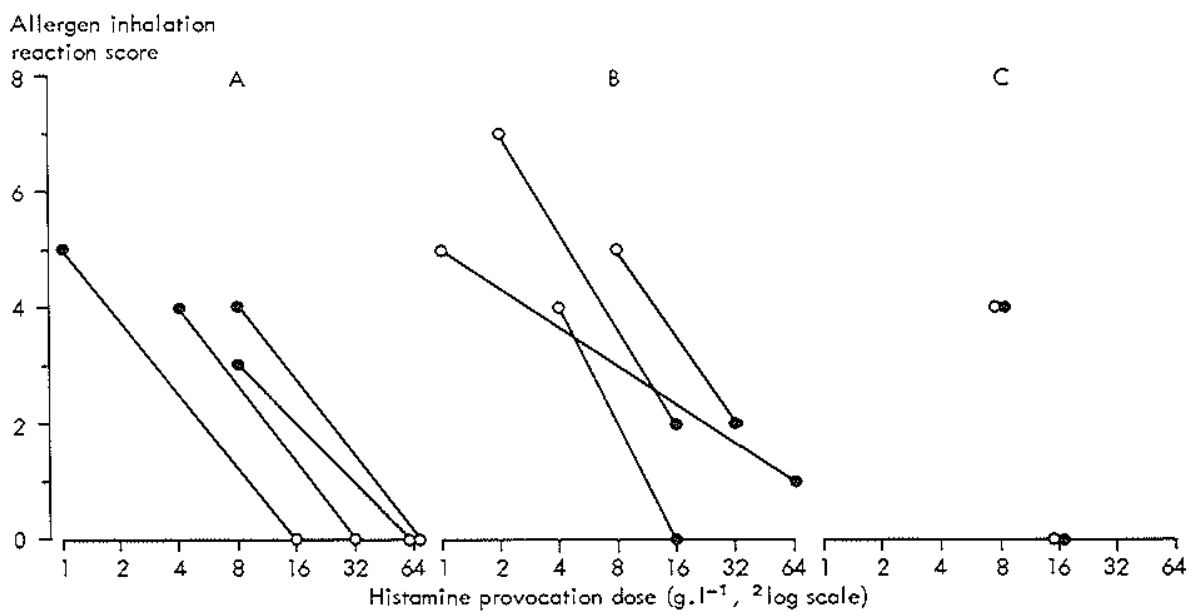

Figure 1. Allergen inhalation reactions on two occasions ( $O$ first: second) in the same patients in relation to their bronchial responsiveness to histarnine.

Three patients groups are distinguished according to the change in histamine provocation dose: $\mathrm{A}=$ Decrease; $\mathrm{B}=$ Increase: $\mathrm{C}=$ Unchanged.

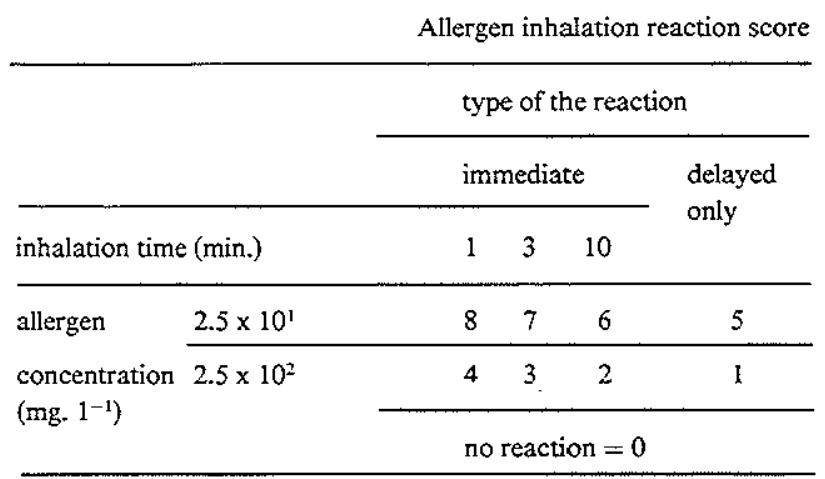

decrease in forced expiratory volume in the first second $\left(\mathrm{FEV}_{1}\right)$ of $15 \%$ or more of the baseline value $\left(\mathrm{PD}_{15}\right)$. This was measured by means of the inhalation of histamine biphosphate in increasing concentrations (doses of $1,2,4,8,16,32$ and 64 g. $\mathrm{L}^{-1}$ ). Histamine was nebulized with the Doppelinhaler (flow of $6 \mathrm{~L} / \mathrm{min}$ ). At the beginning of the inhalation patients performed a submaximal vital capacity manoeuvre, after which they breathed at tidal volume for $30 \mathrm{sec}$. The PD was mea- 
sured on the day prior to the allergen inhalation test. The effect was measured immediately after stopping the administration of histamine. The time between inhalations was about $5 \mathrm{~min}$. With this technique the $\mathrm{PD}_{15}$ to histamine in healthy children is $32 \mathrm{~g}$. $\mathrm{L}^{-1}$. A decrease in $\mathrm{PD}_{15}$ means an increase in $\mathrm{BR}$.

Allergen inhalations were performed with concentrations of $2.5 \times 10^{1}$ and $2.5 \times 10^{2} \mathrm{mg} .1^{-1}$ of a cat dander allergen solution. These concentrations were established from the results of a preliminary test which are not shown here. The nebulizer used is the Doppelinhaler (Blümel, Wiesbaden) with an airflow of $6 \mathrm{~L} / \mathrm{min}$. The allergen was inhaled for a maximum of $10 \mathrm{~min}$. (first for $1 \mathrm{~min}$., for a further $4 \mathrm{~min}$. if there was no reaction within $15 \mathrm{~min}$, and for another $5 \mathrm{~min}$. if $15 \mathrm{~min}$. thereafter still no reaction occurred). The $\mathrm{FEV}_{1}$ was measured prior to, immediately after, and at 1,8 and $24 \mathrm{hr}$. after the inhalation. The inhalation test was considered positive when the $\mathrm{FEV}_{1}$ diminished to less than $85 \%$ of the initial value. The best of five successive measurements was taken. A distinction was made between an immediate reaction taking place within $1 \mathrm{hr}$. after inhalation ad a delayed reaction between 4 and $24 \mathrm{hr}$. afterwards. During the inhalations the subjects breathed slowly and somewhat more deeply than normal. After an immediate reaction, an isoprenaline aerosol was inhaled to prevent the development of an asthma attack. Patients with an isolated delayed reaction on the lower dose were retested with the higher dose, which in all of them resulted in an immediate reaction. The results are expressed in a score, taking into account the dose of allergen needed and the type of reaction (see legend figure 1). In the score the type of the reaction is regarded in terms of quantification of the dose and not in a pathophysiological sense. Because an isolated delayed reaction changes into an immediate type when the dose of the allergen inhaled is increased ${ }^{3}{ }^{12}$, an immediate reaction was rated higher than a delayed reaction after the same dose of allergen.

The degree of sensitization was estimated by the skin titer and the serum concentration of the allergen specific IgE. An intracutaneous skin test was done with four different concentration $\left(2.5 \times 10^{-2}, 2.5 \times 10^{-1}, 2.5\right.$, and $\left.2.5 \times 10^{1} \mu \mathrm{g} / \mathrm{ml}\right)$. In each skin test a control was performed using the solvent. The volar aspect of the forearm was used and injections were at least $3 \mathrm{~cm}$ apart to avoid induction. The reaction was considered positive if the diameter of the wheal was $5 \mathrm{~mm}$ after $20 \mathrm{~min}$. The lowest concentration of allergen to which a positive reaction occurs is called the skin titer.

The concentration of allergen-specific IgE was measured by the RAST using CNBr-activated Sepharose $4 \mathrm{~B}$ as solid phase. To $1 \mathrm{ml}$ packed activated Sepharose, $5 \mathrm{mg}$ allergen was added. Fifty microliters serum or serum dilution was incubated with $0.5 \mathrm{mI}$ of a $1 \%$ suspension. After overnight incubation, the Sepharose beads were washed, and ${ }^{123} \mathrm{I}$-labeled anti-IgE antibodies, isolated as described, were added. After another overnight incubation, Sepharose-bound radioactivity was determined. The counts found were converted to international units (IU) IgE by comparison with a dose-response curve obtained by incubation of dilutions of an IgE standard serum with Sepharose-coupled anti-IgE antiserum.

Cat dander allergen was obtained from Dr. R. Voorhorst in Leiden and from 
Diephuis Inc. in Groningen. Both products were mixed by us, lyophilized, and kept at $-25^{\circ} \mathrm{C}$. Freshly prepared mixture in physiologic saline was used. The batch of cat dander allergen was the same on both occasions.

\section{Results}

As can be seen in Figure 1, in all patients in group $\mathrm{A}$ a decrease in $\mathrm{PD}_{15}$ and thus an increase in $B R$ was associated with the conversion of a negative into a positive allergen inhalation reaction. The reverse was also true. In group $B$ an increase in $\mathrm{PD}_{15}$ was associated with a decrease in the allergen inhalation score, although this became zero in only one patient. The allergen inhalation score and the PD were unchanged in both patients in group $C$.

Table 1 shows that sensitization to cat dander allergen was not significantly different on the two occasions (student $\mathrm{T}$ test). The baseline $\mathrm{FEV}_{1}$ differed slightly in 9 out of the 10 patients.

\section{Discussion}

$\mathrm{BR}$ is increasingly recognized as an important characteristic of asthma ${ }^{13}$. This study demonstrates that variations in BR can influence the bronchial response after allergen challenge. The findings were not due to differences in allergen sensitization. It seems improbable that they were the result of the differences in baseline $\mathrm{FEV}_{1}$. With the exclusion of patient 1 these differences are within the range which is generally accepted as non-significant.

The findings can explain why in many asthmatics the bronchial obstruction after contact with an allergen varies in severity or is even absent and also why it can be more severe after colds or exposure to air pollution. Also the predominance of symptoms at night may be partially explained by the drop in BR due to the circadian rhythm ${ }^{11}, 14$.

We thank Ineke Strik, Edith Bonzet, Marjan van Smalen and Joke Mazée for their technical assistance, Dr. R. Aalberse for measurement of the allergen-specific IgE concentrations, Annelies de Reus for secretarial help and Dr. R. Pearse for correcting the English language.

This work was supported by a grant from the Dutch Asthma Foundation (project number 238).

\section{References}

1. BRYANT D H, BURNS $\mathrm{M}$ W. Bronchial histamine reactivity: its relationship to the reactivity of the bronchi to allergens. Clin Allergy. 1976;6:523-532 
2. COCKCROFT D W. RUFFIN R E. FRITH P A. CARTIER A. JUNIPER E F. DOLOVITCH J, HARGREAVE F E. Determinants of allergen induced asthma: dose of allergen. circulating IgE antibody concentration and bronchial responsiveness to inhaled histamine. Am Rev Respir Dis. 1979: 120: 1053-1058.

3. NEIJENS $H J$, DEGENHART $H$ J, RAATGEEP $H C$, KERREBIJN $K F$. Study of the significance of bronchial hyperreactivity in the bronchusobstruction after inhalation of cat dander allergen. J Allergy Clin Immunol. 1979;64: 507-515.

4. EMPEY D W, LAITINEN L A. JACOBS L. GOLD W M. Mechanisms of bronchial hypersensitivity in normal subjects after upper respiratory tract infections. Am Rev Respir Dis 1976: //3: 131-139.

5. HALL W J, BREESE C. SPEERS D M. Respiratory syncytial virus studies in adults: clinical, virological and serial pulmonary function studies. Ann Intern Med 1978: 88: 203-205.

6. OUELETTE J J, REED C E. Increased response of asthmatic subjects to methacholine after influenza vaccine. J Allergy 1965:36:558-563.

7. GÖKEMELJER J. Bronchiale hyperreactiviteit. Thesis. University of Groningen: WoltersNoordhoff Grafische Bedrijven B.V. 1976.

8. ZIMMERMAN I, ULMER W T. Antigen induzierte Atemweg obstruction und Empfindlichkeitssteigerung der Bronchomotoriek. Respiration 1977; 34: 141-151.

9. HOLTZMAN M J, CUNNINGHAM J H, SHELLER J R, IRSIGLER G B. NADEL J A. BOUSHEY H A. Effect of ozone on bronchial reactivity in atopic and nonatopic subjects. Am Rev Respir Dis. 1979: /20: 1059-1067.

10. MURAKANA M, SUZUKI S, MIYAMOTO T, TAKEDA K. OKUMURA H, MAKINO $\mathrm{S}$. Bronchial reactivities to acetylcholine and $\mathrm{lgE}$ levels in asthmatic subjects after longterm. remissions. J Allergy Clin Immunol. 1974: 54: 32-40.

11. DE VRIES K. GOEI J T. BOOIJ-NOORD H. ORIE N G M. Changes during 24 hours in the lung function and histamine reactivity of the bronchial tree in asthmatic and bronchitic patients. Int Arch Allergy 1962: /20:20-61.

12. VAN LOOKEREN CAMPAGNE $J$ C. The reaction patterns after house dust provocation in children with non-specific lung disease (CNSLD). Thesis. University of Groningen. Assen: van Gorkum \& Comp. 1972.

13. BOUSHEX H A, HOLZMAN M J, SHELLER J R, NADEL J A. Bronchial hyperreactivity (State of the art). Am Rev Respir Dis. 1980:121:389-413.

14. GERVAIS P. REINBERG A, GERVAIS C. SMOLENSKY M. DE FRANCE O. Twentyfour hour rhythm in the bronchial hypersensitivity to house dust in asthmatics. $J$ Allergy Clin Immunol 1977:59:207-213. 


\section{CHAPTER 9. GENERAL DISCUSSION}

Based on data from the literature and our studies, the following conclusions may be drawn.

The interaction of factors which are involved in the occurrence of bronchial obstruction varies according to the dose and kind of stimulus applied, as well as between individuals.

In allergen-induced bronchial obstruction the mast cells, situated inside the bronchial lumen and in the bronchial wall play a primary role, whereas the parasympathetic system is secondarily involved as the pathway along which the reaction spreads and modulates throughout the lung.

In exercise-induced bronchial obstruction both systems are primarily involved whereas the contribution of each seems to differ from one individual to another.

In histamine-induced bronchial obstruction the role of mast cells is less well established than in reactions due to allergens or exercise. Inhaled histamine acts directly on the histamine receptors of the bronchial smooth muscle, but may also generate a parasympathetic reflex as is shown in the recent literature. The relative contribution of both pathways is dependent on the dose of histamine, the site of deposition and the integrity of the bronchial mucosa.

The mechanisms which cause bronchial obstruction are slightly variable while produced by stimuli which differ widely in character. Differences exist between various groups of asthmatic and bronchitic patients in their reactions to various kinds of stimuli (Gökemeijer, 1976). Bronchial responsiveness can be regarded as a dysregulation, relatively little dependent on the applied stimulus. Originally, to test bronchial responsiveness, histamine and acetylcholine were used as non-allergic stimuli and were called aspecific stimuli. A growing number of other triggers have become known which cause bronchial obstruction in subjects with hyperresponsiveness. They include serotonin, bradykinin, prostaglandin $\mathrm{F}_{2 \alpha}$, propanolol, phenylephrine; physical agents, such as carbon dust and fog; chemical agents, such as sulphur dioxide; forced respiratory manoeuvres, exercise, viral infections and emotional stress (Horton et al. 1978).

The bronchial responsiveness to inhaled histamine and to exercise are positively correlated. Thus the bronchial reaction induced by both stimuli seems to be comparable, although differences exist. For instance a refractory period is observed after exercise, but not after the inhalation of histamine. The exercise test has attractive aspects, such as the absence of the administration of a pharmacological agent. However, the degree of the bronchial challenge is not simple to control in exercise tests. Insufficient information is available about the reproducibility of both tests in 
the same persons. Therefore it is at present difficult to draw conclusions about the value of both tests in the determination of bronchial responsiveness.

Bronchial responsiveness can be regarded as a reflection of the integrated action of a number of factors inside and outside the bronchi, in which dysregulation may occur.

The following factors may be responsible for a hyper- instead of a normal responsiveness of the bronchi:

1. Differences in tone and contractibility of bronchial smooth muscle between persons with and without bronchial hyperresponsiveness. This cannot however account for the variability in the degree of bronchial responsiveness completely (see paragraphs 3.2.d and 4.4.2).

2. An increase in the sensitivity and accessibility of the sensory receptors as a result of a disturbed integrity of the bronchial mucosa. This can contribute beyond reasonable doubt to augmented reactions, at least in the case of bronchial inflammation, due to infection and toxic factors. However, infections outside the bronchial mucosa may also increase the bronchial responsiveness (see paragraphs $3.3,4.3 .3$ and 4.4.3).

3. Mediator releasing cells, i.e. mast cells and basophils may also contribute to exaggerated responses. This factor seems to be relevant in bronchial responsiveness as can be concluded from paragraphs $3.9,3.10,4.3 .9 / 10$ and 4.4.9/10. Our results (shown in paragraph 7.1 ), also suggest a role of mediator release from mast cells in bronchial responsiveness due to exercise. Based upon our observations that the releasability in patients with an increased bronchial responsiveness is greater than the that in patients without an increased bronchial responsiveness (paragraphs $7.3 \& 7.4$ ), it may be concluded that the releasability influences the degree of bronchial responsiveness. The variation in releasability cannot be explained by the degree of sensibilization to allergens.

4. The $\beta$-sympathetic system (see paragraphs $3.5,4.3 .5$ and 4.4.5). This is important in the counteraction of the smooth muscle contraction. It can be assumed that a hypofunction contributes to an increase in bronchial responsiveness. The $\beta$-sympathetic receptor function is essential in this respect. Recent studies indicate that diminished $\beta$-function can be the result of a decrease in the number of functional $\beta$-receptors, possibly due to a conversion of $\beta$ into $\alpha$-types. Sympathetic fibres are scarce in the bronchi. Therefore the adrenal output must be important in the activation of sympathetic receptors in the bron'chi in order to counteract obstruction. It is as yet not definitely established whether a diminished activity of the adrenal medulla is partly responsible for the occurrence of bronchial obstruction in patients with bronchial hyperresponsiveness. A recent study (Barnett et al. 1981) indicates that the catecholamines output of the adrenals is relatively low in subjects with, compared to those without, exerciseinduced bronchial obstruction. 


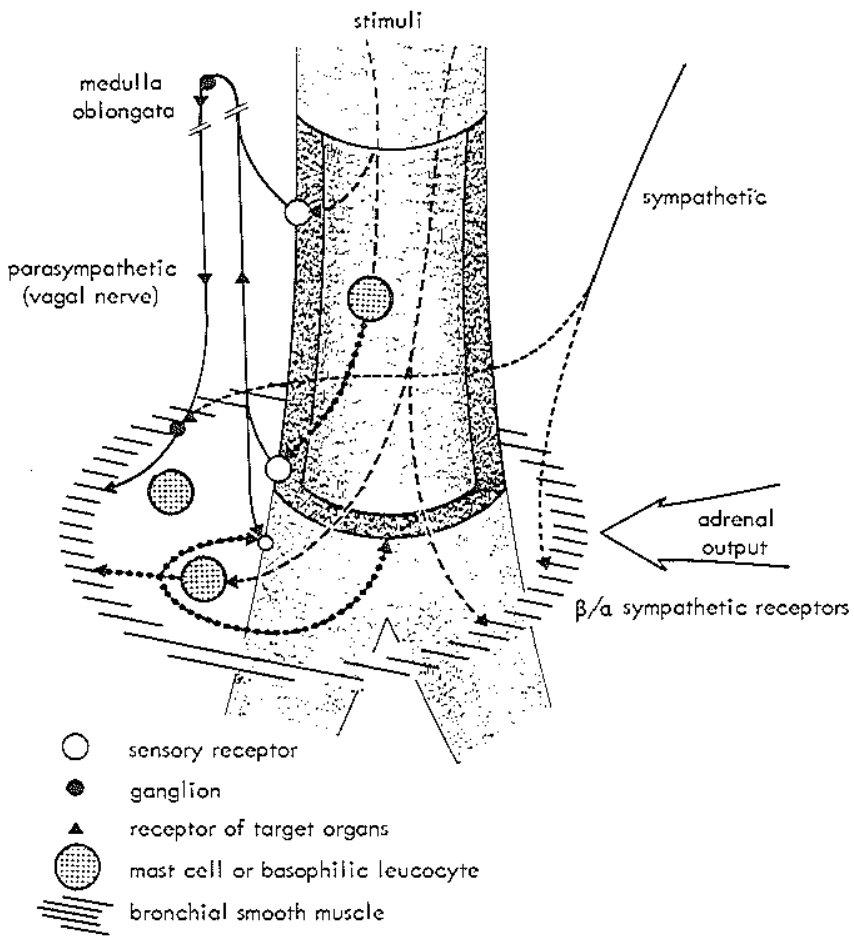

Figure 1. Schematic representation of the regulation of the bronchial diameter and the cooperation of various systems.

According to the evidence, presented in paragraphs 3.3, 3.4, 4.3 and 4.4, it is tempting to speculate that an increase in the parasympathetic reflex activity is more important than a deterioration of the $\beta$-sympathetic function during exacerbations due to exogenous factors. The change in the dose-response curve of the bronchial smooth muscle due to increase in parasympathetic activity is of a pre-synaptic type. The curve shifts towards lower doses of the agonist in a parallel way. This implies smooth muscle contraction after doses of stimuli which are without effect under normal circumstances (see figure 1, page 24).

5. Low initial values. These reflect a greatly diminished baseline bronchial diameter and may be correlated with a relatively strong bronchial responsiveness. However, several studies indicate that this relationship is rather weak and cannot explain in itself the phenomenon of increased bronchial responsiveness.

All these 5 factors may play a role in bronchial responsiveness in children. Probably their interrelationship varies with the circumstances. Little information is available about the variation in the degree of bronchial responsiveness and the rela- 
tive importance of the above mentioned factors with age. Insight into differences between bronchial responsiveness in children and adults has to wait until this information becomes available.

Although the occurrence of bronchial symptoms induced by allergens and other stimuli may influence the state and the reactions of the bronchi temporarily, bronchial hyperresponsiveness is predominantly a basic factor in asthma.

\section{Practical implications}

The degree of bronchial responsiveness in asthmatic patients can indicate the likelihood of the occurrence of symptoms. In some patients the bronchial responsiveness is permanently increased, while in others it may be variable or (sub)normal. Determination of the degree of bronchial responsiveness is particularly useful in the following groups:

a. Subjects with respiratory symptoms. The presence of bronchial hyperresponsiveness affords additional evidence for the diagnosis of asthma, besides other diagnostic information, such as the medical history and the presence of reversible bronchial obstruction.

b. Asthmatic patients (symptomatic). The frequency and severity of symptoms, which increases with the degree of bronchial responsiveness, can be assessed.

c. Asthmatic patients (asymptomatic). The residual risk of symptoms may be estimated.

Apart from diagnostic information, the degree of bronchial responsiveness may also have significance for the policy of the treatment. In asthmatic patients with a marked increased bronchial responsiveness special attention should be paid to the prevention of challenges and a sufficient protection by drug therapy.

\section{Additional studies and recommendations}

We recommend measurement of bronchial responsiveness in asthmatic patients at regular intervals. Further studies are needed to obtain more insight into the practical implications of and the influence of treatment on, bronchial responsiveness. Apart from studies in man, continuation of research in animals is also needed with respect to the pathophysiology of bronchial responsiveness, and the methods which influence it.

We believe that more studies may allow us to further elucidate determining factors between hyper- and normal bronchial responsiveness. The ultimate goal is to design methods which will convert hyper into normal responsiveness in a safe and effective manner. 


\section{Algemene discussie}

Op grond van de gegevens in dit proefschrift kunnen de volgende veronderstellingen en adviezen worden opgesteld. (zie ook figuur 1 in de General Discussion)

Behalve de directe aktivatie van het bronchiale gladde spierweefsel, kunnen de sensorische receptoren in combinatie met het parasympathische zenuwstelsel, alsmede het vrijkomen van mediatoren uit mestcellen en basofiele leucocyten bijdragen aan het ontstaan van bronchus obstructie. Hun onderlinge samenhang lijkt enigszins te verschillen; dit hangt af van de stimulus.

$\mathrm{Bij}$ bronchusobstructie door inademing van allergenen spelen de mestcellen, die zich zowel in het bronchuslumen als in de bronchuswand bevinden, een primaire rol. Hierna is het parasympatische systeem belangrijk bij de verspreiding en mogelijk ook bij de modulatie van de reactie over alle delen van de long.

Bij de bronchusobstructie na inspanning lijken zowel de mestcellen alswel het parasympatische zenuwstelsel te zijn betrokken. De bijdrage van elk verschilt van patiënt tot patiënt.

Bij de bronchusobstructie na inhalatie van histamine is de rol van de mestcellen minder duidelijk dan bij de reactie na allergenen of inspanning. Geïnhaleerd histamine werkt direct op de specifieke receptoren van de bronchiale gladde spieren, maar kan ook een parasympatische reflex induceren via sensorische receptoren in het slijmvlies. De bijdrage van elk van beide mechanismen hangt af van de histamine dosis, de plaats van depositie en de toestand van het bronchiale slijmvlies.

Hoewel grote verschillen bestaan in de aard van de stimuli, lijken de mechanismen waardoor zij bronchusobstructie veroorzaken in grote lijnen vergelijkbaar. Enige verschillen bestaan in de bronchiale reacties door enkele soorten stimuli bij patiënten met astma en bronchitis (Gökemeijer, 1976). Bronchiale prikkelbaarheid kan als een algemene bronchiale dysregulatie worden beschouwd, die relatief weinig afhangt van de soort van de stimulus. Bronchiale prikkelbaarheid is een uiting van de interaktie van een aantal faktoren in en buiten de longen die elk ontregeld kunnen zijn.

Oorspronkelijk zijn histamine en acetylcholine als niet-allergische of zogenaamde aspecifieke stimuli toegepast om de bronchiale prikkelbaarheid te meten. Een groeiend aantal andere stimuli is bekend geworden dat bronchiale obstructie kan veroorzaken bij de aanwezigheid van een toegenomen bronchiale prikkelbaarheid. Deze stimuli betreffen onder meer serotonine, bradykinine, prostaglandine $\mathrm{F}_{2 \alpha}$, propanolol, phenylefrine; fysische factoren zoals koolstof en mist, chemische agentia zoals zwaveloxide; geforceerde adembewegingen, inspanning, virale infecties en emoties (Horton e. a. 1978).

De bronchiale prikkelbaarheid voor het inademen voor histamine en voor inspanning zijn gecorreleerd. Dit suggereert dat een verwantschap bestaat tussen de bronchiale reactie na beide stimuli, hoewel ook verschillen aanwezig zijn (na bron- 
chusobstructie doorinspanning bestaat een refractaire periode die niet gezien wordt na bronchusobstructie door histamine-inhalatie). De inspanningstest heeft aantrekkelijke aspecten, zoals de afwezigheid van exogene pharmacologische stoffen. Het kwantificeren van de stimulus die uitgeoefend wordt op de luchtwegen is echter bij de inspanningstest moeilijk. Onvoldoende gegevens zijn beschikbaar omtrent de reproduceerbaarheid van beide testen bij dezelfde personen, zodat nog geen definitieve uitspraak kan worden gedaan over de waarden van deze testen.

De volgende factoren kunnen een aandeel leveren bij het ontstaan van versterkte reacties bij een toegenomen prikkelbaarheid:

1. Verschillen in tonus en contractiliteit van bronchiale glad spierweefsel tussen personen met en zonder toegenomen bronchiale prikkelbaarheid. Deze kunnen de variabiliteit in bronchiale prikkelbaarheid niet voldoende verklaren (zie de paragrafen 3.2.d en 4.4.2).

2. Toename in de gevoeligheid en de bereikbaarheid van de sensorische receptoren door verstoring van de integriteit van het bronchiale slijmvlies. Dit kan naar alle waarschijnlijkheid een verhoogde bronchiale prikkelbaarheid veroorzaken. Dit geldt vooral bij aangedaan slijmvlies door infecties en toxische factoren. Echter ook infecties buiten het bronchus slijmvlies kunnen de gevoeligheid van de sensorische receptoren en daarmee de bronchiale prikkelbaarheid verhogen (zie de paragrafen $3.3,4.3 .3$ en 4.4 .3 ).

3. De mate van vrijkomen van mediatoren uit mestcellen en basofiele leucocyten. Deze factor lijkt op grond van de gegevens in de paragrafen 3.9, 3.10, 4.3.9/10 en $4.4 .9 / 10$ van belang te zijn voor de mate van bronchiale prikkelbaarheid. Ook de resultaten van ons onderzoek, weergegeven in paragraaf 7.1 , wijzen op een rol van mestcellen bij bronchiale reacties na inspanning. Op grond van onze waarnemingen dat het vrijkomen van mediatoren bij patiënten met een toegenomen bronchiale prikkelbaarheid groter is dan bij diegenen met een normale bronchiale prikkelbaarheid (paragrafen 7.3 en 7.4 ), blijkt dat vrijkomen van mediatoren van belang kan zijn voor de sterkte van de bronchiale obstructie ten gevolge van diverse stimuli. De variatie in het vrijkomen van mediatoren kan niet worden verklaard uit de mate van sensibilisatie voor allergenen (zie appendices bij 7.1 en $7.3 \& 7.4$ ), zodat de aanwezigheid van allergie niet de bepalende factor hierbij is.

4. Het sympatische zenuwstelsel (zie paragrafen 3.5, 4.3.5 en 4.4.5). Dit is belangrijk bij de tegenregulatie van de contractie van het gladde spierweefsel en een verlaagde functie zal, naar mag worden aangenomen, bijdragen tot het vórkomen van toegenomen bronchiale prikkelbaarheid. De $\beta$-sympatische receptor functie is hierbij van essentiële betekenis. Recente studies wijzen op een vaak voorkomende vermindering van de $\beta$-sympatische functie bij Cara door een geringer aantal functionele receptoren. Dit zou kunnen ontstaan door omzetting van $\beta$ - in $\alpha$-receptoren, waardoor het effect na aktivatie tegengesteld wordt. Sympatische vezels zijn schaars in de bronchi. Het lijkt daarom waarschijnlijk dat de 
sympatische tegenregulatie van de bronchi voor een belangrijk deel via de circulerende catecholamines uit het bijniermerg plaatsvindt. Het is nog onzeker of een vermindering hiervan mede verantwoordelijk kan zijn voor een toegenomen bronchiale prikkelbaarheid, hoewel recent onderzoek hiervoor wel aanwijzingen geeft (Barnett e.a. 1981).

Tijdens perioden met verergering van het ziektebeeld door exogene factoren lijkt toename van de parasympatische reflex activiteit van meer belang dan afname van de $\beta$-sympatische functie, althans volgens de huidige inzichten (zie de paragrafen $3.3,3.4,4.3$ en 4.4 ). Onder deze omstandigheden ontstaat een verandering van de dosis-respons kurve van het bronchiale gladde spierweefsel van het pre-synaptische type. De kurve schuift op een parallelle wijze naar een lagere dosis van de agonist. Contractie van de bronchus musculatuur na histamine of andere stimuli treedt op na een dosis die geen of een veel lager effect heeft onder normale omstandigheden. (Zie figuur 1, bladzij 24).

5. Lage uitgangswaarden van de longfunctie, hetgeen een uitdrukking is van een sterk verminderde bronchiale diameter in rust, kan samengaan met relatief sterke bronchiale prikkelbaarheid. Verschillende studies tonen echter aan dat hun samenhang zwak is en geen verklaring vormt voor het fenomeen van verhoogde bronchiale prikkelbaarheid.

In het geval van toegenomen bronchiale prikkelbaarheid bij kinderen kunnen al deze 5 factoren een rol spelen. Hun onderlinge samenhang kan variëren. De veranderingen in de mate van bronchiale prikkelbaarheid met de leeftijd en de betrokkenheid van bovengenoemde factoren bij dit proces zijn nog weinig bestudeerd. $P$ as indien hierover voldoende informatie beschikbaar is, kunnen uitspraken worden gedaan omtrent de bronchiale prikkelbaarheid als functie van de leeftijd.

Hoewel het voorkomen van bronchiale symptomen door allergenen en andere stimuli de toestand en de reacties van de bronchi tijdelijk beinvloeden, lijkt een toegenomen bronchiale prikkelbaarheid bij Cara voornamelijk een zelfstandige factor te zijn.

\section{Praktische betekenis}

De mate van bronchiale prikkelbaarheid geeft een indruk over de kans op symptomen bij patiënten met Cara. De bronchiale prikkelbaarheid is bij een deel van de patiënten permanent verhoogd terwijl deze bij anderen normaal is of dicht bij die van gezonden ligt. Het meten van bronchiale prikkelbaarheid is vooral van belang voor de volgende groepen:

a. Personen met luchtwegsymptomen. De aanwezigheid van toegenomen bronchiale prikkelbaarheid steunt de diagnose Cara, naast andere diagnostische aanwijzingen zoals de anamnese en de aanwezigheid van reversibele bronchus- 
obstructie.

b. Patiënten met Cara. De mate van bronchiale prikkelbaarheid geeft een indruk over de kans op het optreden van symptomen.

c. Patiënten met Cara die sinds geruime tijd geheel of vrijwel geheel symptomenvrij zijn. De mate van bronchiale prikkelbaarheid geeft een indruk over de mate van verbetering en de potentiële kans op recidief.

De mate van bronchiale prikkelbaarheid heeft mogelijk ook betekenis voor het beleid bij de therapie. Bij patiënten met een sterk toegenomen bronchiale prikkelbaarheid is het wenselijk veel aandacht te geven aan het zoveel mogelijk voorkomen van confrontatie met stimuli en aan voldoende bescherming door medicamenten bij exacerbaties en zonodig in perioden met een verhoogde kans hierop.

\section{Aanvullende studies en aanbevelingen}

Aangeraden wordt bepaling van de bronchiale prikkelbaarheid regelmatig te verrichten bij patiënten met Cara. Verdere studies zijn nodig om meer inzicht te krijgen in de praktische betekenis en de beïnvloedbaarheid van bronchiale prikkelbaarheid. Naast studies bij mensen is ook laboratorium- en dierexperimenteel onderzoek nodig met betrekking tot de patho-fysiologie en de methoden ter beïnvloeding van de bronchiale prikkelbaarheid.

Wij geloven dat voortgezet onderzoek in staat zal zijn de factoren te ontrafelen die verantwoordelijk zijn voor een verhoogde in plaats van een normale bronchiale prikkelbaarheid. Het uiteindelijke doel is methoden te vinden die verhoogde prikkelbaarheid normaliseren op een veilige en effectieve wijze. 


\section{CHAPTER 10. SUMMARY}

The aim of this thesis was to review the present knowledge of and to report our own studies on bronchial responsiveness.

In Chapter I the motives and questions of the thesis are discussed. Also some remarks about definitions, methods and terminology are mentioned.

A historical view of the development of the study concerning bronchial re sponsiveness is given in chapter 2 . In chapter 3 attention is paid to the various factors which may modify the patency of the airways. These include bronchial smooth muscles, sensory receptors, parasympathetic and $\beta$ - and $\alpha$-sympathetic nervous systems, as well as release of mediators. The role of these factors in the bronchial responsiveness induced by histamine is analysed in chapter 4 . The methodology regarding the measurement of histamine-induced bronchial responsiveness is discussed. A concept of the mechanisms in bronchial obstruction based on results from animal studies is presented. This concept is compared with results of studies in humans and adapted in order to have a working hypothesis which enables a better understanding of the pathophysiology of bronchial responsiveness in humans. In chapter 5 these mechanisms are discussed with regard to bronchial responsiveness due to exercise.

Our studies are reported in chapter 6,7 and 8.

In paragraph 6.1 the relationship between the dose of inhaled histamine and the degree of bronchial obstruction is measured and analyzed with various methods. The dose-response relationship has a curvilinear pattern, i.e. a second degree polynomial, if the dose is plotted on a logarithmic scale.

The histamine threshold or the provocation dose is considered as the first criterion to quantify the dose-response relationship. It is defined as the histamine dose which causes a given change in $\mathrm{FEV}_{\mathrm{1}}$. Histamine thresholds, which are calculated according to various methods and criteria, correlate well, but differ in value. In our opinion a second degree regression equation is in general the optimal method for the analysis of the dose-response relationship and for the calculation of the provocation dose. A linear regression equation tends to give lower threshold values than a second degree regression equation. The step method, i.e. the method which defines the threshold as the lowest administered dose after which a given percentage change in $\mathrm{FEV}_{1}$ is reached, tends to reveal relatively high values with inevitably less accuracy. However, the step method is easy to apply and gives a fair estimate of the bronchial responsiveness.

The second criterion to quantify the dose-response relationship is the slope of the curve. The slope does not correlate with the threshold and its biological signi- 
ficance is as yet unclear. We have shown that the administration of doses of histamine per inhalation (aerosol) as a geometrical series with an interval of at least three minutes, has no accumulative effect up to the threshold dose.

The method of administration of the stimulus requires standardization. The choice of standardized techniques must be based upon reproducibility and simplicity in performance.

Chapter 7 contains studies of the mechanisms of bronchial responsiveness. Both inhaled histamine and exercise are used as stimuli for this purpose. The degree of bronchial obstruction after exercise correlates well with the histamine threshold. This similarity in responsiveness suggests that the causative mechanisms are comparable.

The study in paragraph 7.1 describes results of protection tests afforded by various agents on bronchial responsiveness due to exercise. The results suggest that exercise-induced bronchial obstruction is generated by mediator release from mast cells in combination with a parasympathetic reflex action. If the contribution of each factor is assessed by means of protection tests, it appears that the combination of their relative contribution approximates to the total bronchial obstructive effect after exercise in most of the patients. However, variability is observed between patients. The importance of the counteraction of the sympathetic nervous system is apparent from the protective effect of sympathomimetics in most patients. This indicates that the bronchial smooth muscle $\beta$-receptors are sufficiently functional in these patients. It seems probable that the sympathetic counteraction is neither sufficiently strong nor sufficiently rapid in the case of bronchial obstruction due to exercise.

In paragraph 7.2 the degree as well as the site of maximal flow-limitation with respect to time in exercise-induced bronchial obstruction is described. In nearly all patients bronchial obstruction shortly after exercise is determined by flow-limitation in the more peripheral airways. Then the bronchial obstruction gradually diminishes, while the site of maximal flow-limitation rapidly returns towards the central airways. The protective action of $\beta$-sympathomimetics was most pronounced in patients with a relative strong bronchial obstruction and peripherally located site of flow-limitation.

In paragraph 7.3 and 7.4 the relationship between the releasability of histamine from basophilic leucocytes and the bronchial responsiveness is described. The amount of histamine release after one hour incubation of $1 \mathrm{ml}$ leucocytes suspension without additional agents (spontaneous histamine release) is compared with both parameters of bronchial responsiveness in vivo, the histamine threshold and the degree of bronchial obstruction after exercise (paragraph 7.3). Paragraph 7.4 reports on a study in which the histamine release due to either increase of calcium influx (using the calcium ionophore A 23187), induction of microtubular aggregation (using deuterium oxide), or stimulation of the $\operatorname{IgE}$ receptor (using anti-IgE) is investigated. The results indicate that the degree of bronchial responsiveness and the releasability of leucocytes after calcium influx or stimulation of the microtubules are related. We conclude that the behaviour of the microtubules determines the 
releasability after calcium influx, as well as after stimulation of the $\operatorname{IgE}$ and probably other receptors.

Chapter 8 deals with the contribution of the bronchial responsiveness in the occurrence of bronchial obstruction after the inhalation of allergens and after exercise.

Paragraph 8.1 shows that the degree of bronchial responsiveness and the severity of the bronchial obstruction after exercise are associated.

Paragraph 8.2 shows that the severity of the bronchial obstruction after the inhalation of cat dander allergen is not only dependent on the degree of sensitization to the allergen, but also to the degree of the bronchial responsiveness to inhaled histamine.

In a further study (paragraph 8.3) it is shown that the bronchial reaction after the inhalation of an allergen switched from negative to positive in association with an increase in the bronchial responsiveness to histamine. The reverse, the fact that a decrease in the bronchial reaction after inhaling an allergen occurs in association with a decrease in the bronchial responsiveness, is also observed. 


\section{Samenvatting}

Het in dit proefschrift beschreven literatuuroverzicht en onderzoek zijn verricht met als doel inzicht te krijgen in een aantal aspecten van bronchiale prikkelbaarheid.

Hoofdstuk 1 beschrijft de motieven en de vraagstellingen van het onderzoek, terwijl ook enkele opmerkingen over definities, methoden en terminologie zijn gemaakt.

In hoofdstuk 2 is in grote lijnen de ontwikkeling in het verleden van het onderzoek naar bronchiale prikkelbaarheid weergegeven.

In het literatuuroverzicht is aandacht besteed aan diverse factoren die de doorgankelijkheid van de luchtwegen bepalen, zoals het gladde spierweefsel, de sensorische receptoren, het parasympatische, het $\beta$ - en $\alpha$-sympatische zenuwstelsel, alsmede het vrijkomen van mediatoren (hoofdstuk 3 ). In hoofdstuk 4 is een overzicht gegeven van de literatuur met betrekking tot de bronchiale prikkelbaarheid voor histamine en in hoofdstuk 5 met betrekking tot inspanning. Hierbij is uitvoerig aandacht besteed aan de meetmethoden bij onderzoek naar reacties op beide stimuli. Geprobeerd is vanuit literatuurgegevens over onderzoek bij dieren en mensen een beeld te verkrijgen van de pathofysiologie van de bronchiale prikkelbaarheid.

Het eigen onderzoek is vermeld in de hoofdstukken 6,7 en 8 .

In hoofdstuk 6.1 is de relatie tussen de dosis geïnhaleerde histamine en de bronchiale respons beschreven alsmede verschillende berekeningsmethoden, waar* mee deze kan worden gekwantificeerd. De dosis-response relatie is op een semilogarithmische schaal curvilineair, d.w.z. kan beschreven worden met een tweede machts polynoom, indien de dosis op een logarithmische schaal is uitgezet.

Als eerste karakteristiek is de drempelwaarde of de provocatie dosis bestu+ deerd. Hieronder wordt de histamine concentratie verstaan, na welke een bepaalde mate van daling van het expiratoire 1 seconde volume $\left(\mathrm{FEV}_{1}\right)$ optreedt, Drempelwaarden die zijn berekend met verschillende analysemethoden en volgens verschillende criteria, hangen in hoge mate samen, maar verschillen in absolute zin. De beste benadering is in het algemeen vanuit een kwadratische analyse van de dosisrespons relatie. Een lineaire analyse leidt tot systematisch lagere en de veel gebruikte stapmethode, waarbij de drempel de toegediende histamine concentratie is waarna een significante daling van het $\mathrm{FEV}_{1}$ optreedt, tot systematisch hogere waarden. Op grond van de geringe verschillen en de hoge correlatie tussen de uitkomsten van de verschillende analysemethoden, lijken de verschillen tussen deze methoden geen grote biologische betekenis te hebben.

Als tweede karakteristiek van de dosis-respons relatie wordt de helling van de curve beschouwd. Tussen deze en de histaminedrempel bestaat geen verband. De biologische betekenis van de helling is nog onduidelijk. Bij de toegepaste procedure, waarbij histamine in oplopende concentraties met intervallen van 3 minuten wordt 
toegediend tot aan de drempel, treedt geen cumulatie op. Bij hogere concentraties moet hiermee in principe wel rekening worden gehouden.

De kennis omtrent de invloed van variabelen bij toediening van stimuli per aerosol is nog lacunair, doch het is duidelijk dat standaardisatie nodig zal zijn teneinde vergelijkbare resultaten te verkrijgen. Praktische uitvoerbaarheid en een zo goed mogelijke reproduceerbaarheid van elk onderdeel van de methodiek zijn belangrijke voorwaarden voor de keuze van de gestandaardiseerde bepalingswijze van de bronchiale prikkelbaarheid.

Bij de onderzoekingen naar de mechanismen die een rol spelen bij de prikkelbaarheid zijn inspanning en inhalatie van histamine als stimuli toegepast. De sterkte van de bronchusobstructie na inspanning is in hoge mate gecorreleerd met de histamine provocatiedosis (hoofdstuk 7.1 en 7.3). Dit suggereert dat de er aan ten grondslag liggende mechanismen in belangrijke mate overeenkomen.

In hoofdstuk 7.1 is het onderzoek beschreven waarin deze ten aanzien van inspanning zijn bestudeerd. Hierbij is gebruik gemaakt van medicamenteuze blokkering en stimulatie. Bronchusobstructie door inspanning ontstaat waarschijnlijk via een vagus reflex in combinatie met activatie van mestcellen. Hoewel het effect van remming van elke factor afzonderlijk van patiënt tot patiënt varieert, komt de som van beide remmingseffecten vaak ongeveer overeen met een volledige bescherming.

Algemeen wordt aangenomen dat het sympatische systeem een belangrijke rol speelt bij de regulatie van de tonus van het bronchiale gladde spierweefsel, en wel des te meer naarmate bronchusobstructie toeneemt. Uit het feit dat toediening van een sympathicomimeticum meestal volledig beschermt tegen bronchusobstructie door inspanning, hebben wij geconcludeerd dat de gevoeligheid van het eindorgaan voor sympatische prikkeling voldoende is. Het lijkt daarom waarschijnlijk dat de sympatische tegenregulatie (circulerende catecholaminen, sympatische innervatie) bij patiënten met bronchusobstructie na inspanning niet adequaat is.

In hoofdstuk 6.2 is het onderzoek naar het verloop van de sterkte van de bronchusobstructie en de plaats van de maximale stroomsnelheid-limitering bij inspanning beschreven. Kort na inspanning schuift deze plaats in de richting van de longblaasjes op en wel des te meer naarmate de bronchusobstructie sterker is. Daarna vermindert de bronchusobstructie langzaam terwijl de plaats van de maximale stroomsnelheidlimitering snel naar de centrale luchtwegen teruggaat. Het beschermend effect door stimulatie van $\beta$-sympatische receptoren is het meest uitgesproken bij patiënten met een sterke bronchusobstructie bij wie de plaats van de maximale stroomsnelheid-limitering ver naar de longblaasjes is verschoven.

In de hoofdstukken 7.3 en 7.4 is de samenhang beschreven tussen prikkelbaarheid op celniveau in vitro, met name van leucocyten, en de bronchiale prikkelbaarheid. Uit een eerste studie hierover (hoofdstuk 7.3) blijkt dat de spontane histamine release uit leucocyten gemiddeld hoger is bij Cara patiënten met een toegenomen bronchiale prikkelbaarheid voor histamine en inspanning dan bij personen met een lage bronchiale prikkelbaarheid. 
In hoofdstuk 7.4 zijn de resultaten besproken van voortgezet onderzoek naar de prikkelbaarheid van leucocyten. Bestudeerd zijn het vrijkomen van histamine na stimulering van de calciuminflux (met de calciumionofoor A 23187), na aktivering van de microtubuli (met deuterium oxide) en de IgE-receptor (met anti-IgE). De uitkomsten wijzen erop dat de prikkelbaarheid van de basofiele leucocyten, waarbij het vrijkomen van histamine de indicator is en de mate van bronchiale prikkelbaarheid correleren. Wij hebben geconcludeerd dat het gedrag van de microtubuli in belangrijke mate de prikkelbaarheid van basofiele leucocyten, zowel na nietallergene als na allergene prikkels, bepaalt.

In de derde groep studies is de correlatie tussen de mate van bronchiale prikkelbaarheid en de bronchiale reactie door enkele stimuli onderzocht. In hoofdstuk 8.1 zijn die gegevens uit de hoofdstukken 7.1 en 7.3 gegroepeerd welke de samenhang beschrijven tussen de mate van bronchiale prikkelbaarheid en de sterkte van de bronchusobstructie door inspanning. Naarmate de bronchiale prikkelbaarheid voor histamine toeneemt, is de sterkte van de bronchusobstructie na inspanning groter.

Bij het ontstaan van bronchusobstructie na inhalatie van kattehuidschilferallergeen is een toegenomen bronchiale prikkelbaarheid van essentieel belang naast de allergeen sensibilisatie (hoofdstuk 8.2).

In hoofdstuk 8.3 wordt aangetoond dat een toename in sterkte van de bronchiale prikkelbaarheid en van de bronchiale reactie na allergeeninhalatie samengaan en omgekeerd. Hieruit blijkt dat de bronchiale prikkelbaarheid niet alleen van essentieel belang is voor het reactiepatroon na allergeeninhalatie en waarschijnlijk ook van diverse andere prikkels, maar tevens kan verklaren waarom bepaalde patiënten soms wel en soms niet op prikkels reageren. 
1. ADOLPHSON R L. ABERN S B, TOWNLEY R G. Human and guinea pig respiratory muscle. J Allergy 1971; $77: 110-111$.

2. AHLQUIST R P. A study of the adrenotropic receptors. Am J Physiol 1948: 153: 586600 .

3. AHMED T. EXRE P. JANUSZKIEWICZ A J. WANNER A. Role of $\mathrm{H}_{1}$ and $\mathrm{H}_{2}$ receptors in airways reactions to histamine in conscious sheep. $J$ Appl Physiol 1980; 49:826-833.

4. ALEXANDER H L. PADDOCK R. Bronchial asthma: response to pilocarpine and epinephrine. Arch Intern Med 192 I : 27: 184-191.

5. ALLEN D H. MATHISON D A. WAGNER P D. ARROYAVE C M. PLOW E, TAN E M. Mediator release during methacholine-induced bronchoconstriction in asthmatic patients. J Allergy Clin Immunol 1978:61: 140 (abstract).

6. ALLISON D J, CLAY T P. HUDGES J M B. JONES H A, SHEVIS A. Effects of nasal stimulation on total respiratory resistance in the rabbit. J Physiol (Lond.) 1974: 239: 23-24.

7. AMERICAN THORACIC SOCIETY. Chronic bronchitis, asthma and pulmonary emphvsema. A statement by the committee on diagnostic standards for nontuberculosis respiratory diseases. Am Rev Respir Dis 1962: $85: 762-768$.

8. AMERICAN THORACIC SOCIETY NEWS. Guidelines for bronchial inhalation challenges with pharmacologic and antigenic agents 1980; spring: 11-19.

9. ANDERSON S D. CONNOLLY N M. GODFREY S. Comparison of bronchoconstriction induced by cycling and running. Thorax 1971:26:396-401.

10. ANDERSON S D, SILVERMAN M, WALKER S R. Metabolic and ventilatory changes in asthmatic patients during and after exercise. Thorax 1972: 27: 718-725.

I1. ANDERSON S D. MC EVOY J D S. BIANCO S. Changes in lung volumes and airway resistance after exercise in asthmatic subjects. Am Rev Respir Dis 1972: 106: 30-37.

12. ANDERSON S D. SILVERMAN M. KONIG P, GODFREY S. Exercise-induced asthma - a review. Br J Dis Chest 1975:69:1-38.

13. ANDERTON R C, CUFF M T, FRITH P A, COCKCROFT D W. MORSE J L C. JONES N L. HARGREAVE F E. Bronchial responsiveness to inhaled histamine and exercisc. J Allergy Clin Immunol 1979;63:315-320.

14. ANKIN M G.. PETERMAN V I. FISH $\mathfrak{J}$ E. Effects of lung inflation on maximum flow responses to methacholine and antigen in hay fever and asthma subjects. Am Rev Respir Dis 1979: 119: (supplement 2): 55.

15. APOLD J, AKSNES L. Correlation between increased bronchial responsiveness to histamine and diminished plasma cyclic adenosine monophosphate response after epinephrine in asthmatic children. J Allergy Clin Immunol 1977:59:343-347.

16. ARMSTRONG D J, LUCK J G. A comparative study on irritant and type $\mathbf{J}$ receptors in the cat. Respir Physiol 1974:21:47-60.

17. ATKINS P C. ROSENBLUM F. DUNSKY E H. COFFEY R. ZWEIMAN B. Comparison of plasma histamine and cyclic nucleotides after antigen and methacholine inhalation in man. J Allergy Clin Immunol 1980:66:478-485.

18. AUSTEN K F. Chemical mediators originating from human mast cells: a commentary. Clin Allergy 1980; 10 (suppl.): 477-479.

19. BANDO T, SHINDO N, SHIMO Y. Non-adrenergic inhibitory nerves in tracheal smooth muscle of guinea pig. Jpn J Physiol 1973: 35: 508-509.

* Except those of chapters 6.7 and 8 which are mentioned at the bottom of each paragraph. 
20. BARNES P J, BROWN J M. SILVERMAN M, DOLLERY C T. Circulating catecholamines in exercise and hyperventilation induced asthma. Thorax 1981:36:435-440.

21. BARNETT D B, CHESROWN S E, ZBINDEN A F. NISAM M, REED B R, BOURNE H R. MELMON K L. GOLD W M. Cyclic AMP and cyclic GMP in canine peripheral lung: regulation in vivo. Am Rev Respir Dis 1978: 118: 723-733.

22. BAR-OR O. NEUMAN I, DOTAN R. Effects of dry and humid climates on exerciseinduced asthma in children and preadolescents. J Allergy Clin Immunol 1977;60:163-168.

23. BARTER C E. CAMPBELL A H. Relationship of constitutional factors and cigarette smoking to decrease in I-second forced expiratory volume. Am Rev Respir Dis 1976; 113: 305-314.

24. BARTLETT D \& SANT AMBROGIO G. Effects of local and systemic hypercapnia on the discharge of stretch receptors in the airways of the dog. Respir Physiol 1976:26: 91-99.

25. BEIL M. DeKOCK M A. Role of alpha-adrenergic receptors in exercise-induced bronchoconstriction. Respiration 1978:351: 78-86.

26. BEAVEN, M A. Histamine. N Engl J Med 1976: 294: 30-36. 320-325.

27. BELMAN M J, MITTMAN C. Ventilatory muscle training improves exercise capacity in chronic obstructive pulmonary disease patients. Am Rev Respir Dis 1980: 121:273-280.

28. BHAT N K, ARROYAVE C M, MARNEY S R. STEVENSON D D, TAN E M. Plasma histamine changes during provoked bronchospasm in asthmatic patients. J Allergy Clin Immunol 1976: $58: 647-656$.

29. BIANCO S. GRIFFIN J P. KAMBUROFF P C, PRIME F J. Prevention of exerciseinduced asthma by Indoramin. Br Med J 1974: 4: 18-20.

30. BIERMAN C W. KAWABORI I. PIERSON W E. Incidence of exercise-induced asthma in children. Pediatrics 1975a: 56 (suppl.): 847-850.

31. BIERMAN C W. PIERSON W E. SHAPIRO G G. Exercise-induced asthma. Pharmacological assessment of single drugs and drug combinations. JAMA. 1975b: 234: 295-298.

32. BLACK J W, DUNCAN W A M. DURANT C J, GANELLIN C R. PARSONS E M. Definition and antagonism of histamine $\mathrm{H}_{2}$ receptors. Nature $1972 ; 236: 385-390$.

37. BOATMAN E S, SATO S, FRANK R. Acute effects of ozone on cat lungs. Am Rev Respi- Dis 1974; 110: 157-169.

34. BOOIJ-NOORD H. ORIE N G M. DE VRIES K. Serotonin (5-hydroxytryptamine) inhalation in patients with chronic non-specific lung disease. Scand J Respir Dis 1969a: 50: $301-308$.

35. BOOIJ-NOORD H. GROBLER N J. ORIE N G M, DE VRIES K. Protective action of various drugs on provocation tests with respiratory irritants in patients with chronic nonspecific lung disease (CNSLD). Respiration 1969b; 26: 182-195.

36. BOUCHER R C. PARC P D, GILMORE N J, MOROZ L A, HOGG J C. Airways mucosal permeability in the ascaris serum-sensitive rhesus monkey. $J$ Allergy Clin Immunol 1977:60: 134-146.

37. BOUCHER R C. RANGE V, PARÉ P D, INOUE S. MOROZ L A, HOGG J C. Effect of histamine and methacholine on guinea pig tracheal permeability to HRP. J Appl Physiol 1978: 45: 939-948.

38. BOUHUYS A. DOUGLAS J S. GUYAFF A R. Pharmacological modifications of histamine mediated airway response. J Clin Invest 1971:50: $9 \mathrm{a}$.

39. BOUSHEY H A, RICHARDSON P S. WIDDICOMBE $J$ G, WISE J C $M$. The response of laryngeal afferent fibres to mechanical and chemical stimuli. J Physiol (Lond) 1974: 240: 153-175. 
40. BOUSHEY H A. HOLTZMAN M J. SHELLER J R, NADEL J A. Bronchial hyperreactivity (State of the art). Am Rev Respir Dis 1980: 121: 389-413.

41. BRAIN J D, VALBERG P A. Deposition of aerosol in the respiratory tract. Am Rev Respir Dis 1979: /20: 1325-1373.

42. BRINKMAN $G$ L. The mast cell in normal human bronchus and lung. J Ultrastruct Res 1968: 23: 115-123.

43. BROOKS S M. Mc GOWAN K, BERNSTEIN I L, ABTENAU P, PEAGLER J. Relationship between numbers of beta-adrenergic receptors in lymphocytes and disease severity in asthma. J Allergy Clin Immunol 1979:63: 401-406.

44. BRUYNZEEL P L B, VAN DEN BERG W, HAMELINK M L, VAN DEN BOGAARD W. HOUBEN L A M J. KREUKNIET J. Desensitisation of the $\beta$-adrenergic receptor on leucocytes after long-term oral use of a $\beta$-sympathicomimetic: its effect on the $\beta$-adrenergic blockade hypothesis of szentivanyi. Ann Allergy 1979; 43: 105-109.

45. BRYANT D H. BURNS $M$ W. The relationship between bronchial histamine reactivity and atopic status. Clin Allergy 1976:6:373-381.

46. BURNSTOCK C. COSTA M. Inhibitory innervation of the gut. Gastroenterology 1973;64: 141-144.

47. BUSSE W W, LEE T P. Decreased adrenergic responses in lymphocytes and granulocytes in atopic eczema. J Allergy Clin Immunol 1976: 58:586-596.

48. BUSSE W W, SOSMAN J. Decreased $\mathrm{H}_{2}$ histamine response of granulocytes of asthmatic patients. J Clin Invest 1977:59:1080-1087.

49. BUSSE W W, ANDERSON S L. DICK E C. WARSHAUWER D. Reduced granulocyte response to isoproterenol, histamine and prostaglandine $\mathrm{E}$, after in vitro incubation with rhinovirus 16. Am Rev Respir Dis 1980; 122: 641-646.

50. CADE J F, PAIN M C F. Bronchial reactivity: its measurement and clinical significance. Aust N Z J Med 1971: 1: 22-25.

51. CALCUTT C R. The role of histamine in the brain. Gen Pharmac 1976: 7:15-25.

52. CASTERLINE C L. EVANS R. WARD JR, G W. The effects of atropine and albuturol aerosols on the human bronchial respons to histamine. J Allergy Clin Immunol 1976: 58: 607-613.

53. CASTERLINE C L. EVANS R. Further studies on the mechanism of human histamine induced asthma. J Allergy Clin Immunol 1979:59:420-424.

54. CASTRO DE LA MATA R, PENNA M, CEVIADO D M. Reversal of sympathomimetic bronchodilation by dichloroisoproterenol. J Pharmacol Exp Ther 1962; 135: 197-203.

55. CHAI H. FARR R S. FREUNLICH L A et al. Standardization of bronchial inhalation challenge procedures. J Allergy Clin Immunol 1975:56:323-327.

56. CHAI H. Antigen and methacholine challenge in children with asthma. J Allergy Clin Immunol 1976:64:575-579.

57. CHAND N. DHAWAN B N, SRIMAL R C. RHAMANI $N H$, SHUKLA $R \quad K$. A.LTUMA B M. Reactivity of trachea, bronchi and lung strips to histamine and carbachol in rhesus monkeys. J Appl Physiol 1980a: 49: 729-734.

58. CHAND N. Is airway hyperreactivity in asthma due to histamine $\mathrm{H}_{2}$ receptor deficiency. Med Hypotheses 1980:6:1105-1112.

59. CHAN-YEUNG M M W. VYAS M N, GRZYBOWSKI S. Exercise-induced asthma. Am Rev Respir Dis 1971: 104: 915-923.

60. CHAN YEUNG M M W. The effect of Sch 1000 and Disodium cromoglycate on exerciseinduced asthma. Chest 1977: 71:320-323. 
61. CHARLES T J, HARTLEY J P R. SEATON A. TAYLOR W H, WESTWOOD A. Arterial histamine in exercise-induced asthma. Clin Sci 1979;56:8p-9p.

62. CHEN W Y. HORTON D J. Heat and water loss from the airways and exercise-induced asthma. Respiration 1977:34: 305-313.

63. CHRYSSANTHOPOULOS $\mathrm{C}$, BRUNS $\mathrm{W}$ T, MAKSUD $M$ G. GALLEN W J, HAUSE L L. Quantitative effect of theophylline anhydrous on exercise-induced asthma after maximal physical effort. Ann Allergy 1979a: 42: 355-361.

64. CHRYSSANTHOPOULOS C, MAKSUD M G, FUNAHOSHI A, HOFFMANN R G. BARBORIAK J J. An assessment of cardiorespiratory adjustments of asthmatic adults to exercise. J Allergy Clin Immunol 1979b:63: 321-327.

65. COBURN R F. TOMITA T. Evidence for non-adrenergic inhibition nerves in the guinea pig trachealis muscle. Am J Physiol 1973: 224: 1072-1080.

66. COCKCROFT D W, KILLIAN D N. MELLON J J A. HARGREAVE F E. Bronchial reactivity to inhaled histamine: a method and clinical survey. Clin Allergy 1977a; 7: 235-243.

67. COCKCROFT D W. KILLIAN D N, MELLON J J A: HARGREAVE F E. Protective effect of drugs on histamine-induced asthma. Thorax I977b: 32: 429-437.

68. COCKCROFT D W, RUFFIN R E. DOLOVICH J, HARGREAVE F E. Allergeninduced increase in non-allergic bronchial reactivity. Clin Allergy 1977c; 7: 503-513.

69. COCKCROFT D W, COTTON D J, MINK J T. Non-specific bronchial hyperreactivity after exposure to western red cedar. Am Rev Respir Dis 1979a: 1/9:505-510.

70. COCKCROFT D W. RUFFIN R E. FRITH P A et al. Determinants of allergen-induced asthma: dose of allergen. circulating $\operatorname{IgE}$ antibody concentration and bronchial responsiveness to inhaled histamine. Am Rev Respir Dis 1979b: /20: 1053-1058.

71. COCKSON D U, REED C E. A comparison of the effects of isoproterenol in the normal and asthmatic subject. Am Rev Respir Dis 1963:88: 636-643.

72. COLEBATCH H J H. HALMAGYI D F J. Effect of vagotomy and vagal stimulation on lung mechanics and circulation. J Appl Physiol 1963: 18:881-887.

73. COLEBATCH H J H. ENGEL L A. Constriction of the lung by histamine before and after adrenalectomy in cats. $J$ Appl Physiol 1974; 37: 798-805.

74. COLEMAN R A, LEVY G P. Non-adrenergic inhibitory nervous pathway in guinea pig trachea. Br J Pharmacol 1974: 52: 167-174.

75. COLERIDGE H M. COLERIDGE J C G, GINZEL K H, BAKER D G. BANZETT R B. MORRISON M A. Stimulation of "irritant" receptors and afferent C-fibres in the lung by prostaglandins. Nature 1976:264: 451-453.

76. COLERIDGE H M, COLERIDGE J C G. Impulse activity in afferent vagal $\mathrm{C}$ fibres with endings in the intrapulmonary airways of dogs. Respir Physiol 1977: 29: 125-142.

77. COLERIDGE H M, COLERIDGE J C G, BANZETT $R$ B. Effects of $\mathrm{CO}_{2}$ on afferent vagal endings in the canine lung. Respir Physiol 1978; 34: I35-15I.

78. COLTEN H R. GABBAY K H. Histamine release from human leucocytes: modulation by a cytochalasin B-sensitive barrier. J Clin Invest 1972:51: 1927-1931.

79. CONOLLY M E, GREENACRE J K. The lymphocyte $\beta$-adrenoreceptor in normal subjects and patients with bronchial asthma. J Clin Invest 1976;58:1307-1316.

80. CORSSEN G. ALLEN C R. Acetylcholine: its significance in controlling ciliary activity of human respiratory epithelium in vitro. J Appi Physiol 1959; 14: 901-904.

81. COX J S G. ALTOUNYAN R E C. Nature and mode of action of disodium cromoglycate (Lomudal). Respiration 1970:27:292-309. 
82. CREMA A. DEL TACCA M, FRIGO G M. LECHINI S. Presence of a non-adrenergic inhibitory system in the human colon. Gut 1968:9:633-637.

83. CROPP G J A. The role of the parasympathetic nervous system in the maintenance of chronic airway obstruction in asthmatic children. Am Rev Respir Dis 1975a: 112: 599-605.

84. CROPP G J A. Relative sensitivity of different pulmonary function tests in the evaluation of exercise-induced asthma. Pediatrics 1975b: 56 (suppl): 860-867.

85. CROSS B A. GUZ A. JAIN S K, ARCHER S, STEVENS J, REYNOLDS $F$. The effect of anaesthesia of the airways in dog and man: a study of respiratory reflexes. sensations and lung mechanics. Clin Sci 1976:50:439-454.

86. CURRY J J. The action of histamine on the respiratory tract in normal and asthmatic subjects. J Clin Invest 1946; 25: 785-791.

87. CUTZ E. CHAN W, WONG V, CONEN P E. Ultra structure and fluorescence histochemistry of endocrine (APUD type) cells in trachea mucosa of human and various animal species. Cell Tissue Res 1975; 158: 425-437.

88. CUTZ E. ORANGE R P. Mast cells and Endocrine (APUD) cells of the lung. In: Lichtenstein L M, Austen K F eds Asthma physiology, immunopharmacology and treatment. Second International symposium. Academic Press. New York 1977: $51-76$.

89. DAEMS W Th. QUANJER P. REERINK-BRONGERS E E, eds. The mast cell in relation to allergic mechanisms. Leusden, 1977.

90. DAUTREBANDE L. PHILLIPPOT E. Crise d'asthma expérimental par aerosols de carbaminoylcholine chez I'homme traite par dispersat de phenylaminopropane. La presse medicale 194 I: 76-77:942-946.

91. DAIN D S. BOUSHEY H A. GOLD W M. Inhibition of respiratory reflex by local anesthetic aerosols in dogs and rabbits. J Appl Physiol 1975; 38: 1045-1050.

92. DAVIES C T M, BARNES C. GODFREY S. Body composition and maximal exercise performance in children. Hum Biol 1972: 44: 195-214.

93. DAVIES S E. Effect of disodium cromoglycate on exercise-induced asthma. Br Med J I968; 3:593-594.

94. DAVIS P B, SHELHAMER J R. KALINER M. Abnormal adrenergic and cholinergic sensitivity in cystic fibrosis. New Engl J Med 1980; 302; 1453-1456.

95. DEAL JR E C. Mc FADDEN JR E R. INGRAM JR R H. JAEGER J J. Effects of atropine on potentiation of exercise-induced bronchospasm by cold air. J Appl Physiol 1978: 45: $238-243$.

96. DEAL JR E C, Mc FADDEN JR E R, INGRAM JR R H, JAEGER J J. Hyperpnoea and heat flux: initial reaction sequence in exercise-induced asthma. $J$ Appl Physiol 1979a: 46:476-483.

97. DEAL JR E C. MC FADDEN JR E R. INGRAM JR R H. STRAUS R H. JAEGER $\mathrm{J} J$. Role of respiratory heat exchange in production of exercise-induced asthma. J Appl Physiol 1979b: 46:467-475.

98. DEAL JR E C, MC FADDEN JR E R, INGRAM JR R H. BRESLIN F J, JAEGER $J \mathrm{~J}$. Airway responsiveness to cold air and hyperpnoea in normal subjects and in those with hay fever and asthma. Am Rev Respir Dis 1980: 121: 621-628.

99. DeKOCK M A. Mechanism of bronchial obstruction in man. In: Orie N G M, van de Lende R eds. Bronchitis III International Symposium on chronic bronchitis. Assen. Royal van Gorcum 1970: 300-315.

I00. DIAMOND J M. Channels in epithelial membranes and junctions. Fed Proc 1978: 37: 2639-2644. 
101. DIAMOND L. Potentiation of bronchomotor responses by beta adrenergic antagonists. J Pharmacol Exp Ther 1972; 181: 434-445.

102. DIXON M, JACKSON D M, RICHARDS I M. The effects of histamine, acetylcholine and 5-hydroxytryptamine on lung mechanics and irritant receptors in the dog. J Physiol (Lond) $1979 \mathrm{a} ; 287: 393-403$.

103. DIXON M. JACKSON D M. RICHARDS I M. The effects of $\mathrm{H}_{1}-$ and $\mathrm{H}_{2}$ receptor agonists and antagonists on total lung resistance. dynamic lung compliance and irritant receptor discharge in the anaesthetized dog. $\mathrm{Br} J$ Pharmacol 1979b:66:203-209.

104. DIXON M. JACKSON D M. RICHARDS I M. The effect of a respiratory tract infection on histamine induced changes in lung mechanics and irritant receptor discharge in dogs. Am Rev Respir Dis 1979c: 120:843-848.

105. DIXON M. JACKSON D M, RICHARDS I M. The effects of sodium cromoglycate on fung irritant receptors and left ventricular cardiac receptors in the anaesthetized $\operatorname{dog} . \mathrm{Br} J$ Pharmacol I979d:67:569-574.

106. DIXON M. JACKSON D M. RICHARDS I M. The effect of 5-hydroxytryptamine. histamine and acetylcholine on the reactivity of the lung of the anaesthetized dog. J Physiol (Lond) 1980a: 307:85-96.

107. DIXON M. JACKSON D M. RICHARDS I M. The action of sodium cromoglycate on $C$ fibre endings in the dog lung. Br J Pharmacol 1980b; 70: $11-13$.

108. DRAZEN J M. AUSTEN K F. Atropine modification of the pulmonary effects of chemical mediators in the guinea pig. J Appl Physiol 1975; 38:834-838.

109. DOUGLAS J S. LEWES A J. OREHEK J. BOUHUYS A. Histamine responses of guinea pig airways in vivo and in vitro. $\mathrm{J}$ Clin Invest 1973a: 52: 24a.

110. DOUGLAS J S. DENNIS $M$ W, RIDGWAY P. BOUHUYS A. Airway constriction in guinea pigs: interaction of histamine and autonomic drugs. J Pharmacol Exo Ther 1973b; 184:169-179.

111. DRAZEN J M. Adrenergic influences on histamine-mediated bronchoconstriction in the guinea pig. J Appl Physiol 1978: 44: 340-345.

112. DRAZEN J M. LEWIS R A, WASSERMAN S I, ORANGE R P. AUSTEN K F. Differential effects of a partially purified preparation of slow-reacting substance of anaphylaxis on guinea pig tracheal spirals and parenchymal strips. J Clin Invest 1979:63:1-5.

113. DUNLOP L S, SMITH A T. The effect of histamine antagonists on antigen-induced contraction of sensitized human bronchus in vitro. Br J Pharmacol 1977;59:475 p.

114. EASTON R E. MURPHY S D. Experimental ozone preexposure and histamine. Arch Environ Health 1967;15:160-166.

115. EDMUNDS A T. TOOLEY M. GODFREY S. The refractory period after exercise-induced asthma, its duration and relation to the severity of exercise. Am Rev Respir Dis 1978: 117: 247.254 .

116. EGGLESTON P A, GUERRANT J L. A standardized method of evaluating exerciseinduced asthma. J Allergy Clin Immunol 1976:58: 414-425.

117. EGGLESTON P A. A comparison of the asthmatic response to methacholine and exercise. J Allergy Clin Immunol 1979:63:104-1 10.

118. EDITORIAL (HARTLEY J P R). Exercise-induced asthma. Thorax 1979:34:571-574.

119. EISER N M. GUZ A. SNASHALL P D. The effect of $H_{1}$ and $H_{2}$ receptors antagonist on bronchial dose-response curves to histamine in normal subjects. Clin Sci 1978:54: 10p-1 1p.

120. EL-BERMANI A W, GRANT M. Acetylcholinesterase-positive nerves of the rhesus monkey bronchial tree. Thorax 1975:30:162-170. 
121. EL-BERMANI A W. Pulmonary nonadrenergic innervation of the rat and monkey. A comparative study. Thorax 1978; 33: 167-174.

122. EMPEY D W, LAITINEN L A, JACOBS L. GOLD W M, NADEL J A. Mechanisms of bronchial hypersensitivity in normal subjects after upper respiratory tract infections. Am Rev Respir Dis 1976: 113: 131-139.

123. EXRE P. The pharmacology of sheep tracheo-bronchial muscle. A relaxant effect of histamine on the isolated bronchi. Br J Pharmacol 1969;36: 409-417.

124. FALliERS $C \mathrm{~J}$, CARDOSO $R$ R de, BANE $H$ N, COFFEY $R$, MIDDLETON E. Discordant allergic manifestations in monozygotic twins: genetic identity versus clinical. physiological and biochemical differences. J Allergy Clin Immunol 1971:47:207-219.

125. FANTA C H. INGRAM JR R H. Mc FADDEN JR E R. A reassessment of the effects of oropharyngeal anaesthesia in exercise-induced asthma. Am Rev Respir Dis 1980; 122: 381-386.

I26. FANTOZZI R. MANSINI E, BLANDINA P, MANNANIONI P F, BANI-SACCHI $T$. Release of histamine from rat mast cells by acetylcholine. Nature 1978: 273: 473-474.

127. FARMER J B. FARRER D G. WILSON J. Antagonism of tone and prostaglandinmediated responses in a tracheal preparation by indomethacin and SC-19220. Br J Pharmacol 1974:52:559-565.

128. FERRIS L. ANDERSON S D. TEMPLE D M. Histamine release in exercise-induced asthma. Br Med J 1978; 1: 1697.

129. FERRON G A. KERREBIJN K F, WEBER J. Properties of aerosols produced with nebulizers commonly used in medicine. Am Rev Respir Dis 1976:114: 899-908.

130. FILLENZ M. WIDDICOMBE J G. Receptors of the lung and airways. In: Neil E eds. Handbook of sensory physiology vol 3, 1971: Heidelberg. Springer-Verlag p 81-I I 2.

131. FISHEL $C$ W, SZENTIVANYI A. TALMAGE D W. Sensitization and desensitization of mice to histamine and serotonin by neurohumors. J Immunol 1962: 89: 8-18.

132. FISHER K H, HANSEN T A. Site of action of inhaled 6 percent carbon dioxide via the lungs of asthmatic subjects before and after exercise. Am Rev Respir Dis 1976: 1J4: 861-870.

133. FITCH K D. MORTON A. R. Specificity in exercise-induced asthma. Br Med J 1971: 4: $577-581$.

134. FITCH K D, MORTON A R, BLANKSKY B A. Effects of swimming training on children with asthma. Arch Dis Child 1976:51: 190-194.

135. FLEISCH J H, KENT K M. COOPER T. Drug receptors in smooth muscle. In: Asthma, physiology. immunopathology and treatment. New York; Acad Press 1973; 139-167.

136. FLEMMING W W. Me PHILLIPS J J, WESTFALL D P. Postjunctional supersensitivity and subsensitivity of excitable tissue to drugs. Rev Physiol Biochem Pharmacol 1973: 68: $55-119$.

137. FLETCHER C M. Definition and classification of bronchitis, asthma and emphysema. In: Bronchitis. An international symposium. Orie N G M. Sluiter H J, eds. Royal Vangorcum Assen 1961, 273-278.

138. FOREMAN J C, MONGAR $\mathrm{J}$ L. The role of the alkaline earth ions in anaphylactic histamine secretion. J Physiol (Lond) 1972; 224: 753-769.

139. FOREMAN J C, MONGAR J L, GOMPERTS B D. Calcium ionophores and movement of calcium ions following the physiological stimulus to a secretory process. Nature 1973:245: 249-25I. 
140. FRANK N R. AMDUR M D. WORCHESTER J, WHITTENBERGER J L. Effects of acute controlled exposure to $\mathrm{SO}_{2}$ on respiratory mechanics in healthy male adults. J Appl Physiol 1962: 17:252-258.

14I. FREEDMAN P M. AULT B. Bronchial hyperreactivity to methacholine in farmers lung disease. J Allergy Clin Immunol 198 I:67:59-63.

142. GADDIE J, LEGGE $\mathrm{J}$ S. PETRIE G. PALMER $\mathrm{K} \mathrm{N} V$. The effect of an alpha-adrenergic receptor blocking drug on histamine sensitivity in bronchial asthma. Br J Dis Chest 1972; $66: 141-146$.

143. GALLAGHER $J$ F, KENT P W, PASSATORE M. PHIPPS $R$ J, RICHARDSON P S. The composition of tracheal mucus and the nervous control of its secretion in the cat. Proc $R$ Soc Lond 1975: 192: 49-76.

144. GAYRARD P, OREHEK J. GRIMAUD C. CHARPIN J. Bronchoconstrictor effects of a deep inspiration in patients with asthma. Am Rev Respir Dis 1975a: 111:433-439.

145. GAYRARD P, OREHEK J, GRIMAUD C. CHARPIN J. Beta-adrenergic function in airways of healthy and asthmatic subjects. Thorax 1975b:30:657-662.

146. GERRARD J W, COCKCROFT D W, MINK J $\Upsilon$, COTTEN D J, POONAWALA R. DOSMAN J A. Increased nonspecific bronchial reactivity in cigarette smokers with normal lungfunction. Am Rev Respir Dis 1980: 122: 577-581.

147. GILLESPIE E. LEVINE R J. MALAWISTA S E. Histamine release from rat peritoneal mast cells: inhibition of colchicine and potentiation by deuterium oxide. J Pharmacol Exp Ther 1968: 164: 158-165.

148. GILLESPIE E. Colchicine binding in tissue slides. J Cell Biol 1971:50:544-549.

149. GILLESPIE E. LICHTENSTEIN L M. Histamine release from human leucocytes: studies with deuterium oxide. colchicine and cytochalasin B. J Clin Invest 1972:51: 2941-2947.

150. GODFREY S, SILVERMAN M. Demonstration by placebo response in asthma by means of exercise testing. J Psychosom Res 1973: 17: 293-297.

151. GODFREY S. SILVERMAN M. ANDERSON S D. Problems of interpreting exerciseinduced asthma. J Allergy Clin Immunol 1973:52: 199-209.

152. GODFREY S. Exercise testing in children. Saunders Co. Ltd.. London. 1974.

153. GODFREY S. Exercise-induced asthma, clinical. physiological and therapeutical implications. J Allergy Clin Immunol 1975:56: 1-17.

154. GODFREY S, KÖNIG P. Inhibition of exercise-induced asthma by different pharmacological pathways. Thorax 1976;31:137-143.

155. GÖKEMEUJER J D M. Hyperreactiviteit van de luchtwegen. Thesis. University of Groningen. Wolters-Noordhoff Grafische Bedrijven BV, 1976.

156. GOLD W M, KESSLER G F, YU D Y C. Role of vagus nerves in experimental asthma in allergic dogs. J Appl Physiol 1972:33: 719-725.

157. GOLD W M. MEYERS G L. DAIN D S, MILLER R L. Changes in airways mast cells and histamine. J Appl Physiol 1977a: 43: 271-275.

158. GOLD W M. Neurohumeral interactions in airways. Am Rev Respir Dis 1977b; 115: 127-137.

159. GOLDEN J A, NADEL J A, BOUSHEY H A. Bronchial hyperirritability in healthy subjects after exposure to ozone. Am Rev Respir Dis 1978: 1/8:287-293.

160. GREEN M. WIDDICOMBE J G. The effects of ventilation of dogs with different gas mixtures on airway calibre and lung mechanics. J Physiol (Lond) 1966: 186: 363-38I. 
161. GRODZINSKA L. PANCZENKO B, GRYGLEWSKI R J. Generation of prostaglandin E-like material by the guinea pig trachea contracted by histamine. J Pharm Pharmacol 1975: 27: 88-91.

162. GROSS G N. SOUHRADA J F. FARR R $S$. The longterm treatment of an asthmatic patient using phentolamine. Chest 1974:66:397-401.

163. GUIRGIS H A. TOWNLEY R G, SCHANFIELD M S. A study of two genetic markers: $\mathrm{Gm}$ allotypes and methacholine sensitivity in asthma. J Allergy Clin Immunol 1976: 57: 227 (abstract).

164. HABIB M. P. PARÉ P D. ENGEL L A. Variability of airway responses to inhaled histamine in normal subjects. J Appl Physiol: 1979: 47:51-58.

165. HADDOCK A M, PATEL K R, ALSTON W C. KERR J W. Response of lymphocyte guanyl cyclase to propanolol, noradrenaline, thymoxamine and acetylcholine in intrinsic bronchial asthma. Br Med J 1975: 2: 357-359.

166. HAFEZ F F. CROMPTON $G \mathrm{~K}$. The forced expiratory volume after hyperventilation in bronchitis and asthma. $\mathrm{Br} J$ Dis Chest 1968:62:4-45.

167. HALL W J. BREESE C. SPEERS D M. Respiratory syncytial virus infection in adults. Ann Intern Med 1978: 88:203-205.

168. HANNA C J, BACH M K. PARE P D. SCHELLENBERG $R R$. Slow-reacting substances (leucotrienes) contract human airways and pulmonary vascular smooth muscle in vitro. Nature 1981: 290: 343-344.

169. HARRES M G. PARKES P E G, LESSOF M H, ORR $\Upsilon \mathrm{S}$ C. Role of bronchial irritant receptors in asthma. Lancet 1981:i. 5-7.

170. HARTLEY I P R, CHARLES T J, SEATON A. Betamethasone valerate inhalation and exercise-induced asthma in adults. $\mathrm{Br} \mathrm{J}$ Dis Chest $1977 \mathrm{a}: 71: 253-258$.

171. HARTLEY J P R. NOGRADY S G. Effect of an inhaled antihistamine on exercise-induced asthma. Thorax 1980:35:675-679.

172. HARTLEY J P R. DAVIES B $H$. Cholinergic blockade in the prevention of exercise-induced asthma. Thorax, 1980; 35:680-685.

173. HEIMLICH E M. STRICK L. BUSSER R J. An exercise response test in childhood astma. J Allergy Clin Immunol 1966:37: 103 (abstract).

174. HENDERSON $W$ R. SHELHAMER J H. REINGOLD D B. SMITH L J. EVANS R. KALINER M. Alpha-adrenergic hyper-responsiveness in asthma. N Engl J Med 1979: 300: 642-647.

175. HERXHEIMER H. Hyperventilation asthma. Lancet 1946: $1: 83-87$.

176. HERXHEIMER $\mathrm{H}$. Bronchial obstruction induced by allergens. histamine and acetyl-betamethylchlorechloride. Int Arch Allergy Appl Immunol 1951;2;27-40.

177. HERXHEIMER H. STRESEMANN E. The effect of bradykinin aerosol in guinea pigs and in man. J Physiol (Lond) 1961: 158:38p-39p.

178. HETZEL M R. BATTEN J C. CLARK $\Upsilon \mathrm{J}$ H. Do sympathomimetic amines prevent exercise-induced asthma by bronchodilatation alone? Br J Dis Chest 1977: 7/: 109-11.

179. HIRATE F, AXELROD J. Enzymatic methylation of phosphatidylethanolamine increases erythrocyte membrane fluidity. Nature $1978 ; 275: 219-220$.

180. HOLTZMAN M J. CUNNINGHAM J H. SHELLER J R. IRSIGLER G B. NADEL J A. BOUSHEY H A. Effect of ozone on bronchial reactivity in atopic and non-atopic subjects. Am Rev Respir Dis 1979; /20: 1059-1067. 
181. HOLTZMAN M J, SHELLER J R. DIMEO M. NADEL J A. BOUSHEY H A. Effect of ganglionic blckade on bronchial reactivity in atopic subjects. Am Rev Respir Dis 1980; 122: $17-25$.

182. HORTON D J, SUDA W L, KINSMAN R A, SOUHRADA J. SPECTOR S L. Bronchoconstrictive suggestion in asthma: a role for airways hyperreactivity and emotions. Am Rev Respir Dis 1978; 117:1029-1038.

183. INOUE S. Effects of epinephrine on asthmatic children. J Allergy 1967: 40:337-348.

184. ISHIZAKA T. SOTO C S. ISHIZAKA K. Mechanisms of passive sensitization. III Number of IgE molecules and their receptor sites on human basophil granulocytes. J Immunol 1973: HI: 500-511.

185. ISHIZAKA T, ISHIZAKA K, CONRAD D H. FROESE A. A new concept of triggering mechanisms of IgE-mediated histamine release. J Allergy Clin Immunol 1978: 61: 320-330.

I86. ISLAM M S、VASTAG E. ULMER W T. Sulpher-dioxide induced bronchial hyperreactivity against acetylcholine. Int Arch Occup Environ Health 1972a; 29: 221-232.

187. ISLAM M S. VASTAG E, ULMER W T. Effect of noxious stimulants on bronchial reactivity. Bull Eur Physiopathol Respir 1972b; 8:509-517.

188. ITKIN I H. Bronchial hyperreactivity to mecholyl and histamine in asthmatic subjects. J Allergy $1967: 40: 245-256$.

189. JACKSON D M. RICHARDS I M. The effects of sodium cromoglycate on histamine aerosol-induced reflex bronchoconstriction in the anaesthetized dog. $\mathrm{Br} \mathrm{J}$ Pharmacol 1977; $61: 257-262$.

190. JACOBOWITZ D. KENT K M, FLEISCH J H. COOPER T. Histofluorescent study of catecholamine-containing elements in cholinergic ganglia from the calf and dog lung. Proc Soc Exp Biol Med 1973; 144: 464-466.

19I. JAMES L. FACIANE J, SLY R M. Effects of treadmill exercise on asthmatic children. J Allergy Clin Immunol 1976:57:408-416.

192. JONES R S, BUSTON M H, WHARTON M J. The effect of exercise on ventilatory function in the child with asthma. Br J Dis Chest 1962:56:78-86.

193. JONES R S. WHARTON M J, BUSTON $M$ H. The place of physical exercise and bronchodilator drugs in the assessment of the asthmatic child. Arch Dis Child 1963: 38 : 539-545.

194. JONES R S. Assessment of respiratory function in the asthmatic child. Br Med J 1966: 2: 972-975.

195. JUNIPER E F. FRITH P A. DUNNETT C, COCKCROFT D W, HARGREAVE F E. Reproducibility and comparison of responses to inhaled histamine and methacholine. Thorax 1978, 33: 705-710.

196. KALINER M A. WASSERMAN S I. AUSTEN K F. Immunologic release of chemical mediators from nasal polyps. $N$ Engl J Med 1973; 289:277-281.

197. KALINER M, AUSTEN K F. Cyclic AMP, ATP and reversed anaphylactic histamine release from rat mast cells. J Immunol 1974a; 1/2: 664-674.

198. KALINER M A. AUSTEN K F. Adenosine $3^{\circ} 5^{\circ}$ monophosphate: inhibition of complementmediated cell lysis. Science 1974b; 183:659-661.

199. KALINER M. Human lung tissue and anaphylaxis; the role of cyclic GMP as a modulator of the immunologically induced secretory process. J Allergy Clin Immunol 1977;60:204-211.

200. KALISKER A. NELSON H E. MIDDLETON E. Drug-induced changes of adenylate cyclase activity in cells from asthmatic and non-asthmatic subjects. J Allergy Clin Immunol 1977:60:259-265. 
201. KANG B, TOWNLEY R G, LEE C K, KOLOTKIN B $M$. Bronchial reactivity to histamine before and after sodium cromoglycate in bronchial asthma. $\mathrm{Br}$ Med J 1976: I: 867-870.

202. KALSNER S. A new approach to the measurement and classification of forms of supersensitivity of autonomic effector responses. Br J Pharmacol 1974: 51: 427-434.

203. KARCZEWSKI $W$, WIDDICOME $J$ G. The role of the vagues nerves in the respiratory and circulatory responses to intravenous histamine and phenyl diguanide in rabbits. $J$ Physiol (Lond) 1969:201:271-292.

204. KARIMAN K. $\beta$-adrenergic receptor binding in lymphocytes from patients with asthma. Lung 1980: $158: 41-51$.

205. KATTAN M. KEENS $\Upsilon$ B. MELLIS C M. LEVISON $H$. The response to exercise in normal and asthmatic children. J Pediatr 1978:92:718-721.

206. KAUFMAN J, WRIGHT G W. The effect of nasal and nasopharyngeal irritation on airway resistance in man. Am Rev Respir Dis 1969: 100:626-630.

207. KERR J W, GOVINDARAJ M. PATEL K R. Effect of alpha receptor blocking drugs and disodium cromoglycate on histamine hypersensitivity in bronchial asthma. Br Med J 1970; 2:139-141.

208. KERREBIJN K F, HOOGEVEEN-SCHROOT H L A, VAN DER WAL M C. Histamine threshold and initial pulmonary function. Acta Paediatr Scand 1977, suppl. 261:35-39.

209. KERREBIJN K F, NEIJENS H J. Measurement of the bronchial responsiveness in children. Progr Respir Res, in press.

210. KERREBIJN K F ed. Summary of the Bronchial Hyperreactivity Working Group meeting. Göteborg, 1981.

211. KESSLER G F, AUSTIN J H M. GRAF P D. GAMSU G. GOLD W M. Airway constriction in experimental asthma in dogs: tantalum bronchographic studies. J Appl Physiol 1973:35:703-708.

212. KHAN A U, OLSON D L. Deconditioning of exercise-induced asthma. Psychosom Med 1977:39:382-391.

213. KIECHEL F, POLLACK J, COOPER D, WEINBERGER M. The comparative efficacy of theophylline and cromolyn in suppressing exercise-induced bronchospasm. $J$ Allergy Clin Immunol 1976:57:240 (abstract).

214. KIERNAN J A. A pharmacological and histological investigation of the involvement of mast cells in cutaneous axon reflex vasodilatation. Q J Exp Physiol 1975:60: 123-130.

215. KILHAM $H$, TOOLEY M. SILVERMAN M. Running. walking and hyperventilation causing asthma in children. Thorax 1979:34: 582-586.

216. KILLIAN D, COCKCROFT D W, HARGREAVE F E, DOLOVICH J. Factors in allergen-induced asthma: relevance of the intensity of the airways allergic reaction and nonspecific bronchial reactivity. Clin Allergy 1976:6:219-225.

217. KING M. COHEN C. VIIRES N. Influence of vagal tone on rheology and transportability of canine tracheal mucus. Am Rev Respir Dis 1979: 120: 1215-1219.

218. KIVILOOG J. Variability of bronchial reactivity to exercise and metacholine in bronchial asthma. Scand J Resp Dis 1973a: 54: 359-368.

219. KIVILOOG J. Bronchial reactivity to exercise and metacholine in bronchial asthma. Scand J Respir Dis 1973b; 54: 347-358.

220. KIVITY S. SOUHRADA $J$ F. A new diagnostic test to access airway reactivity in asthmatics. Bull Eur Physiopathol Respir 1981: 17:243;254. 
221. KNEUSSEL M P. RICHARDSON I B. Alpha-adrenergic receptors in human and canine tracheal and bronchial smooth muscle. J Appl Physiol 1978: 45: 307-311.

222. KOËTER G H. MEURS H, KAUFFMAN H F. VRIES $\mathrm{K}$ DE. The role of the adrenergic system in allergy and hyperreactivity. Eur J Respir Dis, in press.

223. KÖNIG P. GODFREY S. Exercise-induced bronchial lability in monozygotic (identical) and dizygotic (non-identical) twins. J Allergy Clin Immunol 1974:54: 280-287.

224. KÖNIG P. JAFFE P. GODFREY S. Effect of corticosteroids on exercise-induced asthma. J Allergy Clin Immunol 1974: 54: 14-19.

225. KREUKNIET J, PIJPER M M. Response to inhaled histamine and to inhaled allergens in atopic patients. Respiration 1973:30:345-359.

226. KREYE V A W, SCHULTZ G. Inhibition of non-epinephrine-, angiotensin II-, and vasopressin-induced contractions of smooth muscle by acyl derivatives of adenosine $3^{\circ} 5^{\circ}$ monophosphate. Eur J Pharmacol 1972: 18:297-302.

227. KUNOS G. SENTIVANYI M. Evidence favouring the existence of a single adrenergic receptor. Nature 1968: 217: 1077-1078.

228. LAITINEN L A, ELKIN R B, EMPEY D W et al. Changes in bronchial reactivity after administration of live attenuated influenza virus. Am Rev Respir Dis 1976:113-2 (suppl.): 194.

229. LAM S. WONG R. YEUNG M. Nonspecific bronchial reactivity in occupational asthma. J Allergy Clin Immunol 1979:63:28-34.

230. LANDS A M, ARNOLD A, Mc AULIFF J P. LUDUENA F P, BROWN T G. Differentiation of receptor systems activated by sympathomimetic amines. Nature 1967: 214: 597-598.

231. LAUWERIJNS J M. PEUSKENS J C. Argyrophil (kinin and amine producing?) cells in human infant airway epithelium. Life Sci 1969: 8:577-585.

232. LAUWERIJNS J M. PEUSKENS J C. COKELAERE M. Argyrophil, fluorescent and granulated (peptide and amine producing) AFG cells in human infant bronchial epithelium. Light and electron microscopic studies. Life Sci 1970: 9: 14 17-1429.

233. LEE L Y, BLEECKER E F. NADEL J A. Effect of ozone on bronchomotor response to inhaled histamine aerosol in dogs. J Appl Physiol 1977:43: 626-631.

234. LEFKOWITZ R J, HOFFMAN B B. New directions in adrenergic receptor research. TIPS 1980: $314-317$.

235. LEMANSKE R F. ANDERSON C, BRAUN S. SKATRUD J, BUSSE W W. Impaired in vitro $\beta$-adrenergic granulocyte response in chronic obstructive pulmonary disease. Am Rev Respir Dis 1980: 122:213-219.

236. LENDE VAN DER R. VISSER B F. WEVER-HESS J, DE VRIES K. ORIE N G M. Distribution of histamine threshold values in a random population. Rev Inst Hyg Mines 1973: 28: 186-190.

237. LICHTENSTEIN L M. MARGOLIS S. Histamine release in vitro: inhibition by catecholamines and methylxanthines. Science 1968: 161:902-903.

238. LICHTENSTEIN L M. AUSTEN K F eds. Asthma physiology, immunopharmacology and treatment, Second International Symposium, New York. Academic Press. 1977.

239. LICHTENSTEIN L M Mediators and the mechanism of their release. Chest 1978; 73 (suppl): 919-926.

240. LINN W S. BUCKLEY R D. SPIER C E et al. Health effects of ozone exposure in asthmatics. Am Rev Respir Dis 1978: 117:835-843.

241. LOCKEY JR S D, GLENNON J A. REED C E. Comparison of some metabolic responses in normal and asthmatic subjects to epinephrine and glucagon. J Allergy 1967;40:349-354. 
242. LOGSDON P J, CARNRIGHT D V, MIDDLETON JR E. COFFEY R G. The effect of phentolamine on adenylate cyclase and on isoproterenol stimulation in leucocytes from asthmatic and non-asthmatic subjects. J Allergy Clin Immunol 1973: 52: 148-157.

243. LOPES-VIDRIERO M T. DAS I. SMITH A P. PICOT R, REID L. Bronchial secretion from normal human airways after inhalation of prostaglandin $F_{2 \alpha^{*}}$ acetylcholine. histamine and citric acid. Thorax 1977: 32: 734-739.

244. LORING S H. DRAZEN J M. INGRAM JR R H. Canine pulmonary response to aerosol histamine direct versus vagal effects. J Appl Physiol 1977: 42: 946-952.

245. LOVE R G, MUIR D C F. Aerosol deposition and airway obstruction. Am Rev Respir Dis 1976:114:891-897.

246. LUPARELLO T, LYONS H A. BLEECKER E R. Mc FADDEN JR E R. Influences of suggestion on airway reactivity in asthmatic subjects. Psychosom Med 1968; 30:819-825.

247. MAKINO S. Clinical significance of bronchial sensitivity to acetylcholine and histamine in bronchial asthma. J Allergy 1966:38: 127-142.

248. MANN S P. The innervation of mammalian bronchial smooth muscle: the localization of catecholamines and cholinesterases. Histochem J 1971:3: 319-331.

249. MARIN M G. DAVIS B, NADEL J A. Effect of histamine on electrical and ion transport properties of tracheal epithelium. Am J Physiol 1977: 42: 735-738.

250. MATHÉ A A. ASTRÖM A. PERSSON N A. Some bronchoconstricting and bronchodilating responses of human isolated bronchi: evidence for the existence of alpha adrenoceptors. J Pharmacol 1971:23:905-910.

251. MATHE A A. HEDQVIST P, HOLMGREN A, SVANBORG N. Bronchial hyperreactivity to prostaglandin $\mathrm{F}_{2 \alpha}$ and histamine in patients with asthma. Br Med J 1973:1: 193-196.

252. MATSUMURA Y. The effects of ozone, nitrogen dioxide and sulfur dioxide on the experimentally induced allergic respiratory disorder in guinea pigs. Il the effects of ozone on the absorption and retention of antigen in the lungs. Am Rev Respir Dis 1970: 102: 438-443.

253. MATSUMURA Y, TAN E M. VAUGHAN J H. Hypersensitivity to histamine and systematic anaphylaxis in mice with pharmacologic beta-adrenergic blockade: protection by nucleotides. J Allergy Clin Immunol 1976:58:387-394.

254. MAZUREK N. BERGER G. PECHT I. A binding site on mast cells and basophils for the anti-allergic drug cromolyn. Nature 1980: 286: 722-723.

255. Mc CULLOCK M W. PROCTOR C, RAND M J. Evidence for an adrenergic homeostatic bronchodilator reflex mechanism. Eur J Pharmacol 1967:2: 214-223.

256. MC FADDEN JR E R. STEARNS D R. INGRAM JR R H, LEITH D E. Relative contributions of hypocarbia and hyperpnea as mechanisms in postexercise asthma. J Appl Physiol 1977a: 42: 22-27.

257. MC FADDEN JR E R. INGRAM JR R H. HAYNES R H. WELLMAN J. Predominant site of flow-limitation and mechanisms of post-exertional asthma. J Appl Physiol 1977b: 42: 746-752.

258. Mc FADDEN JR E R, SOTER N A. A search for chemical mediators of immediate hypersensitivity and humoral factors in the pathogenesis of exercise-induced asthma. In: Lichtenstein L M. Austen K F eds; Asthma physiology, immunopharmacology and treatment, Second International Symposium. Academic Press New York. 1977:351-366.

259. Mc FADDEN JR E R. INGRAM JR R H. Exercise-induced asthma, observation on the initiating stimulus. N Engl J Med 1979:301: 763-769.

260. MC FADDEN JR E R, SOTER N A. INGRAM JR R H. Magnitude and site of airway response to exercise in asthmatics in relation to arterial histamine levels. $J$ Allergy Clin Immunol 1980:66:472-477. 
261. Mc GEADY S, CONBOY K, TOWNLEY R G. The effect of beta adrenergic blockade on bronchial sensitivity to methacholine in normal and allergic rhinitis subjects. J Allergy 1968: 41: 108-109.

262. Mc NALLY J F, ENRIGHT P. HIRSCH J E, SOUHRADA J F. The attenuation of exercise-induced bronchoconstriction by oropharyngeal anaesthesia. Am Rev Respir Dis 1979: 119:247-252.

263. MELLIS C M. KATTEN M. KEENS $\Upsilon$ G. LEVISON H. Comparative study of histamine and exercise challenges in asthmatic children. Am Rev Respir Dis 1978: 117: 911-915.

264. MILLER G J, DAVIES B H, COLE T J, SEATON A. Comparison of the bronchial response to running and cycling in asthma using an improved definition of the response to work. Thorax 1975; 30: 306-311.

265. MILLER W S. The lung 2nd ed. Springfield III: Charles C. Thomas 1947.

266. MILLS J E. SELLICK H. WIDDICOMBE J G. Activity of lung irritant receptors in pulmonary microembolism. anaphylaxis and drug-induced bronchoconstriction. I Physiol (London) 1969: 203: 337-357.

267. MILLS J E. WIDDICOMBE J G. Role of the vagus nerves in anaphylaxis and histamineinduced bronchoconstriction in guinea pigs. Br J Pharmacol 1970:39: 724-731.

268. MINATOYA H. LUDUENA F P. Effects of propanolol and guanethidine on the bronchodilatation induced by sympathomimetic agents and by stimulation of the stellate ganglia in the anaesthetized dog. Fed Proc 1967;26:293.

269. MITCHELL J, COREY M. WOENNE R. KRASTINS I R B. LEVISON H. Bronchial hyperreactivity in cystic fibrosis and asthma. J Pediatr 1978; 93: 744-748.

270. MONGAR J L. FOREMAN J C. Control of histamine secretion. In: Pepys J, Edwards A M eds. The mast cell. its role in health and disease, 1979. Pitman Medical. London. $\mathrm{p}$ 30-37.

271. MORRIS H G, RUSNAK S A, SELNER J C. BARZENS K, BARNES J. Adrenergic desensitization in leucocytes of normal and asthmatic subjects. J Cyclic Nucleotide Res 1977; 3: 439-446.

272. MORSE J L C, JONES N L. ANDERSON G D. The effect of terbutaline in exerciseinduced asthma. Am Rev Respir Dis 1976: 113: 89-92.

273. MORTOLA J, SANTAMBROGIO G. CLEMENT M G. Localisation of irritant receptors in the airways of the dog. Respir Physiol 1975: 24: 107-114.

274. MURAKANA M. SUZUKI S, MIYAMOTO T. TAKEDA K. OKUMURA H. MAKINO S. Bronchial reactivities to acetylcholine and IgE levels in asthmatic subjects after longterm remissions. J Allergy Clin Immunol 1974: 54: 32-40.

275. NADEL J A, TIERNEY D F. Effect of previous deep inspiration on airway resistance in man. J Appl Physiol 1961: 16:717-719.

276. NADEL J A, WIDDICOMBE J G. Effect of changes in blood gas tensions and carotid sinus pressure on tracheal volume and total lung resistance to airflow. J Physiol (Lond) 1962a: 163: 13-33.

277. NADEL J A, WIDDICOMBE J G. Reflex effects of upper airways irritation on total lung resistance and blood pressure. J Appl Physiol (Lond) 1962b; 17: 861-865.

278. NADEL J A. WIDDICOMBE J G. Reflex control of airway size. Ann N Y Acad Sci 1963; 109: 712-722.

279. NADEL J A. CORN M. ZWI S, FLESCH J, GRAF P. Location and mechanism of airway constriction during inhalation of sulphur dioxide. J Appl Physiol 1965: 20: 164-167.

280. NADEL J A, CABEZAS G A, AUSTIN J H M. In vivo roentgenographic examination of parasympathetic innervation of small airways. Invest Radiol 1971:6:9-17. 
281. NADEL J A. Autonomic control of airway smooth muscle and airway secretions. Am Rev Respir Dis 1977: 115: 117-126.

282. NATHAN R A. SEGALL N. GLOVER G C. SCHOCKET A L. The effects of $H_{1}$ and $\mathrm{H}_{2}$ anthistamines on histamine inhalation challenges in asthmatic patients. Am Rev Respir Dis 1979a: 120: 1251-1258.

283. NATHAN R A. KINSMAN R A. SPECTOR S L, HORTON D J. Reiationship between airways response to allergens and non-specific bronchial reactivity. J Allergy Clin Immunol 1979b: 64: 491-499.

284. NATHAN R A. SEGALL N. SCHOCKET A L. A comparison of the actions of $H_{1}$ and $\mathrm{H}_{2}$ antihistamines on histamine-induced bronchoconstriction and cutaneous wheal response in asthmatic patients. J Allergy Clin Immunol 1981:67: 171-177.

285. NEWHOUSE M T. BECKLAKE M R. MACKLEM P T, MC GREGOR M. Effect of alterations in end-tidal $\mathrm{CO}_{2}$ tension on flow resistance. J Appl Physiol 1964; 19: 745-749.

286. NEIJENS H J. DEGENHART H J. RAATGEEP H C. KERREBIJN K F. Study on the significance of bronchial hyperreactivity in the bronchusobstruction after inhalation of cat dander allergen. J Allergy Clin Immunol 1979:64: 507-515.

287. NEIJENS $H$ J, DEGENHART $H$ J. RAATGEEP $H$ C. KERREBIJN $K$ F. The correlation between increased reactivity of the bronchi and of mediator releasing cells in asthma. Clin Allergy 1980: 10:535-539.

288. NELSON H S. BLACK J W, BRANCH L B et al. Subsensitivity to epinephrine following the administration of epinephrine and ephedrine to normal individuals. J Allergy Clin Immunol 1975: 55: 299-509.

289. O'CAIN C F, DOWLING N B, SLUTZKY A S et al. Airway effects of respiratory heat loss in normal subjects. J Appl Physiol 1980: 49: 975-880.

290. OlSEN C R, COLEBATCH H J H J. MEBEl P E. NADEL J A, STAUB N C. Motor control of pulmonary airways studied by nerve stimulation. J Appl Physiol 1965: 20:202-208.

291. ORANGE R P. AUSTEN W G. AUSTEN K F. Immunologic release of histamine and slow-reacting substance of anaphylaxis from human lung. J Exp Med 1971: 134:136s-148s.

292. OREHEK. J, DOUGLAS J G, LEWES A J. BOUHUYS A. Prostaglandin regulation of airway smooth muscle tone. Nature 1973: 245:84-85.

293. OREHEK J. GAYRARD P. GRIMAUD C. CHARPIN J. Effect of maximal respiratory manoeuvres on bronchial sensitivity of asthmatic patients as compared to normal people. Br Med J 1975a: I: 123-125.

294. OREHEK J. GAYRARD P. GRIMAUD C, CHARPIN J. Effect of beta-adrenergic blockade on bronchial sensitivity to inhaled acetylcholine in normal subjects. J Allergy Clin Immunol 1975b; 55: 164-169.

295. OREHEK, J, MASSARI J P. GAYRARD P, GRIMAUD C. CHARPIN J. Effect of shortterm, low level nitrogen dioxide exposure on bronchial sensitivity of asthmatic patients. J Clin Invest 1976a: 57:301-307.

296. OREHEK J, GAYRARD P. Les tests de provocation bronchique non-specifique dans l'asthme. Bull Eur Physiopathol Respir 1976b; 12: 565-598.

297. OREHEK J, GAYRARD P. SMITH A P. GRIMAUD C. CHARPIN J. Airway response to carbachol in normal and asthmatic subjects / Distinction between bronchial sensitivity and reactivity. Am Rev Respir Dis 1977; 115:937-943.

298. ORIE N G M. Definition and classification of bronchitis, asthma and emphysema. In: Bronchitis X. Orie N G M, Sluiter H J eds Royal Vangorcum Assen, 1961, p 273-288.

299. ORIE N G M. SLUITER H J eds. Bronchitis I. Royal Vangorcum, Assen, 1961. 
300. ORIE N G M, SLUITER H J eds. Bronchitis II, Second international symposium. Royal Vangorcum, Assen. 1964.

301. ORIE N G M, VAN DER LENDE R, eds. Bronchitis III. Proceedings of the third international symposium on bronchitis. Royal Vangorcum Assen. 1970.

302. ORR T S C. ELLIOTT E V. ALTOUNYAN R E C. STERN M A. Modulation of release of neutrophil chemotactic factor (NCF). Clin Allergy 1980: 10 (suppl.): 491-496.

303. OUELLETTE J J, REED C E. Increased response of asthmatic subjects to methacholine after influenza vaccine. J Allergy 1965:36:558-563.

304. OUELLETTE $J \mathrm{~J}$, REED C E. The effect of partial beta adrenergic blockade on the bronchial response of hay fever subjects to ragweed aerosol. J Allergy 1967:39: 160-166.

305. PADAWAR J. Mast cell structure: implications for normal physiology and degranulation. In: Pepys J, Edwards A M eds. The mast cell: its role in health and disease, London. Pitman Medical, 1979.p 1-8.

306. PAINTAL A S. Vagal sensory receptors and their reflex effects. Physiol Rev 1973: 53: 159227.

307. PARKER C D. BILBO R E, REED C. Methacholine aerosol as test for bronchial asthma. Arch Int Med 1965: 115:452-458.

308. PARKER C W, SMITH J W. Alterations in cyclic adenosine monophosphate metabolism in human bronchial asthma. leucocyte responsiveness to $\beta$-adrenergic agents. J Clin Invest 1973: 52: 48-59.

309. PATEL K R. Atropine, sodium cromoglycate and thymoxamine in PGF $2 \alpha$ induced bronchoconstriction. Br Med J 1975; 2: 360-362.

310. PATEL K R, KERR J W. Alpha-receptor blocking drugs in bronchial asthma. Lancet 1975: $i: 348-349$.

311. PATEL $K R$. KERR J W. Mc DONALD E B, Mc KENZIE A $M$. The effect of thymoxamine and cromolyn sodium on post-exercise bronchoconstriction in asthma. J Allergy Clin Immunol 1976:57:285-292.

312. PATEL K R. Calcium antagonists in exercise-induced asthma. Br Med J 1981: 282: 932-933.

313. PATERSON J W, WOOLCOCK A J. SHENFIELD G M. Bronchodilator drugs (State of the art). Am Rev Respir Dis 1979: 120: I 149-I 188.

314. PATTERSON R. Mc KENNA I M, SUSZKO I M et al. Living histamine containing cells from the bronchial lumens of humans. J Clin Invest 1977:59:217-225.

315. PAUWELS R, LAMONT H. VAN DER STREATEN M. Comparison between ketotifen and DSCG in bronchial challenge. Clin Allergy 1978;8:289-293.

316. PAUWELS et al. Personel communication.

317. PEPYS J. EDWARDS A $M$ eds. The mast cell, its role in health and disease. London. Pitman Medical. 1979.

318. PHIPPS R J. RICHARDSON P S. The effects of irritation at various levels of the airway upon tracheal mucus secretion in the cat. J Physiol (Lond) 1976: 26 I: 563-581.

319. PHIPPS R J, NADEL J A. DAVIS B. Effect of alpha-adrenergic stimulation on mucus secretion and on ion transport in cat trachea in vitro. Am Rev Respir Dis 1980; 121: 359365.

320. PLATSHON L F. KALINER M. The effects of the immunologic release of histamine upon human lung cyclic nucleotide levels and prostaglandin generation. J Clin Invest 1978:62: 1113-1121. 
321. PLOY-SONG-SANG V, CORBIN R P ENGEL L A. Effects of intravenous histamine on lung mechanics in man after beta-blockade. J Appl Physiol 1978: 44: 690-695.

322. POON H C. Mc COURTIE D R M. HAUST H L. Opposite changes in blood histamine and forced expiratory volume during bronchial inhalation challenge. Int $\mathrm{J}$ Clin Pharmacol Biopharm 1977; 15:432-437.

323. POPPIUS H. MUITTARI A, KREUS K E. KORHONEN O, VILJANEN A. Exercise asthma and disodium cromoglycate. Br Med J 1970: 4: 337-339.

324. PRIME F J, BIANCO S. GRIFFIN J P. KAMBUROFF P L. The effects on airways conductance of alpha adrenergic stimulation and blocking. Bull Eur Physiopathol Respir 1972:8:99-109.

325. REID L. Measurement of the bronchial mucus gland layer: a diagnostic yardstick in chronic bronchitis. Thorax 1960; 15:132-141.

326. RICHARDSON J B, HOGG J C. BOUCHARD T. HALL D L. Localisation of antigen in experimental bronchoconstriction in guinea pigs. $J$ Allergy Clin Immunol 1973: 52: 772-78 I.

327. RICHARDSON J B, BOUCHARD T. Demonstration of a non-adrenergic inhibitory nervous system in the trachea of the guinea pig. J Allergy Clin Immunol 1075;56:473-480.

328. RICHARDSON J, BELAND J. Non-adrenergic inhibitory nervous system in human airways. J Appl Physiol 1976:41: 764-771.

329. RICHARDSON J B. Nerve supply to the lungs. Am Rev Respir Dis 1979: 119: 785-802.

330. RILEY D J. WEITZ B W. EDELMAN N H. The response of asthmatic subjects to isoproterenol inhaled at different lung volumes. Am Rev Respir Dis 1976: 114: 509-515.

331. ROSENTHAL $R \quad R$ ed. Workshop proceedings on bronchoprovocation techniques for the evaluation of asthma. J Altergy Clin Immunol 1979:64: no. 6. part. 2.

332. RUFFIN R E. DOLOVICH M B. WOLFF R K. NEWHOUSE M T. The effect of preferential deposition of histamine in the human airway. Am Rev Respir Dis 1978; 117: 485-492.

330. RUFFIN R E. ALPERS J H. CROCKETT A J, HAMILTON R. Repeated histamine inhalation tests in asthmatic patients. J Allergy Clin Immunol 198 1:67:285-289.

334. RYAN G. DOLOVICH M B. ROBERTS R S et al. Standardization of inhalation provocation tests: two techniques of aerosol generation and inhalation compared. Am Rev Respir Dis 1981b; I23: 195-199.

335. RYAN G. DOLOVICH M B, OBMINSKI G et al. Standardization of inhalation provocation tests: influence of nebulizer output. particle size, and method of inhalation. J Allergy Clin Immunol 1981:67: 156-161.

336. RYO U Y, TOWNLEY R G. Comparison of respiratory and cardiovascular effects of isoproterenol, propanolol and practolol in asthmatic and normal subjects. J Allergy Clin Immunol 1972:49: 105 .

337. SALOME C M. SCHOEFFEL R E. WOOLCOCK A J. Comparison of bronchial reactivity to histamine and methacholine in asthmatics. Clin Allergy 1980: 10:541-546.

338. SAMPSON S R. VIDRUK E H. Properties of "irritant" receptors in canine lung. Respir Physiol 1975: 25: 9-22.

339. SAMPSON S R. Sensory neurophysiology of airways. Am Rev Respir Dis 1977; 115: 107 I 15 .

340. SAMUELSSON B. HAMMARSTRÖM S. MURPHY R C. BORGEAT P. Leukotrienes and slow reacting substance of anaphylaxis (SRS-A). Allergy 1980a: 35:375-381.

341. SAMUELSSON B. The leucotrienes: a new group of biologicaily active compounds including SRS-A, TIPS 1980b:(l): 227-230. 
342. SANTA CRUZ R. LANDA J, HIRSCH H. SACKNER M A. Tracheal mucous velocity in normal man and patients with obstructive lung disease: effects of terbutaline. Am Rev Respir Dis 1974: 109: 458-463.

343. SCHACHTER E N. KREISMAN H, LITTNER M, BECK G J. VONCKEN F. Airway responses to exercise in mild asthmatics. J Allergy Clin Immunol 1978:61:390-398.

344. SCHILD H O. HAWSKINS D F. MONGAR J L. HERXHEIMER $H$. Reactions of isolated human asthmatic lung and bronchial tissue to a specific antigen: histamine release and muscular contraction. Lancet 1951: ii: 376-382.

345. SCHNALL R P. LANDAU L I. Protective effects of repeated short sprints in exerciseinduced asthma. Thorax 1980:35:828-832.

346. SCHOEFFEL R E. ANDERSON S D. GILLAM I, LINDSAY D A. Multiple exercise and histamine challenge in asthmatic patients. Thorax 1980:35: 164-170.

347. SCHULTZ G. HARDMAN J G, SUTHERLAND E W. Cyclic Nucleotides and smooth muscle function. In: Austen K F. Lichtenstein L M eds. Asthma Physiology, Immunopharmacology and Treatment. Academic Press. New York. 1973: 123-138.

348. SCHULTZ G. SCHULTZ K. HARDMAN J G. Effects of norepinephrine on cyclic nucleotide levels in the ductus deferens in the rat. Metabolism 1975;24:429-437.

349. SCHULTZ G. Possible interrelationship between calcium and cyclic nucleotides in smooth muscle. In: Lichtenstein L M, Austen K F eds. Asthma, physiology, immunopharmacology. and treatment. Second international symposium. Academic Press. New York. 1977: 9: 77-91.

350. SCHWANK S. SCHERRER M. Anstrengungsinduziertes asthma unter placebo. Schweiz Med Wochenschr 1978; 108:225-228.

351. SEALE J R, ANDERSON S D, LINDSAY D A. A comparison of oral theophylline and oral salbutamol in exercise-induced asthma. Aust $\mathrm{N} Z \mathrm{~J}$ Med 1977: 7: 270-274.

352. SELLICK H. WIDDICOMBE $J$ G. The activity of lung irritant receptors during pneumothorax, hyperpnoea and pulmonary vascular congestion. J Physiol (Lond) 1969: 20.3: 359382.

353. SHELHAMER J H. METCALFE D D. SMITH L J. KALINER M. Abnormal beta adrenergic responsiveness in allergic subjects: analysis of isoproterenol-induced cardiovascular and plasma cyclic adenosine monophosphate responses. J Allergy Clin Immunol 1980: 66: $52-60$.

354. SHEPARD R J. On the design and effectiveness of training regiments in chronic obstructive lung disease. Bull Eur Physiopathol Respir 1977: 13:457-469.

355. SHTURMAN-ELLSTEIN R. ZEBALLOS R J. BUCKELY J M. SOUHRADA J F. The beneficial effect of nasal breathing on exercise-induced bronchoconstriction. Am Rev Respir Dis 1978: 118: 65-73.

356. SILVERMAN M. ANDERSON S D. Standardization of exercise tests in asthmatic children. Arch Dis Child 1972a; 47: 882-889.

357. SILVERMAN M, ANDERSON S D. Metabolic cost of treadmill exercise in children. J Appl Physiol 1972b; 33: 696-698.

358. SILVERMAN M. ANDREA T. Time course of effect of disodium cromoglycate on exerciseinduced asthma. Arch Dis Child 1972:47:419-422.

359. SILVERMAN M, CONNOLLY N M. BALFOUR-LYNN L, GODFREY S. Longterm trial of disodium cromoglycate and isoprenaline in children with asthma. Br Med J 1972a: 3: 378$38 \mathrm{I}$.

360. SILVERMAN M, ANDERSON S D. WALKER S R. Metabolic changes preceding exercise-induced bronchoconstriction. Br Med J 1972b: 1: 207-209. 
361. SIMANI A S, INOUE S. HOGG I C. Penetration of the respiratory epithelium of guinea pig following exposure to cigarette smoke. Lab Invest 1974:31:75-81.

362. SIMON R A. STEVENSON D D. ARROYAVE C M. TAN E M. The relationship of plasma histamine to the activity of bronchial asthma. J Allergy Clin Immunol 1977;60:312316.

363. SIMONSSON B G. JACOBS F M. NADEL J A. Role of autonomic nervous system and the cough reflex in the increased responsiveness of airways in patients with obstructive airway disease. I Clin Invest 1967; 46:1812-1818.

364. SIMONSSON B G, SVEDMYR N, SKOOGH B E. ANDERSON R, BERGH N P. In vivo and vitro studies on alpha-receptors in human airways. Potentiation with bacterial endotoxin. Scand J Respir Dis 1972a; 53: 227-236.

365. SIMONSSON B G, SKOOGH B E. EKSTRÖM-IODAL B. Exercise-induced airways constriction. Thorax 1972b; 27:169-180.

366. SIMONSSON B G, SKOOGH B E, BERGH N P, ANDERSON R, SVEDMYR N. In vivo and in vitro effect of bradykinin on bronchial motor tone in normal subjects and patients with airways obstruction. Respiration 1973:30:378-388.

367. SLY R M, MATZEN K. Effect of diethylcarbamaxine permoate upon exercise-induced obstruction in asthmatic children. Ann Allergy 1974: 33: 138-144.

368. SMITH L J, SHELHAMER J H. KALINER M. Cholinergic nervous sytem and immediate hypersensitivity. II An analysis of pupillary responses. J Allergy Clin Immunol 1980: 66: 374-378.

369. SNAPPER J R, BRAASCH P S, INGRAM JR R H, LORING S H, DRAZEN J M. Effects of beta adrenergic blockade on histamine and prostaglandin $F_{2 \alpha}$ responsiveness in the dog. J Allergy Clin Immunol 1981:67: 199-205.

370. SPATARO A C. BOSMANN H B. Mechanism of action of disodium cromoglycate - mast cell calcium ion influx after a histamine-releasing stimulus. Biochem Pharmacol 1976; 25: 505-510.

371. SPECTOR S L. FARR R S. A comparison of methacholine and histamine inhalations in asthmatics. J Allergy Clin Immunol 1975:56:308-316.

372. SPECTOR S, LUPARELLO $T$ J, KOPETSKY M T, SOUHRADA J, KINSMAN R A. Response of asthmatics to methacholine and suggestion. Am Rev Respir Dis 1976: 113: 43-50.

373. SPENCER $H$. LEOF $D$. The innervation of the human lung. $J$ Anat (Lond) I964: 98 : 599-609.

374. STASZEWSKA-BARCZAK J, VANE J R. The release of catecholamines from the adrenal medulla by histamine. Br J Pharmacol 1965: 25: 728-742.

375. STEPHENS N L, MEYERS J L. CHERNIACK R M. Oxygen, carbon dioxide, $\mathrm{H}^{+}$ion and bronchial lengthtension relationships. J Appl Physiol 1968: 25:376-383.

376. STEPHENS N L. MITCHELL R W, ANTONISSEN L A et al. Airway smooth muscle: physical properties and metabolism. In: Hargreave F E ed. Airway reactivity, Mc Master University, Hamilton, 1980: p 110-131.

377. STONE D J, SARKAR I K, KELTZ H. Effects of adrenergic stimulation and inhibition on human airways. J Appl Physiol 1973: 34:624-627.

378. STRAUSS R H. HAYNES R L, INGRAM JR R H, Mc FADDEN JR E R. Comparison of arm versus leg work in induction of acute episodes of asthma. J Appl Physiol 1977a; 42: $565-570$. 
379. STRAUSS R H. INGRAM JR R H. Mc FADDEN JR E R. A critical assessment of the role of circulating hydrogen ion and lactate in the production of exercise-induced asthma. $J$ Clin Invest 1977b: 60:658-664.

380. STRAUSS R H, Mc FADDEN JR E R. INGRAM JR R H. JAEGER J J. Enhancement of exercise-induced asthma by cold air. N Engl J Med 1977c; 297: 743-747.

381. STRAUSS R H. MC FADDEN JR E R. INGRAM JR R H, DEAL JR E C. JAEGER $J \mathrm{~J}$. Influence of heat and humidity on the airway obstruction induced by exercise in asthma. $J$ Clin Invest 1978: 61: 433-440.

382. SUTHERLAND E W. On the biological role of cyclic AMP. JAMA. 1970; 214: 1281-1288.

383. SVENONIUS E. LECEROF H. LILJA B. ARBORELIUS JR M. with technical assistance of Mrs Rosie Kautto. The volume of trapped gas: a new and sensitive test for the detection of exercise-induced bronchospasm in children. Acta paediatr Scand 1978: 67:583-589.

384. SZENTIVANYI A. The beta adrenergic theory of the atopic abnormality in bronchial asthma. J Allergy I 968:42:203-232.

385. SZENTIVANYI A. HEIM O, SCHULZE $P$. Changes in adrenoceptor densities in membranes of lung tissue and lymphocytes from patients with atopic disease. Ann $\mathrm{N} Y$ Acad Sci 1979a:332: 295-298.

386. SZENTIVANYI A. The conformational flexibility of adrenoreceptors and the constitutional basis of atopy. Triangel 1979b: 18: 109-115.

387. TAKAZAWA T. THURLBECK W M. Muscle and mucous gland size in the major bronchi of patients with chronic bronchitis, asthma and asthmatic bronchitis. Am Rev Respir Dis 1971: $104: 331-336$.

388. TAKINO Y. SUGAHARA K, HORINO I. Two lines of guinea pigs sensitive and nonsensitive to chemical mediators and anaphylaxis. J Allergy 1971:47: 247-261.

389. TASHKIN D P, KATZ R M. KERSCHNAR H, RACHELEFSKY G S. SIEGEL S C. Comparison of aerosolized atropine, isoproterenol, atropine plus isoproterenol, disodium cromoglycate and placebo in the prevention of exercise-induced asthma. Ann Allergy 1977; 39: 311318.

390. TAVEIRA DA SILVA A M. HAMOSH P. Aspirin and exercise-induced asthma. Prostaglandins $1976: 1 /: 71-76$.

391. THOMSON N C. PATEL K R, KERR J W. Sodium cromoglycate and ipratropium bromide in exercise-induced asthma. Thorax 1978: 33: 694-699.

392. THOMSON N C. The effect of different pharmacological agents on respiratory reflexes in normal and asthmatic subjects. Clin Sci 1979:56:235-241.

393. TIFFENEAU R, BEAUVALLET M. Epreuve de bronchoconstriction et de bronchodilatation par aérosols. Emploi pour le dépistage, la mesure et la contrôle des insuffisances respiratoire chronique. Bull Acad Natl Med (Paris) 1945; 129: 165-168.

394. TIFFENEAU R. Evaluation du degré de l'asthma par une épreuve pharmacodynamique. Ann Med Interne (Paris) 1955: 56:582-602.

395. TIFFENEAU R. Hypersensibilité cholinergo-histaminique pulmonaire de l'asthmatique. Acta Allergologica 1958; suppl. $V:$ 187-221.

396. TIFFENEAU R. Quantitative relations between the administration of allergens and the production of bronchoconstrictive mediators in allergic asthma. Int Arch Allergy 1961; 19:331-340.

397. TISCHLER A S, DICHTER M A. BIALES B, GREENE L A. Neuroendocrine neoplasms and their cells of origin. N Engl J Med 1977: 296:919-925.

398. TOMORI $Z$. WIDDICOMBE J G. Muscular, bronchomotor and cardiovascular reflexes elicited by mechanical stimulation of the respiratory tract. J Physiol 1969:200:25-49. 
399. TOWNLEY, R G, DENNIS M, ITKIN I M. Comparative action of acetyl beta methylcholine, histamine and pollen antigens in subjects with hayfever and subjects with bronchial asthma. J Allergy 1965: 36:121-137.

400. TOWNLEY R G. RYO U Y. KOLOTKIN B M, KANG B. Bronchial sensitivity to methacholine in current and former asthmatic and allergic rhinitis patients and control subjects. J Allergy Clin Immunol 1975: 56:429-442.

401. TOWNLEY R G. Mc GEADY S. BEWTRA A. The effect of beta adrenergic blockade on bronchial sensitivity to acetyl-beta-methacholine in normal and allergic rhinitis subjects. J Allergy Clin Immunol 1976: 57:358-366.

402. TURNER P. BURMAN J, HICKS D C et al. A comparison of the effects of propanolol and practolol on forced expiratory volume and resting heart rate in normal subjects. Arch Int Pharmacocyn Ther 1971:191: 104-110.

403. UTELL M J. SWINBURNE A J. HYDE R H, SPEERS D M. GIBB F R. MORROW $P$ E. Airway reactivity to nitrates in normal and mild asthmatic subjects. $J$ Appl Physiol 1979: $46: 189-196$.

404. UTELL M J. AQUILINA A T. HALL W J et al. Development of airway reactivity to nitrates in subjects with influenza. Am Rev Respir Dis 1980; 121:233-241.

405. VASSALLO C L, GEE J B L, DOMM B M. Exercise-induced asthma. Observations regarding hypocapnia and acidosis. Am Rev Respir Dis 1972; 105: $42-49$.

406. VERMEIRE P A, VANHOUTTE P M. Inhibitory effects of catecholamines in isolated canine bronchial smooth muscle. J Appl Physiol 1979; 46: 787-791.

407. VIDRUK E H. HAHN H L. NADEL J A. SAMPSON S R. Mechanisms by which histamine stimulates rapidly adapting receptors in dog lungs. J Appl Physiol 1977: 43: 397402.

408. VOELKEL N F, HEGSTRAND L, REEVES J T, Mc MURTY I F, MOLINOFF P B. Effect of hypoxia on density of $\beta$-adrenergic receptors. J Appl Physiol 1981:50:363-366.

409. VRIES K DE, GOEI J T. BOOY-NOORD H. ORIE N G M. Changes during 24 hours in the lungfunction and histamine hyperreactivity of the bronchial tree in asthmatic and bronchitic patients. Int Arch Allergy 1962a: 20:20-101.

410. VRIES K DE, BOOIJ-NOORD H. GOEI J T, ORIE N G M. Reaction of the bronchial tree on chemical or physical stimuli. Proc Fifth European Congress of Allergy. Schwabe \& Co. Basel, 1962b: 316-319.

411. VRIES K DE. BOOIJ-NOORD H. GOEI J T et al. Hyperreactivity of the bronchial tree to drugs, chemical and physical agents. In: Orie N G M. Sluiter H J. eds. Bronchitis II. Royal Vangorcum, Assen 1964; 167-180.

412. VRIES K DE, BOOIJ-NOORD H, VAN DER LENDE R, VAN LOOKEREN CAMPAGNE J G. ORIE N G M. Reactivity of the bronchial tree to different stimuli. Bronches 1968: $18: 439-452$.

413. VRIES $\mathrm{K}$ DE. Histamine thresholds and initial lungfunction values. In: Orie N G M and van der Lende R. eds. Bronchitis III, Royal Vangorcum. Assen 1970: p. 359-362.

414. WARDLEY A C. Inheritance of responsiveness to pertussis HSF in mice. Int Arch Allergy 1970:38:573-589.

415. WASSERMAN K. Breathing during exercise. N Engl J Med 1978: 298: 780-785.

416. WASSERMAN M A. Du CHARME D W. GRIFFIN R L. DE GRAAF G L, ROBINSON F G. Bronchopulmonary and cardiovascular effects of prostaglandin $D_{2}$ in the dogProstaglandins 1977; 13:255-269.

417. WASSERMAN S I. The mast cell and the inflammatory response. In: Pepys J. Edwards A M eds. The mast cell: its role in health and disease. Pittman Medical, London 1977. p. 9-20. 
418. WEINSTEIN R E. ANDERSON J A, KVALE P, SWEET L C. Effects of humification on exercise-induced asthma. J Allergy Clin Immunol 1976:57:250-251.

419. WEISS S, ROBB G P, ELLIS L B. The systemic effects of histamine in man. Arch Intern Med 1932; 49:360-396.

420. WELLS R E, WALKER J E C, HICKLER R B. Effects of cold air on respiratory airflow resistance in patients with respiratory disease. N Engl J Med 1960:263: 268-273.

421. WESTFALL D P. LEE T J F, STITZEL R E. Morphological and biochemical changes in supersensitive smooth muscle. Fed Proc 1975:34: 1985-1989.

422. WIDDICOMBE J G. The site of pulmonary stretch receptors in the cat. J Physiol (Lond) 1954: $125: 336-351$.

423. WIDDICOMBE J G. KENT D G. NADEL J A. Mechanism of bronchoconstriction during inhalation of dust. J Appl Physiol 1962: 17: 613-616.

424. WIDDICOMBE J G. Reflex control of airways smooth muscle. Postgrad Med J 1975: 5 I (suppl. 7):36-43.

425. WIDDICOMBE J G. Some experimental models of acute asthma. J R Coll Physicians Lond 1977: /l: 141-155.

426. WIDDICOMBE J G. Control of secretion of tracheo bronchial mucus. Br Med Bull 1978: 34: 57-61.

427. WOENNE R, KATTAN M. ORANGE R R. LEVISON H. Bronchial hyperreactivity ot histamine and metacholine in asthmatic children after inhalation of Sch 100 and chlorpheniramine maleate. J Allergy Clin Immunol 1978;62: 119-124.

428. WOENNE R. KATTAN M. LEVISON H. Sodium cromoglycate-induced changes in the dose-response curve of inhaled methacholine and histamine in asthmatic children. Am Rev Respir Dis 1970; 1/9:927-932.

429. WOOLCOCK A J, MACKLEM P T, HOGG J C et al. Effect of vagal stimulation on central and peripheral airways in dogs. J Appl Physiol 1969:26:806-813.

430. YAZIGI R, SLY R M. FRAZER M. Effect of tramcinolone acetonide aerosol upon exerciseinduced asthma. Ann Allergy 1978: 40:322-325.

431. YU D Y C. GALANT S P, GOLD W M. Ynhibition of antigen-induced bronchoconstriction by atropine in asthmatic patients. J Appl Physiol 1972:32: 823-828.

432. ZAID G. BEALL $G$ N. Bronchial response to beta-adrenergic blockade. $N$ Engl $J$ Med I966: 275: 580-584.

ZEBALLOS R J. SHTURMAN-ELLSTEIN R. Mc NALLY JR J F. HIRSCH J E, SOUH-

433. RADA J F. The role of hyperventilation in exercise-induced bronchoconstriction. Am Rev Respir Dis 1978: /18:877-884.

434. ZIMMERMANN I, ULMER W T. Antigen induzierte Atemwegobstruction und Empfinglichkeitssteigerung der Bronchomotoriek. Respiration 1977: 34: 141-151. 


\section{Postscriptum}

De afronding van een onderzoeksperiode in deze vorm geeft me de gelegenheid vele mensen te bedanken, een behoefte die ik reeds lang heb gevoeld.

In de eerste plaats gaat mijn dank uit naar mijn ouders, die het mij mogelijk hebben gemaakt de medische studie te volgen.

Voor mijn opleiding tot kinderarts ben ik veel dank verschuldigd aan Prof. Dr. H. K. A. Visser. Je hebt een uitstekend werkklimaat weten te creëren in het Sophia Kinderziekenhuis met goede mogelijkheden voor patiëntenzorg, onderzoek en onderwijs.

Mijn promotor, Prof. Dr. K. F. Kerrebijn, heeft een zeer belangrijk aandeel gehad bij mijn ontwikkeling gedurende de laatste jaren. Binnen zeer goede werkverhoudingen heb je uitstekende voorwaarden voor onderzoek gevormd.

Je kritische en inspirerende begeleiding zijn zeer leerzaam voor het verwerven van vaardigheden in het opzetten en het verslagleggen in woord en geschrift van onderzoek. Ook de vele werkavonden waarop ik bij jullie thuis gastvrijheid heb genoten heb ik op zeer hoge prijs gesteld.

Prof. Dr. H. J. Degenhart, mijn copromotor, dank ik zeer voor de enthousiaste wijze waarop hij steeds weer bereid was laboratoriumtechnische en statistische problemen te bespreken. Jouw inventiviteit heeft voor vele oplossingen gezorgd. Je hebt me spelenderwijs een statistisch prakticum gegeven, waarbij ik veel geleerd heb van de mogelijkheden en grenzen van statistische methoden.

Prof. Dr. C. Hilvering en Prof. Dr. K. de Vries dank ik voor waardevolle kritiek die zij als co-referenten op het gepresenteerde werk leverden. Dat Prof. de Vries vanuit de Groningse Universiteit bereid was deze taak op zich te nemen heb ik op hoge prijs gesteld. Het is het verlengde van de goede en vruchtbare contacten over onderzoekswerk, verricht in jullie en onze kliniek.

Veel dank is verschuldigd aan de medewerksters van het longfunctie laboratorium, Edit Bonzet-v. d. Water, Ineke Strik-Hijman, Marjan van Smaalen, Joke Mazee-Leemans en Jeanette Boogaard, die enthousiast en nauwgezet de praktische uitvoering van de lungfunctiemetingen hebben verricht.

Rolien Raatgeep, chemisch analyste van het Wetenschappelijk Laboratorium, heeft op uitstekende wijze de bepalingen van het vrijkomen van mediatoren verricht. Tevens heeft zij vaak de mathematisch-statistische analyses op zich genomen.

Adrie van Kralingen en Nellie van Weezepoel, medische studenten, hebben in het kader van een keuzeprakticum op enthousiaste wijze aan een deel van het onderzoek meegewerkt. 
Gianfranco Gargani, kinderarts uit Genua (Italië) heeft tijdens een gastperiode alhier de studie van paragraaf 7.2 mee helpen opzetten.

Verschillende onderzoekers, experts op hun gebied, zijn steeds bereid geweest problemen te bespreken. Ik noem hierbij speciaal Dr. R. Aalberse (Centraal Laboratorium Bloedtransfusie Dienst, Amsterdam), Prof. Dr. J. Th. F. Boeles (afdeling fysiologie, Universiteit van Amsterdam), Dr. P. Bruynzeel en Dr. G. Terpstra (afdeling longziekten, Academisch Ziekenhuis Utrecht), Dr. J. Boogaard (afdeling Longziekten, Academisch ZiekenKuis Rotterdam), Dr. M. Dixon, Fisons Research Laboratories, Loughborough, Engeland), de Groningse groep en Prof. Dr. Ph. H. Quanjer (afdeling fysiologie, Universiteit van Leiden). Deze kontakten heb ik zeer op prijs gesteld en hoop ze in de toekomst voort te zetten.

Annelies de Reus heeft steeds opgewekt de artikelen en later het manuscript vele malen getypt. Zij en voordien Marjan de Bruijne-Scharreburg hebben in belangrijke mate bijgedragen aan het groeiproces van de verslagleggingen. Ellen Nelemansvan de Broek is vaak op inventieve wijze behulpzaam geweest bij het speurwerk in de literatuur. De figuren werden vervaardigd door Loek Baars en Hilly Versprille van de Audio Visuele Dienst. De samenwerking met hen heb ik zeer gewaardeerd.

$\mathrm{Bij}$ het perfectioneren van de onnavolgbare Engelse taal ten behoeve van voordrachten, artikelen en het gehele proefschrift zijn steeds Engelstalige vrienden tot hulp bereid geweest: Dr. Noemi Eiser (Londen), Dr. Annemarie Oudesluys-Murphy (Rotterdam), Prof. A. P. Norman (Londen), Dr. Richard Pearse (Sheffield), Dr. Michael Dixon (Nottingham), Dr. Jim Mason (Gouda) en Dr. John Warner (Londen).

Ik dank m'n collegae in het Sophia Kinderziekenhuis, in het bijzonder Eric Duiverman, voor hun bereidwilligheid dagelijkse werkzaamheden van me over te nemen.

Tenslotte dank ik Suzanne, Karlien en Floortje voor hun opofferingen en geduld mij zoveel tijd voor dit "boekje" te gunnen. Ik hoop dit in de toekomst goed te maken.

Zij allen en vele anderen dank ik voor hun samenwerking en vriendschap. 


\section{Curriculum Vitae}

De schrijver van dit proefschrift werd in 1943 te Den Burg (Texel) geboren. In 1962 behaalde hij het diploma HBS-B aan de "Rijks HBS-Texel". Hierna studeerde hij geneeskunde aan de Universiteit van Amsterdam, waar in 1970 het artsdiploma werd behaald. De studie werd een half jaar onderbroken voor een studentenassistentschap op de afdeling Pathologische Anatomie aldaar (hoofd: Prof. Dr. C. Wagenvoort).

Van 1970 tot 1974 specialiseerde hij zich in de pediatrie in het Sophia Kinderziekenhuis/Academisch Ziekenhuis Rotterdam (hoofd van de afd. Kindergeneeskunde: Prof. Dr. H. K. A. Visser). Op 1 juni 1974 werd hij als kinderarts in het specialistenregister ingeschreven. In 1974 en 1975 vervulde hij de functie van chef de clinique (algemene Kindergeneeskunde). Sindsdien is hij werkzaam als wetenschappelijk hoofdmedewerker op de afdeling longziekten (hoofd: Prof. Dr. K. F. Kerrebijn) in hetzelfde instituut.

Naast klinische werkzaamheden en onderzoek hield hij zich bezig met onderwijs, vooral ten behoeve van de specialistenopleiding, o.a. als voorzitter van de artsassistenten opleidingscommissie en de algemene onderwijscommissie. Daarnaast werden een aantal bestuurlijke en commissiefuncties vervuld, zowel in als buiten het kader van het Academisch Ziekenhuis Rotterdam.

Hij is getrouwd met Suzanne Plasschaert en heeft twee kinderen: Karlien en Floortje. 


\section{Copyright H. J. Neijens.}

Fisons bv. Leusden, The Netherlands did the excellent job to make this book broadly available to all who are interested. 

